U.S. Department of the Interior

U.S. Geological Survey

\title{
Procedures for Scour Assessments at Bridges in Pennsylvania
}

by Peter J. Cinotto and Kirk E. White

Open-File Report 00-64

prepared in cooperation with the

PENNSYLVANIA DEPARTMENT OF TRANSPORTATION

Lemoyne, Pennsylvania

2000 


\title{
U.S. DEPARTMENT OF THE INTERIOR
}

\section{BRUCE BABBITT, Secretary}

\author{
U.S. GEOLOGICAL SURVEY
}

Charles G. Groat, Director

Disclaimer: The use of trade, product, or firm names in this report is for identification purposes only and does not constitute endorsement by the U.S. Government.

For additional information write to:

District Chief

U.S. Geological Survey

840 Market Street

Lemoyne, Pennsylvania 17043-1586
Copies of this report may be

purchased from:

U.S. Geological Survey

Branch of Information Services

Box 25286

Denver, Colorado 80225-0286 


\section{CONTENTS}

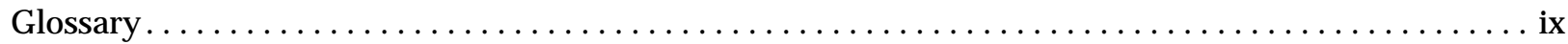

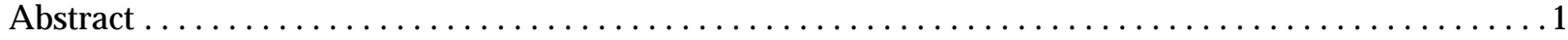

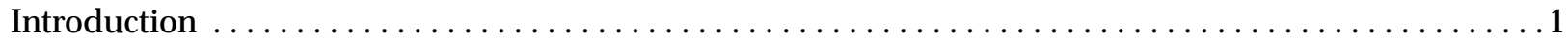

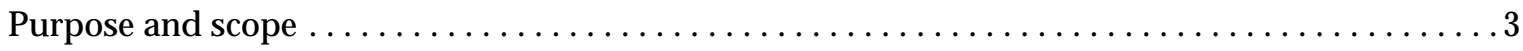

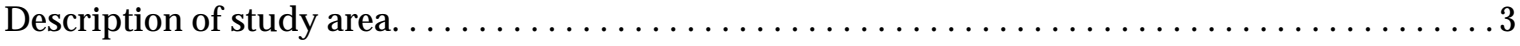

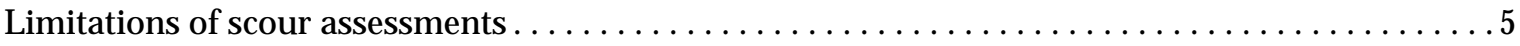

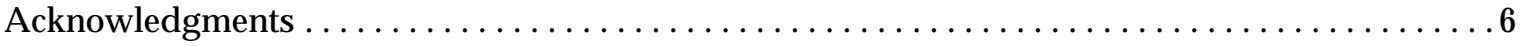

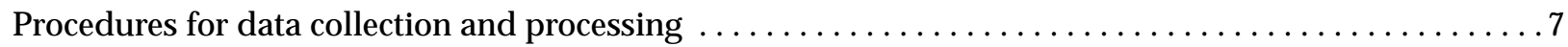

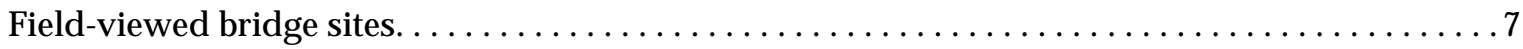

Bridge and channel-characteristics data $\ldots \ldots \ldots \ldots \ldots \ldots \ldots \ldots \ldots \ldots \ldots \ldots \ldots$

Collecting bridge and channel-characteristics data $\ldots \ldots \ldots \ldots \ldots \ldots \ldots \ldots$

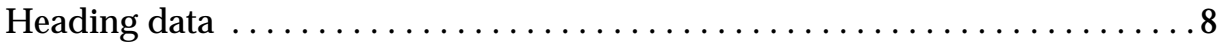

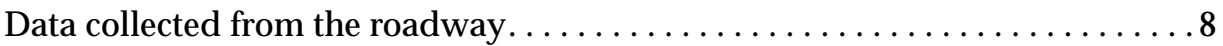

Data collected in the upstream and downstream channel. . . . . . . . . 8

Data collected under the bridge. . . . . . . . . . . . . . .

Summary findings . . . . . . . . . . . . . . . . . . .

Processing bridge and channel-characteristics data . . . . . . . . . . . 10

Quality assuring bridge and channel-characteristics data . . . . . . . . . . 10

Plan-view, undermining, and bridge-opening sketch data . . . . . . . . . . . . 11

Recording sketch data $\ldots \ldots \ldots \ldots \ldots \ldots \ldots \ldots \ldots \ldots \ldots \ldots \ldots \ldots \ldots \ldots \ldots$

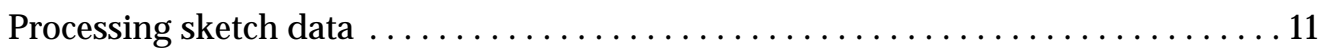

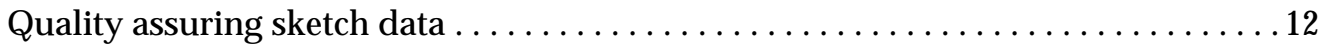

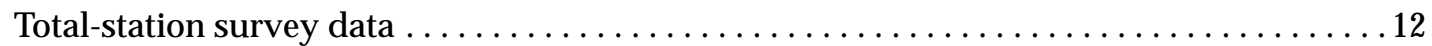

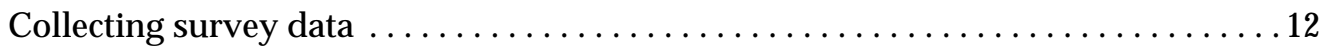

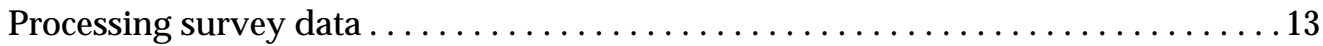

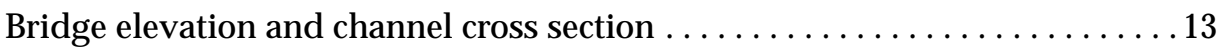

Geomorphic, hydraulic, and hydrologic computations . . . . . . . . . . 13

Quality assuring survey data .................... 15

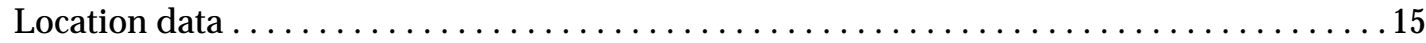

Collecting global positioning system data $\ldots \ldots \ldots \ldots \ldots \ldots \ldots \ldots \ldots \ldots$

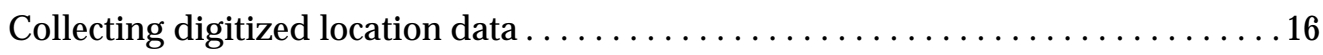

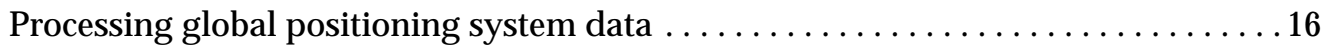

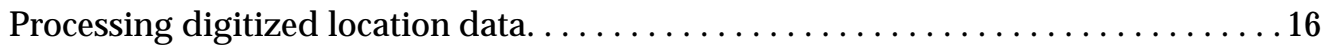

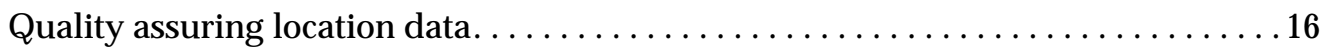

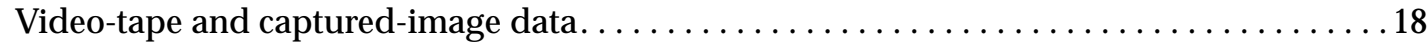

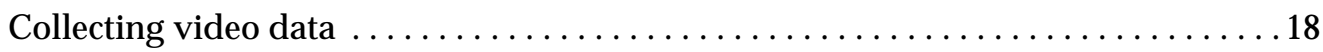

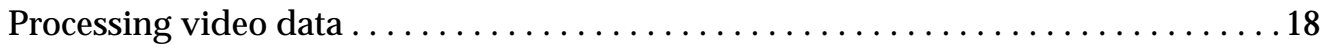

Quality assuring video data . . . . . . . . . . . . . . . . . . . . . . 19

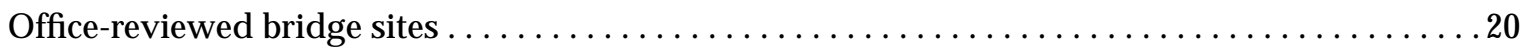

Bridge and channel-characteristics data $\ldots \ldots \ldots \ldots \ldots \ldots \ldots \ldots \ldots \ldots \ldots \ldots \ldots \ldots \ldots \ldots \ldots \ldots \ldots$ 


\section{CONTENTS-Continued}

Procedures for data collection and processing-Continued

Compiling bridge and channel-characteristics data.................. 20

Processing bridge and channel-characteristics data ..................... 21

Quality assuring bridge and channel-characteristics data $\ldots \ldots \ldots \ldots \ldots \ldots 21$

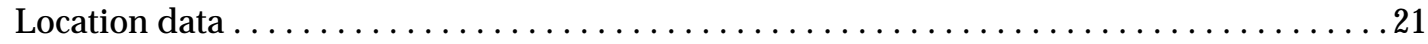

Procedure for drainage-basin description and flood-discharge computations by use of a

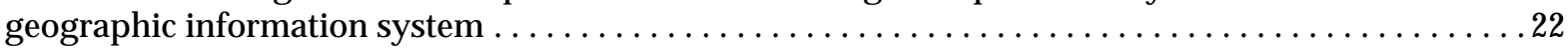

Procedure for computation of Scour-Critical Bridge Indicator Code and

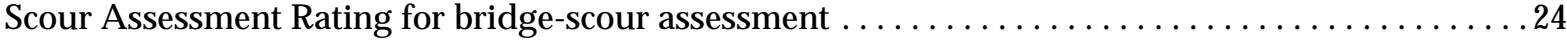

Scour-Critical Bridge Indicator Code . . . . . . . . . . . . . . . . . . . . . . . . . 24

Scour Assessment Rating. . . . . . . . . . . . . . . . . . . . . . . . . . . . . 24

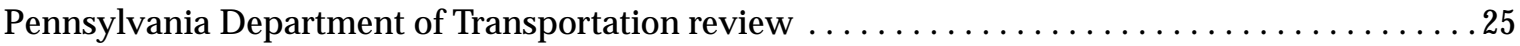

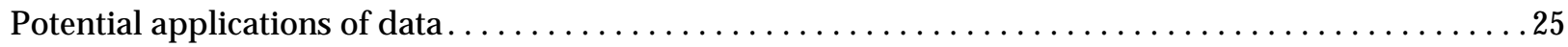

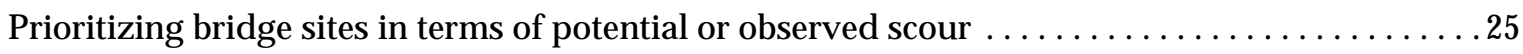

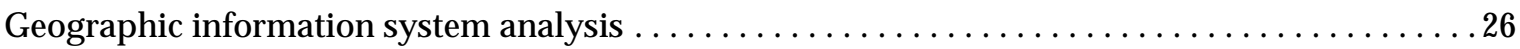

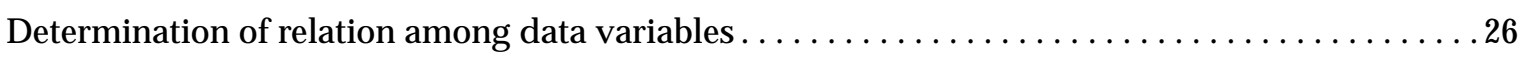

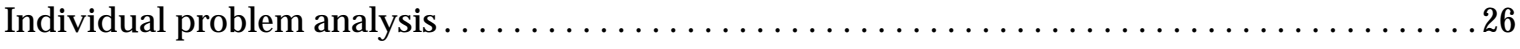

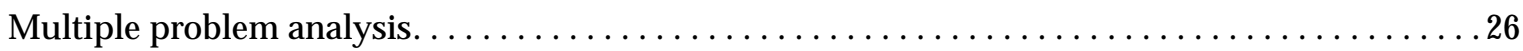

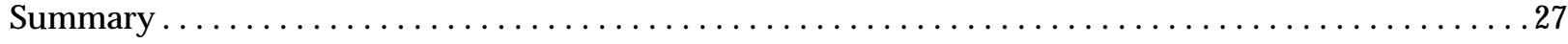

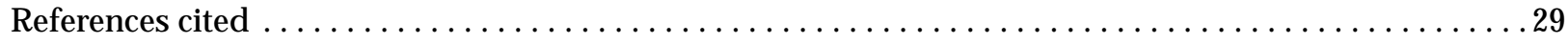

Appendix A - Procedures for completing the "Bridge and Channel Characteristics at Field-Viewed Bridge Sites" form and the "Addendum to Field Form for Non-Accessible Subunits" form. . . . . . . 31

Appendix B - Total-station survey procedures and attributes. . . . . . . . . . . . . . . . . . 75

Appendix C - Location and identification of global positioning system base stations used

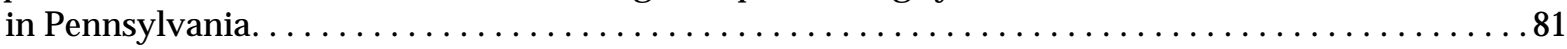

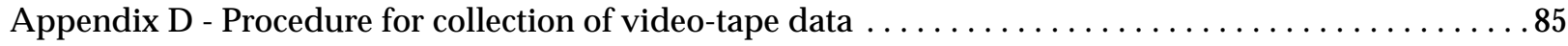

Appendix E - Form and procedures for completion of the "Bridge and Channel Characteristics

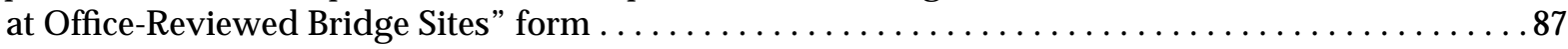

Appendix F - Procedure for determination of the Scour-Critical Bridge Indicator Code for field-viewed bridge sites . . . . . . . . . . . . . . . . . . . . . . . . . . . . 113

Appendix G - Procedure for determination of the Scour-Critical Bridge Indicator Code for

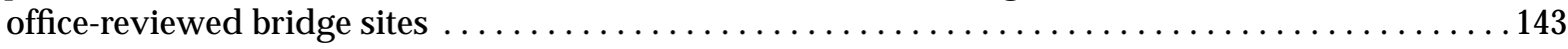

Appendix H - Procedure for computation of the Scour Assessment Rating for field-viewed

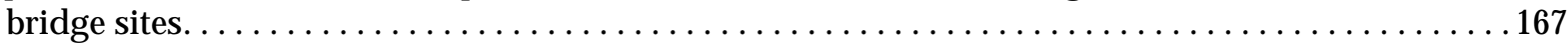

Appendix I - Procedure for computation of the Scour Assessment Rating for office-reviewed bridge sites. 


\section{ILLUSTRATIONS}

Figure 1. Collection and processing of geomorphic, hydrologic, and hydraulic data for

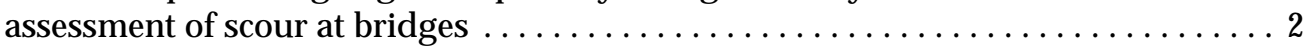

2. Map of Pennsylvania showing Pennsylvania Department of Transportation districts and cities where district headquarters offices are located. $\ldots \ldots \ldots \ldots \ldots \ldots, 4$

3. Map showing physiographic provinces of Pennsylvania $\ldots \ldots \ldots \ldots \ldots \ldots \ldots \ldots$

4. Photographs of channel at bankfull and normal stage .................. 5

5. Diagram of bridge elevation and channel cross section of field-viewed bridge . . . . . . 14

6. Geographic information system spatial data set showing global positioning system locations at bridge abutments . . . . . . . . . . . . . . . . . . . . . 17

7. Video image of upstream face of field-viewed bridge. ................... 19

8. Geographic information system spatial data set showing bridges in Chester County, Pennsylvania, spanning Brandywine Creek and its tributaries............ 27

9. "Bridge and channel characteristics at field-viewed bridge sites" form . . . . . . . . . 32 10-13. Sketches showing:

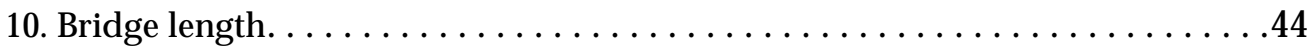

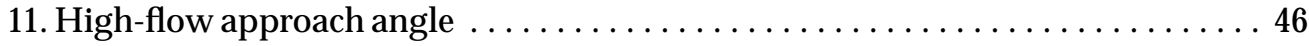

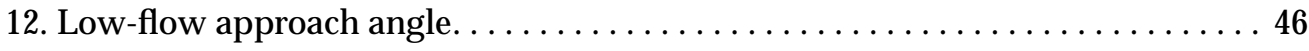

13. High-flow skew angle............................... 47

14. Photograph showing evidence of mass wasting $\ldots \ldots \ldots \ldots \ldots \ldots \ldots \ldots \ldots \ldots$

15-16. Sketches showing:

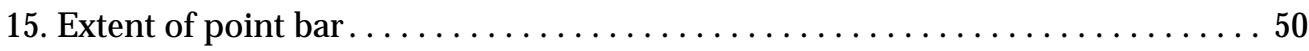

16. Extent of mid-channel bar . . . . . . . . . . . . . . . . . . . . . . . . . . 51

17-18. Photographs showing:

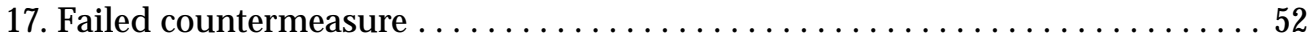

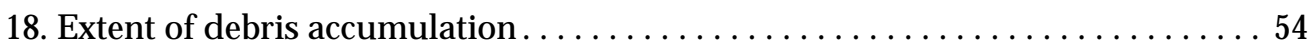

19-20. Sketches showing:

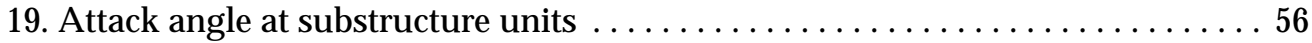

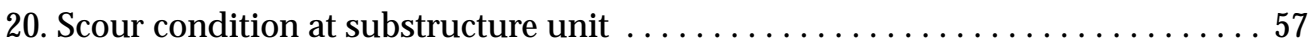

21. Photographs showing abutment location $\ldots \ldots \ldots \ldots \ldots \ldots \ldots \ldots \ldots \ldots \ldots \ldots \ldots \ldots \ldots \ldots \ldots \ldots \ldots$

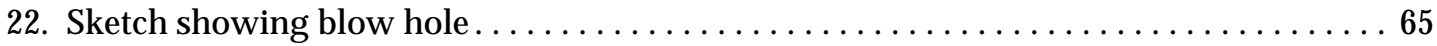

23-25. Sketches showing:

23. Plan-view of field-viewed bridge site. . . . . . . . . . . . . . . . 69

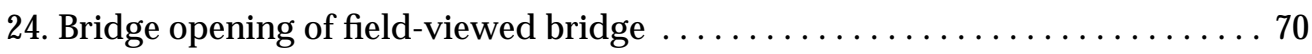

25. Undermining at substructure unit of field-viewed bridge $\ldots \ldots \ldots \ldots \ldots \ldots 70$

26. Map showing location of global positioning system base stations $\ldots \ldots \ldots \ldots \ldots \ldots 82$

27. "Bridge and channel characteristics at office-reviewed bridge sites" form . . . . . . . 88 


\section{ILLUSTRATIONS-Continued}

Figure 28-33. Flowcharts for:

28. Determination of Scour-Critical Bridge Indicator Code for abutments at field-viewed bridge sites . . . . . . . . . . . . . . . . . . . . . 117

29. Determination of Scour-Critical Bridge Indicator Code for piers at

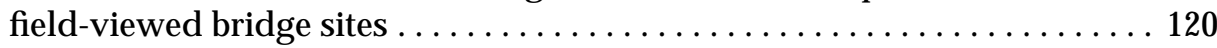

30. Determination of Scour-Critical Bridge Indicator Code for abutments at

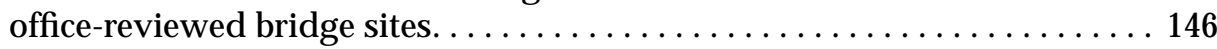

31. Determination of Scour-Critical Bridge Indicator Code for piers at office-reviewed bridge sites. . . . . . . . . . . . . . . . . . . . 148

32. Computation of Scour Assessment Rating for abutments at field-viewed bridge sites................................... 170

33. Computation of Scour Assessment Rating for piers at field-viewed

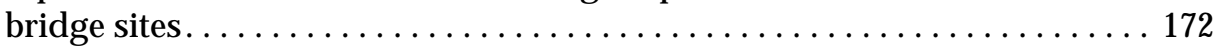

34. Worksheet for computation of Scour Assessment Rating for field-viewed bridge sites .............................................. 177

35-36. Flowcharts for:

35. Computation of Scour Assessment Rating for abutments at office-reviewed bridge sites. . . . . . . . . . . . . . . . . . . . . . . . . 193

36. Computation of Scour Assessment Rating for piers at office-reviewed bridge sites........................................... 194

37. Worksheet for computation of Scour Assessment Rating for office-reviewed bridge

sites ................................................ 197 


\section{TABLES}

Table $\quad$ 1. Methods used for estimation of flood-frequency discharges $\ldots \ldots \ldots \ldots \ldots \ldots \ldots 22$

2. Trapping potential for single- and multi-span bridges...................... 55

3. Streambed material near the bridge substructure units $\ldots \ldots \ldots \ldots \ldots \ldots \ldots \ldots \ldots 61$

4. Channel and Channel Protection Condition Rating ................................. 66

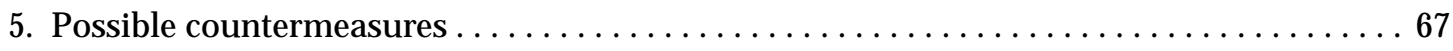

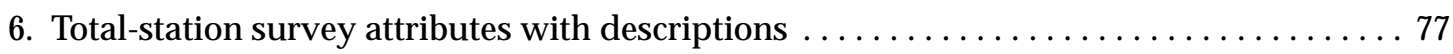

7. Primary and secondary global positioning system base stations for each county in

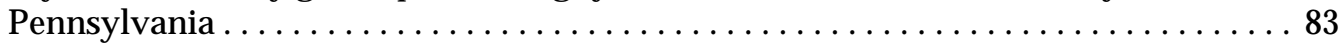

8. Selection of abutment type used in the Scour-Critical Bridge Indicator Code for field-viewed bridge sites . . . . . . . . . . . . . . . . . . . . . . . . . 124

9. Selection of pier type used in the Scour-Critical Bridge Indicator Code for field-

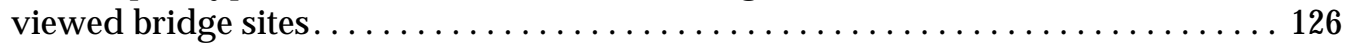

10. Selection of abutment and pier foundation type used in the Scour-Critical Bridge

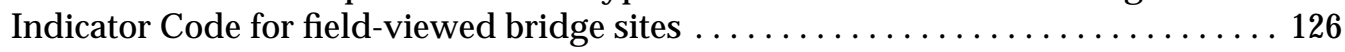

11. Incompatible combinations of abutment types and foundation types in the ScourCritical Bridge Indicator Code for field-viewed bridge sites . . . . . . . . . . 127

12. Incompatible combinations of pier types and foundation types in the ScourCritical Bridge Indicator Code for field-viewed bridge sites . . . . . . . . . . . . 127

13. Criteria for determination of Scour-Critical Bridge Indicator Code for field-

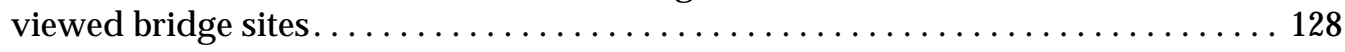

14. Selection of abutment type used in the Scour-Critical Bridge Indicator Code for office-reviewed bridge sites. . . . . . . . . . . . . . . . . . . . . . 150

15. Selection of pier type used in the Scour-Critical Bridge Indicator Code for officereviewed bridge sites . . . . . . . . . . . . . . . . . . . . . 150

16. Selection of abutment and pier foundation type used in the Scour-Critical Bridge Indicator Code for office-reviewed bridge sites. . . . . . . . . . . . . . . . . . 151

17. Criteria for determination of Scour-Critical Bridge Indicator Code for office-

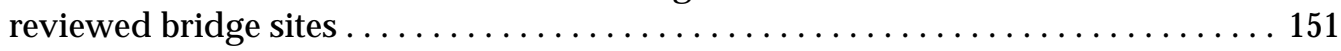

18. Selection of abutment type used in the Scour Assessment Rating for field-viewed

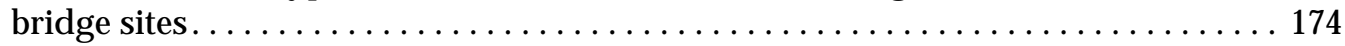

19. Selection of pier type used in the Scour Assessment Rating for field-viewed bridge

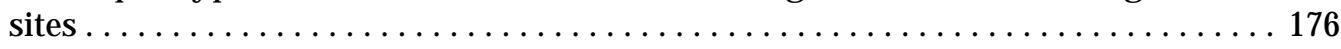

20. Selection of abutment and pier foundation type used in the Scour Assessment

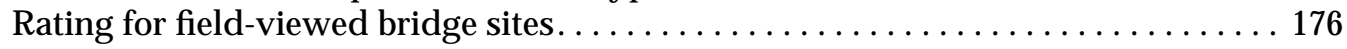

21. Incompatible combinations of abutment types and foundation types in the Scour Assessment Rating for field-viewed bridge sites................. 176

22. Selection of abutment type used in the Scour Assessment Rating for officereviewed bridge sites . . . . . . . . . . . . . . . . . . . . . . . . 195

23. Selection of pier type used in the Scour Assessment Rating for office-reviewed

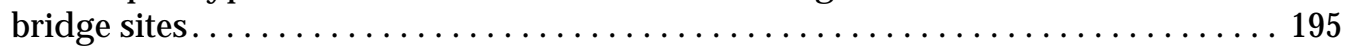

24. Selection of abutment and pier foundation types used in the Scour Assessment

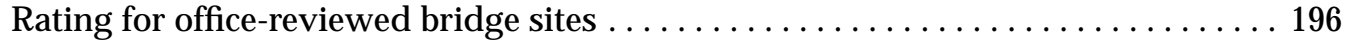




\section{CONVERSION FACTORS AND ABBREVIATIONS}

Multiply

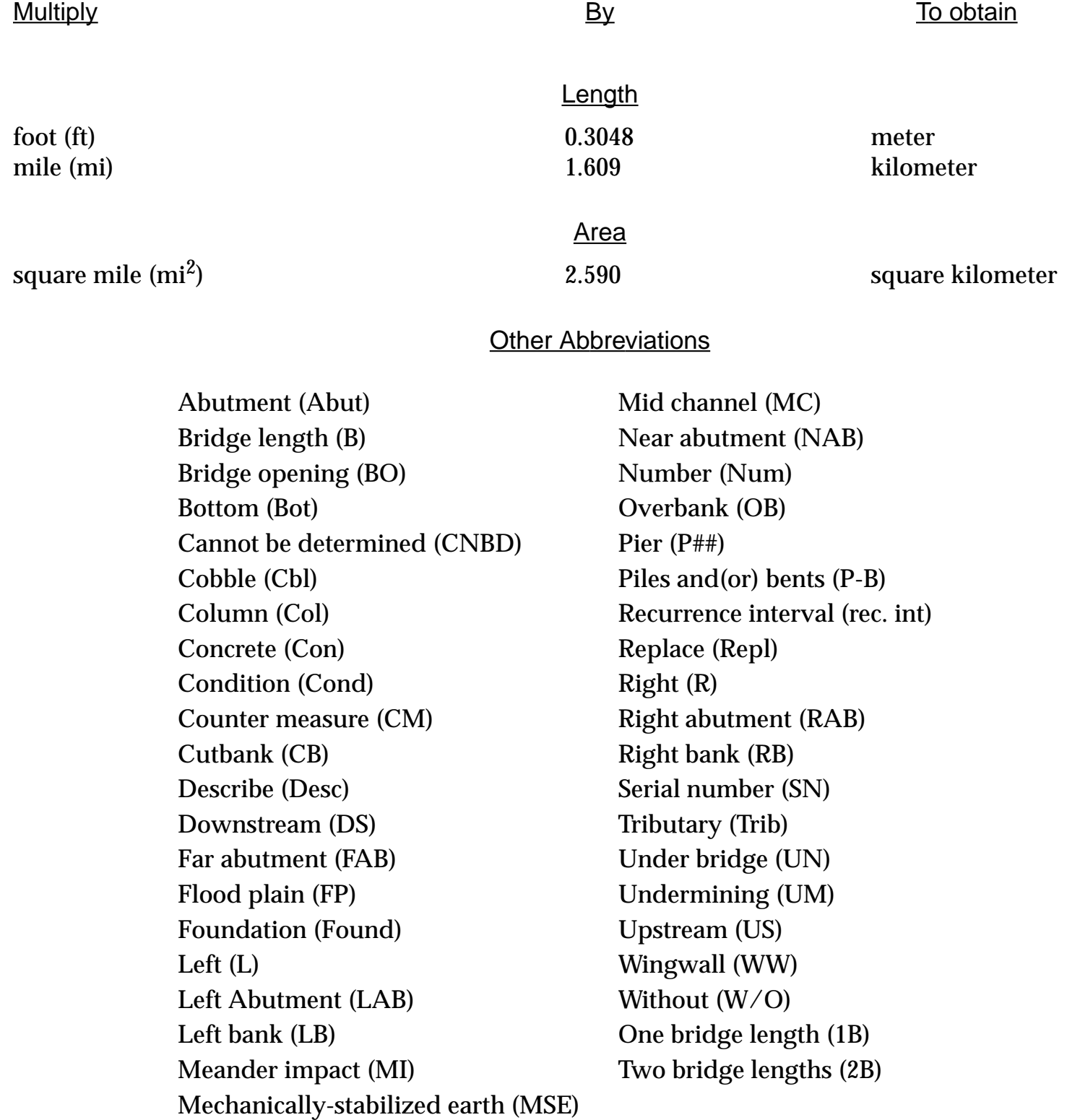




\section{GLOSSARY}

The terms in this glossary were compiled from numerous sources. Some definitions have been modified and may not be the only valid ones for these terms.

ABUTMENT - The structure that supports the end of a bridge.

ADVANCED SCOUR - Scour that has occurred to such an extent that the footing of bridge substructure is exposed to very slightly undermined (Pennsylvania Department of Transportation, 1993).

AGGRADATION - Progressive deposition of sediment within the channel and flood plain of a stream.

ALLUVIUM - Waterborne materials deposited by running water, including clay, silt, sand, gravel, and(or) cobbles (Pennsylvania Department of Transportation, 1993).

APPROACH - The stream reach directly upstream from the bridge structure, generally two to three bridge lengths.

ASSESSMENT - The appraisal or evaluation of a bridge and bridge site in order to collect sufficient data to compute a Scour Assessment Rating and a Scour-Critical Bridge Indicator Code.

BANK MATERIAL - The material that comprises the bank from the toe of the bank to the break in slope indicative of the minimum elevation of the floodplain.

BANKFULL DISCHARGE - The minimum discharge that, on average, completely fills a stream channel to the bankline.

BANKFULL FLOW - The flow that occurs at bankfull discharge and bankfull stage and, on average, completely fills a stream channel to the bankline.

BANKFULL INDICATOR - Physical evidence of bankfull flow including, but not limited to: banklines, depositional bars, and riparian vegetation.

BANKFULL STAGE - The minimum stage that, on average, completely fills a stream channel to the bankline.

BANKLINE - The horizontal line coinciding with the top of bank along a stream reach. The bankline is often determined by breaks in slope, changes in riparian vegetation, or staining along the banks.

BED MATERIAL - The material that comprises the channel bed from the toe of one bank to the toe of the other.

BENT - A framework transverse to the length of a structure, usually designed to carry lateral as well as vertical loads.

BLOWHOLE - Concentric bank erosion, usually on both banks, directly downstream from the bridge, caused by eddy currents and rapid expansion of water as it exits the bridge.

BOTTOM OF BANK - The line that delineates the boundary between the streambank and the channel bed; also known as "toe of bank."

BRIDGE - A structure, 20 feet long or greater, erected over a depression or an obstacle such as a stream, lake, and(or) roadway.

BRIDGE MANAGEMENT SYSTEM (BMS) - A PennDOT-designed database that computes needs estimates and rankings and stores structure inventory, inspection, and appraisal data.

CANTILEVER ABUTMENT - A structural member, as a wall, that projects beyond a fulcrum and is supported by a balancing member or a downward force behind the fulcrum. 


\section{GLOSSARY—Continued}

CODE - Abbreviation for the Scour-Critical Bridge Indicator Code. The Code rates the bridge site for vulnerability to scour based on site conditions. This Code is based on the Pennsylvania Department of Transportations interpretation of the Federal Highway Administration Code as referred to in Richardson and others, 1993.

COUNTERMEASURE - An object or objects specifically placed to prevent or repair damage from erosion.

CROSS-SECTION PIER WIDTH - The width of a bridge pier perpendicular to a cross section at the most restrictive opening of the bridge.

CULVERT - Culverts are defined and coded by PennDOT as structures with integral top, sides, and usually bottom (Pennsylvania Department of Transportation, 1993). Culverts are further defined by FHWA as structures with less than $20 \mathrm{ft}$ clear opening width (Federal Highway Administration, 1989).

CUTBANK- A streambank that exhibits progressive erosion.

DEGRADATION - Progressive erosion of material from the stream channel and banks at a rate faster than sediments are being deposited.

ENCASEMENT - A covering of concrete placed to repair damage from erosion or protect bridge substructure units from erosion.

FAR - The northern or easternmost side of a bridge structure (generally) as the bridge structure relates to the trend of the roadway crossing the structure.

FIELD-VIEWED BRIDGE SITE - A bridge site at which USGS field personnel collect date-specific data from USGS field observation and also from existing PennDOT data sources.

FLUVIAL EROSION - The removal of streambank and channel material on a particle by particle basis.

FOOTING - The supporting base of a substructure unit, as for a bridge pier or abutment, also known as "footer."

FOUNDATION APPROVAL LETTER - A letter issued by PennDOT approving the foundation design of a bridge.

FOUNDATION REPORT - A report issued by PennDOT describing the foundation type and requirements for the construction of a bridge.

GABION - A wire basket filled with stone of specified size.

GEOMORPHIC - Relating to the earth, its shape, or its landforms.

GLOBAL POSITIONING SYSTEM (GPS) - An instrument composed of a receiver unit, antenna, and external data logger that calculates the location of the instrument on the globe by means of satellites located in fixed orbits around the earth.

GRAVITY CONCRETE ABUTMENT - A concrete abutment type that supports the superstructure and retains the approach roadway fill through its own mass.

HYDRAULIC - Relating to the static and dynamic behavior of fluids.

HYDROLOGIC - Relating to the properties, distribution, and effects of water in the atmosphere, on the Earth's surface, and in soil and rocks.

HYDROLOGIC AND HYDRAULIC (H and H) REPORT - A comprehensive report prepared before construction of a bridge structure on the hydrologic and hydraulic aspects of a bridge structure and bridge site according to PennDOT Design manual 2, Chapter 10, page 2.10.71 (Pennsylvania

Department of Transportation, 1994).

LANDWARD - The direction perpendicular to, and away from, the stream. 


\section{GLOSSARY—Continued}

MASS WASTING - The removal of streambank and channel material in blocks or clumps of material.

MEANDER - A bend or turn in the path of a stream, usually caused by lateral migration of the stream channel.

MEANDER IMPACT - An erosive force upon the streambank resulting from lateral migration of the stream channel.

MECHANICALLY STABILIZED EARTH - A method of construction that uses straps or wire mesh placed as part of the backfill to anchor the face of prefabricated wall panels; also known as mechanically stabilized panels.

MID-CHANNEL BAR - A sedimentary deposit within the stream channel in an area of relatively low energy.

MINOR SCOUR - Scour that has occurred to such an extent that the streambed may exhibit slight holes or depressions; footing of the bridge substructure not exposed (Pennsylvania Department of Transportation, 1993).

NEAR - The southern or westernmost side of a bridge structure (generally) as the bridge structure relates to the trend of the roadway crossing the structure.

OFFICE-REVIEWED BRIDGE SITE - A bridge site for which data was compiled by USGS personnel from only existing PennDOT data sources.

OVERFLOW BRIDGE - A bridge located in a flood plain that has no streamflow beneath it except during periods of flooding.

PARAPET - A protective railing or wall along the edge of the bridge.

PENNDOT INSPECTION REPORT - PennDOT D-488F form, or equivalent, as completed according to PennDOT Publication 100A (Pennsylvania Department of Transportation, 1993).

PENNDOT UNDERWATER INSPECTION REPORT - PennDOT D-488W form, or equivalent, as completed according to PennDOT Publication 100A (Pennsylvania Department of Transportation, 1993).

PIER - An intermediate support for the adjacent ends of two bridge spans.

PILE - A long and slender member usually of timber, steel, or reinforced concrete, driven or drilled into the ground to carry a vertical load, resist a lateral force, water, or earth pressure.

POINT BAR - A lateral sedimentary deposit on the inside of a bend in a meandering channel.

PRESSURE FLOW - The flow that occurs when the stream stage exceeds the clearance of the bridgeopening.

RATING - Abbreviation for the Scour Assessment Rating. The Rating rates the bridge site based on the observed scour conditions at the bridge site.

RIPRAP - Unconsolidated rock that is sized to resist substantial movement from stream or other erosive processes and placed in a location so as to protect that location from erosive processes.

ROAD OVERTOPPING - The passing of streamflow over the bridge and (or) adjacent roadway.

ROADWAY APPROACH - The roadway that crosses the bridge structure as it leads up to and exits the bridge.

SERIOUS SCOUR - Scour that has occurred to such an extent that the bridge substructure has been significantly undermined (Pennsylvania Department of Transportation, 1993).

SPILL-THROUGH ABUTMENT - Type classification given to a bridge abutment constructed to slope outwards from the stream channel to the bottom of the bridge deck. 


\section{GLOSSARY-Continued}

STONE-MASONRY - Type classification give to a bridge-substructure unit constructed of stonework.

STREAMWARD - The direction perpendicular to and towards the stream.

STUB ABUTMENT - Type classification given to a concrete bridge abutment when a shallow abutment is set back from the stream and has a sloping earthen or reinforced bank leading from the stream to the abutment.

SUBUNIT - Bridge substructure unit, such as a pier.

TRIBUTARY - A river or stream flowing into a larger river or stream.

TOP OF BANK - The line that delineates the boundary between the streambank and the flood plain.

TOTAL STATION - An instrument composed of an integrated electronic distance measurement instrument, electronic digital theodolite, and computer that measures distance and direction simultaneously and transmits the results to a built-in computer (Wolf and Brinker, 1994).

UNKNOWN CONCRETE - Type classification given a bridge-substructure unit when personnel cannot determine information over and above visually noting the use of concrete construction material.

WINGWALL - A structure attached to the side a bridge abutment and so placed as to protect the material behind the bridge abutment from the erosive processes of a stream. 


\title{
Procedures for Scour Assessments AT BRIDGES IN PENNSYLVANIA
}

\author{
by Peter J. Cinotto and Kirk E. White
}

\begin{abstract}
Scour is the process and result of flowing water eroding the bed and banks of a stream. Scour at nearly 14,300 bridges $^{1}$ spanning water, and the stability of river and stream channels in Pennsylvania, are being assessed by the U.S. Geological Survey (USGS) in cooperation with the Pennsylvania Department of Transportation (PennDOT). Procedures for bridge-scour assessments have been established to address the needs of PennDOT in meeting a 1988 Federal Highway Administration mandate requiring states to establish a program to assess all public bridges over water for their vulnerability to scour. The procedures also have been established to help develop an understanding of the local and regional factors that affect scour and channel stability.

This report describes procedures for the assessment of scour at all bridges that are 20 feet or greater in length that span water in Pennsylvania. There are two basic types of assessment: field-viewed bridge site assessments, for which USGS personnel visit the bridge site, and office-reviewed bridge site assessments, for which USGS personnel compile PennDOT data and do not visit the bridge site. Both types of assessments are primarily focused at assisting PennDOT in meeting the requirements of the Federal Highway Administration mandate; however, both assessments include procedures for the collection and processing of ancillary data for subsequent analysis. Date of bridge construction and the accessibility of the bridge substructure units for inspection determine which type of assessment a bridge receives. A Scour-Critical Bridge Indicator Code and a Scour Assessment Rating are computed from selected collected and compiled data. PennDOT personnel assign the final Scour-Critical Bridge Indicator Code and a Scour Assessment Rating on the basis of their review of all data.
\end{abstract}

\section{INTRODUCTION}

Scour at bridge foundations and channel instability during flooding are primary causes of bridge failure. In response to the scour-related catastrophic failure of several bridges in the United States, the Federal Highway Administration (FHWA) issued a mandate in 1988 requiring states to establish a program to assess all public bridges over water for vulnerability to scour (William Williams, Federal Highway Administration, oral commun., 1999). In 1993, the U.S. Geological Survey (USGS) entered into a cooperative agreement with the Commonwealth of Pennsylvania, Department of Transportation (PennDOT), to create procedures and to conduct assessments of scour and channel stability to aid PennDOT in complying with the FHWA mandate. As part of this agreement, the USGS has established procedures for assessment of scour at all bridges identified by PennDOT as $20 \mathrm{ft}$ or greater in length that span water in Pennsylvania. Scour assessments are scheduled for completion in January 2001.

\footnotetext{
${ }^{1}$ Words presented in bold type are defined in the Glossary section of this report.
} 
Two categories of bridge sites are assessed for scour by collecting and processing geomorphic, hydrologic, and hydraulic data indicative of the existing or potential effects of stream processes on a bridge or the stream channel (fig. 1). The first category of bridge sites (field-viewed bridge sites) consists of sites visited by USGS field personnel. Field-viewed bridge-site assessments include collecting and processing geomorphic and channel-stability data; surveying bridge-geometry, cross-section, and site characteristics; determining bridge location with a global positioning system (GPS) or by digitizing USGS

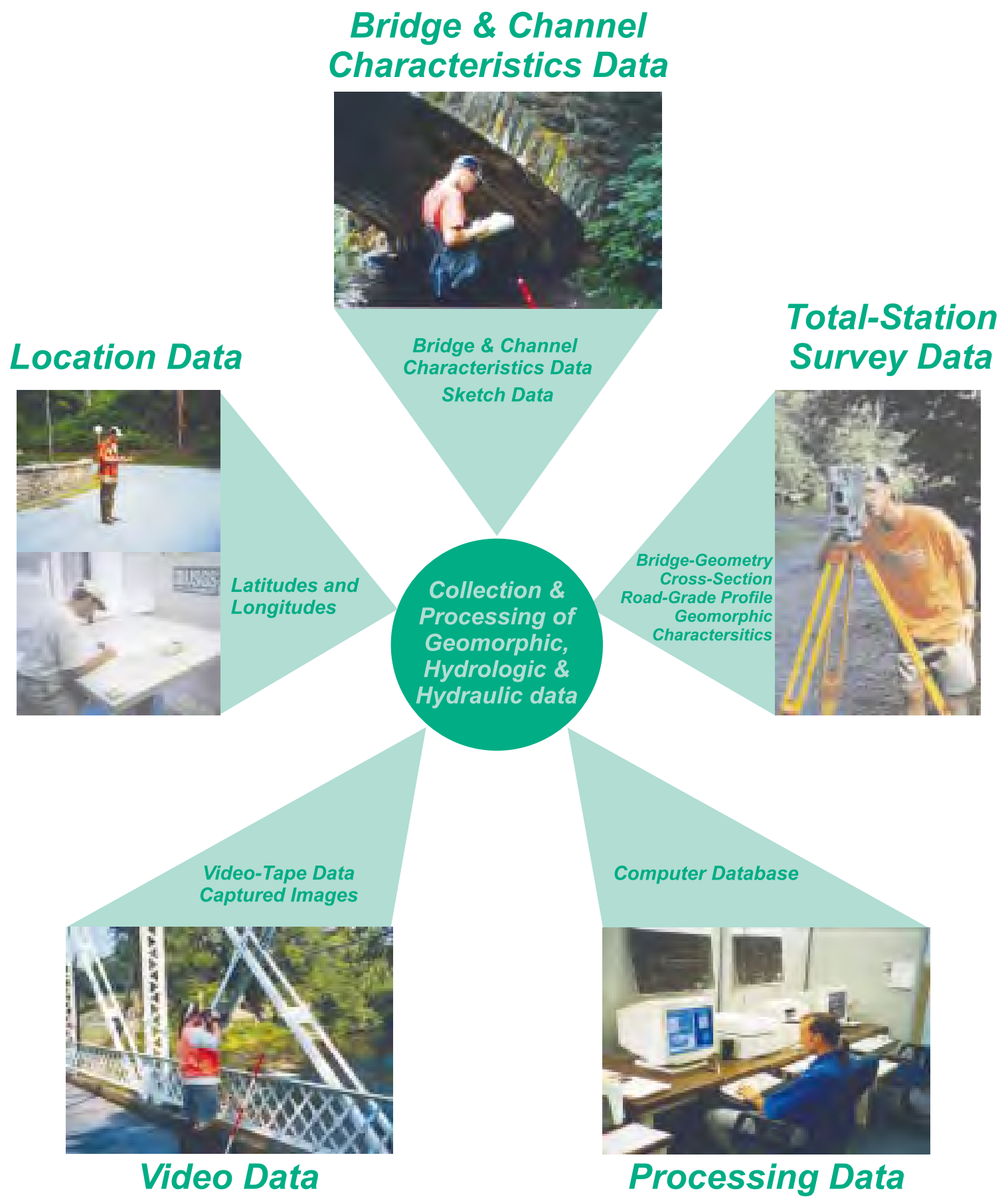

Figure 1. Collection and processing of geomorphic, hydrologic, and hydraulic data for assessment of scour at bridges. 
topographic maps; collecting and processing video data; preparing field sketches; estimating flood recurrence-interval discharges; and compiling basin characteristics for the drainage basin upstream from the bridge. The second category of bridge sites (office-reviewed bridge sites) consists of sites where the bridges were built after 1982 or are not accessible to USGS field personnel. Office-reviewed bridge sites are assessed by compiling and reviewing PennDOT data. These sites receive no field-verification by USGS personnel. Office-reviewed bridge-site assessments include compiling and reviewing geomorphic and stream-stability data, digitizing bridge location from USGS topographic maps, estimating flood recurrence-interval discharges, and compiling basin characteristics for the drainage basin upstream from the bridge.

Selected data are used to compute a Scour-Critical Bridge Indicator Code (Code) and a Scour Assessment Rating (Rating). The Code is based on the PennDOT interpretation of the FHWA code (Federal Highway Administration, 1989) and is primarily intended to comply with the FHWA mandate by indicating the degree to which scour is currently a factor at the bridge site and the vulnerability of the bridge to future scour. The Rating was developed by PennDOT with USGS assistance in geomorphic, hydrologic, and hydraulic aspects. The Rating is primarily intended to assist in further interpreting the Code and to assist PennDOT in prioritizing remedial and maintenance needs at bridge sites. The Code and Rating assigned to a bridge site are indicative of the condition of a specific bridge site and its vulnerability to future scour at the time of data collection. Subsequent hydrologic events can seriously alter the bridge site, resulting in a change to the variables that influence the Code and Rating that a bridge site would receive. Data, in addition to that specifically required for the computation of the Code and the Rating, also are collected to assist PennDOT in determining the vulnerability of the bridge site to scour. For example, if two independent bridge sites have identical Code and Rating values, additional data are presented, such as drainage-basin characteristics and flood discharges, that may be used to further prioritize the vulnerability of those sites to scour.

\section{Purpose and Scope}

This report describes the procedures used by USGS personnel to assess approximately 14,300 bridges in Pennsylvania for the degree to which scour is currently a factor at the bridge site and the vulnerability of the bridge to future scour. Included are two basic components: a general overview of procedures and nine detailed appendixes that are more technical in content. The variables and procedures used for computation of a Code and a Rating by use of PennDOT-derived algorithms are described. Procedures for the collection of ancillary data used to assist in the interpretation of the Code and Rating also are described. Figures and tables provided throughout this report are not intended to imply order or priority of importance and merely serve to clarify difficult concepts and present information in an efficient manner.

\section{Description of Study Area}

Scour assessments are done at bridge sites in the 11 PennDOT Engineering Districts that encompass the entire Commonwealth of Pennsylvania (fig. 2). Bridges within the boundaries of individual PennDOT Engineering Districts may have slight discrepancies in availability and type of data because of variations in contract personnel, bridge ownership, and(or) ability to archive historical data. These district boundaries also serve as convenient operational units for USGS personnel.

Pennsylvania contains parts of seven physiographic provinces (fig. 3). This physiographic diversity results in a broad spectrum of factors with the potential to affect scour at bridges and channel stability. The Atlantic Coastal Plain (ACP), for example, exhibits a very low local topographic relief and consists of 


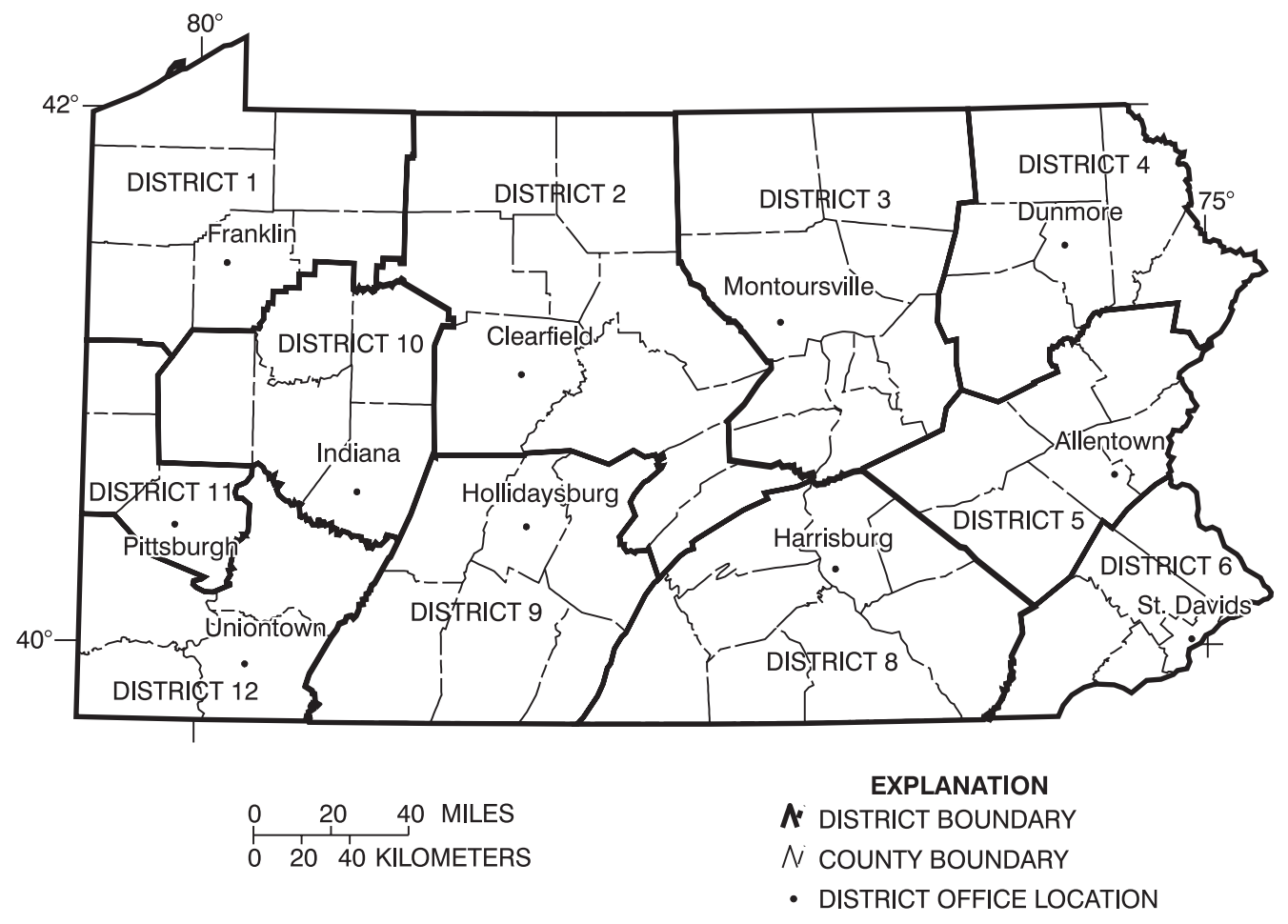

Figure 2. Pennsylvania Department of Transportation districts and cities where district headquarters offices are located.

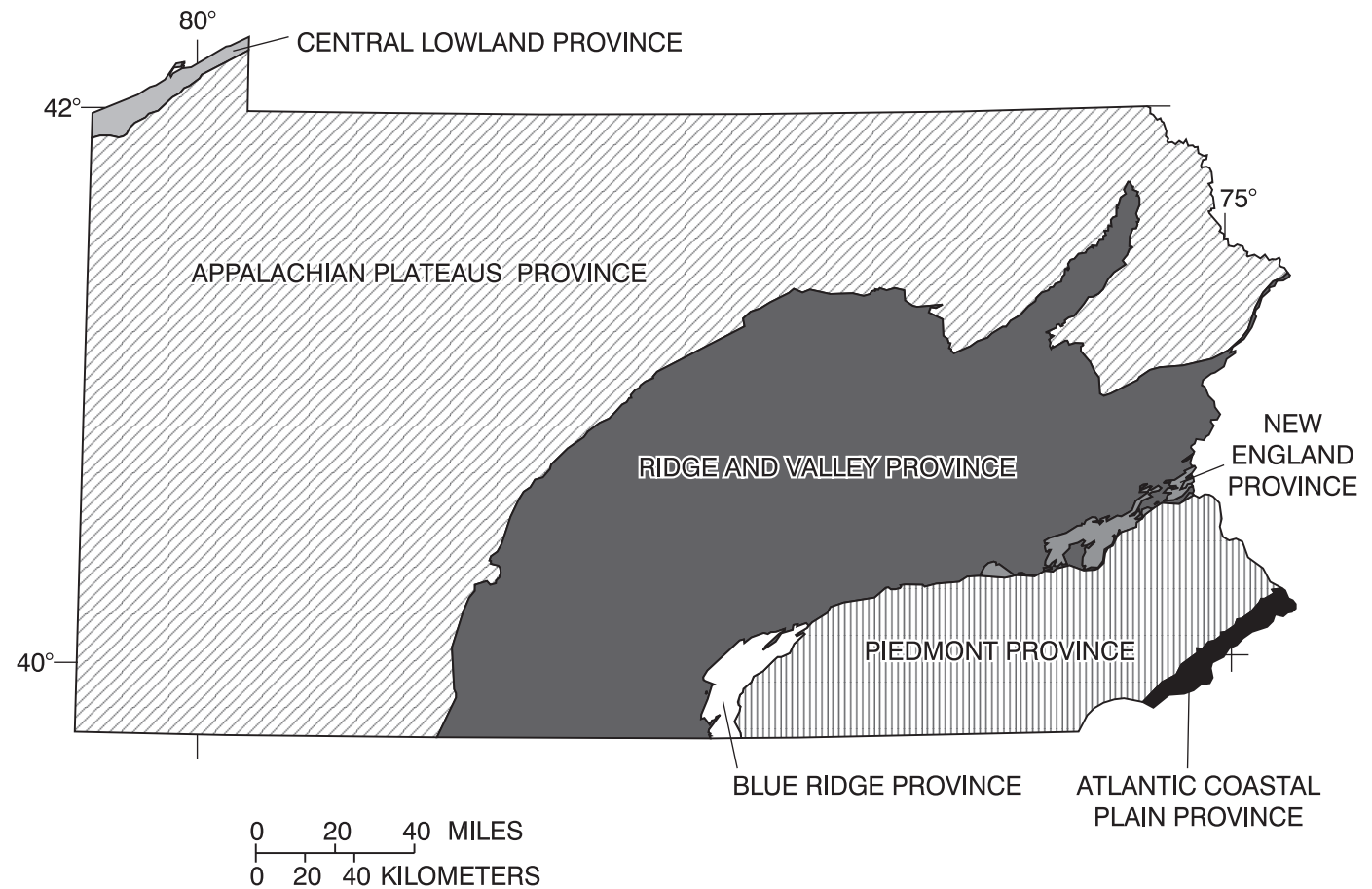

Figure 3. Physiographic provinces of Pennsylvania. 
unconsolidated to poorly consolidated sand and gravel underlain by schist, gneiss, and other metamorphic rocks. In contrast to the ACP, the Blue Ridge Province exhibits a moderate to high local relief and is underlain by metavolcanic rocks, quartzite, and some dolomite (Berg and others, 1989). As a result of these physiographic differences between provinces, stream channels within the different provinces may respond differently to similar hydrologic events. The three most extensive physiographic provinces in Pennsylvania are the Appalachian Plateaus, the Ridge and Valley, and the Piedmont.

\section{Limitations of Scour Assessments}

Scour assessments are based on a specific set of data, discussed herein, and the assumption of downgradient flow at bankfull discharge and bankfull stage (fig. 4). This assumption of scour as related to the bankfull concept, however, may not represent the worst possible scour condition for all bridges (Doheny, Helinsky, and McGregor, 1996). Such variables as drainage area, flood recurrence-interval discharges, overbank flow, and tidal effects can alter the vulnerability of a bridge to scour but are not included in the computation of the Code and Rating. Description of the procedures for the collection and

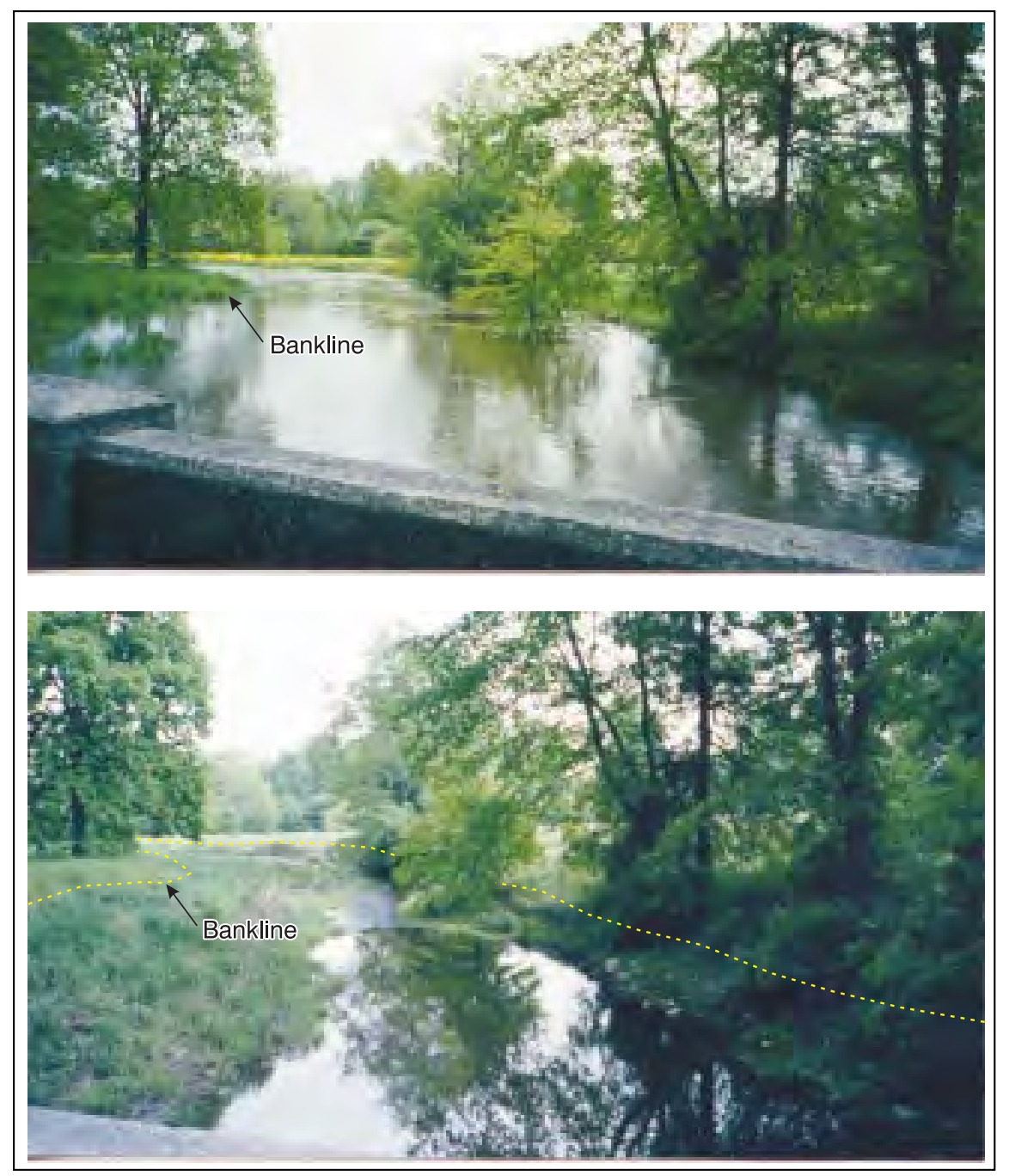

Figure 4. Channel at bankfull (top) and normal (bottom) stage. 
compilation of data to support the Code and Rating are included in this report. All data elements are considered before any judgement is made regarding the vulnerability of a bridge structure to scour or the stability of a stream channel.

Channel and bridge-site conditions at a particular or specific time can change substantially due to subsequent hydrologic events, human-induced development within the drainage basin, and(or) many other factors; therefore, scour assessments accurately describe the channel and bridge-site conditions only from the time data were initially collected until some impact changes those conditions for that bridge site. As as result of this limitation, the assessments of field-viewed bridge sites describe that bridge site only for the date the site was visited by USGS personnel; assessments of office-reviewed bridge sites describe that site only for the date PennDOT personnel or PennDOT contract personnel completed the PennDOT Inspection Report (form D-488F) and(or) the PennDOT Underwater Inspection Report (form D-488W)(Pennsylvania Department of Transportation, 1993).

Data for scour assessments are incorporated from various sources, including (but not limited to) PennDOT; private contractors; various federal, state, and municipal government agencies; and the USGS. All data from sources outside of the USGS are received through and accepted as correct by PennDOT (Bryan Spangler, P.E., Pennsylvania Department of Transportation, oral commun., 1999). For the purposes of this project, PennDOT quality-control procedures are considered to be acceptable.

\section{Acknowledgments}

The authors thank Bryan Spangler, P.E. and John Ferry of PennDOT for providing information, training, and technical advice. Numerous USGS staff also contributed to this report. Pamela A. Telis contributed significantly to the development of the Scour-Critical Bridge Indicator Code and Scour Assessment Rating; Mark V. Truhlar and Karen M. Shumac prepared the majority of the office-reviewed bridge-site forms and procedures; Raymond G. Davis, Jr. and Michael A. Hott were instrumental in the creation of the software required for the automated processing of survey data; Mark F. Henneberg helped to create procedures for collection and processing of GPS data; Jeffrey L. Strause along with Linda F. Zarr created and managed the computer databases; Lloyd A. Reed along with Marla H. Stuckey developed the procedures described in the section on drainage-basin descriptions and flood-discharge computations; Scott A. Hoffman and Debra A. Town created the maps for this report; and many other USGS field and management personnel also contributed great amounts of time and effort to all aspects of the project and this report. 


\section{PROCEDURES FOR DATA COLLECTION AND PROCESSING}

Two categories of bridges are addressed in this report: bridges visited by USGS personnel in the field (field-viewed bridge sites) and bridges with data compiled solely from information supplied by PennDOT (office-reviewed bridge sites). Field-viewed bridge-site assessments involve extensive data collection for characterizing bridge-site conditions and providing input for the computation of the Code and Rating. Office-reviewed bridge-site assessments are less extensive and use compiled data to compute the Code and Rating and, if possible, to characterize the bridge-site conditions.

\section{Field-Viewed Bridge Sites}

Approximately 13,800 field-viewed bridges will have had data collected by USGS personnel during the study. Field visits are made by three-person or, less commonly, two-person teams. All data are recorded on the "Bridge and Channel Characteristics at Field-Viewed Bridge Sites" form and, when applicable, the "Addendum to Data Collection Form for Non-Accessible Subunits" form (Appendix A).

If 50 percent or more of the bridge substructure units are observed, by USGS personnel, to be affected by streamflow and are fully accessible, a field-viewed assessment is completed for the bridge site. A bridge substructure unit affected by streamflow at normal and(or) flood stage is considered to be in contact with water. USGS field personnel consider bankfull indicators and other historical evidence, such as scour holes at or near flood-plain substructure units, high-water marks, and information from PennDOT Inspection Reports, to determine those substructure units considered to be in contact with water. Data for all field-viewed substructure units that are in contact with water but are not accessible to USGS personnel are compiled from PennDOT Inspection Reports and(or) PennDOT Underwater Inspection Reports (Pennsylvania Department of Transportation, 1993).

\section{Bridge and Channel-Characteristics Data}

Bridge and channel-characteristics data include geomorphic, sediment, vegetative, and hydraulic data. These data provide an indication of scour condition and channel stability, as well as a baseline to which future inspections can be compared. Previously collected PennDOT information is used in conjunction with bridge and channel characteristics collected in the field to assist in interpretation of structural characteristics, to gauge the changes of site conditions over time, and to provide data for bridge components that are not accessible to USGS personnel.

\section{Collecting bridge and channel-characteristics data}

Bridge and channel-characteristics data are recorded in the field on a form designed to promote a methodical assessment of each bridge site as described in detail in Appendix A and shown in figure 1. This form includes multiple-option data fields for each variable, narrative comment fields, and at least one plan-view sketch of the site. Information for nonaccessible substructure units is recorded on an addendum to the data-collection form and is identified as PennDOT data. USGS personnel collect all geomorphic data as they relate to banklines that approximate bankfull flow. Additional features of significance such as point bars, mid-channel bars, and deflected flows are noted in comment and data fields. PennDOT design and construction plans, if available, are used to verify USGS findings and to aid in obtaining an accurate bridge description. 
Heading data.-USGS personnel complete a heading for each data-collection form. This heading identifies the bridge by use of a 14-digit Bridge Management System (BMS) bridge number (Pennsylvania Department of Transportation, 1993) and lists the USGS assessor, date and time of assessment, and computer file names used by global positioning system (GPS) and total-station equipment. A multiple-option data field indicates if the bridge is an overflow bridge. A comment field is provided to describe these characteristics as needed.

Data collected from the roadway.-While standing on the bridge deck or an equivalent vantage point chosen for safety reasons, USGS field personnel determine the high-flow skew angle and the highand low-flow approach angles, describe general land use around the site, and describe the stream profile. Beginning from this vantage point also affords USGS field personnel the opportunity to get an overview of the bridge site and to begin interpreting the geomorphic, hydraulic, and hydrologic processes occurring throughout the reach.

Data collected in the upstream and downstream channel.-Bridge and channel-characteristics data are collected in a reach approximately two bridge-lengths upstream and downstream from the bridge or approximately $200 \mathrm{ft}$ upstream and downstream for bridges of great size. Distances relative to the bridge are measured along the stream channel and not as a straight line. Site characteristics deemed significant but beyond two bridge lengths in distance from the bridge also are included on the data-collection form. In the upstream and(or) downstream channels, the following data are collected: evidence of road overtopping, evidence of pressure flow, significant scour holes within the channel, bed-material composition, vegetation cover along the bank, bank-material composition, bank erosion, tributary descriptions, cut-bank and meander-impact locations, indications of stream impact of roadway approaches, blowhole presence and description, depositional-bar descriptions, and observed countermeasure type, location, and condition.

Data collected under the bridge.-Bridge and channel-characteristics data, information on the hydrologic and hydraulic effects of the stream on the bridge structure, and summarized descriptions of each bridge substructure unit are collected from beneath the bridge. Substructure units that cannot be assessed by USGS field personnel, because of water depth or other limitations of accessibility, are described by use of data acquired from PennDOT Inspection Reports and(or) PennDOT Underwater Inspection Reports (Pennsylvania Department of Transportation, 1993). Any PennDOT data used to complete the field-viewed assessment are identified as PennDOT data on an addendum to the datacollection form.

The procedures for collection of data under the bridge are divided into seven components: channel, piers, abutments, wingwalls, classification of bed material at individual substructure units, completion of an Observed-Scour Rating table (W-11A)(modified from Pennsylvania Department of Transportation, 1993), and observed under-bridge countermeasures. The channel characteristics under the bridge are similar to those collected upstream and downstream, with the addition of descriptors for debris accumulation, potential of the bridge to trap debris, potential supply of debris from upstream, and any scour holes not in contact with a bridge substructure unit.

Piers, if present, require the completion of 12 multiple-option data items and a narrative description for each pier. The multiple-option data items are pier number, pier location, nose shape, pier type, foundation type, water depth, attack angle, debris width relative to pier width, evidence of pier movement, scour condition at the pier (none, minor, advanced, or serious scour), scour depth from the normal streambed elevation, and inspection type (normal, partial, or addendum required). 
The data-entry format for abutments is similar to that required for piers; each abutment has 11 multiple-option data items and a narrative description. The multiple-option data items are bank location (left or right bank), abutment location in relation to the bankline, abutment type, foundation type, water depth, bridge-opening type, attack angle, evidence of abutment movement, scour condition, scour depth from the normal streambed elevation, and inspection type.

Wingwalls are described in two multiple-option data fields: presence and condition. An optional comment field is supplied to describe significant conditions at each wingwall.

The predominant streambed material at each bridge substructure unit is categorized by use of one of 10 alphanumeric descriptors (Pennsylvania Department of Transportation, 1993). Each of the 10 descriptors categorizes bed material in terms of paving, rock, or alluvium with several levels of competence assigned to each category.

The PennDOT-derived W-11A table describes and rates each bridge substructure unit in eight different categories by use of a rating scale of 0 to $9-0$ being the worst case and 9 being the best. Ratings of 0 through 2 require structural evaluation that is not within the USGS purview; therefore, USGS personnel assign ratings only from 3 to 9 . Assignment of ratings 0 to 2 is deferred to PennDOT personnel and takes place during a final review of the assessment by PennDOT personnel. An overall W-11A rating is issued to each substructure unit on the basis of the findings in the eight descriptive categories. PennDOT has prioritized the categories used within the $\mathrm{W}-11 \mathrm{~A}$ table according to their effect on the structure as follows: change since last inspection, scour hole, debris potential, scourability, opening adequacy/channel, sediment, alignment, and velocity/stream slope. In addition, certain categories are considered critical to the bridge structure if they are rated at or below certain values. These categories can dictate the overall $\mathrm{W}$-11A rating assigned to a substructure unit in the table. The observed under-bridge countermeasures document type, location, and condition of countermeasures under the bridge with multiple-option dataentry and comment fields.

Summary findings.-After collecting data, USGS field personnel write a short narrative description that summarizes any significant site problems. This narrative includes only a general description of those factors deemed significant to the stability and integrity of the bridge and bridge site; specific details are left to the appropriate sections of the data-collection form. When conditions warrant, PennDOT personnel are notified of any significant site problems and asked to make the final determination as to the extent and urgency of any needed remedial action.

USGS field personnel also complete three multiple-option data fields that qualitatively summarize the bridge site: the PennDOT derived "Channel and Channel-Protection Condition Rating" (Pennsylvania Department of Transportation, 1993); the stage of reach evolution adopted and modified from Simon (1989); and the determination of whether the structure is affected by ocean tides. The Channel and Channel-Protection Condition Rating is a qualitative determination of overall channel condition and ranges from 0 to $9-0$ being a highly unstable channel and 9 being a stable channel. Ratings of 0 through 2 make structural implications regarding the bridge; therefore, the USGS defers assignment of these ratings to PennDOT personnel and only assigns ratings of 3 through 9. Ratings of 0 through 2 can be assigned by PennDOT personnel during a final review of the complete site report. The stage of reach evolution qualitatively assigns a description to the stream reach in terms of channel adjustments and reactions by means of seven multiple-choice options. The options for the stage of reach evolution are undisturbed, constructed, degradation, aggradation, lateral migration, stable, and lateral migration and degradation. The stage of reach evolution options are in no order of significance and serve solely as descriptors. Only a small percentage of bridges in Pennsylvania are affected by ocean tides; these bridges are located in the 
ACP Physiographic Province (fig. 3). The USGS determines if there are tidal effects at these bridges by visual inspection of geologic and topographic conditions throughout the stream reach. Options for this data field are yes, no, and cannot be determined.

Possible countermeasures at the site are listed along with location and estimated quantity. Entries for this field are based on PennDOT guidance specifying the type of countermeasures warranted to remediate the observed conditions. Quantities of countermeasures required are given as a qualitative estimate to show relations throughout the reach; for example, at a specific bridge given an entry of 10 cubic yards of riprap for a cutbank upstream and 5 cubic yards of riprap for a cutbank downstream, it is implied that the upstream cutbank is more extensive than the downstream cutbank. This value does not imply an actual amount of riprap required to stabilize a specific bank.

USGS field personnel assign a designation to the bridge indicating whether certain factors should be brought to the attention of PennDOT personnel and, if so, the urgency of the contact. This designation is determined by means of two multiple-option data fields, the first being the PennDOT derived field "should substructure be inspected after heavy rainfall or high flow" (Pennsylvania Department of Transportation, 1993). This field is completed by indicating yes or no. If answered yes, PennDOT personnel are notified that USGS field personnel observed problems, and a record of the discussion is documented on the data-collection form. This designation is for relatively minor issues that are not currently threatening the bridge site. Second is the designation of "none, flag, or phone." The designation of "none" indicates no contact with PennDOT personnel is warranted on the basis of USGS field observations. The designation of "flag" indicates the bridge site has minor problems that are identified through submitted bridge reports rather than direct contact with PennDOT personnel. The designation of "phone" indicates potentially serious problems were observed by USGS field personnel, such as displacement of a bridge substructure unit, and a formal contact with PennDOT personnel is warranted. A designation of "phone" results in forwarding a copy of the field data-collection form to the appropriate PennDOT Engineering District and documenting the contact on the data-collection form. These contacts are usually made weekly; however, in extreme cases when USGS field personnel feel that their safety or that of the general public is at risk, PennDOT personnel are notified immediately. For example, a stonemasonry bridge exhibiting significant undermining at a substructure unit and subsequent displacement would be classified as a "phone" bridge, and the appropriate PennDOT Engineering District would be notified immediately from the field.

\section{Processing bridge and channel-characteristics data}

Bridge and channel-characteristics data are entered into a computer site-indexed database (fig. 1) when field personnel return to the USGS office. All entries are checked for consistency. Any questionable entries are verified by USGS field personnel present during the bridge site visit and by video-tape data. All data acquired from PennDOT data sources and subsequently recorded on the addendum to the datacollection form are identified within the database as PennDOT data.

\section{Quality assuring bridge and channel-characteristics data}

USGS personnel review all data-collection forms before leaving the bridge site. This is a collaborative process among all team members to ensure accuracy and consistency in data collection. This process requires a signature by a team member, other than the data collector, indicating concurrence with the data entries on the form. At the USGS office during data entry, project personnel ensure all abbreviations and field notes are expanded and in an acceptable format, all required entries are in place, and any questionable data are verified by USGS field personnel present at the time of the site visit and by 
video-tape data. Subsequent to data entry, all bridge and channel-characteristics data receive a third review before being classified as "entered." In this phase, project personnel check the input data against the original data-collection form to ensure that field notes have been transcribed correctly. A final check is made of data entries along with all other associated data, such as location and survey data, before submission of a "final" bridge report. Data-verification checks are rotated among all USGS project personnel after the assessment of the bridge sites were completed in order to ensure consistency and preclude introduction of individual bias.

To ensure adherence to established data-collection procedures, consistent data, and to promote quality assurance, training and oversight of personnel is emphasized. Preceding each field season, a 2-week training course is completed by all USGS field personnel to introduce and(or) review datacollection and other project procedures. Intermittently throughout the field season, random USGS personnel are rotated to different USGS field offices to ensure consistent data-collection procedures between offices. During the first 2 months of the field season, bridge-site video tapes are reviewed in the office to confirm that established field procedures are being followed and data entries accurately reflect site conditions. As field personnel become more familiar with data collection, the percentage of bridge-site videos reviewed is reduced to approximately 10-15 percent.

\section{Plan-View, Undermining, and Bridge-Opening Sketch Data}

The information and data in this section are intended to provide a general description of site conditions. Plan-view sketches are completed for all sites to show the hydraulic features described on the data-collection form. Undermining and bridge-opening sketches are completed when required to show unusual, site-threatening, and(or) difficult to describe conditions. Sketches are not to scale but are merely to show relative positions and extents of significant site conditions and characteristics.

\section{Recording sketch data}

During the site visit, USGS field personnel complete a plan-view sketch of the site. A preformatted checklist of symbols for common features is used to ensure completeness of the sketch and consistency throughout the project. This checklist may be amended as required to show uncommon, yet significant, site features. A sketch of undermining at substructure units is required when USGS personnel list a substructure unit as having "serious scour." Estimates of the extent of the undermining length, height, and depth under the substructure unit are included on the sketch. If a standard entry on the datacollection form does not adequately describe the bridge opening and USGS personnel enter the bridgeopening type as "other," a bridge-opening sketch is completed.

\section{Processing sketch data}

Completed sketches are scanned into an image-processing software package. The PennDOTsupplied BMS (Pennsylvania Department of Transportation, 1993) bridge number is added to the top of the image, and all page numbers are removed. Because of field conditions, sketches can be water stained, dirty, and(or) otherwise marked; therefore, all sketches are cleaned up as much as possible by darkening line weight, removing smudge marks, and making sure all writing is legible. The sketch is stored in bitmap format in a computer directory and subsequently moved into a site-indexed database for use. 


\section{Quality assuring sketch data}

Field personnel review all sketches before leaving the bridge site. Consistency between the datacollection form and all applicable sketches is checked as well as completeness and quality of the sketches. The sketches are subsequently rechecked when scanned. Any incomplete or questionable data are verified with field personnel present at the time of the site visit and filled in as possible.

\section{Total-Station Survey Data}

Bridge-geometry, cross-section, road-grade profile, and geomorphic characteristics are surveyed with a total station (fig. 1). Survey data are subsequently downloaded and stored in a computer directory. A bridge elevation and a channel cross section are produced with a computer-aided drafting (CAD) application. Bridge-opening area, stream slope, cross-section pier width, and bank angles are computed from compiled survey data. Finalized survey presentations and computed values are stored in a computer database.

\section{Collecting survey data}

Angle and distance measurements are collected and recorded with a Nikon DTM750 total station. Each surveyed point is assigned an attribute, using an established convention, indicating the location from which the point is collected (Appendix B). All data are stored internally in a hard drive and on a PCMCIA data card. Initial station coordinates are state plane coordinates and are entered into the total station as an arbitrary 5,000 ft north and 5,000 ft east. A reference point on the bridge is given an arbitrary elevation of $10,000 \mathrm{ft}$ and marked with a square that is chiseled into the bridge structure. In this manner, no actual location in Pennsylvania is inadvertently confused with this survey. Final coordinates and elevations are established and applied later in the process. Actual elevations, if available, are from PennDOT supplied information and actual coordinates are from GPS data or USGS 7.5-minute topographic maps.

Each survey is composed of a series of interlocking radial surveys (Wolf and Brinker, 1994) in which a control point from the previous station is resurveyed from the current station and the relative positions of the two points are compared. For the purpose of this project, established tolerances allow for a closure error of $0.1 \mathrm{ft}$ per instrument set up. This tolerance allows an acceptable representation of the hydraulic and hydrologic aspects of the bridge site as well as minimizes the time spent at each site. A closure tolerance of $0.1 \mathrm{ft}$ per instrument set up also accounts for adverse surveying conditions such as deep mud around the bridge site and(or) hot asphalt on the roadway.

Bridge geometry, cross-section elements, a reference point for the cross section, road-grade profile, water-surface slope, bank angles, GPS reference points, high-water marks indicating pressure flow, and available control points, such as bench marks, are surveyed. Significant features directly observable but beyond $200 \mathrm{ft}$ from the bridge are included in the survey. If the site includes components that are not safely accessible, alternative survey methods are used, including using weighted engineering tapes and offsetting side shots (data points), to gather the required data. Features deemed significant in helping to describe site conditions, but for which there are no established attributes, are surveyed and assigned the attribute GENPT (Generic Point). A comment is added to the total-station file describing the feature. Examples are exposed utility pipes and(or) natural and unnatural changes to stream slope.

Some bridges receive abbreviated surveys if they are deemed by field personnel to have structural components that will not be affected by any flood and will not be otherwise hydrologically or hydraulically affected because of the height of the bridge deck and(or) the lateral extent of the bridge 
structure. Examples are bridges crossing high gorges or elevated roadways in urban areas. This abbreviated survey extends laterally to the first substructure unit on each bank that rests entirely on or above the established flood plain and is not affected by streamflow; vertically, the abbreviated survey may exclude all upper bridge components including parapet, road-grade profile, wingwalls, and bottom of beams but it includes, when safety and conditions permit, at least one point common to available PennDOT plans, bench marks, PennDOT plaques, and GPS locations. If a complete cross section is not possible because of accessibility or safety concerns, only the road-grade profile, GPS locations, water-surface slope, and any significant features directly observable are surveyed.

\section{Processing survey data}

Total-station data are downloaded weekly to a computer directory. During the download process, surveyed angle and distance data are converted to northing, easting, and elevation data. This conversion allows the survey data to be used by other computer programs and applications. All comments are reported on data-processing forms and in the folder containing information relating to that specific bridge. Survey data is subsequently used to create a bridge elevation and cross-section plot and compute geomorphic, hydraulic, and hydrologic values. Finalized data are stored in a computer database.

Bridge elevation and channel cross section.-Processed northing, easting, and elevation data are used by a CAD computer application to create a plot illustrating the elevation of the bridge structure, road-grade profile, and cross-section elements (fig. 5). Scour holes, debris piles, deposition accumulation, protective works, reference marks, and unusual features are included in the presentation along with bridge structural elements. The bridge elevation and channel cross section are oriented parallel to the roadway crossing the bridge; therefore, the view is looking straight at the bridge, not necessarily as the water approaches or passes through the structure. The cross section and associated bridge structural elements, such as bottom of beam locations, are surveyed by adhering as closely as possible to an invisible line across the channel at the most restrictive opening of the bridge.

Geomorphic, hydraulic, and hydrologic computations.-Bridge-opening area, pier width, water-surface slope, and bank angles on the upstream and downstream banks are computed by computer applications using coordinate data created during the download process. Bridge-opening area is computed for the most restrictive opening of the bridge through which water can pass, taking into account utilities, piers, and other objects that restrict flow by a CAD computer application. This process is completed span by span; the sum of all individual areas comprises the overall bridge-opening area. The computation of bridge-opening area is intended for approximations of flood capacity and identifying long-term degradational or aggradational trends; it does not consider any substructure units that are skewed against streamflow or any upstream and(or) downstream geomorphic features. Pier width is computed as a cross-sectional pier width—that is, the horizontal distance through the widest part of the pier at the streambed and within the plane of the cross section including exposed footings and(or) permanent protective works. If the widest part of the pier cannot be determined from field observation (for example, if large amounts of debris partially or totally prevent access to the pier), no pier width is computed. Exposed footing on only one side of a pier is considered unstable and no pier width is computed because slight hydrologic events can greatly increase pier width by exposing the obscured footing. Water-surface slope through the bridge, or the slope of the streambed in the case of dry channels, is determined over a distance of approximately two bridge lengths or $200 \mathrm{ft}$, whichever is smaller, upstream and downstream from the bridge. Stream slope is determined on either the right or left side of the channel at the edge of water; this choice is arbitrary and is made by USGS field personnel depending solely on conditions at the bridge site. Using the change in elevation between the upstream and 
BMS Structure ID $X X X X X X X X X X X X X X$

survey of Bridge and Channel by USGS on 09-08-98

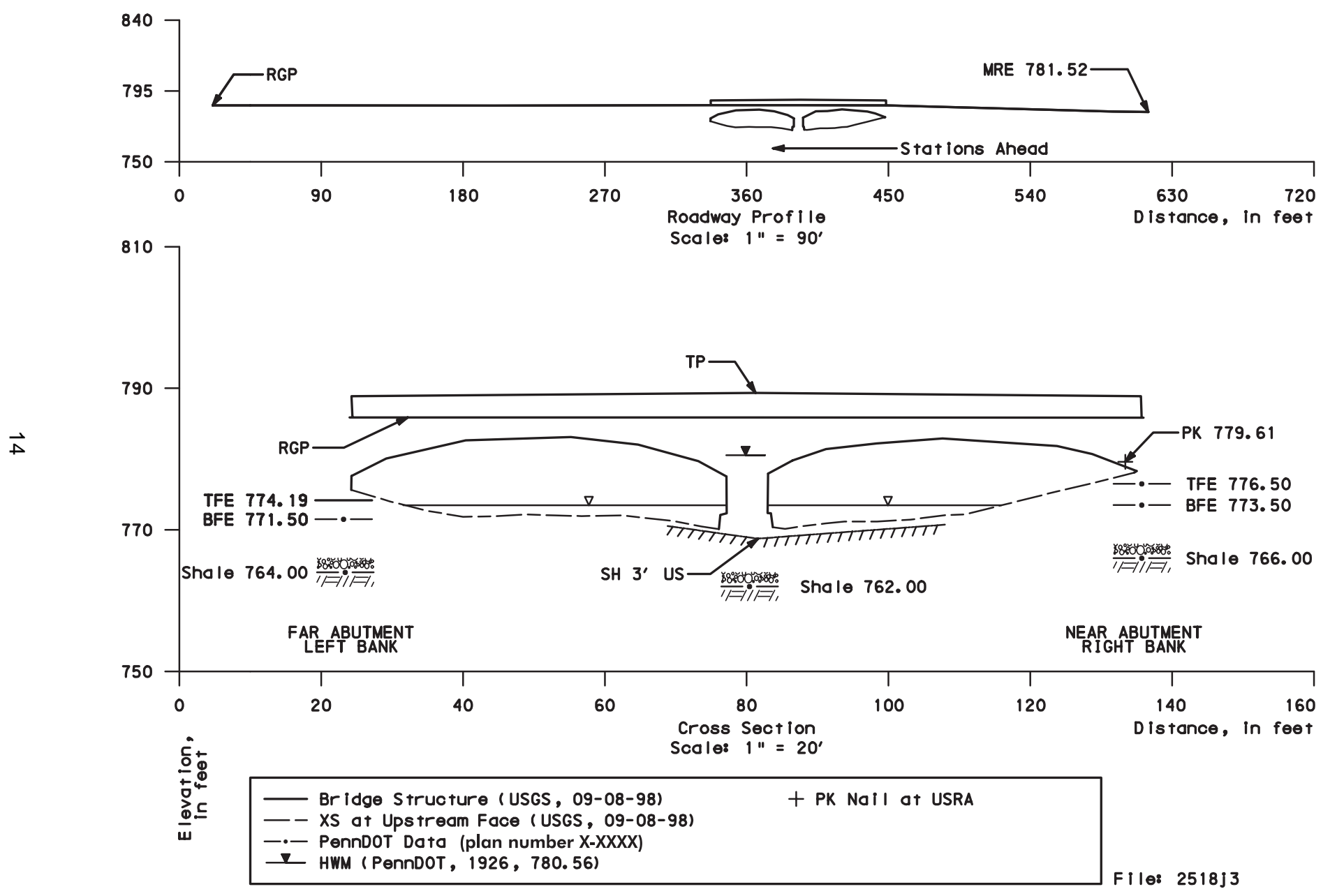

\section{EXPLANATION}

BMS - PennDOT bridge management system RGP - road grade profile MRE - mean road elevation TP - top of parapet

TFE - top of footing elevation BFE - bottom of footing elevation PK - PK masonry nail US - upstream $\mathrm{SH}$ - scour hole XS - cross section HWM - high-water mark USRA - upstream right abutment

Figure 5. Bridge elevation and channel cross section of field-viewed bridge. 
downstream surveyed points divided by the horizontal distance through the bridge, the water-surface slope is computed and reported in units of "percent slope." For sites that are described by USGS personnel as having a straight reach, the surveyed point at the bridge may be omitted because this point is used only to account for meanders through the bridge opening. A bank angle for each of the upstream and downstream banks is computed at a representative location by use of two surveyed points collected at the top of bank and the edge of water. A point approximating top of bank is used when a well defined bankline does not exist and a point located at the bottom of bank is used when water does not contact the bank. By use of these two surveyed points, an angle is computed and reported in "degrees;" zero degrees indicates a horizontal bank and 90 degrees indicates a vertical bank. Angles in excess of 90 degrees are possible in the case of cantilevered banks; however, for the purpose of this project, all angles greater than 85 degrees are considered vertical and are reported as "greater than 85 degrees."

Quality assuring survey data.-All survey data are checked for completeness and accuracy during and after the download process. Survey data are checked manually by USGS personnel to ensure that closures are within allowable $0.1 \mathrm{ft}$ tolerances. All required attributes are checked for inclusion in the survey. All comments are noted on a data-processing form and in the folder assigned to the specific bridge. A computer application, run during data processing, verifies that proper attributes have been used. Any errors detected at this phase are corrected and noted on the data-processing form. A plan view of the bridge site is created and viewed to ensure that the bridge site has been surveyed properly and that all features are present and properly located. A subsequent computer application sorts and rechecks the processed data for use in creating opening-area, pier-width, stream-slope, and bank-angle data and crosssection plots. Computer-generated cross-section plots and calculations are manually reviewed by USGS personnel for completeness and accuracy to ensure that all coordinates and elevations associated with survey attributes have been properly applied and computed by the computer-processing software.

\section{Location Data}

The bridge location is determined with a Trimble, code-based GPS (fig. 1) or, if conditions prohibit data collection with GPS, by digitizing USGS 7.5-minute topographic maps (fig. 1). GPS location data are corrected subsequent to collection (postprocessed) to improve accuracy, and all locations are stored in a computer database. Whenever possible, GPS locations are reported for the centerline of the road at the near abutment; however, locations are reported for alternate substructure units with various offsets in the event that GPS data collection at the near abutment is not possible or is not representative of the site. All digitized locations are collected at the bridge and stream intersection as indicated on topographic maps.

\section{Collecting Global Positioning System data}

GPS uses an array of satellites, in fixed orbits around the earth, to determine the latitude and longitude of a bridge substructure unit in degrees, minutes, and seconds. When possible, 100 positions are collected at 1-second intervals at each bridge abutment upon arrival at the bridge site. The mean of each group of 100 positions subsequently determines the actual latitude and longitude of a specific abutment. Upon completion of the site assessment, or 1 to 2 hours after initial data collection, 100 additional positions are collected at the near abutment in an effort to confirm accuracy. If duplicate data collection is not possible at the near abutment because of loss of communication with satellites and(or) multipath (reflected signal) errors, an attempt is made to collect duplicate data at another substructure unit such as the far abutment; in this case, notation is made on the data-collection form describing if, and where, duplicate data was collected. 
USGS personnel generally collect GPS data while standing on the centerline of the roadway directly above the bridge abutment; however, site conditions commonly require data to be collected streamward and(or) landward of this position. Notation of the streamward- and(or) landward-offset distance is recorded in the GPS data logger and stored with the final latitude and longitude of the substructure unit in a computer database. When USGS field personnel determine that the bridge abutments do not accurately represent the true location of the bridge and stream intersection, GPS data are collected at alternate substructure units closer to that intersection; for example, elevated urban bridges, at which the abutments may be miles from the bridge and stream intersection, will generally have GPS data collected at piers on alternate sides of the stream channel. Such cases are recorded in the GPS data logger and noted on the data-collection form, data-processing form, and in the computer database. The locations at which GPS data are collected are marked on the bridge with paint and surveyed along with the bridge-geometry in order to accurately associate the bridge survey with the latitude and longitude.

\section{Collecting digitized location data}

When conditions are prohibitive to collecting GPS data because of the available constellation of satellites, excessive tree cover, topography, or other impeding conditions, the bridge location is determined by digitizing in North American Datum of 1927 (NAD 27) from a USGS 7.5-minute topographic map. Digitized locations are determined at the center of bridge and stream intersection as indicated on the 7.5-minute topographic map. Sites requiring digitizing are noted as such in a comment field within the computer database.

\section{Processing Global Positioning System data}

Base stations, located throughout Pennsylvania and adjacent states, are fixed points of reference used to remove errors that are inherent in the reception of GPS signals. The base station nearest the bridge (generally within $150 \mathrm{~km}$ ) is determined (Appendix C) and data from that base station are downloaded to a computer via the internet or a modem. GPS data collected at the bridge site also are downloaded to a computer and subsequently corrected by use of data from the associated base station. This correction results in a latitude and longitude accurate to within about $1 / 10$ of a second or about $3 \mathrm{~m}$. Without this correction, accuracy is within the range of approximately $100 \mathrm{~m}$ for code-based GPS. The datum used and output by the processing software is World Geodetic Survey of 1984 (WGS 84). This WGS 84 datum is considered to be equivalent to the North American Datum of 1983 (NAD 83) that is used for processing digitized locations. Processing results in three separate locations for each bridge, two substructure units and a duplicate location for quality assurance. The primary latitude and longitude reported for a bridge site is for the near abutment. Locations for alternate substructure units are reported when it is determined that the primary location fails to meet established criteria.

\section{Processing digitized location data}

All digitizing is done in NAD 27 and stored in a computer database. All latitudes and longitudes are subsequently converted to NAD 83 by means of a commercially available computer software package that performs datum shifts automatically within the computer database. Conversion to NAD 83 is required to maintain consistency with data collected by GPS and to facilitate subsequent GIS data analysis.

\section{Quality assuring location data}

At each bridge site, an attempt is made to collect duplicate GPS data for one location with a 1- to 2-hour interval between each data-collection attempt. The duplicate data are intended to yield a latitude and longitude similar to the preceding data but, because of the time element, does so by use of a different 
constellation of satellites. The change in time and satellite constellation commonly can be used to identify locations with errors due to reflected signals off buildings or the bridge superstructure termed "multipath errors."

Each location, subsequent to postprocessing, is the mean of approximately 100 individual positions. The criteria for determining an acceptable location are the following: (1) the distribution of the positions must have a standard deviation equal to or less than $1.5 \mathrm{~m}$ (with a standard deviation of $1.5 \mathrm{~m}$, about 95 percent of all positions should be within $3 \mathrm{~m}$ of the calculated location) or (2) an initial location and the associated duplicate location of that feature are within $3 \mathrm{~m}$ of each other. If at least one location does not meet the established criteria and if a second attempt has been made to collect GPS data with the same result, the latitude and longitude are digitized from a topographic map.

Both GPS-determined locations and digitized locations are plotted on GIS spatial data sets to visually identify any obvious erroneous data (fig. 6). All bridges that are identified by a computer program as having GPS locations plotting greater than approximately $100 \mathrm{~m}$ from a bridge and stream intersection are manually reviewed. This criteria is primarily designed to identify bridges that were potentially

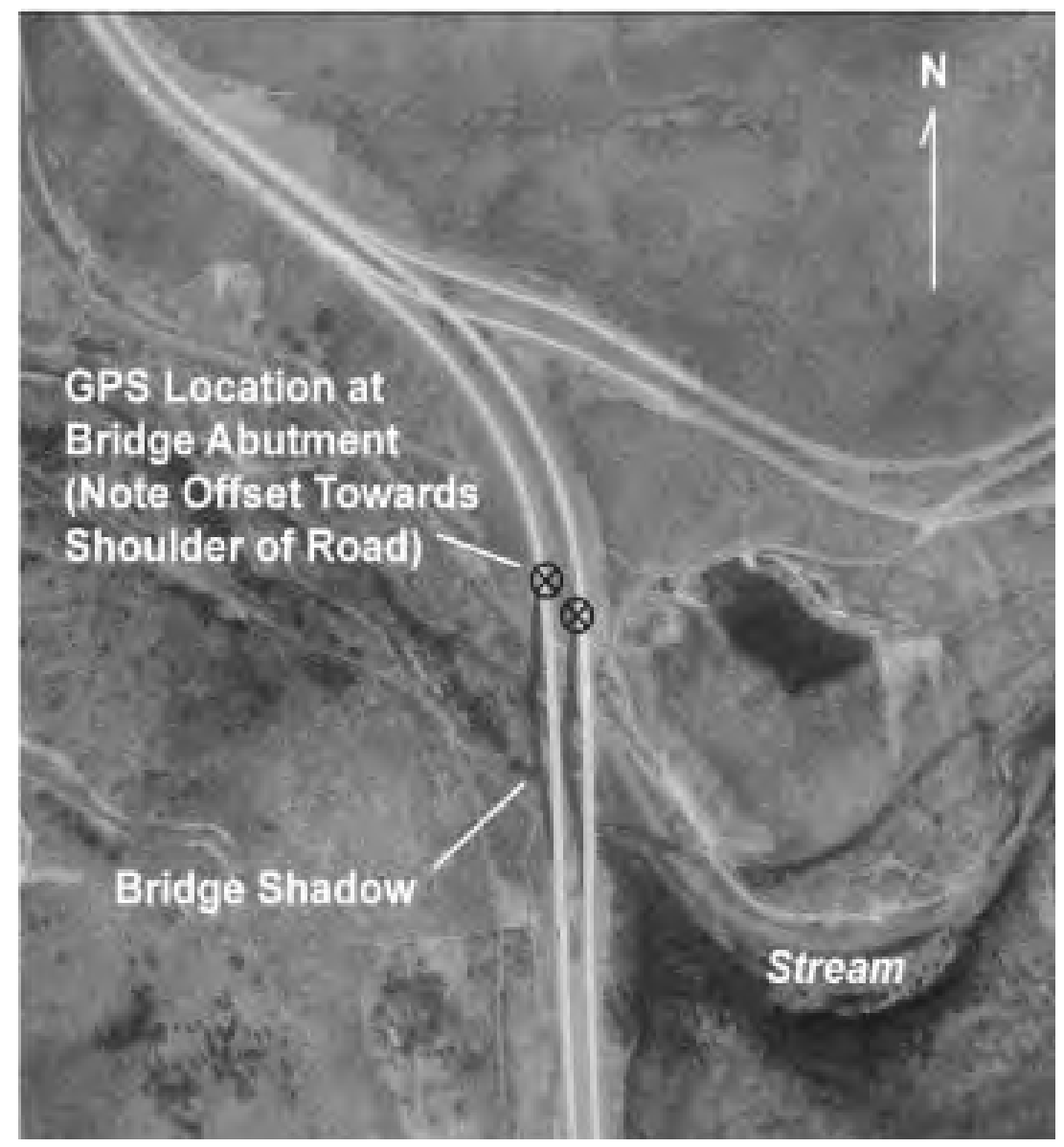

Figure 6. Geographic information system spatial data set showing global positioning system locations at bridge abutments. 
processed with an incorrect datum; however, bridges crossing smaller streams that are not yet included in GIS coverages and bridges crossing streams with expansive floodplains also fail to meet this criteria and are subsequently manually reviewed.

\section{Video-Tape and Captured-Image Data}

Video-tape and captured image data are collected at each field-viewed bridge site on the day of the site visit (fig. 1). Video-tape data and narration by field personnel are intended to give the viewer a brief overview of site conditions on the day of the site visit as well as to document any site conditions that USGS personnel deem as significant, such as stream impacts of the roadway approaches or undermining of bridge substructure units. Video-tape and captured-image data are not intended to provide comprehensive coverage of all site conditions.

\section{Collecting video data}

Each field-viewed bridge site is video taped in a structured, sequential order (Appendix D). The taping includes narration by field personnel and describes site characteristics of structural and geomorphic significance. Field personnel begin and end each video by recording the bridge number and date of video, usually shown on a large, erasable whiteboard. Video of the bridge site begins by first looking at the upstream and downstream channels from the bridge. Collection of video data for the upstream and downstream channels is accomplished by standing on the bridge deck above the respective face of the bridge or by standing in an equivalent position if no access is available to the bridge deck. Video taping starts with a view of the near roadway approach, then pans out towards the channel and around to the far roadway approach; this provides coverage of channel and overbank areas and conditions. Taping continues from the far roadway approach and pans down and across the face of the bridge, ending with another view of the near roadway approach. Panning down and across the bridge face shows debris and(or) any feature directly at the face. Field personnel then move out into the channel approximately two bridge lengths or $200 \mathrm{ft}$, whichever is less, upstream, and then subsequently downstream. From these locations, a 360-degree pan is taped, starting and ending looking away from the bridge at the upstream and, subsequently, downstream channel. Field personnel pause momentarily on the view of each bridge face to facilitate the capture of an image later in the processing. After routine procedures are completed, field personnel are free to continue with additional taping as required in order to document bridge-site conditions and obtain the best possible image of the bridge. Often, additional taping is required to document an oblique view of the bridge face or significant conditions that are not visible from standard locations.

\section{Processing video data}

Selected video images are captured from video tape, enhanced, edited, and subsequently stored in a computer directory by use of commercially available software. An attempt is made to provide an image of the upstream opening of the bridge (fig. 7). If it is not possible to capture an image of the upstream bridge opening because of unfavorable site conditions, such as poor lighting or dense vegetation, the following images are captured in order of highest priority:

1. downstream bridge opening

2. oblique shot of the upstream bridge face

3. oblique shot of the downstream bridge face 


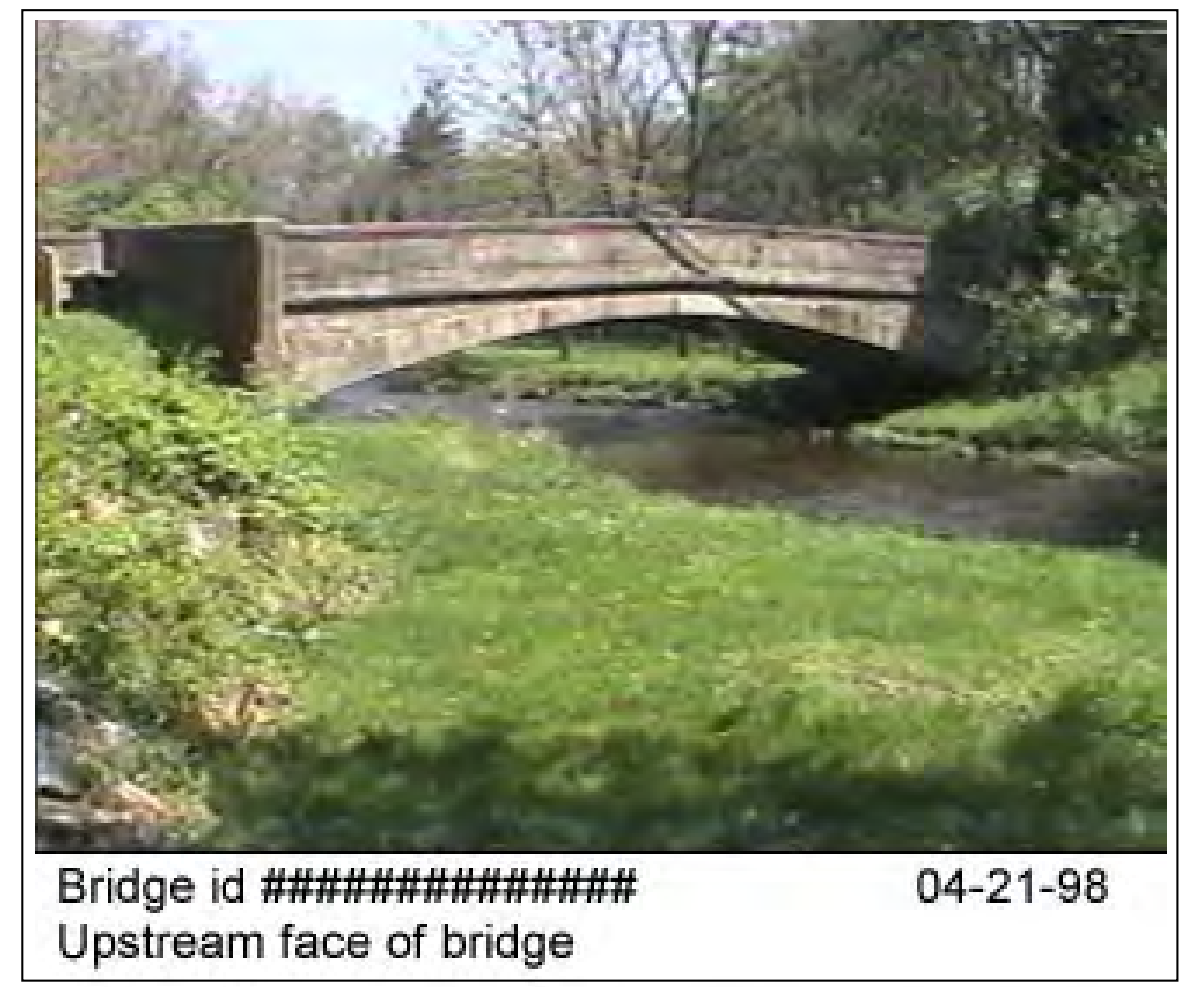

Figure 7. Video image of upstream face of field-viewed bridge.

Additional images indicative of existing or potential structural stability problems also are captured as required to fully document significant site conditions. Captured images are enhanced with commercially available photographic-processing software in order to maximize clarity and edited to add associated information such as bridge number, date, and a description of the image. Edited images are stored in a separate computer directory from the raw, unedited images. In the event that an image does not pass inspection or if an error is detected in the quality-assurance process, the original image can be used again.

\section{Quality assuring video data}

Video-tape data for approximately 10 percent of all bridge sites are reviewed subsequent to collection in the USGS office. Office review of video-tape data is to confirm the accuracy of field procedures and data elements collected as well as to confirm the quality and operation of video equipment. Equipment malfunctions such as inoperable audio or dirty recording heads are difficult to detect in the field and must be determined by subsequent review of collected data. All video images captured from the video tape are reviewed for quality of image and correctness of information added to the image during the processing phase. 


\section{Office-Reviewed Bridge Sites}

PennDOT-supplied office data are being compiled for approximately 500 bridges throughout the course of the study. Office-reviewed bridge sites are not visited by USGS personnel and rely solely on PennDOT-supplied data. Data for bridges that fall into the office-reviewed category are recorded on the "Bridge and Channel Characteristics at Office-Reviewed Bridge Sites" form. A detailed description of this form and its components is presented in Appendix E.

Scour assessments based on office-reviewed data are being conducted for two categories of bridge sites. The first category includes bridges built or extensively renovated after 1982. In 1982, PennDOT revised the requirements for hydrologic and hydraulic reports resulting in substantially more data becoming available for bridges constructed after this time. Data sources used to complete the assessment of office-reviewed bridge sites include PennDOT Inspection Reports and(or) PennDOT Underwater Inspection Reports, hydrologic and hydraulic reports, foundation reports, foundation approval letters, plan and design data, and photographs documenting site conditions. These data are used to characterize the bridge site, as well as to assist PennDOT in meeting the 1988 FHWA mandate. The second category includes bridges built before 1983 but at which, because of hydraulic conditions or safety concerns, greater than 50 percent of the substructure units are inaccessible to USGS personnel for data collection in the field. For this second category of bridge sites, all available PennDOT information is reviewed; however, data sources are frequently limited to the most recent PennDOT Inspection Report, Bridge Management System data, and, if available, the most recent PennDOT Underwater Inspection Report. Because of the lack of data to sufficiently characterize the bridge site for this second category, the primary objective is to assist PennDOT in satisfying the 1988 FHWA mandate. No video or survey data are compiled for office-reviewed bridge sites.

\section{Bridge and Channel-Characteristics Data}

The information and data in this section include geomorphic, sediment, vegetative, and hydrauliccharacteristics data collected from PennDOT data sources and compiled by USGS personnel. These data are qualitative and provide an indication of channel stability and scour condition as well as a baseline to which future inspections can be compared. Office-reviewed bridge data represent bridge-site conditions for the time and date that data was collected by PennDOT or PennDOT contract personnel. The date of all data sources used by USGS personnel is recorded on the data-collection form to document this time frame.

\section{Compiling Bridge and Channel-Characteristics Data}

Bridge and channel-characteristics data for office-reviewed bridge sites are housed in PennDOT District Engineering offices, offices of consultant engineers, and the offices of local bridge owners throughout the Commonwealth of Pennsylvania. USGS personnel travel to these locations to record the required data as they become available.

Office-reviewed data are reported on a form designed to promote a methodical description of the bridge site as described in detail in Appendix B. This form includes data entry by use of multiple menu options for each variable and narrative comment fields. For bridges that are office reviewed, bridge and channel-characteristics data similar to those at field-viewed sites are compiled. Additionally, design information such as recurrence interval, discharge, elevation, and maximum velocity for the design flood; discharge, elevation, maximum velocity, and calculated scour depths for the 100-year flood; and more specific descriptors of substructure units are compiled when available. Flagged data fields (noted by an asterisk placed at the data-entry field) indicate those data required to meet the 1988 FHWA 
mandate. Data fields that are boxed may commonly have no data available and are filled in as possible. These boxed fields are not used in the computation of the Code and Rating and are used primarily to better define the bridge site in terms of channel stability. Data sources for office-reviewed bridge sites include plan data, design drawings, hydrologic and hydraulic reports, foundation reports and(or) foundation approval letters, most current PennDOT Inspection Reports, PennDOT Underwater Inspection Reports (if applicable), and all available photographs. All data sources used for the assessment of officereviewed bridge sites are collected by PennDOT personnel according to PennDOT protocols. PennDOT data such as flood-recurrence interval and discharge data, while similar to USGS data, are not compared to that determined by the USGS.

Upon completing compilation of the bridge and channel-characteristics data, USGS personnel assign a final designation indicating whether a site visit is warranted to verify or collect more extensive data. PennDOT personnel are consulted throughout the data-compilation process and their input is considered in making this final designation. Bridge sites constructed or renovated before 1983 (limited data) where data indicate highly unstable channels or substantial scour-related problems are examples of office-reviewed bridge sites that may warrant a site visit by USGS field personnel. Additional information such as surface cover near the bridge, upstream and downstream bed material, vegetative cover near the bridge, and other data not readily available from older, office-reviewed data are collected at these sites and incorporated into the database to more accurately represent problematic bridge sites.

\section{Processing Bridge and Channel-Characteristics Data}

Bridge and channel-characteristics data for office-reviewed bridge sites are entered into a computer database upon return to the USGS office. This database entry program differs from that for field-viewed bridge sites because of the required changes in the format of the data-collection form and the source of the compiled data. Questionable entries are verified during data entry by the USGS personnel that reviewed and compiled the data and(or) PennDOT personnel as required.

\section{Quality Assuring Bridge and Channel-Characteristics Data}

PennDOT personnel are consulted at the time of data compilation to verify any questionable characteristics or data entries. During data entry, USGS personnel ensure that all abbreviations are expanded or are consistent with established guidelines for acceptable abbreviations, all required entries are in place, and questionable data are verified by USGS personnel present at the time of the data compilation and by PennDOT personnel as required. All bridge and channel-characteristics data are subsequently reviewed again before being archived. In this phase, USGS personnel check the computer data entries against the original data-collection form to ensure that notes have been transcribed correctly.

\section{Location Data}

Locations for office-reviewed bridge sites are digitized from USGS 7.5-minute topographic maps. The digitized location is the center of the bridge-stream intersection. All digitizing is done in North American Datum 1927 then converted to North American Datum 1983 by means of a commercially available software package. Locations are plotted on GIS road and stream coverages to identify any errors caused by incorrect datums or equipment malfunction. 


\section{PROCEDURE FOR DRAINAGE-BASIN DESCRIPTION AND FLOOD-DISCHARGE COMPUTATIONS BY USE OF A GEOGRAPHIC INFORMATION SYSTEM}

Drainage-basin characteristics upstream from the bridge site are compiled for nearly all sites by means of various GIS computer applications and USGS topographic maps in order to assist PennDOT in interpreting data and prioritizing remedial actions as required. Drainage basins are delineated, for most sites, by use of a digital elevation model (DEM) with available stream and topographic GIS coverages. Drainage basins in counties that have surficial carbonate rock are manually-delineated from USGS topographic maps because of uncertainties in drainage patterns caused by karst topography. Drainage basins inside metropolitan Philadelphia are identified from previously published data or manually delineated from USGS topographic maps. Manually delineated drainage-basin boundaries are digitized and used along with those obtained by GIS methods to develop basin criteria. All drainage-basin areas computed by GIS methods are compared to areas determined from USGS topographic maps to ensure accuracy of the automated system of computation. Bridge sites are located within a drainage basin by means of GPS or digitized latitude and longitude data.

A statewide GIS-coverage database has been compiled that includes carbonate, crystalline, siliciclastic, and unconsolidated rock types; land use; soil types; drainage-basin boundaries; flood regions and precipitation index maps; and skew coefficients for flood-frequency computations. From these coverages, percentage of forest cover, percentage of urbanized area, surface area of reservoirs, percentage of carbonate geology, and mean basin slope are determined for the drainage basin upstream from the bridge site.

Peak flood discharges are estimated for the 10-, 25-, 50-, 100-, and 500-year recurrence intervals by use of as many as four computational methods based on location of the bridge site and the size of the drainage basin in which the bridge site is located (table 1). Bridge sites are determined as being outside or inside of the Philadelphia metropolitan area on the basis of the incorporated area of the city of Philadelphia, Philadelphia County, Pa. (Federal Emergency Management Agency, 1996).

Table 1. Methods used for estimation of flood-frequency discharges

[USGS 82-21, U.S. Geological Survey Water-Resources Investigations 82-21, Evaluation of the Streamflow Data Program in Pennsylvania; FIS, Federal Emergency Management Agency, Flood Insurance Study; PSU-IV, Penn State University equation IV; <, less than; >, greater than; $\leq$, less than or equal to; Q10, 10-year flood-frequency discharge; Q25, 25-year flood-frequency discharge; Q50, 50-year flood-frequency discharge; Q100, 100-year flood-frequency discharge; Q500, 500-year flood-frequency discharge]

\begin{tabular}{|c|c|c|c|}
\hline Location & $\begin{array}{l}\text { Drainage basin area } \\
\quad \text { (square miles) }\end{array}$ & Flood-frequency discharge & Method used for estimation \\
\hline \multicolumn{4}{|c|}{ Outside metropolitan Philadelphia area } \\
\hline & $>500$ & Q10, Q50, Q100, Q500 & FIS \\
\hline & $\leq 500$ & Q10, Q25, Q50, Q100, Q500 & USGS $82-21$ \\
\hline & $>150$ & Q10, Q25, Q50, Q100, Q500 & USGS streamflow-measurement station data \\
\hline & $\leq 150$ & Q10, Q25, Q50, Q100, Q500 & PSU-IV \\
\hline \multicolumn{4}{|c|}{ Inside metropolitan Philadelphia area } \\
\hline & All basins & Q10, Q50, Q100, Q500 & FIS \\
\hline & $>150$ & Q10, Q25, Q50, Q100, Q500 & USGS streamflow-measurement station data \\
\hline & $\leq 150$ & Q10, Q25, Q50, Q100, Q500 & PSU-IV \\
\hline
\end{tabular}


Inside the Philadelphia metropolitan area, three computational methods are used: transference of Federal Emergency Management Agency (FEMA), Flood Insurance Study data (FIS) (Federal Emergency Management Agency, 1976-1996), the Penn State University regional equation method number IV (PSU-IV) (Aron and Kibler, 1981), and transference of USGS streamflow-measurement station data (Flippo, 1977). FIS data are used for bridge sites within the metropolitan Philadelphia area in all sizes of drainage basins. Peak discharges for most recurrence intervals are extrapolated from the locality of the FIS study to bridge sites within the same drainage basin by the use of drainage-area ratios; the 25-year peak discharge, however, is not estimated using FIS data in this area. Methods used to compute discharges in the FIS studies are identified in the individual FIS study reports and are not presented with the discharge data computed for the bridge site. The PSU-IV method uses regional equations to determine the 10-, 25-, 50-, and 100-year peak discharges for bridge sites with drainage basins of less than or equal to $150 \mathrm{mi}^{2}$. USGS streamflow-measurement station data are used to estimate the 10-, 25-, 50-, 100- and 500 -year peak discharges for bridge sites with drainage basins of greater than $150 \mathrm{mi}^{2}$. Under this method, peak discharges are determined for streamflow-measurement stations located within the same drainage basin as the bridge site. These peak discharges are subsequently extrapolated to the bridge site by use of drainage-area ratios.

Outside of the Philadelphia metropolitan area, four computational methods are used to estimate peak discharges: FIS, PSU-IV, USGS streamflow-measurement station data, and the USGS 82-21 regional equation method (Flippo, 1982). The FIS, PSU-IV, and USGS streamflow-measurement station data methods are applied in a similar manner to this region with the exception that FIS data is only applied to drainage basins greater than or equal to $500 \mathrm{mi}^{2}$. In addition to FIS, PSU-IV, and USGS streamflowmeasurement station data methods, the USGS 82-21 regional equation method is used for bridge sites with drainage basins less than $500 \mathrm{mi}^{2}$ for estimates of the 50- and 100-year peak discharges; the 10-, 25-, and 500-year peak discharges are subsequently calculated from extrapolation of the 50- and 100-year peak discharges.

Peak discharges are determined for all USGS streamflow-measurement stations with greater than 10 years of data available with drainage basins of greater than $150 \mathrm{mi}^{2}$. The computed data for the Q10, Q25, Q50, Q100, and Q500 values are extrapolated to bridge sites within 0.3 to 3.0 times the drainage basin area from the location of the streamflow-measurement station. Exceeding the 0.3 to 3.0 times range in drainage basin area will result in increased error because of inherent changes within the drainage basin such as basin slope, land use, and(or) other possible variables. If a stream reach has two or more streamflow-measurement stations within a given proximity such that the computed statistics will overlap for areas along that reach, statistics for the area of data overlap were computed from the streamflowmeasurement station with the longest period of record (Ehlke and Reed, 1999). 


\section{PROCEDURE FOR COMPUTATION OF SCOUR-CRITICAL BRIDGE INDICATOR CODE AND SCOUR ASSESSMENT RATING FOR BRIDGE SCOUR ASSESSMENT}

The Code and Rating use PennDOT derived algorithms (Bryan Spangler, written commun., 1998) to rate bridge sites for observed and potential scour on the basis of USGS field observations and(or) existing PennDOT data. While the Code is primarily directed at satisfying the 1988 FHWA mandate, the Code and Rating are designed to work in conjunction with each other. The Code and Rating are computed on the basis of site conditions observed on a specific date and time; hydrologic events subsequent to data collection can significantly alter the site conditions that determine the Code and Rating.

\section{Scour-Critical Bridge Indicator Code}

The Scour-Critical Bridge Indicator Code indicates the vulnerability of the bridge to future scour (Appendixes F and G). The Code refers to the FHWA code (Federal Highway Administration, 1989) and is based on the PennDOT interpretation of that code (Bryan Spangler, written commun., 1999). The Code is selected from a range between 9 and 2 with each code divided into a subset of cases. Codes and cases are not a straight-forward numeric sequence, they describe a specific type of site condition only; for example, a code 6 is not necessarily better or worse than a code 5 . A field-viewed or office-reviewed substructure unit can be coded only if data are available for the following data fields: substructure-unit type; substructure-unit foundation type; scour condition; change since last inspection; streambed material near the substructure unit or, when not available, under-the-bridge primary bed material; condition of countermeasures at substructure unit if any; recommendations of possible countermeasures under the bridge, if any; evidence of movement; and BMS item C05A (Structural Configuration and Material Used for Main Unit and Approach Span). A substructure unit may meet the criteria for more than one code and(or) case within a code; however, codes are ranked according to priority as detailed in Appendixes F and G. Therefore, all substructure units receive only one code but can have multiple cases presented within that code. The overall bridge structure only receives a code value, and no case values are presented. This overall code assigned to the entire bridge structure is the highest priority code assigned to any assessed substructure unit. If insufficient data or site conditions prohibit the computation of the Code, the bridge will automatically be given a code of 6 ; a code of 6 indicates further review of the bridge site is required by PennDOT personnel. The Code is used only in conjunction with the Scour Assessment Rating; because the Code primarily addresses the potential for future scour and the Rating primarily addresses current observed scour conditions, as stand-alone data, they may misrepresent the bridge site.

\section{Scour Assessment Rating}

The Scour Assessment Rating is composed of component values for each substructure unit of a bridge structure and selected site conditions that are combined to provide an overall bridge rating from 0 to 100 (Appendixes $\mathrm{H}$ and I). This rating indicates the observed-scour condition of a bridge site and can be generally interpreted as: $\geq 80=$ good, $>50=$ average, 50 to $20=$ potential problems, and $<20=$ poor; however, all bridge-site data must be reviewed before making this interpretation because the Rating is designed to represent bridge-site conditions only in conjunction with other data. A field-viewed substructure unit can be rated only if data are available for the following data fields: substructure-unit type; substructure-unit foundation type; scour condition; evidence of movement; wingwall condition, if present; and condition of countermeasures at the substructure unit, if any. Rating an entire field-viewed bridge site requires that all applicable substructure units are rated and that the following site-condition data are available as defined in appendixes A and E: trapping potential, debris potential, debris horizontal and vertical location, and evidence of pressure flow. Substructure units that do not meet the criteria for scour assessments are not rated and do not contribute to the overall bridge rating; for example, 
expansive bridges that carry elevated roadways are only rated on those substructure units that are in contact with streamflow. Rating an office-reviewed bridge site requires that all substructure units are rated in a similar manner to those with field-collected data and that the site-condition data fields for debris potential and evidence of pressure flow are complete. Substructure units for field-viewed and officereviewed bridge sites that cannot be rated because of missing or contradictory data receive a rating of "999." Because the substructure units are components of the overall bridge structure, if a substructure unit receives a "999" the overall structure cannot be rated and also receives a rating of "999." Both the Code and the Rating are required to adequately portray site conditions and vulnerability to scour because the Code and the Rating are designed to look at different aspects of the bridge site; as stand-alone data, the Code and Rating may misrepresent the bridge site.

Because of differences in data-collection methods between PennDOT and the USGS (for example, PennDOT design and construction information in contrast to USGS field observation), PennDOT BMS data are compared with data collected by USGS personnel for substructure-unit type and substructureunit foundation type to determine the data source used in computation of the Code and Rating. This comparison serves to give an accurate representation of site conditions that may be otherwise erroneous and(or) incomplete. For field-viewed sites at which PennDOT information is incomplete, or an indication of contradictory data is present either within or between USGS and PennDOT data sources, the bridge is flagged or does not receive a Code and(or) Rating. Office-reviewed bridge sites rely only on PennDOT data and all discrepancies observed within PennDOT data sources are corrected at the time of office review.

\section{Pennsylvania Department of Transportation Review}

All bridge-site data generated by the USGS undergo a review by experienced PennDOT bridgeinspection personnel before final assignment of the Code and Rating. This review enables PennDOT personnel to provide an alternative Code and Rating, if needed, for a particular bridge site on the basis of structural conditions and(or) historical evidence that may not be known or available to the USGS at the time of Code and Rating computation. USGS personnel work with PennDOT personnel during this phase to resolve all discrepancies.

\section{POTENTIAL APPLICATIONS OF DATA}

The field-viewed and office-reviewed bridge-site data, along with the Scour-Critical Bridge Indicator Code and Scour Assessment Rating, have several potential applications. These applications may include, but are not limited to, prioritizing bridge sites in terms of potential or observed scour, GIS analysis, determination of relation among data variables, and individual and multiple problem analysis. Applications may consider spatial relations such as the relation of multiple bridges along a stream reach or within a specific drainage basin as well as the relations among specific data such as the relation of scour condition to date of bridge construction. The scope of this project requires mixed populations of data to exist; subsequent analysis should, therefore, confirm that data-collection procedures and data sources are consistent with the requirements of that analysis before it is undertaken.

\section{Prioritizing Bridge Sites in Terms of Potential or Observed Scour}

Data collected for field-viewed and office-reviewed bridge sites are compiled in a computer database that may be queried to retrieve significant information. This information may be used to prioritize bridge sites in terms of potential or observed scour. For example, bridges may be prioritized 
according to the Code. This list may then be weighted by such variables as the Rating, the drainage area upstream from the bridge, and the bridge-opening area. Prioritizing bridges in terms of potential or observed scour assists PennDOT personnel in determining potential maintenance and remedial actions.

\section{Geographic Information System Analysis}

GIS analysis allows the user to generate spatial data sets (SDS) showing the location of bridges along with selected characteristics. SDS are, essentially, layers of data, stacked one on top of the other, with each layer, or coverage, representing a different variable. All data within the coverage corresponds to a specific location such as a latitude and longitude. For example, data collected for each bridge corresponds to the latitude and longitude of that bridge within a computer database. This location enables the user to query the database and create coverages for specific aspects of each bridge site. An example analysis might attempt to imply how urban development within a specific county is affecting bridges spanning a specific stream. The analysis might first create a coverage showing the county boundary. Then a coverage showing the stream, its tributaries, and the drainage basin would be added. Finally, a coverage of all bridges assessed in that county that also span the stream and tributaries in question would be added. Bridges assessed in Chester County, Pa., that span Brandywine Creek and its tributaries are shown in figure 8. This SDS, could be created to determine if sufficient data exists and if the data are consistent with the needs of the analysis. For example, there might not be enough bridges crossing the stream to provide sufficient data for an analysis. This SDS could subsequently be expanded to show the physiographic provinces and(or) only those bridges with footing exposure. Once the required coverages are assembled into the appropriate SDS, a map may be printed for field use.

\section{Determination of Relation Among Data Variables}

Data variables may be analyzed by statistical and(or) other methods to identify any significant relation between those variables. For example, all bridges with footing exposure (advanced or serious scour condition) may be analyzed with respect to the date of bridge construction (from PennDOT BMS data) and the attack angle on the substructure unit. This analysis might show that footing exposure is more or less common with one variable than the other, or possibly that there is no relation at all between any of the variables. By identifying any significant relations between scour and(or) other data variables, PennDOT may subsequently prioritize maintenance and required remedial actions by looking at significant variables.

\section{Individual Problem Analysis}

Data, when queried from a computer database, may be used for a statistical analysis of individual problems. For example, a list of bridges may be generated to show all bridges with footing exposure at one or more substructure units within a specific physiographic province. This sample may then be compared to similar samples from other physiographic provinces. This comparison may subsequently lead to a correlation of scour condition to a specific physiographic province.

\section{Multiple Problem Analysis}

Data from a computer database also may be queried for multiple problem analysis. This statistical analysis may be used in order to determine which site characteristic is more significant in terms of potential and(or) observed scour condition. For example, the high-flow angle of approach and the debris accumulation at the bridge might be queried for bridges within a specific physiographic province. 


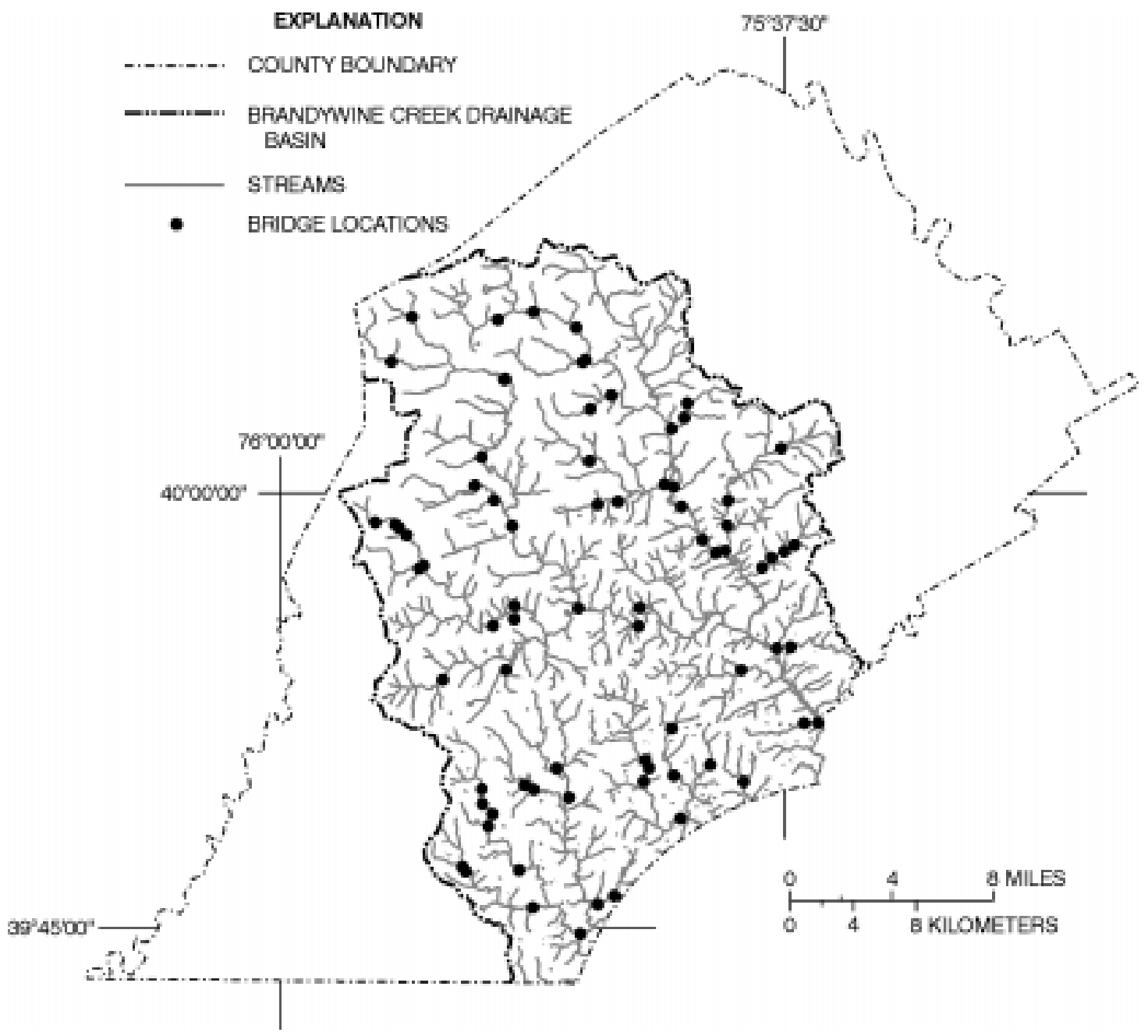

Figure 8. Geographic information system spatial data set showing bridges in Chester County, Pennsylvania, spanning Brandywine Creek and its tributaries.

Statistical analysis of these data may subsequently prove that either the high-flow angle of approach or the debris accumulation is of greater significance to scour condition at bridges within that specific physiographic province.

\section{SUMMARY}

Scour at bridge foundations and channel instability during high flows of rivers and streams are primary causes of bridge failure. In response to the scour-related failure of several bridges in the United States, the U.S. Department of Transportation, Federal Highway Administration (FHWA), issued a mandate requiring States to conduct assessments of scour vulnerability at all public bridges over water. The U.S. Geological Survey (USGS) entered into a cooperative agreement with the Pennsylvania Department of Transportation (PennDOT) to create procedures and conduct scour and channel-stability assessments to aid PennDOT in complying with the FHWA mandate. 
Scour assessments are conducted for two categories of bridge sites, field-viewed bridge sites and office-reviewed bridge sites. USGS personnel acquire geomorphic, hydraulic, and hydrologic data that are indicative of the existing or potential effects of stream processes on the bridge or stream channel for these sites. Ancillary data are collected and compiled in order to assist in interpretation of data and to create a baseline against which future assessments can be measured.

Characteristics of the drainage basin upstream from each bridge and flood-frequency discharges are computed and described using GIS data sets and USGS topographic maps. Drainage-basin characteristics include percentage of forest cover, percentage of urbanized area, drainage area, surface area of reservoirs, percentage of carbonate geology, and the mean basin slope. Flood-frequency discharges are computed for each site using several computational methods. These methods vary depending on bridge-site location and drainage-basin size. Regional regression equations are compared and modified on the basis of findings from USGS streamflow-measurement stations.

Using data acquired from USGS site visits and(or) PennDOT data sources, a Scour-Critical Bridge Indicator Code and Scour Assessment Rating are computed for each site. These Codes and Ratings are numeric rankings based on PennDOT-developed algorithms that include a variety of significant factors that influence channel stability and scour vulnerability of bridges. The completed Codes and Ratings are reviewed by PennDOT personnel before final assignment of Code and Rating values. The primary purpose of the Code is to satisfy the FHWA mandate; the Rating assists in the qualification and interpretation of the Code. The drainage-basin characteristics and flood-frequency discharges assist PennDOT in the interpretation of the Code and Rating and provide a baseline against which future assessments can be measured.

Collected data along with computed Code and Rating have several potential applications. These include prioritizing bridge sites in terms of potential or observed scour to assist in maintenance and remedial actions, GIS analysis, analysis of relations among variables, multiple problem analysis, and individual problem analysis. These applications can assist PennDOT in the interpretation of the data and in prioritizing maintenance activities and possible remedial actions. 


\section{REFERENCES CITED}

Aron, G., and Kibler, D.F., 1981, Procedure PSU-IV for estimating design flood peaks on ungaged Pennsylvania watersheds: Institute of Research on Land and Water Resources, FHWA/PA 81-013, 211 p.

Berg, T.M., Barnes, J.H., Sevon, W.D., Skema, V.W., Wilshusen, J.P., Yannacci, D.S., 1989, Physiographic provinces of Pennsylvania: Harrisburg, Pa., Pennsylvania Department of Environmental Resources, Bureau of Topographic and Geologic Survey Map 13.

Doheny, E.J., Helinsky, B.M., and McGregor, R.A., 1996, A technique for preliminary appraisal of potential and observed scour as applied to state-maintained highway bridges in Maryland: U.S. Geological Survey OpenFile Report 95-135, 75 p.

Ehlke, M.H., and Reed, L.A., 1999, Comparison of methods for computing streamflow statistics for Pennsylvania streams: U.S. Geological Survey Water-Resources Investigations Report 99-4068, 80 p.

Federal Emergency Management Agency, Federal Insurance Administration, 1976-1996, Flood insurance study, (Published for individual municipalities throughout Pennsylvania).

Federal Highway Administration, 1989, Recording and coding guide for the structure inventory and appraisal of the nation's bridges: Federal Highway Administration Report FHWA-ED-89-044, 115 p.

Flippo, H.N., Jr., 1977, Floods in Pennsylvania: Commonwealth of Pennsylvania, Department of Environmental Resources Bulletin 13, 59 p.

1982, Evaluation of the streamflow data program in Pennsylvania: U.S. Geological Survey Water-Resources Investigations 82-21, $56 \mathrm{p}$.

Lagasse, P.F., Schall, J.D., Johnson, F., Richardson, J.R., and Chang, F., 1990, Stream stability at highway structures: Federal Highway Administration Hydraulic Engineering Circular 20, Publication FHWA-IP-014, $195 \mathrm{p}$.

Pennsylvania Department of Transportation, 1993, Bureau of Design, Bridge management system (BMS), coding manual, office version: Pennsylvania Department of Transportation Publication 100A, 123 p. 1994, Bureau of Design, Design manual part 2: Pennsylvania Department of Transportation, chap. 10, 145 p.

Richardson, E.V., Harrison, L.J., Richardson, J.R., and Davis, S.R., 1993, Evaluating scour at bridges (2d ed.): Federal Highway Administration Hydraulic Engineering Circular 18, Publication FHWA-IP-90-017, 236 p.

Simon, A., 1989, A model of channel response in disturbed alluvial channels: Earth surface processes and landforms, v. 14, no. 1, p. 11-26.

Wolf, P.R., and Brinker, R.C., 1994, Elementary surveying (9th ed.): New York, Harper Collins College Publishing, $760 \mathrm{p}$. 


\section{APPENDIX A}

Procedures for Completing the "Bridge and Channel Characteristics at Field-VIEWEd BRIDGe Sites”' Form AND THE "ADDENDUM TO FIELD FORM FOR NON-ACCESSIBLE SUBUNITS" FORM 


\section{BRIDGE AND CHANNEL CHARACTERISTICS AT FIELD-VIEWED BRIDGE SITES}

Assessed Bridge No.: \#1 Inspector:

\#2

Date:

\#3 (mm-dd-yy) Arrival Time (military):

\#3A GPS File-SN: \#4

Total Station File-SN \#5 Overflow Bridge: \#6 $0=$ No $1=$ Yes

\section{Comments}

\section{FROM THE ROADWAY}

Surface Cover USLOB: \#7 USROB:__ DSLOB:___ DSROB:__ Overall:

$$
1=>50 \% \text { Paved } 2=10 \%-50 \% \text { Paved } 3=\text { Row crop } 4=\overline{\text { Pasture }} 5=\text { Brush } \quad 6=\text { Forest } 7=\text { Wetland } 8=\text { Structures }
$$

High Flow Angle of Approach (degrees): \#8 (+ = Pushes RB - = Pushes LB)

High Flow Skew (degrees): \#9 (+= Pushes RB - = Pushes LB)

Low Flow Angle of Approach (degrees): \#8A (+ = Pushes RB - = Pushes LB)

$1=90$ to $85 \quad 2=84$ to $75 \quad 3=74$ to $60 \quad 4=59$ to $45 \quad 5=44$ to 0

$1=0$ to $5 \quad 2=6$ to $153=16$ to $30 \quad 4=31$ to $45 \quad 5=46$ to 90

US Channel Profile:\#10

DS Channel Profile:\#11

$$
\begin{gathered}
1=\text { Pool } 2=\text { Riffle } \\
3=\text { No Flow }
\end{gathered}
$$

IN THE UPSTREAM CHANNEL

Is There Evidence of Road Overtopping:\#12

Is There Evidence of Pressure Flow:\#13

Bed Material:\#14

$$
\begin{aligned}
& 1=\text { Silt/Clay } \quad 2=\text { Sand } \\
& 3=\text { Gravel } \quad 4=\mathrm{Cbl} / \text { Boulde } \\
& 5=\text { Bedrock } \quad 6=\text { Con } / \text { Steel }
\end{aligned}
$$

$$
\begin{aligned}
& \multicolumn{3}{c}{\text { Vegetation }} \\
& \text { Cover (\%) } \\
& \text { LB RB } \\
& \begin{array}{ll}
\text { \#15 } & \\
=0-25 \% & 2=26-50 \% \\
=51-75 \% & 4=76-100 \%
\end{array}
\end{aligned}
$$

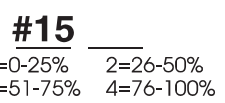

$$
\begin{gathered}
\text { Bank } \\
\text { Material }
\end{gathered}
$$

$\mathrm{RB}$

$$
\text { Bank }
$$

Erosion LB RB

$$
\begin{aligned}
& \text { \#16 } \\
& 1=\overline{\text { Silt/Clay }} \overline{2=\text { Sand }} \\
& 3=\text { Gravel } \quad 4=\mathrm{Cbl} / \text { Boulder } \\
& 5 \text { = Bedrock } \quad 6=\text { Con } / \text { Steel }
\end{aligned}
$$

LB RB

\section{$\# 17$}

$\overline{0=\text { None }}$

$1=$ Light Fluvial

$2=$ Heavy Fluvia

$3=$ Mass Wasting

Tributary:\#18 Bank:

Distance: (ft US)

\section{Comments}

$0=$ No $1=$ Yes $1=\overline{L B \quad 2=R B}$

(If First CB/MI US From Bridge Extends Into Bridge Opening, Record That CB/MI As Under Bridge; Record Next US CB/MI Here)

Cutbank: \#19

$$
0=\overline{\text { No } 1}=\text { Yes }
$$

Cutbank Location:

Distance to Middle of Cutbank: (ft US)

$$
0=\text { No } 1=\text { Yes } 1=\mathrm{LB} \quad 2=\mathrm{RB}
$$

Roadway Approach Impacted: \#21

$$
\begin{array}{ll}
1=\text { Near } & =\text { Far } \\
3=\text { Adjacent } & 4=\text { No }
\end{array}
$$

(If CB/MI On Approaches, Briefly Describe Effect On Roadway Integrity and Estimate Roadway Distance From Near/Far Abutments)

\section{Comments:}

Figure 9. "Bridge and Channel Characteristics at Field-Viewed Bridge Sites" form. 
Point Bar: \#22

$0=$ No $1=$ Yes

$\mathrm{P}$ Bar Vegetated: $0=$ No $1=$ Yes

Mid-Channel Bar:\#23

$0=$ No $1=$ Yes

MC Bar Vegetated: $0=$ No $\overline{1=\text { Yes }}$

\section{IN THE UPSTREAM CHANNEL (cont)}

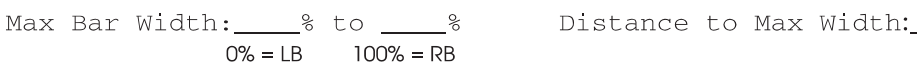

Vegetation Location:___ \% to __ \% Vegetation Height:__ \% to ___ \%

$\overline{0 \%}=\mathrm{LB} \quad \overline{100 \%}=\mathrm{RB}$

$0 \%=$ Bed $100 \%=$ Bot. Beam

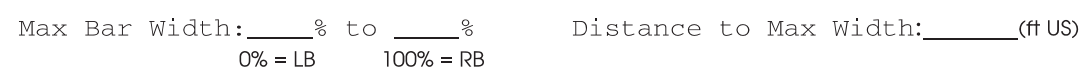

Vegetation Location:___ \% to ___ \% Vegetation Height:__ $\%$ to ___ $\%$

$0 \%=\mathrm{LB} \quad \overline{00} \%=\mathrm{RB} \quad 0 \%=\mathrm{Bed} \quad 100 \%=\overline{\text { Bot. Beam }}$

\section{Comments}

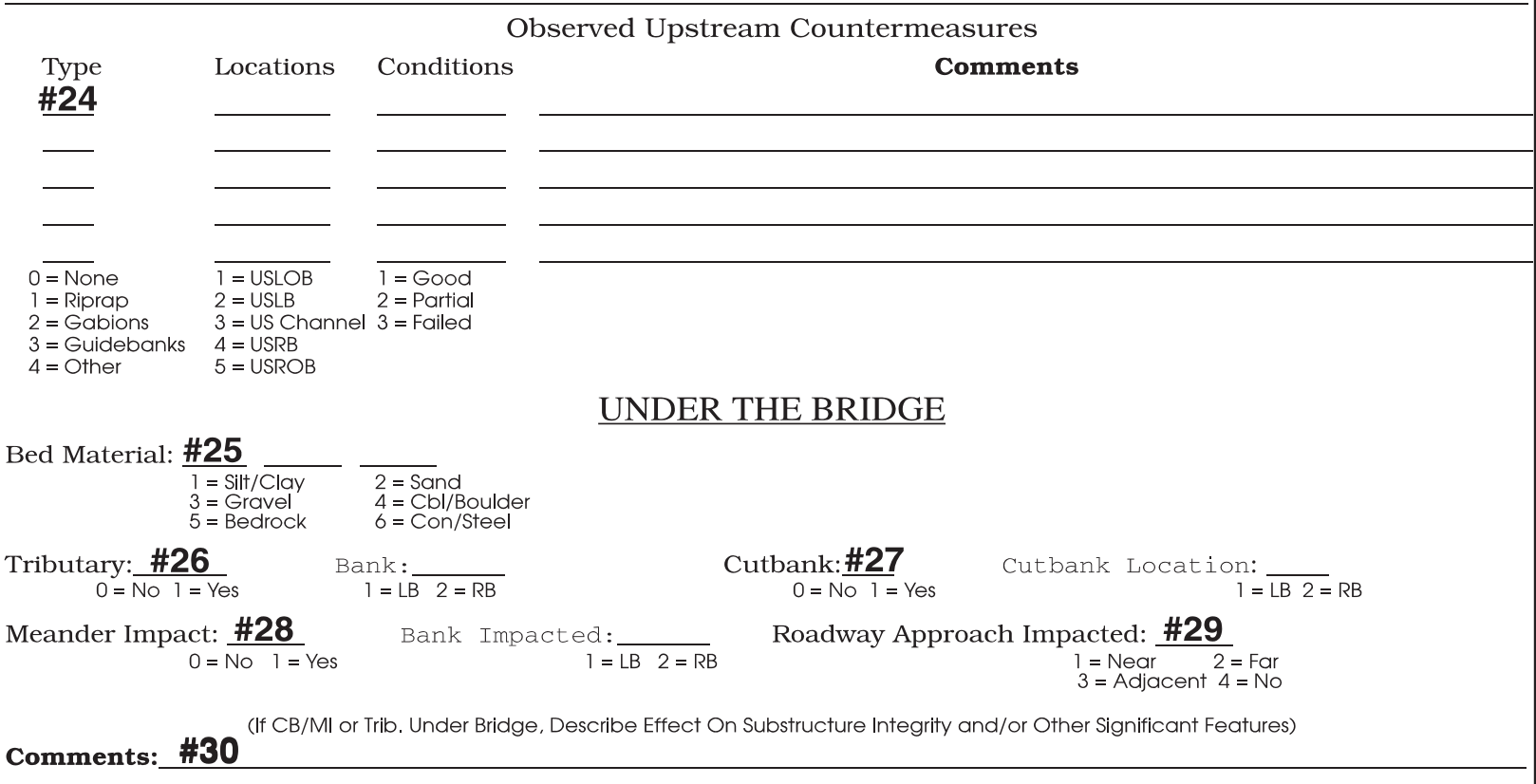

Point Bar: \#31

$0=$ No $1=$ Yes

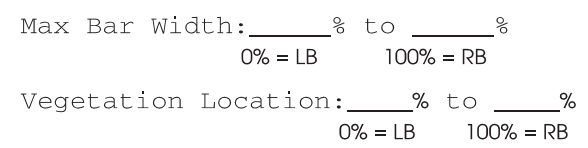

Bar Height:

$\%$ to $\%$

P Bar Vegetated:

$$
0=\text { No } 1=\text { Yes }
$$

Mid-Channel Bar:\#32 Max Bar Width:____ to ____ $\%$ Bar Height:___ to ___ $\%$

$$
0=\text { No } 1=\text { Yes } \quad \overline{0 \%=L B} \quad 100 \%=\mathrm{RB} \quad 0 \%=\mathrm{Bed} \quad 100 \%=\mathrm{Bot} \text {. Beam }
$$

MC Bar Vegetated:

$$
\text { Vegetation Location: } \sum_{0 \%=L B} \% \text { to } \frac{100 \%=R B}{2}
$$

\section{Comments:}

$$
\mathrm{O}=\mathrm{No} \overline{1=\mathrm{Yes}}
$$

Debris Accumulation:\#33

$$
\begin{array}{cc}
\text { Tytion:\#33 } & \begin{array}{c}
\text { Type of Debris: } \\
0=\text { No } 1 \text { 34 Yes }
\end{array} \\
1=\text { Brush } & 2=\text { Whole Trees } \\
3=\text { Trash } & 4=\text { All Others }
\end{array}
$$

Horizontal Location: \#35 \% to \% Vertical Height: \#36 \% to

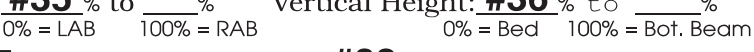

Present Depth

1 - \#39

Trapping Potential:\#37 Debris Potential: \#38 Scour Holes (Not in Contact with Substructure):

$$
\begin{array}{lll}
0=\text { Low } & 0=\text { Low } & 2- \\
1=\text { Medium } & 1=\text { Medium } & 0=\text { Absent } \\
2=\text { High } & 2=\text { High } & 1=\text { Present }
\end{array}
$$




\section{$\underline{\text { UNDER THE BRIDGE (cont) }}$}

PIERS

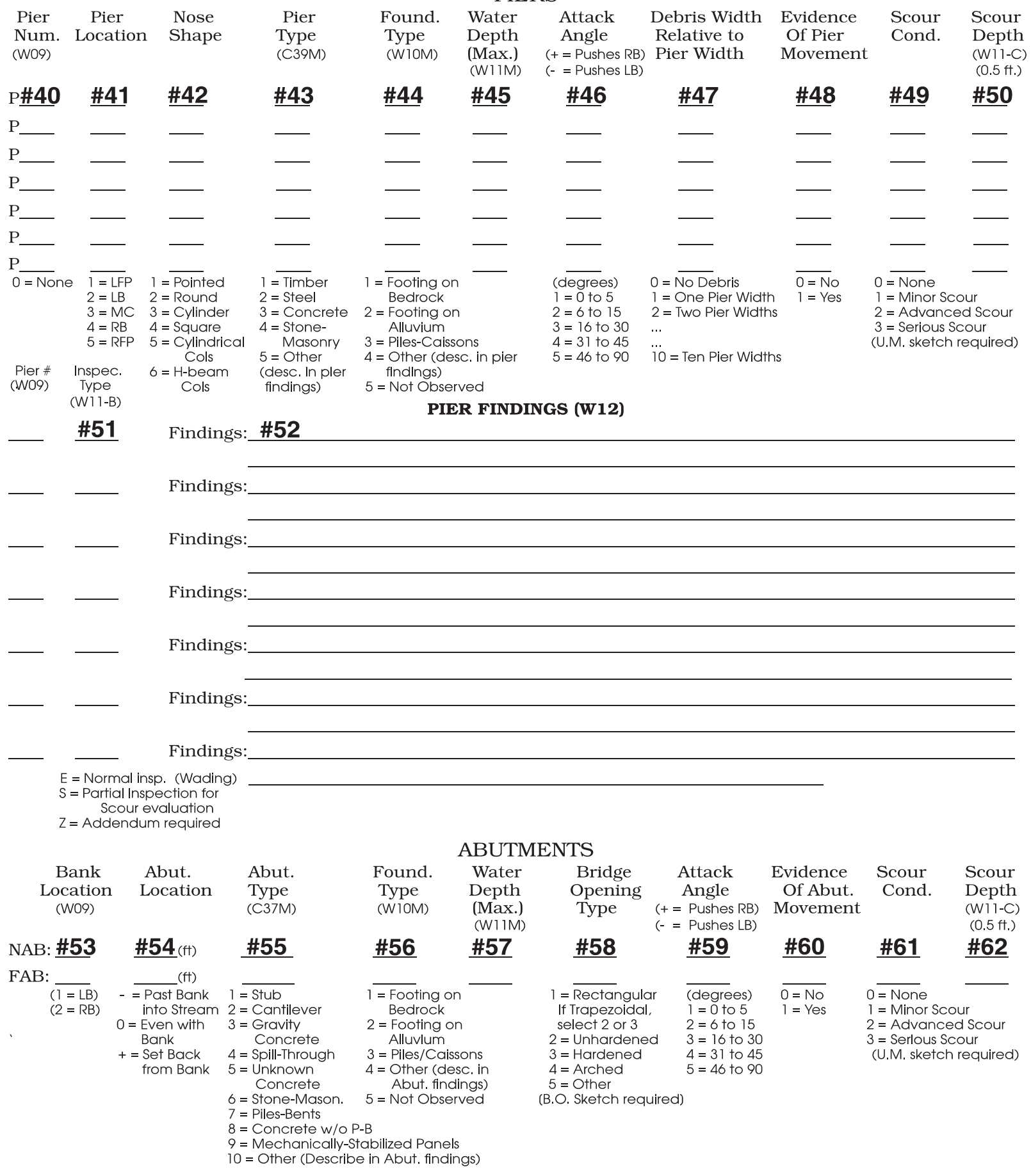

Figure 9. "Bridge and Channel Characteristics at Field-Viewed Bridge Sites" form—Continued 
$\overline{\mathrm{E}=\text { Normal insp. (Wading) }}$

FAB Findings:

$\begin{aligned} \mathrm{S}= & \text { Partial Inspection for } \\ \text { Scour evaluation } & \end{aligned}$

$\mathrm{Z}=$ Addendum required

\section{WINGWALLS}

Present Condition Comments

Upstream Left Wingwall:

\#65

Upstream Right Wingwall:

Downstream Left Wingwall:

Downstream Right Wingwall:

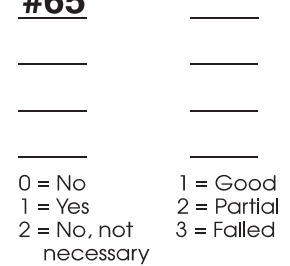

STREAMBED MATERIAL NEAR THE BRIDGE SUBSTRUCTURE UNITS

(The numeric values for this field (2nd digit) can be directly transferred to the coding of Scourability for W11-A, unless the substructure units are founded on piles/caissons or adequately protected by rip rap, in which case, that condition is considered in the scourability coding.)

NAB:\#66 FAB:

P01:

P02:

P03:

P04:

P05:

P06:

P07:

A6: Stable streambed predominantly consisting of larger native cobbles and boulders (Not rip rap) with small amounts of fine material filling voids. Little scour potential, even during high flows.

A5: Stable, naturally armored streambed composed of cobbles, boulders, gravel, with some fine material that has not shown signs of scour over a long time period. Potential for scour under high velocities exists.

A4: Alluvium consisting of a mixture of fine particles with some larger aggregate. Some cobbles and an occasional boulder may be present. Scour is present or has occurred in the past.

A3: Highly erodible alluvium material predominantly composed of very small particles: clays, silts, and/or fine sands. High potential for scour.

R9: Non-erodible rock. Some faulting or weathering may be present.

R8: Erodible rock that has no signs of scour. Rock may be faulted, weathered, and/or soft.

R7: Erodible rock that may have some minor scour, but there is little risk that could cause failure during high flows. Rock may be weathered, faulted, and/or soft.

R4: Highly erodible rock with on-going scour that could advance during a high flow event. Rock may be highly weathered, faulted, and/or very soft.

P8: Streambed paved with concrete, gabions, or masonry units in good condition and adequate to resist scour.

P7: Streambed paved with concrete, gabions, or masonry units in good condition. Minor problems may exist, but protec tion against scour is adequate.

Figure 9. "Bridge and Channel Characteristics at Field-Viewed Bridge Sites" form—Continued 
UNDER THE BRIDGE (cont)

W-11A

OBSERVED SCOUR RATING GUIDE

\begin{tabular}{|c|c|c|c|c|c|c|c|c|c|}
\hline \multirow[b]{3}{*}{ Rating } & \multicolumn{8}{|c|}{ ITEM NUMBER } & \multirow[b]{3}{*}{ Rating } \\
\hline & 1 & 2 & 3 & 4 & 5 & 6 & 7 & 8 & \\
\hline & $\begin{array}{c}\text { Change } \\
\text { since last } \\
\text { inspection }\end{array}$ & $\begin{array}{l}\text { Scour } \\
\text { hole }\end{array}$ & $\begin{array}{c}\text { Debris } \\
\text { potential }\end{array}$ & Scourability & $\begin{array}{l}\text { Opening } \\
\text { Adequacy/ } \\
\text { Channel }\end{array}$ & Sediment & Alignment & $\begin{array}{l}\text { Velocity/ } \\
\text { stream } \\
\text { slope }\end{array}$ & \\
\hline 9 & None & None & None & Rock/P & Good & None & Good & Low & 9 \\
\hline 8 & None & Minor & None & Rock/P/C & Good & Minor & Good & Low & 8 \\
\hline 7 & Minor & Minor & Minor & Rock/C & Fair & Minor & Good & Medium & 7 \\
\hline 6 & Minor & Advanced & Medium $^{*}$ & Stable & Fair & Medium & Medium & Medium & 6 \\
\hline 5 & Medium ${ }^{\star}$ & Advanced & High $^{\star}$ & Stable & Fair & High & Medium & High & 5 \\
\hline 4 & Medium & Serious $^{*}$ & High & Alluvium ${ }^{\star}$ & Poor ${ }^{*}$ & High & Poor $^{*}+$ & High & 4 \\
\hline 3 & $\mathrm{High}^{\star}$ & Serious* & Present $^{*}$ & Alluvium & Overtop* & High & Poor & High & 3 \\
\hline 2 & \multicolumn{8}{|c|}{ Bridge is scour critical, IMMEDIATE action is required * } & 2 \\
\hline 1 & \multicolumn{8}{|c|}{ Bridge is scour critical, bridge is CLOSED * } & 1 \\
\hline 0 & \multicolumn{8}{|c|}{ 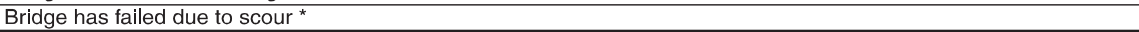 } & 0 \\
\hline
\end{tabular}

NOTES:

Rating considerations given in highest to lowest level of importance from left to right.

$C=$ Effective Countermeasure

* If an item is so marked, it cannot be given a higher ranking.

+ A higher ranking may be given if the unit is founded on competent rock and no problems exist.

DETERMINATION OF RATING FOR BMS ITEM

W11-A

\begin{tabular}{|c|c|c|c|c|c|c|c|c|c|}
\hline & 1 & 2 & 3 & 4 & 5 & 6 & 7 & 8 & W11-A \\
\hline $\begin{array}{c}\text { Substructure } \\
\text { unit }\end{array}$ & $\begin{array}{l}\text { Change } \\
\text { since last } \\
\text { inspection }\end{array}$ & $\begin{array}{l}\text { Scour } \\
\text { hole }\end{array}$ & $\begin{array}{l}\text { Debris } \\
\text { potential }\end{array}$ & Scourability & $\begin{array}{l}\text { Opening } \\
\text { Adequacy/ } \\
\text { Channel }\end{array}$ & Sediment & Alignment & $\begin{array}{l}\text { Velocity/ } \\
\text { stream } \\
\text { slope }\end{array}$ & $\begin{array}{c}\text { Overall } \\
\text { observed } \\
\text { scour } \\
\text { rating }\end{array}$ \\
\hline \#67A & \#67B & \#67C & \#67D & \#67E & \#67F & \#67G & \#67H & \#67I & \#67J \\
\hline & & & & & & & & & \\
\hline & & & & & & & & & \\
\hline & & & & & & & & & \\
\hline & & & & & & & & & \\
\hline & & & & & & & & & \\
\hline & & & & & & & & & \\
\hline & & & & & & & & & \\
\hline & & & & & & & & & \\
\hline
\end{tabular}

Figure 9. "Bridge and Channel Characteristics at Field-Viewed Bridge Sites" form—Continued. 
UNDER THE BRIDGE (cont)

Observed Under Bridge Countermeasures

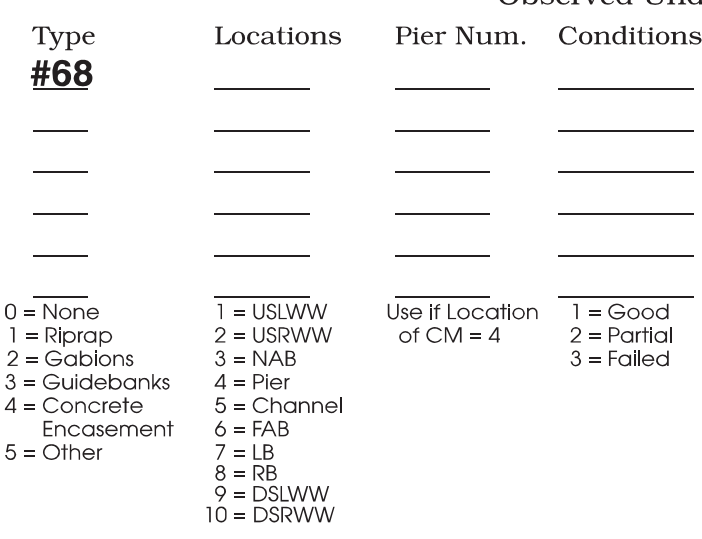

Comments

IN THE DOWNSTREAM CHANNEL

Bed Material: \#69

$$
\begin{array}{lll}
\hline 1=\text { Silt } / \text { Clay } & 2 & =\overline{\text { Sand }} \\
3=\text { Gravel } & 4=\mathrm{Cbl} / \text { Boulder } \\
5=\text { Bedrock } & 6=\text { Con } / \text { Steel }
\end{array}
$$

Vegetation

Cover (\%)

LB RB

Material

LB

Bank

Bank

Erosion

\#70

\#71

LB RB

$1=0-25 \% \quad 2=26-50 \% \quad 1=$ Silt/Clay $2=$ Sand

$3=51-75 \% \quad 4=76-100 \% \quad 3=$ Gravel $\quad 4=\mathrm{Cbl} /$ Boulde

$5=$ Bedrock $\quad 6=$ Con $/$ Steel

\#72

$0=$ None

$1=$ Light Fluvial

$2=$ Heavy Fluvial

$3=$ Mass Wasting

Tributary:\#73 Bank:

$$
0=\text { No } 1=\text { Yes } \quad 1=\overline{L B} \quad 2=R B
$$

Cutbank: $\frac{\# 74}{0}=\frac{\text { No } 1=\text { Yes } \quad \text { Cutbank Location: }}{1=L B} 2=R B \quad$ Distance to Middle of Cutbank:

Comments

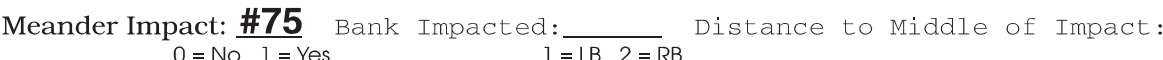

$0=$ No 1 = Yes
proach Impacted: \#76

$\begin{aligned} \text { Roadway Approach Impacted: } & \text { \#76 } \\ 1 & =\text { Near } 2=\text { Far } \\ 3 & =\text { Adjacent } 4=\text { No }\end{aligned}$

Comments

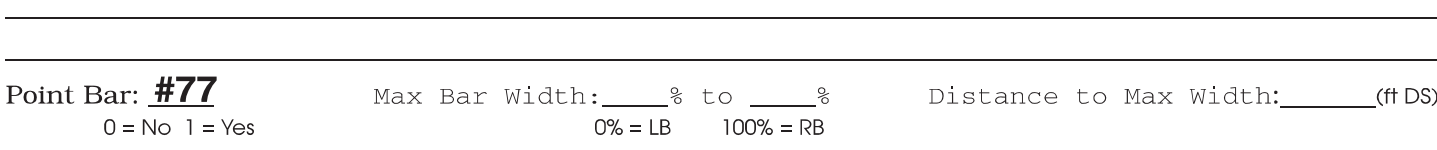

P Bar Vegetated:____ Vegetation Location:___ $\%$ to ___ $\%$ Vegetation Height:___ $\%$ to ___ $\%$ $0=\mathrm{No} 1=$ Yes $\quad 0 \%=\mathrm{LB} \quad 100 \%=\mathrm{RB} \quad 0 \%=$ Bed $100 \%=$ Bot. Beam

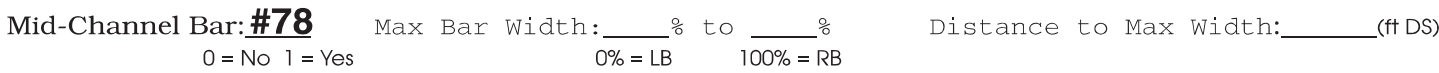

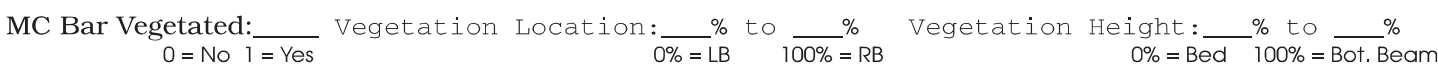

Comments

Figure 9. "Bridge and Channel Characteristics at Field-Viewed Bridge Sites" form—Continued. 


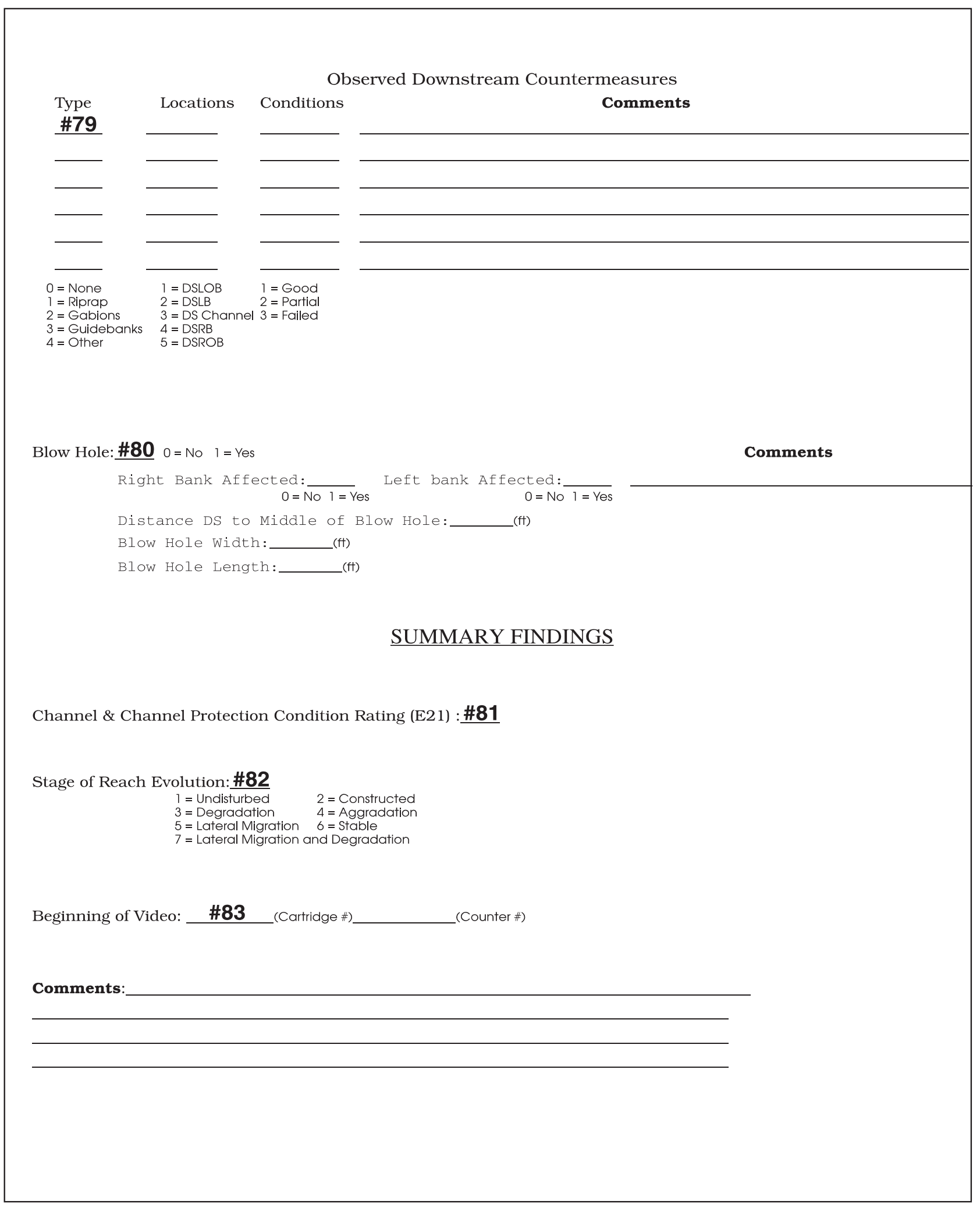

Figure 9. "Bridge and Channel Characteristics at Field-Viewed Bridge Sites" form—Continued. 


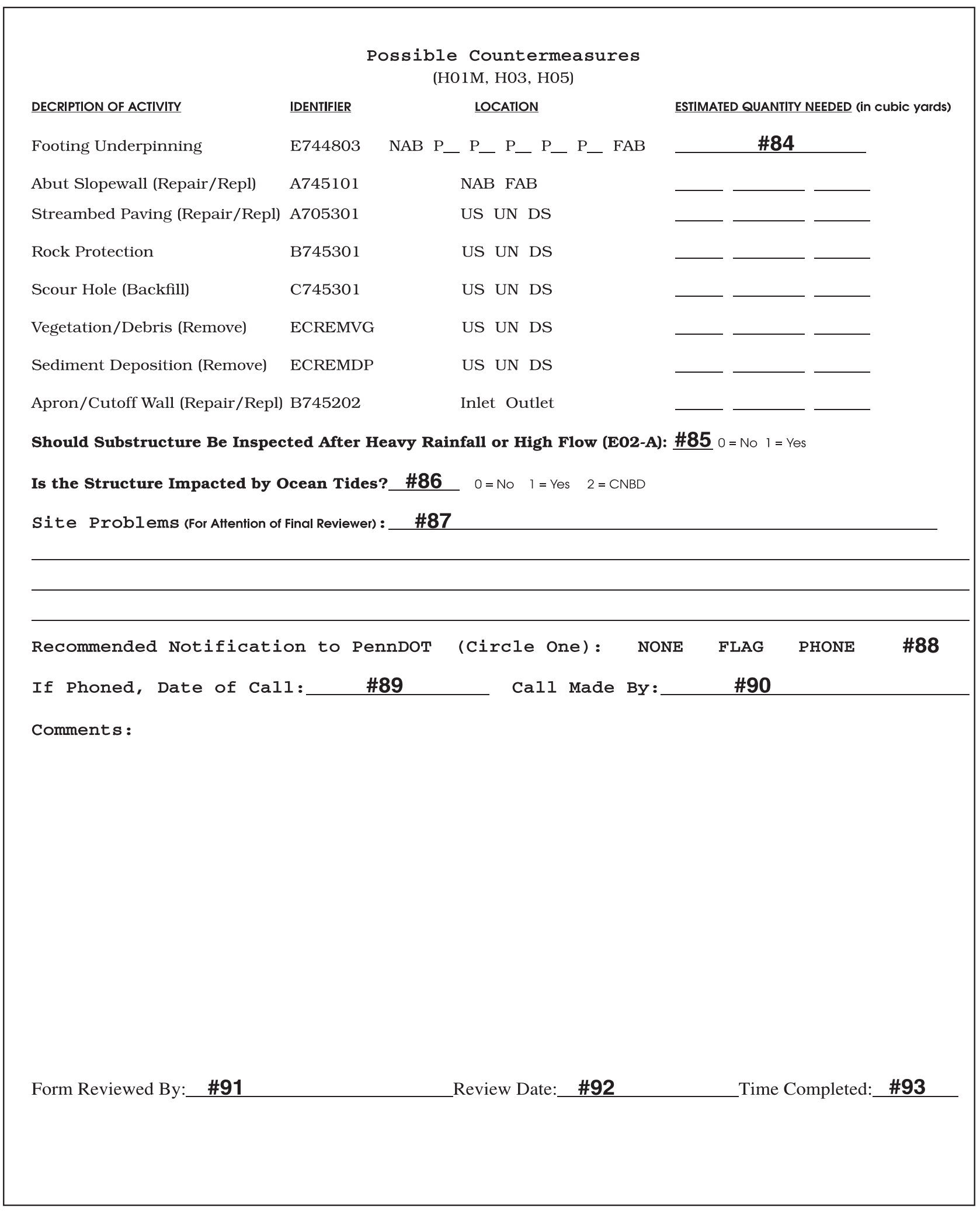

Figure 9. "Bridge and Channel Characteristics at Field-Viewed Bridge Sites" form-Continued 


\section{Checklist of Significant Items}

$\checkmark=$ Done $X=$ Not Appropriate

North Arrow $\mathrm{N}$

Flow Direction $\mathrm{F}$

Video Image Locations \& Directions (V)

Tributary Confluences TC

Abutments NAB \& FAB

Piers $\bigcirc \&$ Columns ${ }_{0}^{O}$ (dash outlines)

Wing Walls WW

Debris $\bigotimes$

Meander Impacts/Cutbanks $\mathrm{MI}_{\text {or }} \mathrm{CB}$

Countermeasures (label, e.g. riprap $\mathrm{RR}$ )

Water Surface Survey Points WS

Bank Angle Survey Points BA

Point Bars DPB

Mid-Channel Bars OMCB

Location of Cross Section $\uparrow$

Footings or Encasementse

Scour Hole $\mathrm{\theta}$

Guide Rail +++ GR

Reference Mark Location(s) $\%$

Other (label): $\underline{\text { Plan View Sketch }}$

\#94

Figure 9. "Bridge and Channel Characteristics at Field-Viewed Bridge Sites" form—Continued. 
\#96

Figure 9. "Bridge and Channel Characteristics at Field-Viewed Bridge Sites" form—Continued. 


\section{BRIDGE AND CHANNEL CHARACTERISTICS}

AT FIELD-VIEWED BRIDGE SITES

ADDENDUM TO DATA COLLECTION FORM FOR NON-ACCESSIBLE SUBUNITS

\section{PENNDOT DATA}

Assessed Bridge \#

\#97

Complete Cross Section Surveyed \#101

\section{$0=$ No}

$1=$ Yes

$\begin{array}{cc}\text { Pier } & \text { Found. } \\ \text { Type } & \text { Type } \\ \text { (C39M) } & \text { (W10M) }\end{array}$

(W10M)

Date of USGS site visit_ \#98

Date of previous bridge inspection_ \#99

Date of previous underwater inspection \#100

\section{PIERS}

Water

Depth

(Max.)

Attack

Angle

(W11M)

$(+=$ Pushes RB $)$
$(-=$ Pushes $\mathrm{LB})$

\#105 \#106

\#108

\#109

\#110

\#111

Scour Scour

Pier Width

Evidence

Of Pier Cond.

Movement

Depth

\#107

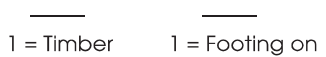

$2=$ Steel

$3=$ Concrete 2 = Footing on

$4=$ Stone- $\quad$ Alluvium

$4=$ Stone-

$3=\mathrm{MC} \quad 3=$ Cylinder

$4=\mathrm{RB} \quad 4=$ Square

Cylindrical Masonry $3=$ Piles-Caissons

$\begin{array}{ccc}\begin{array}{c}\text { Cols } \\ \text { H-beam } \\ \text { Cols }\end{array} & \begin{array}{l}5=\text { Other } \\ \text { (desc. in USGS } \\ \text { findings) }\end{array} & \begin{array}{c}4=\text { Other (desc. in } \\ \text { findings) }\end{array} \\ 5=\text { Not Observed }\end{array}$

P__ W12 Findings: \#113

\section{(degrees)}

$1=0$ to 5

$2=6$ to 15

$3=16$ to 30

$4=31$ to 45

$5=46$ to 90 $0=\overline{\text { No Debris }} \quad \overline{0=\mathrm{NO}}$

$1=$ One Pier Width

$2=$ Two Pier Widths

...

$\dddot{10}=$ Ten Pier Widths

$0=$ None

$1=$ Minor Scour

2 = Advanced Scour

3 = Serious Scour

P__ W12 Findings:

USGS Findings:

\section{$\# 114$}

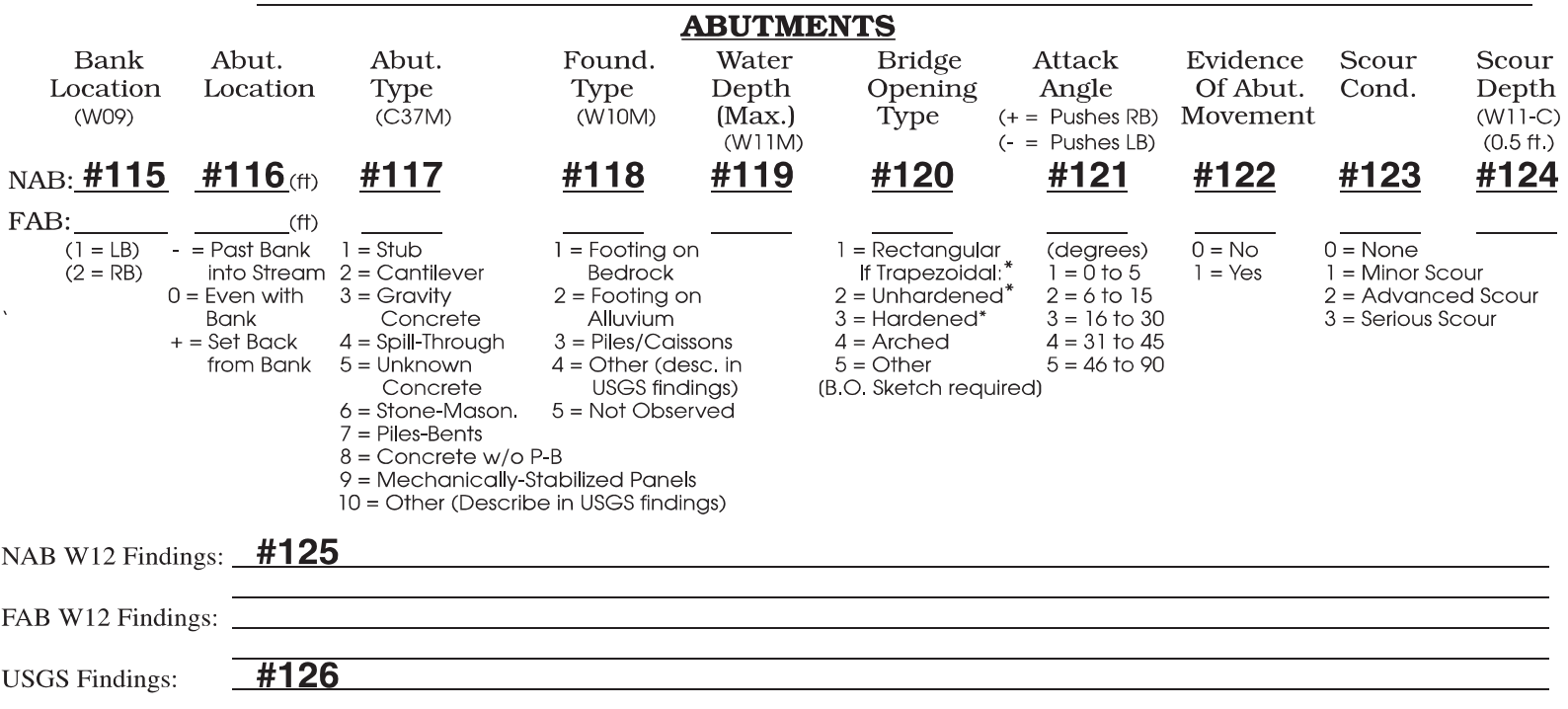

STREAMBED MATERIAL NEAR THE BRIDGE SUBSTRUCTURE UNITS

(The numeric values for this field (2nd digit) can be directly transferred to the coding of Scourability for W1 1-A, unless the substructure units are founded on piles/caissons or adequately protected by rip rap, in which case, that condition is considered in the scourability coding.)

NAB:\#127 FAB:

P01: P02: P03: P04: P05: P06: P07:

Figure 9. "Bridge and Channel Characteristics at Field-Viewed Bridge Sites" form—Continued. 
PENNDOT OBSERVED SCOUR RATING (W-11A)

OBSERVED SCOUR RATING GUIDE

\begin{tabular}{|c|c|c|c|c|c|c|c|c|c|}
\hline \multirow[b]{3}{*}{ Rating } & \multicolumn{8}{|c|}{ ITEM NUMBER } & \multirow[b]{3}{*}{ Rating } \\
\hline & 1 & 2 & 3 & 4 & 5 & 6 & 7 & 8 & \\
\hline & $\begin{array}{l}\text { Change } \\
\text { since last } \\
\text { inspection }\end{array}$ & $\begin{array}{l}\text { Scour } \\
\text { hole }\end{array}$ & $\begin{array}{l}\text { Debris } \\
\text { potential }\end{array}$ & Scourability & $\begin{array}{l}\text { Opening } \\
\text { Adequacy/ } \\
\text { Channel }\end{array}$ & Sediment & Alignment & $\begin{array}{l}\text { Velocity/ } \\
\text { stream } \\
\text { slope }\end{array}$ & \\
\hline 9 & None & None & None & Rock/P & Good & None & Good & Low & 9 \\
\hline 8 & None & Minor & None & Rock/P/C & Good & Minor & Good & Low & 8 \\
\hline 7 & Minor & Minor & Minor & Rock/C & Fair & Minor & Good & Medium & 7 \\
\hline 6 & Minor & Advanced & Medium ${ }^{*}$ & Stable & Fair & Medium & Medium & Medium & 6 \\
\hline 5 & Medium* & Advanced & High $^{\star}$ & Stable & Fair & High & Medium & High & 5 \\
\hline 4 & Medium & Serious* & High & Alluvium* $^{*}$ & Poor $^{*}$ & High & Poor* + & High & 4 \\
\hline 3 & High $^{*}$ & Serious* & Present $^{*}$ & Alluvium & Overtop* & High & Poor & High & 3 \\
\hline 2 & \multicolumn{8}{|c|}{ Bridge is scour critical, IMMEDIATE action is required * } & 2 \\
\hline 1 & \multicolumn{8}{|c|}{ Bridge is scour critical, bridge is CLOSED * } & 1 \\
\hline 0 & \multicolumn{8}{|c|}{ Bridge has failed due to scour * } & 0 \\
\hline $\begin{array}{l}\text { TES: } \\
\text { lating co } \\
\text { If an iter }\end{array}$ & rations give & highest to & st level of & rtance from & to right. & & \multicolumn{3}{|c|}{$\begin{array}{l}C=\text { Effective Countermeasures } \\
P=\text { Pile Supported Substructures }\end{array}$} \\
\hline
\end{tabular}

DETERMINATION OF RATING FOR BMS ITEM W11-A

\begin{tabular}{|c|c|c|c|c|c|c|c|c|c|}
\hline \multirow[b]{2}{*}{$\begin{array}{l}\text { Substructure } \\
\text { unit }\end{array}$} & 1 & 2 & 3 & 4 & 5 & 6 & 7 & 8 & \multirow{2}{*}{$\begin{array}{l}\text { W11-A } \\
\text { Overall } \\
\text { observed } \\
\text { scour } \\
\text { rating }\end{array}$} \\
\hline & $\begin{array}{l}\text { Change } \\
\text { since last } \\
\text { inspection }\end{array}$ & $\begin{array}{l}\text { Scour } \\
\text { hole }\end{array}$ & $\begin{array}{c}\text { Debris } \\
\text { potential }\end{array}$ & Scourability & $\begin{array}{l}\text { Opening } \\
\text { Adequacy/ } \\
\text { Channel }\end{array}$ & Sediment & Alignment & $\begin{array}{l}\text { Velocity/ } \\
\text { stream } \\
\text { slope }\end{array}$ & \\
\hline \#128A & \#128B & \#128C & \#128D & \#128E & \#128F & \#128G & \#128H & \#128I & \#128J \\
\hline & & & & & & & & & \\
\hline & & & & & & & & & \\
\hline & & & & & & & & & \\
\hline & & & & & & & & & \\
\hline & & & & & & & & & \\
\hline & & & & & & & & & \\
\hline & & & & & & & & & \\
\hline & & & & & & & & & \\
\hline
\end{tabular}

REASON SUBSTRUCTURE UNIT COULD NOT BE ACCESSED

NAB:\#129 FAB:__ P01:__ P02:__ P03:___ P04:__ P05:__ P06:__ P07:__

1. Water too deep 2. Water too swift 3. Safety concerns 4 . No access

Figure 9. "Bridge and Channel Characteristics at Field-Viewed Bridge Sites" form-Continued. 


\section{PROCEDURES FOR COMPLETING THE "BRIDGE AND CHANNEL CHARACTERISTICS AT FIELD-VIEWED BRIDGE SITES” FORM}

The information and required data elements collected according to this appendix include geomorphic, sediment, and hydraulic data elements. Each entry is recorded directly onto the datacollection form. For items below that list the data-collection location as two bridge lengths (fig. 10) upstream or downstream from the structure, this distance may be reduced to $200 \mathrm{ft}$ in the case of expansive bridges. Distances, relative to the bridge, are measured along the stream channel, not as a straight line. Significant features directly observable but beyond $200 \mathrm{ft}$ from the bridge are to be included on the datacollection form. Any item that receives an entry of "Other" is to be discussed in the comment field that is provided in the vicinity of that item and(or) have the appropriate sketch completed. PennDOT items in parentheses refer to items modified from or taken directly from PennDOT publication 100A (Pennsylvania Department of Transportation, 1993).

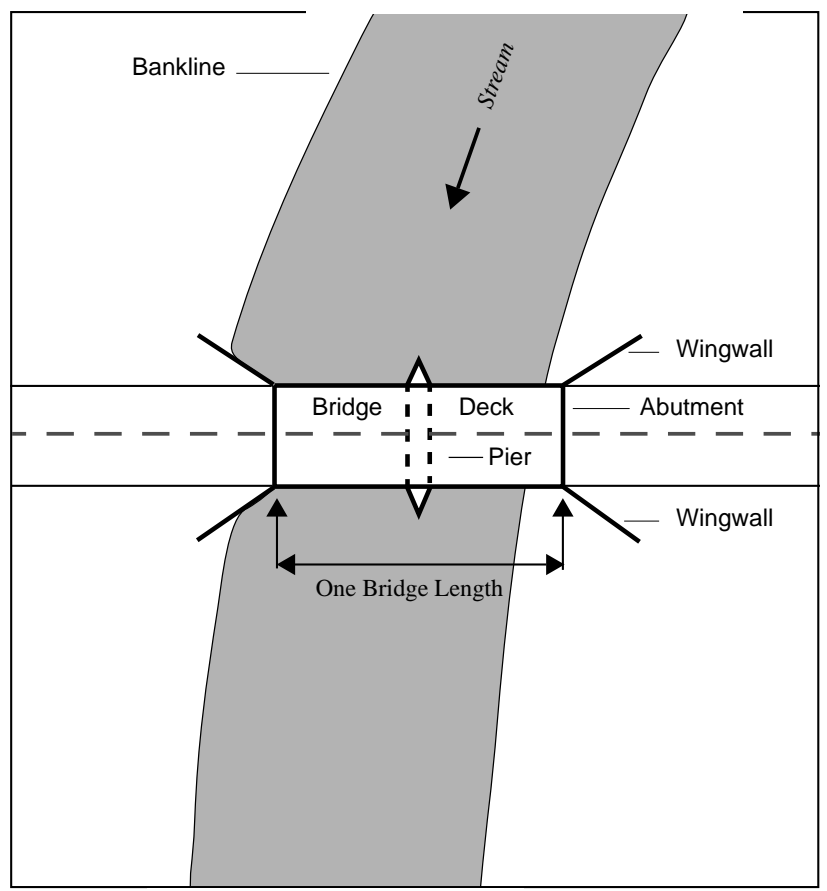

Figure 10. Bridge length.

\section{The Following Items are to be Recorded in the Vehicle:}

\section{Assessed Bridge Number (PennDOT item A01)}

The assessed bridge number is the 14-digit structure-identification number according to item A01 of BMS Pub 100A on the day of the field visit. This number is provided by PennDOT and serves to identify a bridge location and to indicate the bridge owner.

\section{Inspector}

The inspector is the USGS person collecting the data. The format for entry includes the person's first initial, middle initial (if appropriate), and last name. 
3 and 3A. Inspection Date and Time of Arrival on Site

The date is the month, day, and year of the site assessment. The time that field personnel arrive at a bridge site is recorded in military time (24-hour system).

\section{GPS File Name and Serial Number}

The GPS file name consists of eight characters. The first two characters are the county code indicating where the GPS data is collected (for example, 22 would indicate that data was collected in Dauphin County. Appendix A of BMS Pub 100A lists codes for all counties within Pennsylvania). Characters three through five represent the Julian Day on which the GPS data was collected (for example, day 152 is representative of June 1). Character six indicates the year in which the GPS data is collected (for example, 8 indicates the data was collected during 1998). The seventh character is a unique letter assigned to each field team. This letter is used to distinguish between files collected by different field teams on the same day. The eighth character is a numeral that is used to distinguish between bridges assessed on the same day by an individual field team. The numbering sequence begins at one at the start of each day and increases by increments of one as each subsequent bridge is assessed during a particular day. This item ends with a dash (-) and the last two digits of the serial number for the GPS unit that has collected the data. Examples of this file naming procedure for Team A working in Dauphin County on June 1, 1994, using GPS unit \#73 would be 221524A1-73 for the first file of the day and 221524A2-73 for the second file of the day. Team B may collect GPS data in the same county and on the same day however the "B" in their GPS file names would distinguish between the files collected by other teams.

\section{Total Station File Name-Serial Number}

A six-character file name is assigned to each total station file. This item utilizes the same file-naming convention as that discussed for the GPS data, including the last two digits of the total station serial number, with the exception that the county code is omitted.

\section{Is This An Overflow Bridge}

Entries are $0=$ no or $1=$ yes, indicating whether or not the bridge is an overflow bridge. An overflow bridge is a structure that is located on the flood plain and receives streamflow only during overbankflow conditions.

\section{The Following Items are to be Recorded From the Roadway On or Near the Bridge Deck:}

\section{Surface Cover}

Surface cover in the immediate vicinity of the bridge is described using options from the eight surfacecover categories $(1=>50 \%$ paved, $2=10 \%-50 \%$ paved, $3=$ row crop, $4=$ pasture, $5=$ brush, $6=$ forest, $7=$ wetland, and $8=$ structure) listed on the field form. Surface cover, for the upstream right, upstream left, downstream right, and downstream left quadrants, is described within an area defined by two bridge lengths upstream and downstream and up to two bridge lengths landward of the bridge. The category that best describes the overall ground cover of the bridge site also is recorded.

\section{8 and 8A. High Flow and Low Flow Angles of Approach}

Standing near the bridge deck, field personnel determine the direction from which bankfull flow (high flow) and low flow approach the bridge location and the direction along which bankfull flow and low flow exit the bridge location. The approach angles are a measure of the angle created by the intersection of these two imaginary lines (figs. 11 and 12). These parameters are not a measure of the attack angles on the bridge. They are a comparison of the upstream and downstream reaches. Entries are $1=0$ to $5,2=6$ to $15,3=16$ to $30,4=31$ to 45 , or $5=46$ to 90 degrees. Flow paths directed toward the left bank are recorded with the angle category preceded by a minus (-) sign. Flow paths directed toward the right bank are recorded with the angle category; a positive sign is assumed. 


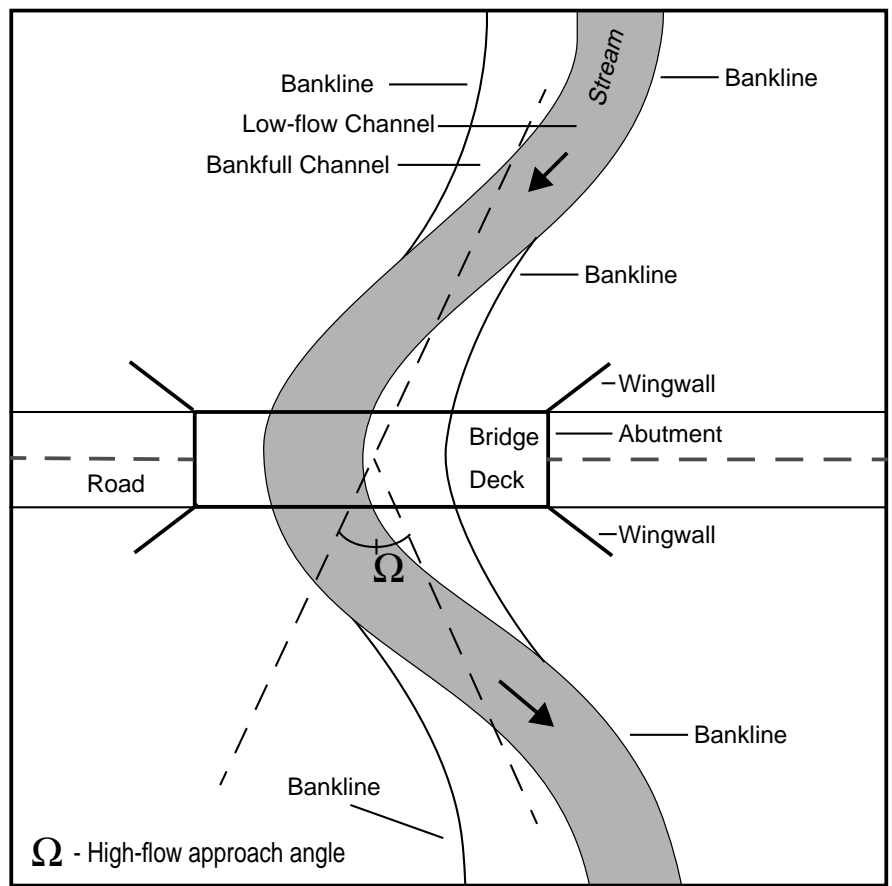

Figure 11. High-flow approach angle.

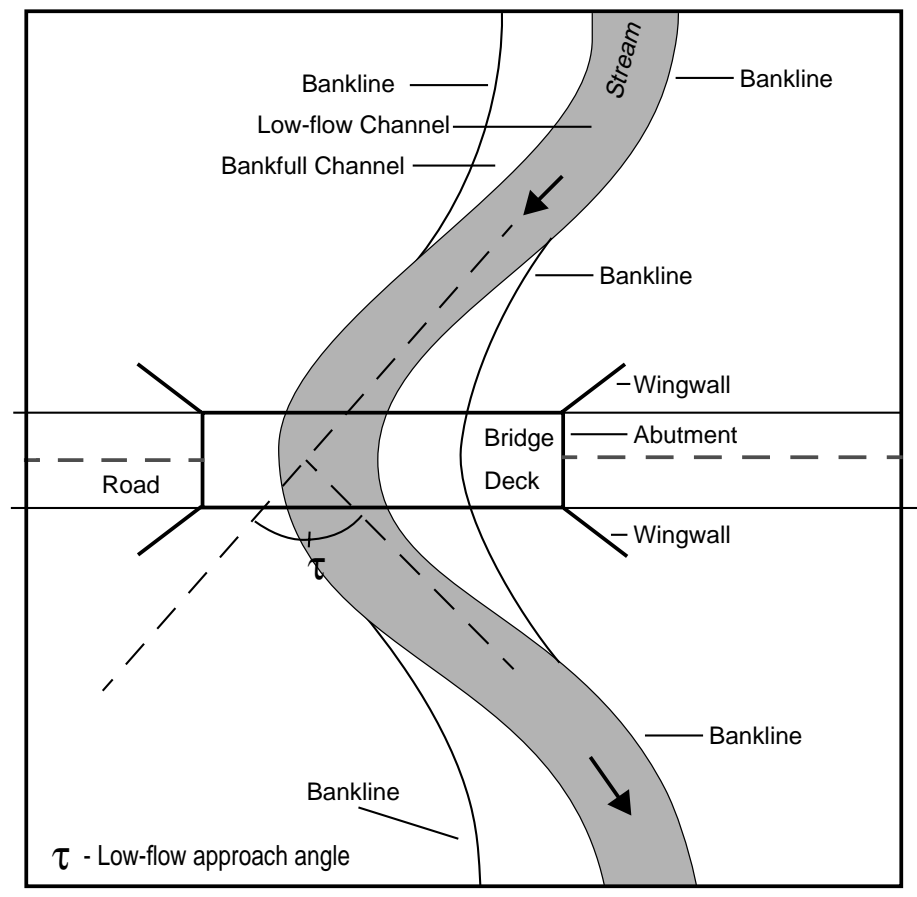

Figure 12. Low-flow approach angle. 


\section{High Flow Skew to Upstream Bridge Face}

Standing on the bridge deck, field personnel record the angle at which bankfull flows (high flows) approach the upstream face of the bridge (fig. 13). Entries are $1=90$ to $85,2=84$ to $75,3=74$ to 60 , $4=59$ to 45 , or $5=44$ to 0 degrees. Flow paths directed toward the left bank are recorded with the angle category preceded by a minus (-) sign. Flow paths directed toward the right bank are recorded with the angle category; a positive sign is assumed.

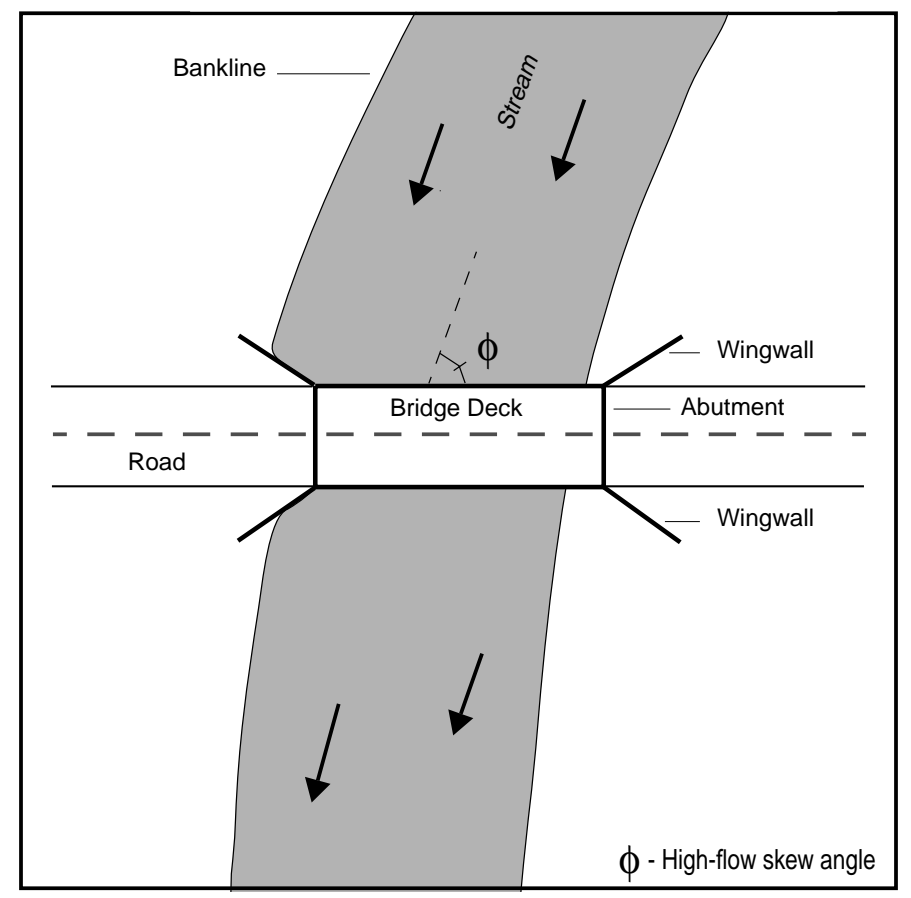

Figure 13. High-flow skew angle.

\section{Upstream Channel Profile}

This item indicates if the stream, between the bridge and two bridge lengths upstream of the bridge, when practical, is dominated by a pool (1) or a riffle (2). When the stream is dry or consists of nonflowing, isolated pools, an entry of $3=$ no flow.

\section{Downstream Channel Profile}

This item indicates if the stream, between the bridge and two bridge lengths downstream of the bridge, when practical, is dominated by a pool (1) or a riffle (2). When the stream is dry or consists of nonflowing, isolated pools, an entry of $3=$ no flow.

\section{The Following Items Are to be Recorded in the Upstream Channel:}

The upstream channel is defined as an area beginning at the upstream end of the upstream wingwalls and extending to a distance of two bridge lengths upstream. If no wingwalls are present, the toe of the road berm is used as downstream ends of the upstream channel. 


\section{Is There Evidence of Road Overtopping}

Field personnel inspect the vicinity of the bridge for evidence that the roadway may have been overtopped. The field form entries are $0=$ no evidence of overtopping or $1=$ evidence of overtopping. Examples of evidence of overtopping are debris piles, seed lines, or nearby markers indicative of the water-surface elevation for a high-water event. A comment field is provided to discuss affirmative responses.

\section{Is There Evidence of Pressure Flow}

Field personnel inspect the bridge site for evidence that the entire bridge opening was fully submerged. The field form entries are $0=$ no evidence of pressure flow or $1=$ evidence of pressure flow. Debris lodged in the bridge beams is a good indicator of pressure flow. A comment field is provided to discuss affirmative responses.

\section{Bed Material}

This item describes the three most abundant particle sizes found in the channel bed upstream of the bridge. Descriptive categories used for bed and bank material (Lagasse and others, 1990) include silt/clay (up to $0.062 \mathrm{~mm}$ ), sand $(0.062-2.0 \mathrm{~mm}$ ), gravel $(2.0-64 \mathrm{~mm})$, and cobble/boulder (over $64 \mathrm{~mm}$ ). Additional bed-material categories used in scour assessments are bedrock and concrete/steel. The first two sizes selected are to be used to modify the dominant particle size recorded in the last blank (for example, bed material composed of 10 percent gravel, 25 percent silt/clay, and 65 percent sand is described as a gravely silty sand and is recorded as a 312-each number indicating a specific sediment type). The presence of silt/clay can be determined by attempting to form the material into a cohesive ribbon or ball. At some sites, all three blanks are not filled in with a number (for example, silty sand). Dashes are used to complete the entry when the data to be entered do not fill the number of allotted spaces.

\section{Vegetative Cover}

This item reflects the amount of woody vegetation growing between the water's edge and the top of the right and left upstream banks. Entries are $1=0$ to 25 percent, $2=26$ to 50 percent, $3=51$ to 75 percent, or $4=76$ to 100 percent. The category selected describes what percentage of the bank is being stabilized by the woody vegetation.

\section{Bank Material}

This item describes the three most abundant particle sizes found in the channel banks upstream of the bridge. Descriptive categories used for bed and bank material (Lagasse and others, 1990) include silt/clay (up to $0.062 \mathrm{~mm}$ ), sand $(0.062-2.0 \mathrm{~mm})$, gravel $(2.0-64 \mathrm{~mm})$, and cobble/boulder (over $64 \mathrm{~mm}$ ). Additional bed-material categories used in scour assessments are bedrock and concrete/steel. The first two sizes selected are to be used to modify the dominant particle size that is recorded in the last blank (e.g. bank material composed of 10 percent gravel, 25 percent silt/clay, and 65 percent sand is described as a gravely silty sand and is recorded as a 312-each number indicating a specific type of sediment). The presence of silt/clay can be determined by attempting to form the material into a cohesive ribbon or ball. At some sites, all three blanks are not filled in with a number (e.g. silty sand). Dashes are used to complete the entry when the data to be entered does not fill the number of allotted spaces.

\section{Bank Erosion}

This item is used to describe the dominant mechanism by which material is being eroded from the upstream banks. Entries to describe erosion conditions at a site are $0=$ no bank erosion, $1=$ light fluvial erosion, 2 = heavy fluvial erosion, or 3 = mass wasting (fig. 14). Fluvial erosion is the particle by particle removal of sediment over a period of time. The distinction between light and heavy fluvial erosion is qualitative and is indicative of whether or not the removal of soil is deemed to be significant. Mass wasting is the slumping or sliding of a section of competent bank material that generally occurs within a very short time period. To be classified as mass wasting, some evidence of the failed mass of 


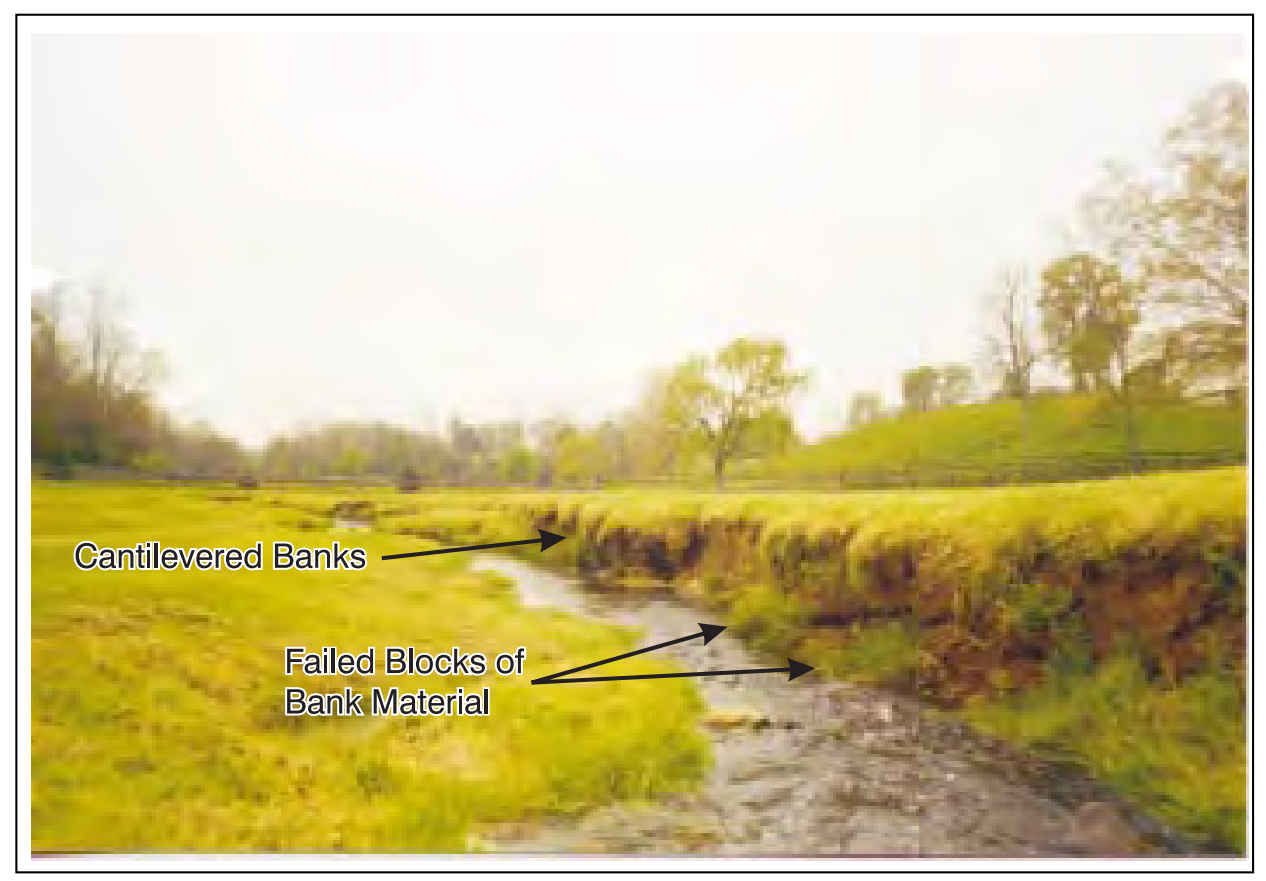

Figure 14. Evidence of mass wasting.

bank material should still be present at the toe of the bank. The mass-wasting category also is reserved for those sites at which mass wasting is a widespread mechanism of bank failure and not isolated in small areas within the stream reach.

\section{Locations of Tributary Confluences and Drains within Two Bridge Lengths Upstream}

The existence of any significant tributaries and drains is noted as well as the bank from which they enter the stream and their distance upstream from the bridge. Drainage ditches or small drainage pipes (less that $3 \mathrm{ft}$ in diameter) are not considered tributaries unless the inflow is having a significant effect on the structure or the geomorphology at the site. The comment field is used to address significant aspects of the tributary.

\section{Existence of Cutbank}

This item is used to note the presence of a cutbank, the bank ( $1=$ left or $2=$ right $)$ affected by the flow, and the horizontal distance from the upstream bridge face to the center of the scarp. Minor abrasion along the edge of the active channel is not considered a cutbank.

\section{Meander Impacts}

Field personnel locate the apex along the outside of any meander bends present along the stream reach. On the field form, personnel note that a meander does or does not exist within two bridge lengths or $200 \mathrm{ft}$. If a meander exists, field personnel indicate the bank affected by the flow $(1=$ left or $2=$ right $)$ and the distance from the bridge to the apex along the outside of each meander.

\section{Is a Roadway Approach Subject to Meander Impact/Cutbank}

This item is used to describe potential problems with the roadway approaches extending from the bridge and also adjacent roadways, not carried by the bridge, that may be affected as a result of the channel's meandering or cutting. The entries are $1=$ near, indicating the near roadway approach is affected by meandering or cutting in the upstream part of the channel; $2=$ far, indicating the far roadway approach is affected by meandering or cutting in the upstream part of the channel; 3 = adjacent, indicating an adjacent roadway, not carried by the bridge, is affected by meandering or 
cutting in the upstream part of the channel; or $4=$ no, indicating no roadway is affected by meandering or cutting in the upstream part of the channel. If a roadway is affected, field personnel briefly describe, in the comment field provided, the effect on roadway integrity and estimate the distance from the closest abutment.

\section{Point Bar}

This item is used to note any lateral accumulations of sediment that may act to significantly affect the direction of bankfull flow (fig. 15). Entries for this item are $0=$ no or $1=$ yes, depending on whether a point bar exists. The percent of the channel affected by the point bar is described by entries from 0 to 100 percent $(0$ percent $=$ left bank and 100 percent $=$ right bank) and the distance from the upstream bridge face to the widest part of the bar. For example, a point bar on the left side of the stream may extend from 0 percent to 10 percent; therefore blocking 10 percent of the channel. Field personnel also note whether or not the point bar contains woody vegetation, the location of the vegetation in terms of the percentage of the channel affected $(0$ percent $=$ left bank, 100 percent $=$ right bank $)$, and the height of the vegetation in terms of the percentage of the bridge opening obstructed $(0$ percent $=$ streambed, 100 percent $=$ bottom of beam).

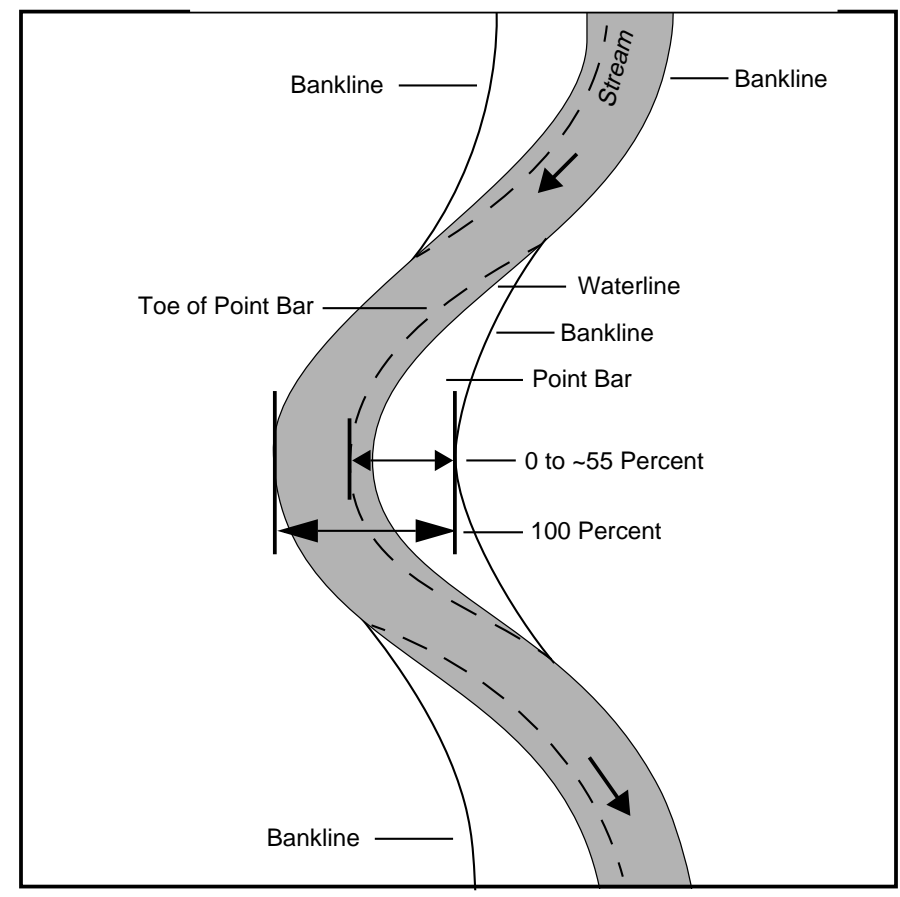

Figure 15. Extent of point bar.

\section{Mid-Channel Bar}

This item is used to note any accumulations of bed sediment, in the middle of the stream channel, that may act to significantly affect the direction of bankfull flow (fig. 16). Entries for this item are $0=$ no or $1=$ yes, depending on whether a mid-channel bar exists. The percentage of the channel affected by the mid-channel bar is described by entries from 0 to 100 percent $(0$ percent $=$ left bank and 100 percent $=$ right bank) and the distance from the upstream bridge face to the widest part of the bar. For example, a mid-channel bar in the middle of the stream may extend from 45 percent to 55 percent, therefore blocking 10 percent of the channel. Field personnel also note whether or not the mid-channel bar contains woody vegetation, the location of the vegetation in terms of the percentage of the channel 


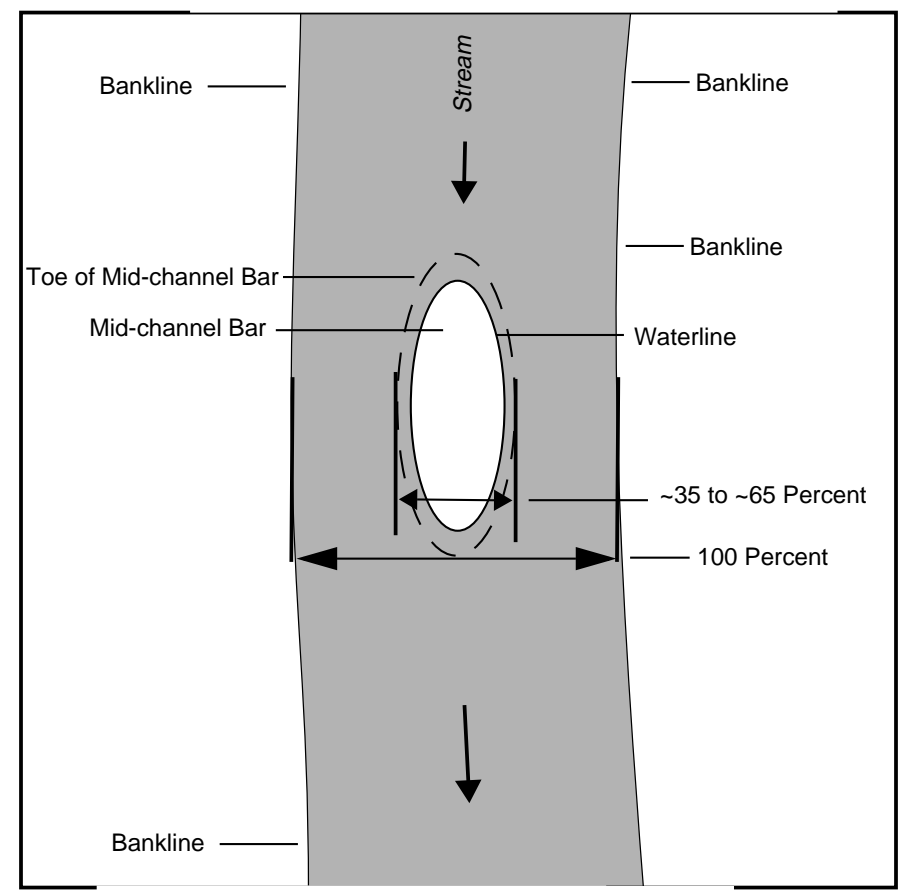

Figure 16. Extent of mid-channel bar.

affected ( 0 percent $=$ left bank, 100 percent $=$ right bank $)$, and the height of the vegetation in terms of the percentage of the bridge opening obstructed $(0$ percent $=$ streambed, 100 percent $=$ bottom of beam).

\section{Type, Location, and Condition of Countermeasures}

If no countermeasures are in place, an entry of " 0 " (none) is entered under the heading "type." If countermeasures are in place, field personnel describe the type, location, and condition of the countermeasures. Entries for the type of countermeasure(s) are 1 = riprap, 2 = gabions, $3=$ guide banks, or $4=$ other. An entry of "other" or any significant aspect about an existing countermeasure is described in a comment field provided in this section of the form. Locations of existing countermeasures are to be recorded by selecting from the list of abbreviations that includes $1=$ USLOB (upstream left overbank), 2 = USLB (upstream left bank), 3 = US Channel (upstream channel), $4=$ USRB (upstream right bank), and $5=$ USROB (upstream right overbank). Descriptors of countermeasure condition are to include one of the following entries: $1=$ good, a countermeasure is present and its placement and condition are sufficient to provide a protective barrier to erosive mechanisms at high flow; 2 = partial, either the placement, quantity, or condition of the countermeasure is insufficient to provide a total protective barrier to erosive mechanisms at high flow; or 3 = failed (fig. 17), obvious evidence of movement or deterioration of a countermeasure such that the countermeasure is not providing the protection from erosive processes for which it was installed.

\section{The Following Items are to be Recorded from Under the Bridge:}

Under the bridge is defined as an area beginning at the upstream ends of the upstream wingwalls and extending to the downstream ends of the downstream wingwalls. If no wingwalls are present, the upstream and downstream headwalls of the bridge are used as the under-the-bridge boundaries.

\section{Bed Material}

See item 14 for description 

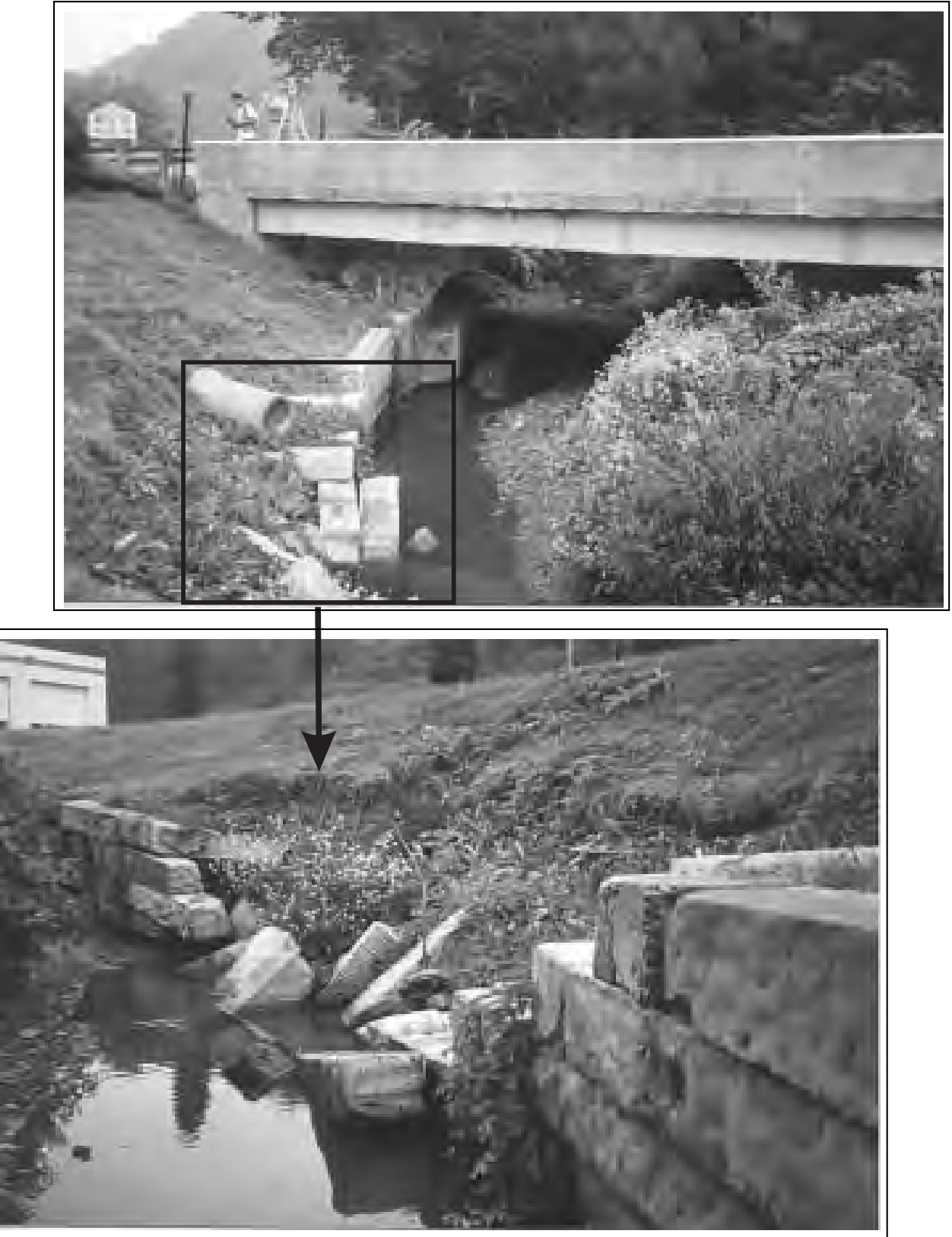

Figure 17. Failed countermeasure. 
26. Locations of Tributary Confluences and Drains Under Bridge

See item 18 for description.

\section{Existence of Cutbank}

See item 19 for description.

\section{Meander Impacts}

See item 20 for description.

\section{Is a Roadway Approach Subject to Meander Impact/Cutbank}

See item 21 for description.

\section{Effect of Cutbank/Meander Impact on Structure Integrity}

This item is a qualitative judgement on the part of field personnel as to whether or not a cutbank or meander impact, that has been noted as existing under the bridge, may affect the structural integrity of the bridge. The entry explains, in narrative form, the effect, or lack of effect, of the cutbank or meander impact on the bridge-structure integrity.

\section{Point Bar}

This item is used to note any lateral accumulations of sediment that may act to significantly affect the flow direction. Entries for this item are $0=$ no or $1=$ yes, depending on whether a point bar exists, the percentage of the channel affected by the point bar ( 0 percent $=$ left bank and 100 percent $=$ right bank), and the vertical extent of the point bar relative to the streambed ( 0 percent) and the bottom of the beam (100 percent). The presence of vegetation, if any, is included when making this determination. Field personnel also note whether or not the point bar contains woody vegetation and the location of the vegetation in terms of the percentage of the channel affected $(0$ percent $=$ left bank, 100 percent $=$ right bank).

\section{Mid-Channel Bar}

This item is used to note any accumulations of bed sediment in the middle of the stream channel that may act to significantly affect the flow direction. Entries for this item are $0=$ no or $1=$ yes, depending on whether a mid-channel bar exists, the percentage of the channel affected by the mid-channel bar $(0$ percent $=$ left bank and 100 percent $=$ right bank $)$, and the vertical extent of the mid-channel bar relative to the streambed ( 0 percent) and the bottom of the beam (100 percent). The presence of vegetation, if any, is included when making this determination. Field personnel also note whether or not the mid-channel bar contains woody vegetation and the location of the vegetation in terms of the percentage of the channel affected ( 0 percent $=$ left bank, 100 percent $=$ right bank).

\section{Debris Accumulation}

This item is used to note the presence of any significant accumulation of debris within the bridge opening (fig. 18). The entries for this item are $0=$ no debris accumulation or $1=$ debris accumulation.

\section{Type of Debris Material}

This item uses the key provided on the field form to note the type of material that is the most significant constituent within the debris accumulation. Entries to describe the debris are $1=$ brush, $2=$ trees, $3=$ trash, or $4=$ all others.

\section{Horizontal Location of Debris}

Field personnel note the percentage of the channel affected by the debris pile. The entry for this item consists of the location in the stream (entered as a percentage), relative to the left bank ( 0 percent $=$ left bank, 100 percent = right bank), where the debris pile starts and stops. 


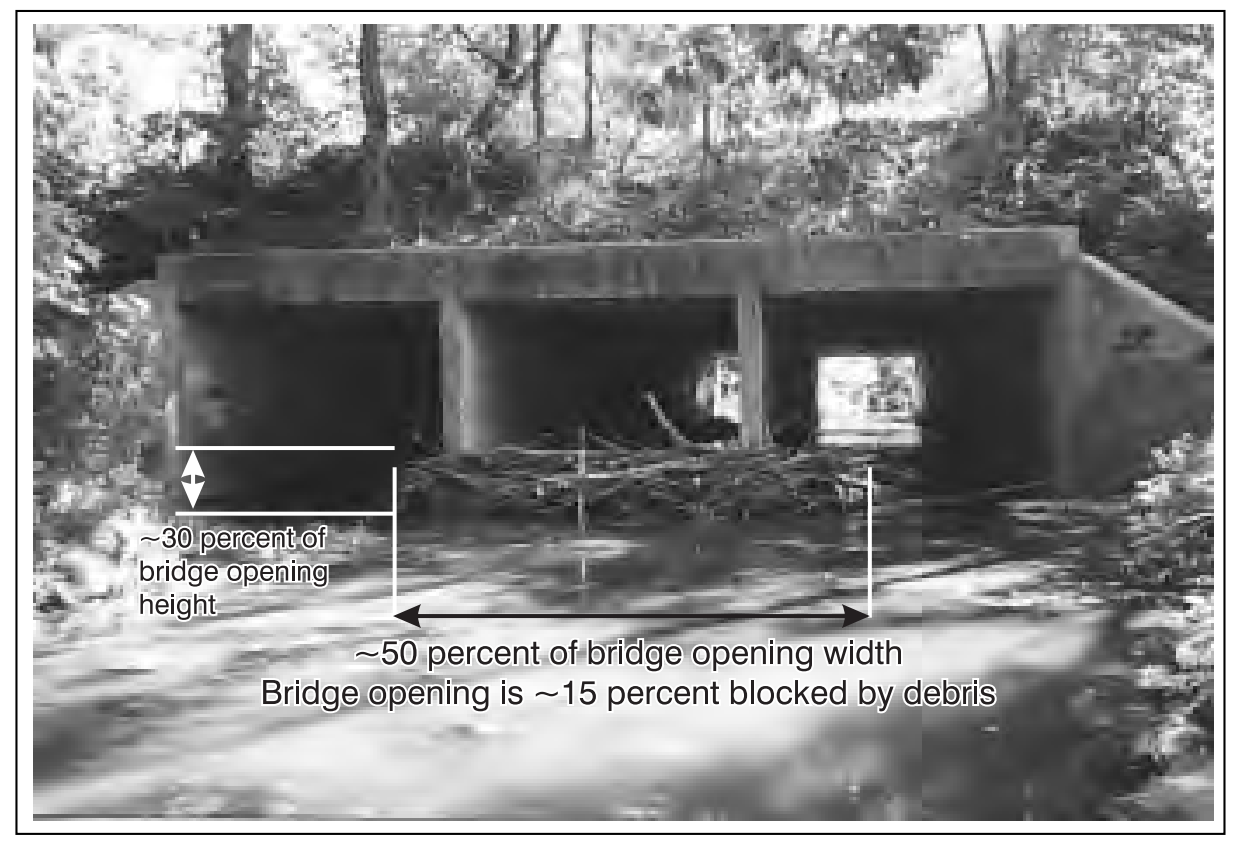

Figure 18. Extent of debris accumulation.

\section{Vertical Height of Debris}

Field personnel note the vertical height of the debris pile affecting the bridge opening. The entry for this item consists of the percent of the bridge opening, in a vertical sense, relative to the streambed $(0$ percent $=$ streambed, 100 percent $=$ bottom of beam $)$ obstructed by debris .

NOTE: In an attempt to indicate the effect that the debris has on the bridge or channel, the results of horizontal location of debris (item 35) and vertical height of debris (item 36) are multiplied then divided by 100 in the database to provide an overall estimate of the percentage of bridge opening blocked by debris. Field personnel perform the same operation for the purpose of determining if the amount of the debris requires any further action on the part of USGS personnel. As a general rule, if less than 20 percent of the bridge opening is blocked by debris the condition is presumed acceptable. A bridge opening 20 percent to 40 percent blocked by debris results in a "flag" designation. A bridge opening greater than 40 percent obstructed by debris results in a "phone" designation and is reported to the appropriate PennDOT district office. The highest classification (indicating the most serious situation) is used if a site is questionable.

\section{Trapping Potential}

This item is used to record how much potential the bridge has for trapping debris. Factors to consider for determination of trapping potential are listed in table 2. Other site conditions, such as stock fencing across the bridge opening, also are taken into account.

\section{Debris Potential}

This item is used to record field personnel impressions as to what potential the upstream drainage basin has for producing debris. If field personnel observe debris accumulated at a bridge site or abundant debris nearby, the basin has a high potential for debris production. Extensive tree growth along the bank with some evidence of undercutting also would fall into the high-potential category. Moderate tree growth along the bank or in the flood plain would be considered medium debris potential. A bridge site with some woody vegetation and little or no apparent debris at the bank, in the 
Table 2. Trapping potential for single- and multi-span bridges

[Other items that may affect trapping potential: 1. Rock protection; 2, Pier orientation; 3, Attack angle; >, greater than; $\leq$, less than or equal to]

\begin{tabular}{lccc}
\hline \multicolumn{1}{c}{ Single-span parameters } & Low & Medium & High \\
\hline Clear span & $>50 \mathrm{ft}$ & $>40 \mathrm{ft}$ & $\leq 40 \mathrm{ft}$ \\
Underclearance & $>15 \mathrm{ft}$ & $>10 \mathrm{ft}$ & $\leq 10 \mathrm{ft}$ \\
Opening adequacy & Good - fair & Poor* & Overtopping* \\
Sediment deposits & None - minor* & Medium* & High* \\
\hline \multicolumn{1}{c}{ Multi-span parameters } & Low & Medium & High \\
\hline Clear span & $>100 \mathrm{ft}$ & $>75 \mathrm{ft}$ & $\leq 75 \mathrm{ft}$ \\
Underclearance & $>15 \mathrm{ft}$ & $>10 \mathrm{ft}$ & $\leq 10 \mathrm{ft}^{*}$ \\
Opening adequacy & Good-fair* & Poor & Overtopping* \\
Sediment deposits & None-minor* & Medium* & High* \\
Pier location & No piers in main channel & Piers may be in main channel & Piers in main channel \\
\hline
\end{tabular}

* Refer to PennDOT item W11-A.

stream, or on the flood plain would be assigned the rating of low debris potential. Also, very large streams, very large drainage basins, and streams that flow through heavily forested basins are all rated as having high potential for debris production. At the other extreme, small streams and drainage basins with very little woody vegetation can be assumed to have a low potential for debris production.

\section{Presence and Depth of Scour Holes Not in Contact With Bridge Substructure}

This item is used to note the presence of the two most significant scour holes at the bridge site that are not in contact with the substructure. The entries for absence or presence of scour holes are $0=$ none or $1=$ present. Field personnel also estimate the depth of the scour hole, to the nearest half foot, relative to the average streambed elevation.

\section{Identification of Specific Piers (PennDOT item W09)}

If no piers exist at a bridge site, the entry is 0; no further entry in the "Pier" section of the field form is necessary. If piers are present, identification of each specific pier includes a " $\mathrm{P}$ " followed by the number of the pier. The convention used for specifying piers is the pier closest to the near abutment is assigned P01. The number of each successive pier increases by one as the structure continues across the stream; the highest $\mathrm{P \#}$ is assigned to the pier that is closest to the far abutment. A more complete description of the numbering convention is provided in item W09 of BMS Pub 100A. The piers to be inspected include the streamward-most pier on each flood plain and all piers in the main stream channel.

\section{Location of Specific Piers}

The field form contains five abbreviations used to specify the location of each pier relative to the stream cross section. The entries for pier location are LFP = left flood plain (landward of the bankline); $\mathrm{LB}=$ left bank (between the toe of the bank and the top of the bank or bankline); $\mathrm{MC}=$ mid channel (between the left and right toe of the banks); RB = right bank; or RFP = right flood plain.

\section{Pier Nose Shape(s)}

The entries for the shape of the upstream end of each pier are $1=$ pointed, $2=$ round nose, $3=$ cylinder, $4=$ square nose, $5=$ multiple cylinders, or $6=$ multiple H-beam.

\section{Pier Type (PennDOT item C39M)}

This item indicates the material used in construction of each pier at a bridge site. Entries for this item are $1=$ timber, $2=$ steel, $3=$ concrete, $4=$ stone-masonry, or $5=$ other. 


\section{Foundation Type (PennDOT item W10M)}

This item indicates the foundation type at specific piers. Entries for this item are $1=$ footing on bedrock, 2 = footing on alluvium, 3 = piles /caissons, $4=$ other, or $5=$ not observable.

\section{Water Depth (Maximum) (PennDOT item W11)}

This item indicates the water depth at the time of inspection at a specific pier. The water depth is measured at the point of maximum depth at the specific pier and recorded to the nearest half foot.

\section{Pier Attack Angle(s)}

While standing at the downstream end of the pier, field personnel measure the internal angle created between the long axis of a pier and the direction of high flow as flow impinges on that pier (fig. 19). If the flow would tend to push the pier toward the left abutment, the angle is recorded as negative. Where the flow would tend to force the pier toward the right abutment, the angle is recorded as positive. The comment field is used to address any significant effects of low flow on the pier.

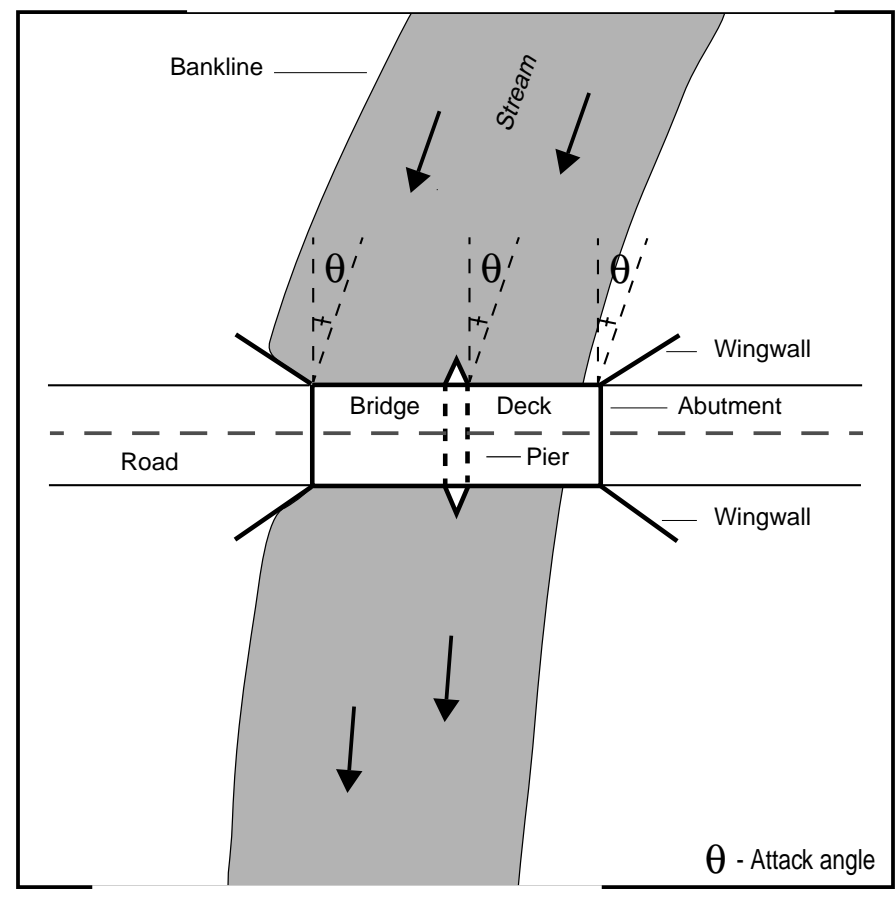

Figure 19. Attack angle at substructure units.

\section{Debris Width Relative to Pier Width}

Field personnel indicate the approximate width of debris piles at each pier relative to pier width. If no debris is present at a particular pier, the entry is 0 . If debris is present, field personnel estimate the width of the debris pile relative to pier width. A debris pile approximately $20 \mathrm{ft}$ wide on a $5 \mathrm{ft}$ pier would receive an entry of " 4 ," indicating the debris pile is approximately four times the width of the pier.

\section{Evidence of Pier Movement}

Field personnel note any evidence of pier movement. Movement may be indicated by open cracks where there has been some apparent lateral or vertical displacement of a part of the pier, significant displacement of stone-masonry units, or obvious settlement of a pier. 


\section{Scour Conditions At Piers}

This item is used to record the scour condition at each pier (fig. 20). The entries for this item are $0=$ none (no scour is evident), $1=$ minor scour, 2 = advanced scour, or $3=$ serious scour. If neither the footing or a pile can be detected but some scour is evident at the pier, minor scour is indicated. If any part of the footing can be observed or detected by probing with a range pole, advanced scour is indicated. Minor undermining, where a small part of the abutment or pier is undermined, is entered as advanced scour. If a pile or piles can be observed, detected by probing with a range pole, or if undermining of the footing can be seen or detected, serious scour is indicated. The lateral extent of the undermining at a pier as well as the depth that the undermining extends back from the face of the footing are the primary criteria for determining the appropriate entry for this item. A sketch illustrating the dimensions of the undermining is required when an entry of 3 is assigned to any substructure unit.

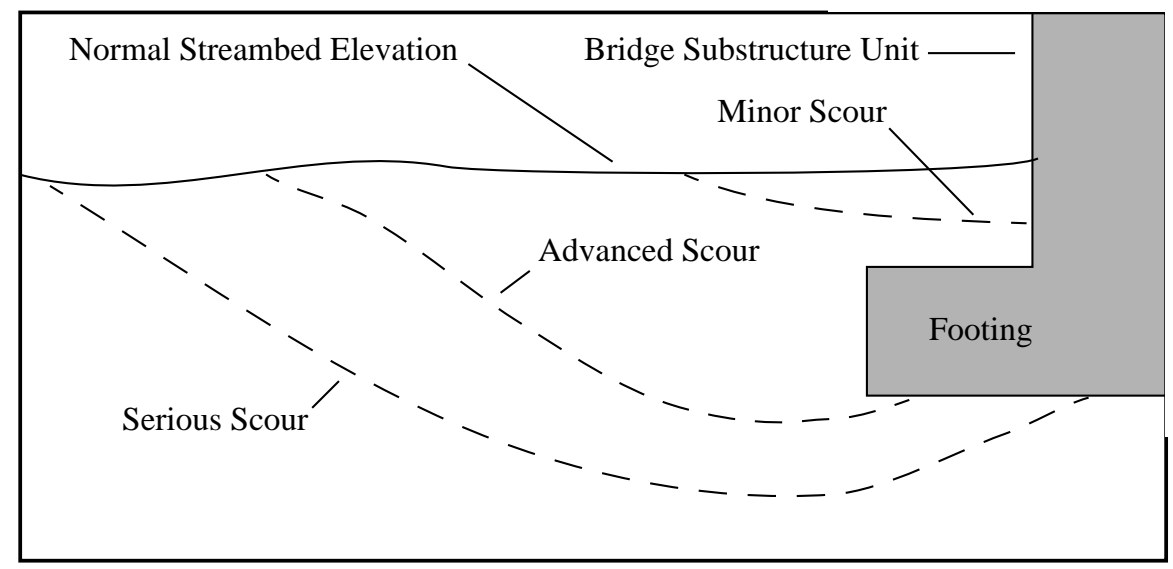

Figure 20. Scour condition at substructure unit.

\section{Scour Depths (PennDOT item W11-C)}

Field personnel estimate, to the nearest half foot, the observed scour depth at the deepest point of scour at a specific pier. The depth of the scour hole is relative to the average streambed elevation.

\section{Unit Inspection Type (PennDOT item W11-B)}

This entry is used to record the type of inspection performed at a specific pier as identified in item 40 . Entries for this item are $\mathrm{E}=$ normal inspection performed (wading), $\mathrm{S}=$ partial inspection for scour evaluation, or $Z$ = addendum required. An entry of " $S$ " indicates field personnel were unable to assess the entire substructure unit but were able to assess a sufficient percentage such that data is adequate to represent the condition of the pier. This type of inspection may include probing of a pier foundation or the ability to assess sections of the pier foundation that are most susceptible to scour. An entry of " $Z$ " indicates field personnel were unable to assess the pier foundation adequately enough to feel confident in assigning entries for some pier characteristics. This code results in attachment of an addendum sheet that incorporates data from previous PennDOT inspections. Substructure units beyond the first unit located entirely on the flood plain and which USGS field personnel feel are not going to be affected by streamflow are deemed as "not in contact with water" and are not assessed.

\section{Pier Findings (PennDOT item W12)}

This is a narrative description of inspection findings at a specific pier. An entry is used to indicate the pier being discussed as described in item 40 . 


\section{Abutment Bank Location}

For state routes, the near abutment (NAB) is determined by the segment stationing with the near abutment being that abutment falling on the lowest numbered segment station. Segments on state routes generally increase in number as the road trends from west to east or from south to north. For locally owned roads, where no plans or inspection reports are available, the near abutment is identified as the south abutment on roads predominantly trending north/south or the west abutment on roads trending east/west. If PennDOT plans or PennDOT inspection reports are available, USGS field personnel use the same near and far designations for abutments in order to prevent conflicting data within the database. Any discrepancies in determinations of the near and far abutments are noted in provided comment fields on the first page of the field form. The far abutment (FAB) is always the abutment that opposes the near abutment. Each abutment is identified either with a " 1 " indicating a left-bank position or a "2" indicating a right-bank position.

\section{Abutment Location}

The location of the near and far abutments, relative to the bankline, is provided in feet (fig. 21). For those abutments that extend beyond the bank into the stream, a negative sign precedes the distance. The entry is 0 for those abutments even with the bankline. For those abutments set back from the bank, a positive sign precedes the distance. For bridges that have sloping abutments, this entry is indicative of the distance from the bankline to the vertical member of the abutment that physically supports the bridge deck.

\section{Abutment Type (PennDOT item C37M)}

This item indicates the types of abutments at a bridge. The entries for this item are $1=$ stub, 2 = cantilever, 3 = gravity concrete, $4=$ spill-through, $5=$ unknown concrete, $6=$ stone-masonry, $7=$ piles $/$ bents, $8=$ concrete $\mathrm{w} / \mathrm{o}$ piles $/$ bents, $9=$ mechanically stabilized panels, or $10=$ other.

\section{Foundation Type (PennDOT item W10M)}

This item indicates the foundation type at each abutment. Entries for this item are $1=$ footing on piles / caissons, $4=$ other, or $5=$ not observable.

\section{Water Depth (Maximum) (PennDOT item W11)}

This item indicates the water depth at the time of inspection at each abutment. The water depth is measured at the point of maximum depth at the specific abutment and recorded to the nearest half foot.

\section{Type of Bridge Opening}

The general shape of the bridge opening is noted for each bridge. If the bridge opening is characterized by vertical walled abutments the entry is $1=$ rectangular. If the bridge opening is trapezoidal, the entries are $2=$ unhardened or $3=$ hardened. An example of an unhardened trapezoidal opening would be one with a horizontal cap on piles laterally supported on the streamward side by fill material with no surficial countermeasures. The same type of feature with a concrete apron on the fill material surface would be considered a hardened trapezoidal opening. The entry for an arched bridge is 4 . Openings that do not seem to fit exclusively into one of these categories receive an entry of 5 (other) and are described in a comment field that is provided with this item. A sketch of the bridge opening is required when an entry of 5 is assigned.

\section{Abutment Attack Angle}

While standing at the downstream end of the abutment, the internal angle created between the long axis of the abutment and the direction of high flow as flow impinges on the abutment is measured. The direction of the force created as flow impacts the abutment is indicated by the sign attributed to the angle. If the flow would tend to push the abutment toward the left bank, the angle is recorded as negative. Where the flow would tend to force the abutment toward the right bank, the angle is 

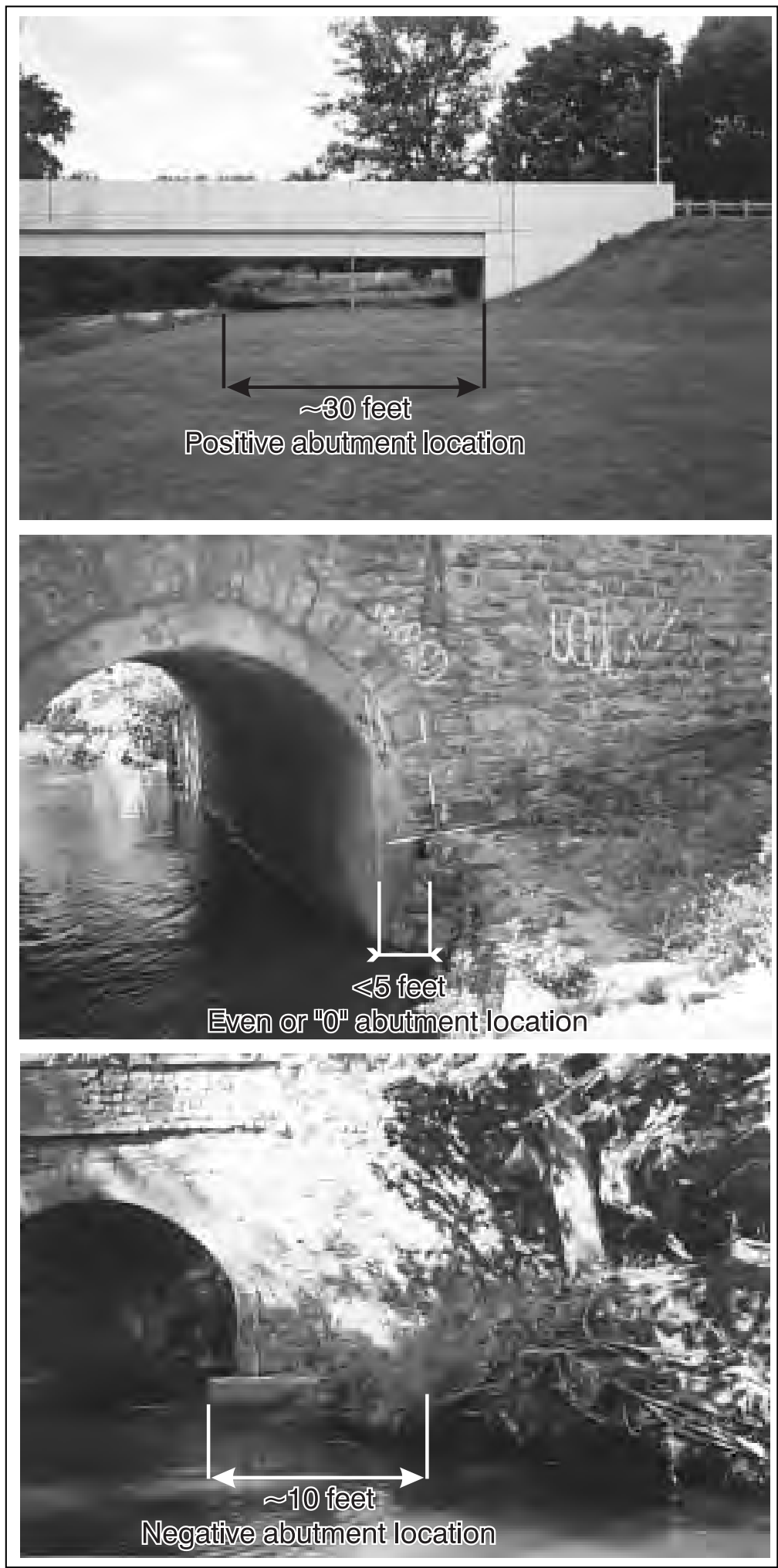

Figure 21. Abutment location. 
recorded as positive. For bridges that have sloping abutments, this entry is indicative of the attack angle on the vertical member of the abutment that physically supports the bridge deck. The comment field addresses any significant effect of low flow on the abutments.

\section{Evidence of Abutment Movement}

Field personnel note any evidence of abutment movement. Movement may be indicated by open cracks where there has been some apparent lateral or vertical displacement of a part of the abutment or obvious settlement of an abutment.

\section{Scour Conditions at Abutments}

This item is used to describe any scour conditions that have led to surface exposure of abutment footings or piles. The entries for this item are $0=$ none (no scour evident), $1=$ minor scour, $2=$ advanced scour, or $3=$ serious scour. If neither the footing or a pile can be detected, but some scour is evident at the abutment, minor scour is indicated. If any part of the footing can be observed or detected by probing with a range pole, advanced scour is indicated on the field form. If a pile or piles can be observed, detected with a range pole, or if undermining of a footing can be seen or detected, serious scour is indicated. Wingwalls are coded with the attached abutment or culvert end unless the scour problem relates solely to the wingwall, where it is noted in the comment field provided on the field form. For bridges that have sloping abutments, this entry is indicative of the scour condition at the vertical member of the abutment that physically supports the bridge deck, not the scour condition at the toe of the sloping abutment. Entries of " 3 " require a sketch illustrating the dimensions of the undermining.

\section{Scour Depths (PennDOT item W11-C)}

Field personnel estimate, to the nearest half foot, the observed scour depth at the deepest point of scour at a specific abutment. The depth of the scour hole is relative to the average elevation of the streambed.

\section{Unit Inspection Type (PennDOT item W11-B)}

This entry is used to record the type of inspection performed at a abutment. Entries for this item are $\mathrm{E}=$ normal inspection performed (wading) $\mathrm{S}=$ partial inspection for scour evaluation, or $\mathrm{Z}=$ addendum attached. An entry of " $\mathrm{S}$ " indicates field personnel were unable to assess the entire substructure unit but were able to assess a sufficient percentage such that they feel they have an adequate idea of the condition of the abutment foundation. This type of inspection may include probing of the abutment foundation or the ability to assess sections of the abutment foundation that are most susceptible to scour. An entry of " $Z$ " indicates field personnel were unable to assess the abutment foundation adequately enough to feel confident in assigning entries for some of the abutment characteristics. This code results in attachment of an addendum sheet that incorporates some items from previous PennDOT inspections. Substructure units beyond the first unit on the flood plain are beyond the scope of this project and are not to be assessed.

\section{Abutment Findings (PennDOT item W12)}

This is a narrative description of inspection findings at a specific abutment. A W09 entry is used to indicate the abutment being discussed.

\section{Presence and Condition of Wingwalls}

Field personnel note the presence or absence of Upstream left, Upstream right, Downstream left, and Downstream right wingwalls. The entries to describe wingwall condition are $1=$ good, if a wingwall of sufficient length, angle to flow, and condition is present such that it provides adequate protection to the abutment; 2 = partial, which indicates either the size, placement, or condition of the wingwall is insufficient to provide adequate protection to the abutment; or 3 = failed, which indicates evidence of movement or deterioration of a wingwall such that the wingwall is not providing adequate protection to the abutment. The failed category also is used when the stream has significantly eroded behind the wingwall (the wingwall has been "turned") or there is significant loss of fill material from behind the wingwall. A comment field is provided for further description of a wingwall when needed. 


\section{Streambed Material Near The Substructure Units}

This item is used to indicate the type of the streambed material near a substructure unit correlated with its potential for scour by use of an alpha-numeric entry; for example A4 or P7. The field form has allotted space for abutments and up to seven piers. Additional piers are entered on an additional sheet as needed. The numeric value (for example, the 7 from P7) can be directly transferred to item 67E (Scourability), unless the substructure units are observed to be founded on piles/caissons or adequately protected by riprap. The list of possible entries for streambed material is noted in table 3 .

Table 3. Streambed material near the bridge substructure units

[Adapted from Pennsylvania Department of Transportation, 1993.]

A6 Stable streambed material predominantly consisting of larger native cobbles and boulders (Not riprap) with small amounts of fine material filling voids. Little scour potential, even during high flows.

A5 Stable, naturally armored streambed composed of cobbles, boulders, gravel, with some fine material that has not shown signs of scour over a long time period. Potential for scour under high velocities exists.

A4 Alluvium consisting of a mixture of fine particles with some larger aggregate. Some cobbles and an occasional boulder may be present. Scour is present or has occurred in the past.

A3 Highly erodible alluvium material predominantly composed of very small particles: clays, silts and(or) fine sands. High potential for scour.

R9 Non-erodible rock. Some faulting or weathering may be present.

R8 Erodible rock that has no signs of scour. Rock may be faulted, weathered, and(or) soft.

R7 Erodible rock that may have some minor scour, but there is little risk that could cause failure during high flows. Rock may be weathered, faulted, and(or) soft.

R4 Highly erodible rock with on-going scour that could advance during a high-flow event. Rock may be highly weathered, faulted, and(or) very soft.

P8 Streambed paved with concrete, gabions, or masonry units in good condition and adequate to resist scour.

P7 Streambed paved with concrete, gabions, or masonry units in good condition. Minor problems may exist, but protection against scour is adequate.

\section{Determination of BMS Observed Scour Rating (Modified from PennDOT item W11-A)}

This item, that is modified from item W11-A of BMS Pub 100A, is provided for the inspector's on-site evaluation of each substructure's risk from scour. The "Observed Scour Rating" is based on entries in 8 different sub-items. Because of the fact that ratings below 3 demand structural interpretation, USGS personnel defer ratings of 0,1 , and 2 to PennDOT personnel and use the following adaptation of PennDOT procedures as follows below to complete the W11-A table.

\section{A. Substructure Unit}

As previously discussed in items 40 and 53, this item identifies the substructure unit being rated in the respective row (NAB, FAB, P01, P02, and so forth).

\section{B. Change Since Last Inspection}

This field indicates the amount of change in the channel banks, streambed, or appearance of scour holes since the last inspection. The following rating criteria is followed:

- None (8-9) - No change is detected through visual inspection or probing.

- Minor (6-7) - No significant changes are detected.

- Medium (4-5) - Some changes are apparent, but these changes pose no threat to the structure.

- High (3) - Significant changes that could affect the structure are detected. 
In the event that improvements have been made to the site (such as armoring the channel banks, debris removal, or refilling of scour holes with riprap or concrete), the following rating criteria is followed, with comments made in the countermeasure sections of the data-collection form:

- 9 - Improvements or repairs have resolved all scour problems.

- 5 to 8 - Improvements that solve some, but not all, of the scour problems are in place. For example, backfilling scour holes without correcting the cause of the scour.

- 4 - Repairs that appear to be inadequate to solve the scour problems are in place.

- 3 - Newly placed repairs that have failed or worsened scour conditions are in place.

\section{C. Scour Hole}

This field indicates evidence of scour through visual inspection and(or) probing. Scour holes refilled with sediment dissimilar to the natural bed material are recorded as scour holes (see fig. 12). The following rating criteria is followed:

- None (9) - Normal streambed (no scour of the bridge substructure unit within one bridge length upstream and downstream).

- Minor (7-8) - Streambed may exhibit slight holes and depressions, however, the footing is not exposed and(or) detected by probing.

- Advanced (5-6) - Footing is exposed and(or) detected by probing to very slightly undermined.

- Serious (3-4) - Significant undermining of the bridge substructure unit has occurred.

\section{D. Debris Potential}

This field indicates the risk to the structure for blockage or partial blockage caused by debris. If the opening is constricted, a higher coding may be warranted.

- None (8-9) - Waterway opening appears capable of handling debris, or for small structures, no apparent debris sources are present along the stream reach.

- Minor (7) - Bridge opening appears reasonably sized and debris appears to be able to pass smoothly through the structure.

- Medium (6) - Increased risk of debris blocking or partially blocking adjoining bridge span is apparent.

- High (4-5) - High probability of debris blocking or partially blocking adjoining bridge span.

- Present (3) - Debris presently blocking or partially blocking a significant part of the adjoining bridge span.

\section{E. Scourability}

This field is used to quantify the ability of the foundation or streambed material to resist scour. A suffix of $P$ indicates the substructure unit is founded on piles, and a suffix of $C$ indicates good countermeasures are in place. A minimum of 12-in. diameter riprap defines a "good" countermeasure.

- Rock/P (9) - Footing appears founded on competent rock, may be founded on piles.

- Rock/P/C (8) - Footing appears founded on competent rock, may be founded on piles and(or) good countermeasures may be in place.

- Rock/C (7) - Footing appears founded on competent rock, good countermeasures may be in place.

- Stable (5-6) - Naturally armored streambed with long-term history of stability.

- Alluvium (3-4) - Water-borne materials deposited by running water, including, clay, silt, sand, gravels, and cobbles. 


\section{F. Opening Adequacy/Channel}

This field describes the capacity of the waterway opening or approach channel to handle anticipated flows.

- Good (8-9) - Approach channel appears capable of handling design flows with little or no out of bank flow and the bridge structure opening also appears adequate to handle the design flood.

- Fair (5-7) - There appears to be only a slight chance of overtopping the roadway or the majority of the flow remains in the approach channel during major storms.

- Poor (4) - There is a significant probability of flows passing over the roadway behind the abutments, or there is a large part of the flow in the overbank area upstream from the bridge.

- Overtopping (3) - There is a high probability of flood flows passing over the bridge structure.

67G. Sediment

This field describes the accumulation of alluvium blocking or partially blocking the bridge structure.

- None (9)- Channel is clear of depositional features with no blockage during low-flow conditions.

- Minor (7-8) - Slight accumulation of unvegetated alluvium that appears capable of becoming mobile during the next flood event.

- Medium (6) - Partial span blockage under low-flow conditions. Vegetation is minimal.

- High (3-5) - Full-span blockage for multi-span structures. Depositional features are well vegetated.

\section{H. Alignment}

This field describes the stream alignment at or near the bridge structure. Pier geometry and pier-nose shape can be considered when selecting among higher or lower values of the same ranking; for example, rounded shapes are less susceptible to skewed flow than square shapes and are ranked higher under equal conditions.

- Good (7-9) - Relatively straight alignment, shallow skew angle for piers and abutments.

- Medium (5-6) - Smooth channel meander through the structure, skew angle in relation to flood flow is less than 30 degrees.

- Poor (3-4) - Sharp bend or meander is present. Abutments and(or) piers are skewed against flood-flow conditions.

\section{I. Velocity/Stream Slope}

This field describes the assumed flood-flow velocity and stream slope accounting for restrictions that could accelerate the flows.

- Low (8-9) - Typically broad, smooth flow with no signs of abrasion on the structure or banks, Stream slope is less than 1 percent.

- Medium (6-7) - Very little sediment remaining on the streambed with some erosion on the banks. Stream slope is between 1 and 5 percent.

- High (3-5) - Very rocky streambed with only large cobbles remaining. Noticeable abrasion of the structure and erosion of the banks. Stream slope is greater than or equal to 5 percent. Bridges that exhibit pressure flow also are rated as having high velocity/stream slope.

\section{J. Overall Observed Scour Rating}

This field describes the overall observed scour rating on the basis of items 67B through 67I. Flagged ratings within several fields indicate the allowable upper limits for the overall observed scour rating field. The allowable range for USGS personnel is 3 to 9 . 


\section{Type, Location, and Condition of Countermeasures}

If no countermeasures are in place, the entry is 0 (none) under the heading "type." If countermeasures are in place, field personnel describe the type, location, and condition of the countermeasures. Entries for the type of countermeasure/s are 1 = riprap, 2 = gabions, 3 = guide banks, $4=$ concrete encasements, or $5=$ other. An entry of "other" or any significant aspect about an existing countermeasure is described in the comment field provided in this section of the field form. Locations of existing countermeasures are to be recorded by selecting from the list of abbreviations that includes 1 = USLWW (upstream left wingwall), 2 = USRWW (upstream right wingwall), 3 = NAB (near abutment), $4=$ pier (this entry requires the pier number to be included in the adjacent space provided), $5=$ channel, $6=$ FAB (far abutment), 7 = LB (left bank), $8=$ RB (right bank), $9=$ DSLWW (downstream wingwall), or $10=$ DSRWW (downstream right wingwall). Description of countermeasures is as stated in item 24 .

\section{The Following Items Are to be Recorded from the Downstream Channel:}

The downstream channel is defined as an area beginning at the downstream ends of the downstream wingwalls and extending to a distance of two bridge lengths downstream. If no wingwalls are present, the toe of the road berm is used as the upstream end of the downstream channel.

\section{Bed Material}

See item 14 for description

70. Vegetative Cover

See item 15 for description.

\section{Bank Material}

See item 16 for description.

\section{Bank Erosion}

See item 17 for description.

\section{Locations of Tributary Confluences and Drains within Two Bridge Lengths Downstream}

See item 18 for description.

\section{Existence of Cutbank}

See item 19 for description.

\section{Meander Impacts}

See item 20 for description.

\section{Is a Roadway Approach Subject to Meander Impact/Cutbank}

See item 21 for description.

\section{Point Bar}

See item 22 for description.

\section{Mid-Channel Bar}

See item 23 for description.

\section{Type, Location, and Condition of Countermeasures}

See item 24 for description. Locations of existing countermeasures downstream from the bridge are recorded using the abbreviations DSLOB (downstream left overbank), DSLB (downstream left bank), DS Channel (downstream channel), DSRB (downstream right bank), or DSROB (downstream right bank). 


\section{Presence of a Blowhole}

This item is used to note the presence of a blowhole (fig. 22), its distance from the bridge measured to the middle of the blowhole, as well as its width and length. Generally, a blowhole is a symmetrical erosional feature created by lateral eddies that occur when the stream rapidly expands upon exiting a bridge.There may be instances when the bank material on one side of the channel is non-erodible therefore yielding an asymmetrical feature. The field form accommodates this situation by requiring field personnel to document the existence of a blowhole at both banks. If a blowhole is asymmetrical, dimensions of the most significant side are noted in a comment field.

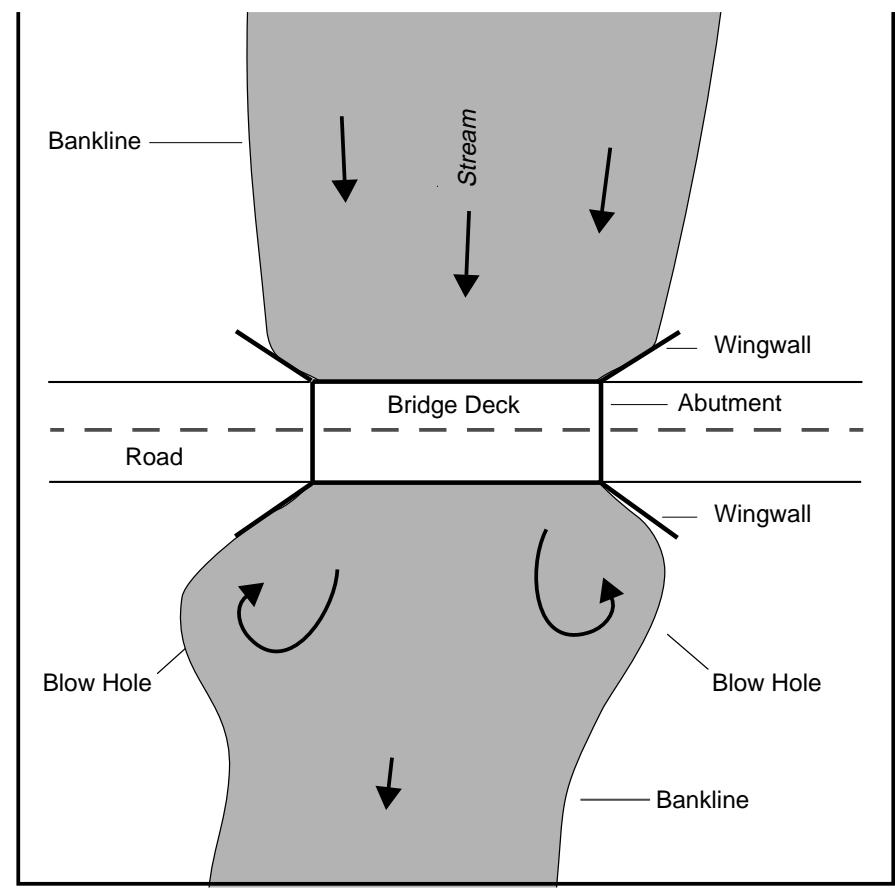

Figure 22. Blow hole.

\section{The Following Items Are to be Entered Upon Completion of the Assessment of All Accessible Substructure Units:}

The following items are regarded as "Summary Findings" of the field assessment. Field personnel are to consider the overall site conditions in the determination of each entry.

\section{Channel \& Channel Condition Rating (PennDOT item E21)}

This item is indicative of the condition of channel and channel protection NOT the bridge waterway. The stability and condition of protective works are considered in this determination; however, the accumulation of debris does not receive consideration in the condition code rating. Descriptions of each possible entry for this item are included on table 4.

\section{Stage of Reach Evolution}

This item is used to record the overall stability of the site excluding the area under the bridge, as previously defined, which is not considered in this determination (adopted and modified from Simon, 1989). Those channels that look truly pristine and stable are described as undisturbed (option 1).

Those sites that have been channelized are described as constructed (option 2). Those sites that have 
Table 4. Channel and Channel Protection Condition Rating

[Adapted from Pennsylvania Department of Transportation, 1993.]

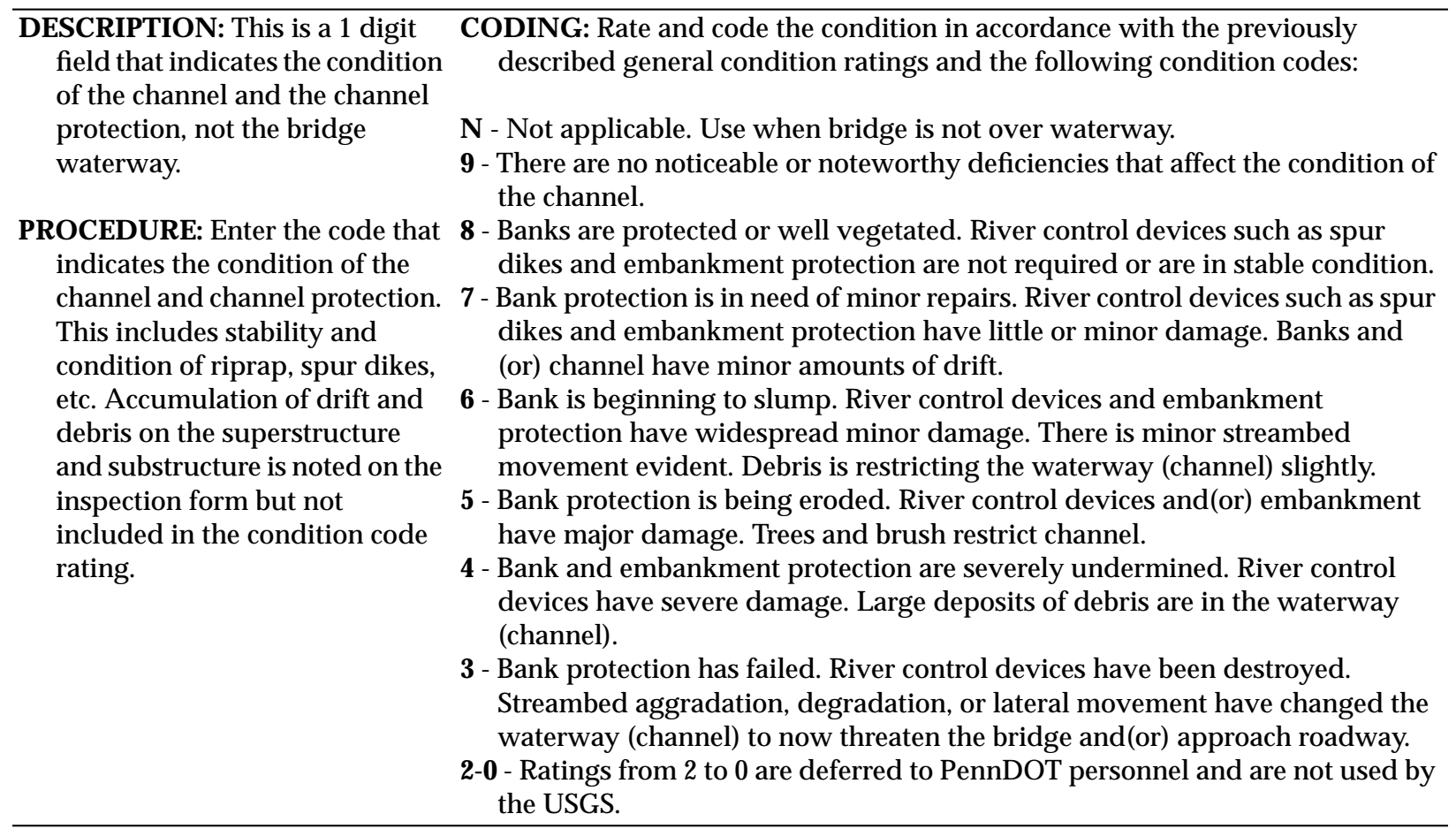

over-steepened banks and significant evidence of bank retreat are described as degradational (option 3). Those sites that show significant evidence of recent sediment accumulation over a majority of the observed reach are described as aggradational (option 4). Those sites that show geomorphic or vegetative evidence of recent lateral migration are described as migrating laterally (option 5). Sites that exhibit none of the above characteristics are described as stable (option 6). Sites that exhibit evidence of degradation and lateral migration receive an entry of "7."

\section{Video}

A data-entry field is provided on the data-collection form for entry of the video cartridge number as well as the counter reading that indicates the start time of the video for a specific bridge. A comment field is provided if the site video requires some explanation regarding the content or collection of the video record. Video-collection procedures are described in detail in Appendix D.

\section{Possible Countermeasures}

Field personnel provide suggestions on methods and estimates of quantities of material needed, if appropriate, to remedy the problems sited. The countermeasures that may be suggested are listed in table 5. Footing underpinning is suggested when a footing is noted as being significantly undermined. Repair or replacement of the abutment slopewall is suggested when the slope wall shows signs of failure or significant deterioration. Repair or replacement of streambed paving is suggested when existing streambed paving has been undermined or shows signs of significant deterioration. Rock protection is suggested when a specific feature (such as a cutbank), within two bridge lengths upstream or downstream of the bridge, requires some protection from stream effect. Scour hole (backfill) is selected when a scour hole exists at the bridge site and field personnel recommend that the hole be filled with riprap. Recommendations for vegetation and(or) debris removal as well as sediment removal are made when the presence of deposited material effects the bridge and(or) the ability of that bridge to convey water. Repair or replacement of the apron cutoff wall is suggested when the cutoff wall at the inlet or the outlet of the culvert is no longer preventing erosion from 
Table 5. Possible countermeasures

\begin{tabular}{lll}
\hline \multicolumn{1}{c}{ Description of activity } & \multicolumn{1}{c}{ Location } & \multicolumn{1}{c}{ Quantities } \\
\hline Footing underpinning (E744803) & NAB P_P_P_P_P_FAB & Cubic yards \\
Abut slopewall (repair/repl) (A745101) & NAB/FAB & Square yards \\
Streambed paving (repair/repl) (A705301) & UP/UN/DS & Cubic yards \\
Rock protection (B745301) & UP/UN/DS & Cubic yards \\
Scour hole (backfill) (C745301) & UP/UN/DS & Cubic yards \\
Vegetation/debris (remove) (ECREMVG) & UP/UN/DS & Cubic yards \\
Sediment deposition (remove) (ECREMDP) & UP/UN/DS & Cubic yards \\
Apron/cutoff wall (repair/repl) (B745202) & UP/UN/DS & Square yards \\
\hline
\end{tabular}

undermining the structure. Under the heading of "Location," UP = upstream from the bridge, $\mathrm{UN}=$ under the bridge, and DS = downstream from the bridge. Field personnel also estimate the quantity of material required at the site, either installed or removed, to remedy the problem.

\section{Should Substructure Be Inspected After Heavy Rainfall or High Flow (PennDOT item E02-A)}

This item indicates if, in the opinion of field personnel, the condition of the bridge is such that a visit, subsequent to a heavy rainfall or high flow, is warranted. Entries for this item are $0=$ no, there is no immediate need to perform a special inspection because of heavy rainfall or flooding or $1=$ yes, the structure should be inspected shortly after a heavy rainfall or flooding.

\section{Is the Structure Impacted by Ocean Tides}

This item is used to indicate whether the structure is affected by tidal conditions. Entries for this item are $0=$ no, there is no tidal influence, $1=$ yes, there is tidal influence, or CNBD = bridge location suggests potential for tidal effect but absence or presence of tidal influence can not be determined.

\section{Site Problems}

This item is used to record a narrative description of significant inspection findings at specific pier, abutment, and(or) wingwall sites. Site problems are listed in order of severity. Every effort is made to be clear and concise when describing site problems.

\section{Recommended Notification to PennDOT}

Field personnel circle one of three options to indicate if any further action is required by USGS personnel and the immediacy with which problems are brought to the attention of PennDOT personnel. Entries are None = there are no existing problems that would warrant special attention on the part of PennDOT personnel; Flag = there are some existing problems because of scour; however, they are not severe enough to warrant immediate attention on the part of PennDOT personnel; and Phone $=$ field personnel feel the problems at the bridge site are so severe that a vehicle traveling over the structure would be in danger because of some form of bridge failure.

\section{Date Action Was Taken}

This item indicates the date a call was made to the appropriate PennDOT District Office if, in the opinion of USGS personnel, the condition of a bridge warrants prompt notification of PennDOT personnel.

\section{Action Was Taken By}

This item indicates the individual that notified PennDOT personnel regarding the condition of a particular bridge. 


\section{Form Reviewed By}

The person who reviews the field form signs on the form that they have reviewed the data on the form and that, in their opinion, it gives an accurate description of the existing conditions at the bridge site on the day of the assessment. The format of this entry is the same as that discussed in item 2. Under all cases, the review is to be done at the bridge site and is the last thing done prior to considering the bridge completed.

\section{Review Date}

The individual responsible for the review enters the date of the review. This date is the same as that entered in item 3.

\section{Time Completed}

Field personnel enter the time that the entire bridge assessment, including on-site review, was completed.

\section{Site Sketch in Plan View}

A plan view sketch is made of each bridge site. A preformatted checklist of symbols for common features, as shown in figure 23, is used to ensure completeness of the sketch.

\section{Bridge Opening Sketch}

A sketch of the bridge opening is done only for bridge openings that receive an entry of "Other" in Item 58 or when a bridge has some extraordinary characteristics (fig. 24). This sketch illustrates the rough geometry of the bridge opening and any characteristics deemed significant.

\section{Sketch of Undermining at Substructure Units}

Field personnel sketch a plan view of undermining at any substructure unit where it occurs, including dimensions of the undermining (fig. 25). This sketch is required for all substructure units listed as having a serious scour condition 


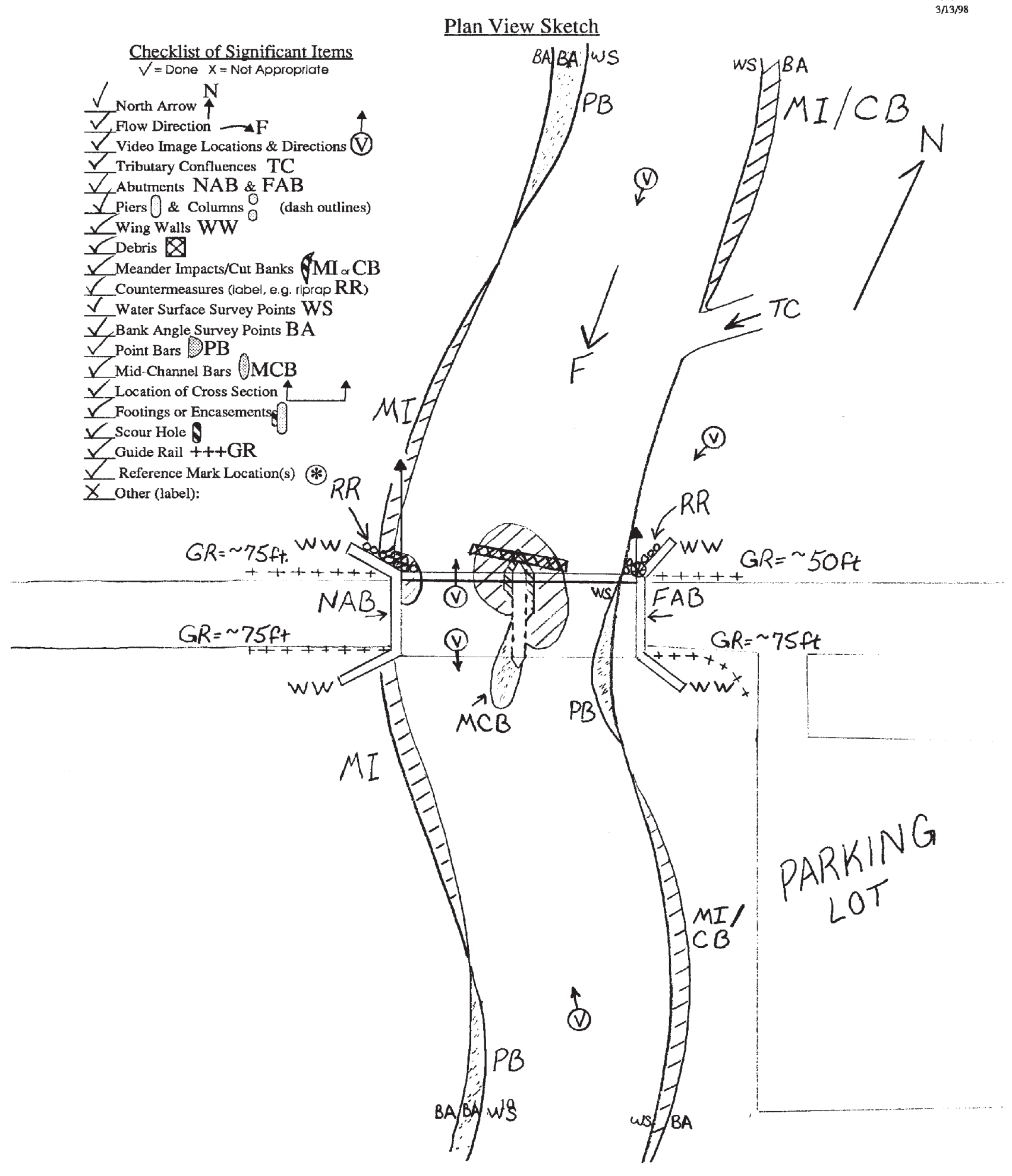

Figure 23. Plan-view of field-viewed bridge site. 


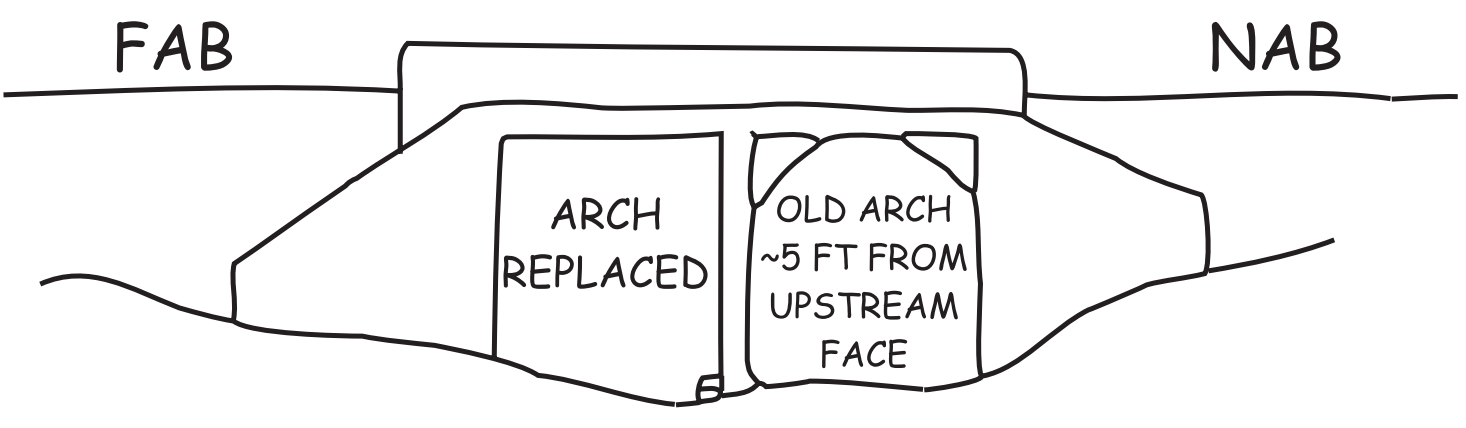

Figure 24. Bridge opening of field-viewed bridge.

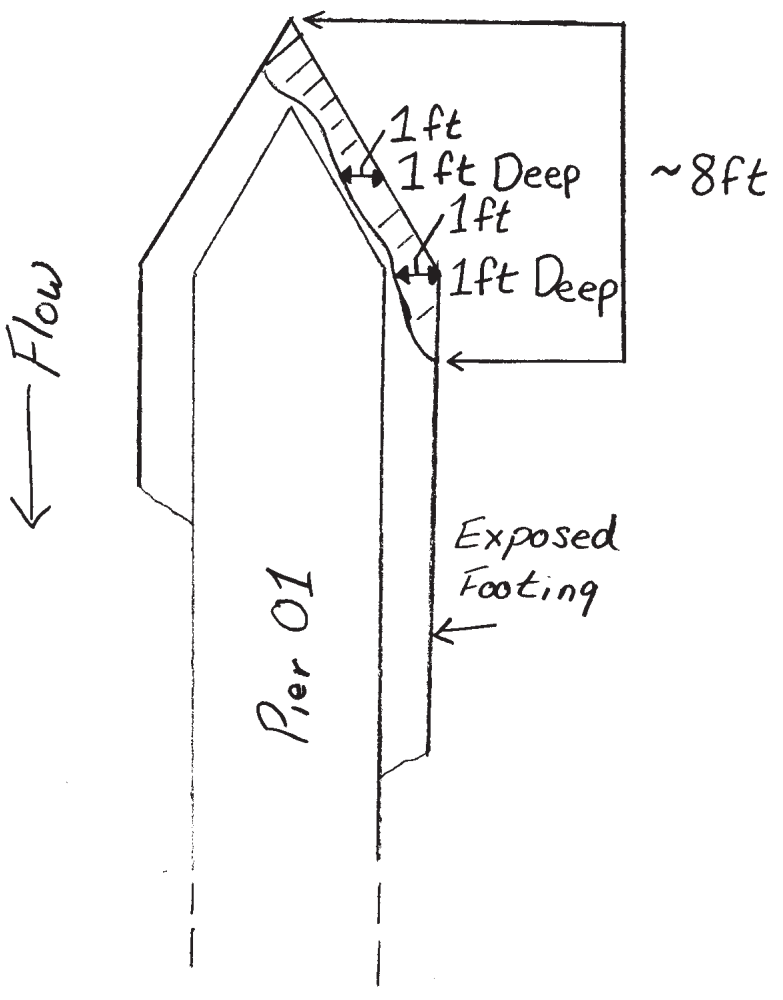

Figure 25. Undermining at substructure unit of field-viewed bridge. 


\section{PROCEDURES FOR COMPLETING THE ADDENDUM: "BRIDGE AND CHANNEL CHARACTERISTICS AT FIELD-VIEWED BRIDGE SITES - ADDENDUM TO FIELD FORM FOR NON-ACCESSIBLE SUBUNITS"}

These guidelines describe the elements collected and the field techniques used to collect the scourassessment data for limited-access bridge sites on the addendum "Bridge and Channel Characteristics at Field-Viewed Bridge Sites - Addendum to Field Form for Non-Accessible Subunits." This addendum provides a means to collect and record supplemental data for bridge substructure units that are not accessible to USGS field personnel during field inspection and is used in conjunction with the form "Bridge and Channel Characteristics at Field-Viewed Bridge Sites." Bridges at which 50 percent or more of the substructure units in contact with water are fully accessible for USGS field inspection are eligible for a limited-access inspection and the use of the addendum. If less than 50 percent of these substructure units are accessible for USGS field inspection, the bridge site is not field assessed.

In cases where water depth is too great to allow for USGS inspection of particular substructure units, PennDOT underwater inspection reports are the primary data source for those data fields not utilizing USGS field observations. In cases where substructure units are not accessible because of site conditions other than water depth, such as fencing around constructed stream channels or other development that prohibits access, regular PennDOT previous inspection reports are the primary data source for those entries not utilizing USGS field observations.

Commonly, a limited-access bridge site has two PennDOT inspections, a regular PennDOT inspection, done on a 2-year inspection cycle, for the substructure units accessible to PennDOT personnel and a PennDOT underwater inspection, done on a 4-year inspection cycle, for non-accessible substructure units. The most current PennDOT previous inspection report or PennDOT underwater inspection report used for the non-accessible substructure units is used to complete the addendum. The date of this PennDOT inspection is listed in items 99 and(or) 100, respectively.

Generally, only one PennDOT inspection (regular or underwater) is required to complete the addendum; however, at rare sites that have substructure units not accessible because of several different reasons, an underwater inspection and a regular inspection may be required to complete the addendum. In this case, the date of both inspections are listed in items 99 and 100 and a note is made in "USGS Findings" data fields listing the source, for example: "P02=previous inspection, $\mathrm{P} 06-\mathrm{P} 08=\mathrm{UW}$ inspection." Additional information and clarification for these substructure units is noted in item 129 "Reason substructure unit could not be accessed."

Discrepancies between data collected from PennDOT sources and USGS field observations, along with other questionable scenarios, are noted in the "USGS Findings" data fields on the addendum. If the inspection report does not meet the above listed criteria, a note is made in "USGS Findings" data fields, for example: "Water depth = >20 ft P01-P02, reservoir drained 3-31-98 for repairs, regular PennDOT inspection performed."

The Following Items Are to be Filled Out from the Best Available Vantage Point Upon Completion of Assessment of All Accessible Substructure Units:

\section{Bridge Number}

See item 1 for description.

\section{Date of USGS Site Visit}

See item 2 for description. 


\section{Date of Previous Bridge Inspection}

The date is the month, day, and year of the PennDOT previous bridge inspection and contains six digits that are subset into three two-digit fields (e.g., May 15, 1999 is entered as 051599).

\section{Date of Previous Underwater Inspection}

The date is the month, day, and year of the PennDOT previous underwater inspection and contains six digits that are subset into three two-digit fields (e.g., May 15, 1999 is entered as 051599).

\section{Complete Cross Section Surveyed}

Yes (1) is entered if a complete cross section is surveyed as detailed in Appendix B. No (0) is entered if the survey of a cross section is not possible and an abbreviated survey is completed.

102. Identification of Specific Piers (PennDOT item W09)

See item 40 for description.

Primary data source is USGS field observation.

\section{Location of Specific Piers}

See item 41 for description.

Primary data source is USGS field observation.

\section{Pier Nose Shape(s)}

See item 42 for description.

Primary data source is USGS field observation.

\section{Pier Type (PennDOT item C39M)}

See item 43 for description.

Primary data source is USGS field observation.

\section{Foundation Type (PennDOT item W10M)}

This item indicates the foundation type at specific piers. Entries for this item are $1=$ footing on bedrock, 2 = footing on alluvium, $3=$ piles/caissons, $4=$ other, or $5=$ not observed.

Primary data source is USGS field observation.

In cases where USGS field observation is inconclusive, an entry of "not observed" is entered.

\section{Water Depth (Maximum) (PennDOT item W11)}

See item 45 for description. Entries for this item are transcribed directly from PennDOT previous bridge inspection data.

Primary data source is PennDOT previous inspection or PennDOT previous underwater inspection.

\section{Pier Attack Angle(s)}

See item 46 for description. If low flow has significant effect on the pier, it is addressed in the comment field 114 "USGS Findings."

Primary data source is USGS field observation.

\section{Debris Width Relative to Pier Width}

See item 47 for description.

Primary data source is USGS field observation.

\section{Evidence of Pier Movement}

See item 48 for description.

Primary data source is PennDOT previous inspection or PennDOT previous underwater inspection. USGS field observation is secondary source of information; all discrepancies are noted in item 114 "USGS Findings." 


\section{Scour Conditions at Piers}

See item 49 for description.

Primary data source is PennDOT previous inspection or PennDOT previous underwater inspection. USGS field observation is secondary source of information; all discrepancies are noted in item 114 "USGS Findings."

\section{Scour Depths (PennDOT item W11-C)}

See item 62 for description.

Primary data source is PennDOT previous inspection or PennDOT previous underwater inspection. USGS field observation is secondary source of information; all discrepancies are noted in item 114 "USGS Findings."

\section{Pier Findings (PennDOT item W12)}

This is a narrative description of inspection findings at a specific pier. A W09 entry is used to indicate the pier being discussed.

Data for this entry is transcribed directly from PennDOT previous bridge inspection data or PennDOT underwater inspection data.

\section{USGS Findings}

This is a narrative description of any discrepancies noted between PennDOT information and USGS field observation along with questionable characteristics and data sources as relating to non-accessible piers as listed on the addendum.

\section{Abutment Bank Location}

See item 53 for description.

Primary data source is USGS field observation.

\section{Abutment Location}

See item 54 for description.

Primary data source is USGS field observation.

\section{Abutment Type (PennDOT item C37M)}

See item 55 for description.

Primary data source is USGS field observation.

\section{Foundation Type (PennDOT item W10M)}

This item indicates the foundation type at each abutment. Entries for this item are $1=$ footing on bedrock, 2 = footing on alluvium, $3=$ piles/caissons, $4=$ other, or $5=$ not observed.

Primary data source is USGS field observation.

In cases where USGS field observation is inconclusive, the entry is "not observed."

\section{Water Depth (Maximum) (PennDOT item W11)}

See item 57 for description.

Primary data source is PennDOT previous inspection or PennDOT previous underwater inspection.

\section{Type of Bridge Opening}

See item 58 for description.

Primary data source is USGS field observation.

\section{Abutment Attack Angle}

See item 59 for description. If low flow has significant effect on the abutments, it is addressed in the comment field 126 "USGS Findings."

Primary data source is USGS field observation. 


\section{Evidence of Abutment Movement}

See item 60 for description.

Primary data source for this item is PennDOT previous inspection data and(or) PennDOT underwater inspection data. USGS field observation is secondary source of information. All discrepancies between PennDOT data and USGS field observations are noted in item 126 "USGS Findings."

\section{Scour Conditions at Abutments}

See item 61 for description.

Primary data source is PennDOT previous bridge inspection data or PennDOT underwater inspection data. USGS field observation is secondary source of information; all discrepancies are noted in item 126 "USGS Findings."

\section{Scour Depths (PennDOT item W11-C)}

See item 62 for description.

Primary data source is PennDOT previous inspection or PennDOT previous underwater inspection. USGS field observation is secondary source of information; all discrepancies are noted in item 126 "USGS Findings."

\section{Abutment Findings (PennDOT item W12)}

This is a narrative description of inspection findings at a specific abutment. A W09 entry is used to indicate the abutment being discussed.

Information for this entry is transcribed directly from PennDOT previous bridge inspection data or PennDOT underwater inspection data.

\section{USGS Findings}

This is a narrative description of any discrepancies noted between PennDOT information and USGS field observation along with questionable characteristics and data sources as relating to non-accessible abutments as listed on the addendum.

\section{Streambed Material Near the Bridge Substructure Units}

See item 66 for description. The addendum only encompasses substructure units that are not accessible, data for other accessible substructure units are recorded on the "Bridge and Channel Characteristics at Field-Viewed Bridge Sites" form.

Primary information for this data field comes from PennDOT previous bridge inspection data or PennDOT underwater inspection data. USGS field observations confirm these data, all discrepancies are noted in items 114 and(or) 126 "USGS Findings."

\section{A - 128J. PennDOT Observed Scour Rating (PennDOT item W11-A)}

The addendum only encompasses W11-A entries for substructure units that are not accessible; data for other accessible substructure units are recorded on the "Bridge and Channel Characteristics at FieldViewed Bridge Sites" form as described in item 67.

Data for items 128A through 128J for limited-access subunits are transcribed directly from PennDOT previous bridge inspection data or PennDOT underwater inspection data.

\section{Reason Substructure Unit Could Not Be Inspected}

This item is intended to give a general idea of why the addendum is needed. One of four multiplechoice data items is selected and entered next to the appropriate substructure unit. Entries are $1=$ water too deep, 2 = water too swift, 3 = safety concerns, or $4=$ no access.

Data for this item comes solely from USGS field observation. 


\section{TOTAL-STATION SURVEY PROCEDURES AND ATTRIBUTES}

Data elements, unless otherwise specified, are directly logged and temporarily stored in the total station. "Left" and "right" are determined while facing downstream. Bridge geometry and cross-section elements are collected concurrently. Distances, relative to the bridge, are measured along the stream channel. Significant features, such as high-water marks, directly observable but beyond $200 \mathrm{ft}$ from the bridge are surveyed. Significant features, without specific attributes, are assigned a generic-point attribute (GENPT) and described with a comment within the total station file. All attributes along with a description of the usage of that attribute are listed in table 6.

Bridges that have structural components that will not be impacted by flooding and will not be otherwise hydrologically or hydraulically affected as a result of the height of the bridge deck and (or) the lateral extent of the bridge structure receive abbreviated surveys. Abbreviated surveys extend laterally to the landward side of the first substructure unit on each bank resting entirely in the flood plain or otherwise out of flow and vertically may exclude all upper bridge components including: parapet, road-grade profile, wingwalls, and bottom of beams. Abbreviated surveys include, when safety and conditions permit; points common to PennDOT plans, such as exposed footing; PennDOT plaques and other reference marks; and GPS locations.

Bridges at which the survey of a complete cross section is not possible, such as limited-access sites, receive a second type of abbreviated survey. At these bridge sites, only the following data elements are required: GPS locations, road-grade profile (unless bridge superstructure will not be hydrologically or hydraulically effected by high flows), edge of water upstream, near the bridge, and downstream, and high-water marks when available. Edge of water data elements are required on one bank only for this type of abbreviated survey because of access limitations. 
Table 6. Total-station survey attributes with descriptions

\begin{tabular}{|c|c|c|}
\hline Bridge site feature & Attribute & Description \\
\hline \multirow[t]{2}{*}{$\begin{array}{l}\text { Upstream attribute } \\
\text { prefix }\end{array}$} & & $\begin{array}{l}\text { This prefix is added to attributes to indicate a position at, or relatively near, the } \\
\text { upstream face of the bridge. }\end{array}$ \\
\hline & US & $\begin{array}{l}\text { Attribute prefix used to denote a position at, or relatively near, the upstream face of } \\
\text { the bridge; for example USRWWT (upstream right wingwall top). }\end{array}$ \\
\hline \multirow[t]{2}{*}{$\begin{array}{l}\text { Downstream attribute } \\
\text { prefix }\end{array}$} & & $\begin{array}{l}\text { This prefix may replace upstream (US) in any attribute for which the downstream } \\
\text { bridge feature is deemed significant and requires definition. In addition, the DS } \\
\text { prefix must be attached to the attributes for the cross section and bottom of beam } \\
\text { shots when the cross section is taken at the downstream face of the bridge structure. }\end{array}$ \\
\hline & DS & $\begin{array}{l}\text { Attribute prefix used to denote a position at the downstream face of the bridge; for } \\
\text { example DSXS (downstream, cross section). }\end{array}$ \\
\hline \multirow[t]{2}{*}{$\begin{array}{l}\text { Cross- } \\
\text { section }\end{array}$} & & $\begin{array}{l}\text { Surveyed points define the streambed at the most restrictive opening at the bridge } \\
\text { site, taking into account exposed utilities and (or) other permanent obstructions. }\end{array}$ \\
\hline & XS & $\begin{array}{l}\text { Attribute defining a break in slope in the channel along the cross section. This } \\
\text { attribute may also be used as a prefix to other attributes in order to denote a feature } \\
\text { as being within the plane of the cross section; for example, XSRA (cross section, } \\
\text { right abutment). }\end{array}$ \\
\hline \multirow[t]{6}{*}{ Abutment } & & $\begin{array}{l}\text { Surveyed points define various locations at the right and (or) left abutments for use in } \\
\text { determining exposed footing elevations and (or) defining bridge geometry. An " } \mathrm{R} \text { " } \\
\text { is used to indicate the right side of the abutment, an " } \mathrm{L} \text { " to indicate the left side of } \\
\text { the abutment. }\end{array}$ \\
\hline & RA or LA & $\begin{array}{l}\text { Attribute used in conjunction with a suffix to define features of significance at the } \\
\text { right or left abutment, for example, RAF (right abutment, exposed footing) or } \\
\text { LAPW (left abutment, protective works). }\end{array}$ \\
\hline & XSRA or XSLA & $\begin{array}{l}\text { Attribute defining right or left side of cross section at the abutment. A "J" suffix may } \\
\text { be attached to indicate this is also the junction with the streamward bottom of the } \\
\text { right or left wingwall if applicable. }\end{array}$ \\
\hline & $\begin{array}{l}\text { USRAT or } \\
\text { USLAT }\end{array}$ & Attribute used to define the streamward top of the right or left abutment mass. \\
\hline & $\begin{array}{l}\text { USRLEAT or } \\
\text { USLLEAT }\end{array}$ & Attribute used to define the landward top of the right or left abutment mass. \\
\hline & $\begin{array}{l}\text { USRLEA or } \\
\text { USLLEA }\end{array}$ & Attribute used to define the landward bottom of the right or left abutment mass. \\
\hline \multirow[t]{4}{*}{ Pier } & & $\begin{array}{l}\text { Surveyed points define the shape of the pier as it appears in a plot of the cross section } \\
\text { and elevation of the bridge. The pier number is added to the attribute in numeric } \\
\text { format }(01,02,03 \text {, and so forth). Pier number is displayed here as "\#\#." An " } R \text { " is } \\
\text { used to indicate the right side of the pier, an " } \mathrm{L} \text { " to indicate the left side of the pier. }\end{array}$ \\
\hline & RP\#\# or LP\#\# & $\begin{array}{l}\text { Attribute used to define the point where the streambed and pier intersect outside of } \\
\text { the plane of the cross section along the side of the pier. This attribute is used in con- } \\
\text { junction with a suffix to define features of significance along the side of a pier, for } \\
\text { example, RP\#\#F (right side of pier \#\#, exposed footing) or LP\#\#PW (left side of pier } \\
\text { \#\#, protective works). }\end{array}$ \\
\hline & $\begin{array}{l}\text { XSRP\#\# or } \\
\text { XSLP\#\# }\end{array}$ & $\begin{array}{l}\text { Attribute used to define the point where the streambed and pier intersect in the plane } \\
\text { of the cross section on the right or left side of the pier. A suffix may be attached to } \\
\text { describe features of significance at this point, such as exposed footing (XSRP\#\#F), } \\
\text { deposition (XSRP\#\#DP), and so forth. }\end{array}$ \\
\hline & USNP\#\# & $\begin{array}{l}\text { Attribute used in conjunction with a suffix to define the nose of pier in cases where } \\
\text { debris, deposition, or scour holes are at, or around, the pier nose (for example, } \\
\text { USNP\#\#DP, or USNP\#\#DEP). Attribute used also in cases where pier nose requires } \\
\text { definition due to pier location outside of the plane of the cross section. }\end{array}$ \\
\hline
\end{tabular}


Table 6. Total-station survey attributes with descriptions-Continued

\begin{tabular}{|c|c|c|}
\hline Bridge site feature & Attribute & Description \\
\hline \multirow[t]{6}{*}{ Wingwall } & & $\begin{array}{l}\text { Surveyed points define the shape of the upstream wingwall or wingwalls. An " } \mathrm{R} \text { " is } \\
\text { used to indicate the right wingwall, an " } \mathrm{L} \text { " to indicate the left wingwall. }\end{array}$ \\
\hline & $\begin{array}{l}\text { USRWWT or } \\
\text { USLWWT }\end{array}$ & $\begin{array}{l}\text { Attribute defining the streamward top of the upstream right or left wingwall at the } \\
\text { bridge. }\end{array}$ \\
\hline & $\begin{array}{l}\text { USRLEWWT or } \\
\text { USLLEWWT }\end{array}$ & $\begin{array}{l}\text { Attribute defining the top of the landward-most extent of the upstream right or left } \\
\text { wingwall. }\end{array}$ \\
\hline & $\begin{array}{l}\text { USRLEWW or } \\
\text { USLLEWW }\end{array}$ & $\begin{array}{l}\text { Attribute defining the bottom of the landward-most extent of the upstream right or } \\
\text { left wingwall. }\end{array}$ \\
\hline & USRAJ or USLAJ & $\begin{array}{l}\text { Attribute defining the streamward bottom of the upstream right or left wingwall at } \\
\text { the junction where it joins the bridge abutment when that junction is located } \\
\text { upstream of the surveyed cross section. }\end{array}$ \\
\hline & XSRAJ or XSLAJ & $\begin{array}{l}\text { Attribute defining the streamward bottom of the upstream right or left wingwall at } \\
\text { the junction where it joins the bridge abutment when that junction is located within } \\
\text { the surveyed cross section. }\end{array}$ \\
\hline \multirow[t]{3}{*}{ Parapet } & & $\begin{array}{l}\text { Surveyed points define the shape of the bridge parapet, truss, or covered superstruc- } \\
\text { ture. Generally, only the most significant parapet is surveyed, either on the } \\
\text { upstream or downstream side of the bridge. }\end{array}$ \\
\hline & USPB & Attribute defining the upstream parapet of bridge. \\
\hline & DSPB & Attribute defining the downstream parapet of bridge. \\
\hline \multirow[t]{4}{*}{ Bottom of beam } & & $\begin{array}{l}\text { Surveyed points define the bottom of the bridge deck as it intersects bridge substruc- } \\
\text { ture units within the plane of the cross section. An " } \mathrm{R} \text { " is used to indicate the right } \\
\text { bottom of beam, an "L" to indicate the left bottom of beam. }\end{array}$ \\
\hline & BBR or BBL & $\begin{array}{l}\text { Attribute used to define the point where the bottom of the bridge deck intersects the } \\
\text { right or left abutment within the plane of the cross section. }\end{array}$ \\
\hline & $\begin{array}{l}\text { BBRP\#\# or } \\
\text { BBLP\#\# }\end{array}$ & $\begin{array}{l}\text { Attribute used to define the point where the bottom of the bridge deck intersects the } \\
\text { right or left side of the pier within the plane of the cross section. }\end{array}$ \\
\hline & BB & $\begin{array}{l}\text { Attribute used to define additional points along the bottom of the bridge deck not } \\
\text { located at the intersection of a substructure unit; for example, to define the curva- } \\
\text { ture of an arched bridge. }\end{array}$ \\
\hline \multirow[t]{4}{*}{ Road grade profile } & & $\begin{array}{l}\text { Surveyed points define road elevation and trend for a landward distance on each side } \\
\text { of the bridge sufficient to depict all areas of hydraulic and hydrologic significance. } \\
\text { Additional RGP shots are taken on the bridge deck if the bridge is arched. GPS loca- } \\
\text { tions are defined as part of the RGP if GPS collection occurs on the roadway. }\end{array}$ \\
\hline & RGP & Attribute defining road grade profile. \\
\hline & RGPGPSNA & GPS location on the roadway at the near abutment. \\
\hline & RGPGPSFA & GPS location on the roadway at the far abutment. \\
\hline \multirow[t]{2}{*}{ GPS locations } & & $\begin{array}{l}\text { Surveyed points are used to define the location of GPS data collection when data col- } \\
\text { lection is not possible on the roadway; the attribute is used in conjunction with } \\
\text { notation describing location. }\end{array}$ \\
\hline & GPS & Attribute defining a GPS location other than on the roadway. \\
\hline \multirow[t]{3}{*}{$\begin{array}{l}\text { Water surface and } \\
\text { edge of water }\end{array}$} & & $\begin{array}{l}\text { Surveyed points at the bridge define a water level elevation for use in stream slope } \\
\text { computations. An " } R \text { " is used to indicate the right side of the channel, an "L" to } \\
\text { indicate the left side of the channel. }\end{array}$ \\
\hline & $\begin{array}{l}\text { XSREW or } \\
\text { XSLEW }\end{array}$ & $\begin{array}{l}\text { Attribute defining the edge of the water on the right or left side of the channel within } \\
\text { the cross section. "XS" may be deleted if this shot is taken outside of the cross sec- } \\
\text { tion. }\end{array}$ \\
\hline & RWS or LWS & $\begin{array}{l}\text { Attribute defining the water surface elevation against a substructure unit at any loca- } \\
\text { tion on the right or left side of the stream channel. }\end{array}$ \\
\hline Bank angle & & $\begin{array}{l}\text { Surveyed points define the representative bank angle from the edge of water to the } \\
\text { top of bank. Mid-bank and bottom of bank attributes are provided to assist in the } \\
\text { definition of the banks of dry channels or other banks which are not well repre- } \\
\text { sented with two points. An "R" is used to indicate the right side of the channel, an } \\
\text { "L" to indicate the left side of the channel. }\end{array}$ \\
\hline
\end{tabular}


Table 6. Total-station survey attributes with descriptions-Continued

\begin{tabular}{|c|c|c|}
\hline \multirow[t]{9}{*}{ Bridge site feature } & Attribute & Description \\
\hline & $\begin{array}{l}\text { USRTB or } \\
\text { USLTB }\end{array}$ & Attribute used to define the upstream right or left top of bank. \\
\hline & $\begin{array}{l}\text { USREW or } \\
\text { USLEW }\end{array}$ & Attribute used to define the upstream right or left edge of water. \\
\hline & $\begin{array}{l}\text { USRMB or } \\
\text { USLMB }\end{array}$ & $\begin{array}{l}\text { Attribute used to define various breaks in slope in mid-bank locations between the } \\
\text { upstream right or left bottom of bank and the upstream right or left top of bank } \\
\text { locations. }\end{array}$ \\
\hline & $\begin{array}{l}\text { USRBOB or } \\
\text { USLBOB }\end{array}$ & Attribute used to define the upstream right or left bottom of bank. \\
\hline & $\begin{array}{l}\text { DSRTB or } \\
\text { DSLTB }\end{array}$ & Attribute used to define the downstream right or left top of bank. \\
\hline & $\begin{array}{l}\text { DSREW or } \\
\text { DSLEW }\end{array}$ & Attribute used to define the downstream right or left edge of water. \\
\hline & $\begin{array}{l}\text { DSRMB or } \\
\text { DSLMB }\end{array}$ & $\begin{array}{l}\text { Attribute used to define various breaks in slope in mid-bank locations between the } \\
\text { downstream right or left bottom of bank and the downstream right or left top of } \\
\text { bank locations. }\end{array}$ \\
\hline & $\begin{array}{l}\text { DSRBOB or } \\
\text { DSLBOB }\end{array}$ & Attribute used to define the downstream right or left bottom of bank. \\
\hline \multirow[t]{7}{*}{ Debris piles } & & $\begin{array}{l}\text { Surveyed points define significant debris piles at any location throughout the bridge } \\
\text { site. }\end{array}$ \\
\hline & DP & $\begin{array}{l}\text { Attribute used in conjunction with other attributes to denote the presence of debris; } \\
\text { for example, XSDP (cross section, debris pile) }\end{array}$ \\
\hline & DPUS & Attribute used to define the farthest upstream extent of the debris pile. \\
\hline & DPRS & Attribute used to define the farthest right extent of the debris pile. \\
\hline & DPLS & Attribute used to define the farthest left extent of the debris pile. \\
\hline & DPDS & Attribute used to define the farthest downstream extent of the debris pile. \\
\hline & DPT & Attribute used to define the greatest elevation (top) of the debris pile. \\
\hline \multirow[t]{7}{*}{ Deposition } & & $\begin{array}{l}\text { Surveyed points define significant areas of deposition at any location throughout the } \\
\text { bridge site. }\end{array}$ \\
\hline & DEP & $\begin{array}{l}\text { Attribute used in conjunction with other attributes to denote the presence of a signifi- } \\
\text { cant depositional feature; for example, XSDEP (cross section, deposition) }\end{array}$ \\
\hline & DEPUS & Attribute used to define the farthest upstream extent of the area of deposition. \\
\hline & DEPRS & Attribute used to define the farthest right extent of the area of deposition. \\
\hline & DEPLS & Attribute used to define the farthest left extent of the area of deposition. \\
\hline & DEPDS & Attribute used to define the farthest downstream extent of the area of deposition. \\
\hline & DEPT & Attribute used to define the greatest elevation (top) of the area of deposition. \\
\hline \multirow[t]{7}{*}{ Scour Hole } & & $\begin{array}{l}\text { Surveyed points define significant scour holes at any location throughout the bridge } \\
\text { site. }\end{array}$ \\
\hline & $\mathrm{SH}$ & $\begin{array}{l}\text { Attribute used in conjunction with other attributes to denote the presence of a signifi- } \\
\text { cant scour hole; for example, SH01US (scour hole, number 01, upstream end) }\end{array}$ \\
\hline & SH\#\#US & Attribute used to define the farthest upstream extent of the scour hole. \\
\hline & SH\#\#RS & Attribute used to define the farthest right extent of the scour hole. \\
\hline & SH\#\#L & Attribute used to define the farthest left extent of the scour hole. \\
\hline & SH\#\#DS & Attribute used to define the farthest downstream extent of the scour hole. \\
\hline & SH\#\#B & Attribute used to define the lowest elevation (bottom) of the scour hole. \\
\hline \multirow[t]{3}{*}{$\begin{array}{l}\text { Bench marks, monuments, } \\
\text { and reference points }\end{array}$} & & $\begin{array}{l}\text { These features are surveyed when located at, or in the immediate vicinity, of the } \\
\text { bridge. }\end{array}$ \\
\hline & PDOTPLAK & $\begin{array}{l}\text { Attribute used for all established monuments including, but not limited to, USGS } \\
\text { benchmarks, Coast and Geodetic Survey (CGS) monuments, and PennDOT, county, } \\
\text { or township plaques. }\end{array}$ \\
\hline & PK & Attribute used to define the location of the USGS-installed PK masonry nail. \\
\hline
\end{tabular}


Table 6. Total-station survey attributes with descriptions-Continued

\begin{tabular}{|c|c|c|}
\hline Bridge site feature & Attribute & Description \\
\hline & $\mathrm{RM}$ & $\begin{array}{l}\text { Attribute used to define previously existing survey marks such as, old chiseled } \\
\text { squares, old PK masonry nails, and so forth. }\end{array}$ \\
\hline \multirow[t]{4}{*}{ Exposed Footing } & & $\begin{array}{l}\text { Surveyed points define exposed footing on abutments, piers, and wingwalls. Footing } \\
\text { attributes are used in conjunction with other attributes which describe the location } \\
\text { of the exposed footing; for example, RAF (right abutment, footing). }\end{array}$ \\
\hline & F & $\begin{array}{l}\text { Attribute suffix used to define the top of the exposed footing as it abuts the bridge } \\
\text { substructure unit. }\end{array}$ \\
\hline & FC & Attribute suffix used to define an edge, or corner, on exposed footing. \\
\hline & FS & $\begin{array}{l}\text { Attribute suffix used to define the point of intersection between the footing and the } \\
\text { streambed. }\end{array}$ \\
\hline \multirow[t]{5}{*}{ Protective work } & & $\begin{array}{l}\text { Surveyed points define protective works on or around abutments, piers, wingwalls, } \\
\text { stream banks and channel. Protective work attributes are used in conjunction with } \\
\text { other attributes which describe the location of the protective work; for example, } \\
\text { XSRR (cross section, riprap). }\end{array}$ \\
\hline & RR & Attribute suffix indicating the presence of riprap. \\
\hline & PW & $\begin{array}{l}\text { Attribute suffix used to define the top of a protective work as it abuts the bridge sub- } \\
\text { structure unit. }\end{array}$ \\
\hline & PWC & Attribute suffix used to define an edge, or corner, on a protective work. \\
\hline & PWS & $\begin{array}{l}\text { Attribute suffix used to define the point of intersection between the protective work } \\
\text { and the streambed. }\end{array}$ \\
\hline \multirow[t]{2}{*}{ Unknown points } & & $\begin{array}{l}\text { Those points that are not addressed by standard attributes must be assigned a generic } \\
\text { point with notation describing the location of the surveyed point. }\end{array}$ \\
\hline & GENPT & $\begin{array}{l}\text { Attribute used for non-standard surveyed points. Requires the input of notation } \\
\text { describing the location of the surveyed point. }\end{array}$ \\
\hline
\end{tabular}




\begin{tabular}{c} 
APPENDIX C \\
Location ANd IDENTIFICATION OF GLOBAL POSITIONING \\
SySTEM BASE StaTIONS USED IN PENNSYLVANIA \\
\hline
\end{tabular}


GPS base stations are located throughout Pennsylvania and adjacent states. Data from the nearest base station (fig. 26) is used to correct GPS data collected at bridge sites throughout Pennsylvania.

Base stations are independently operated and no guarantee is made that data will be available from any specific base station for the times required; therefore, a primary and alternate base station are assigned to each county in Pennsylvania as given in table 7. In the event that the primary base station is not operational, data from the alternate base station is downloaded to a computer directory and used to correct GPS data. Each base station establishes unique procedures for acquisition of data from that site; these procedures are generally available on the internet.

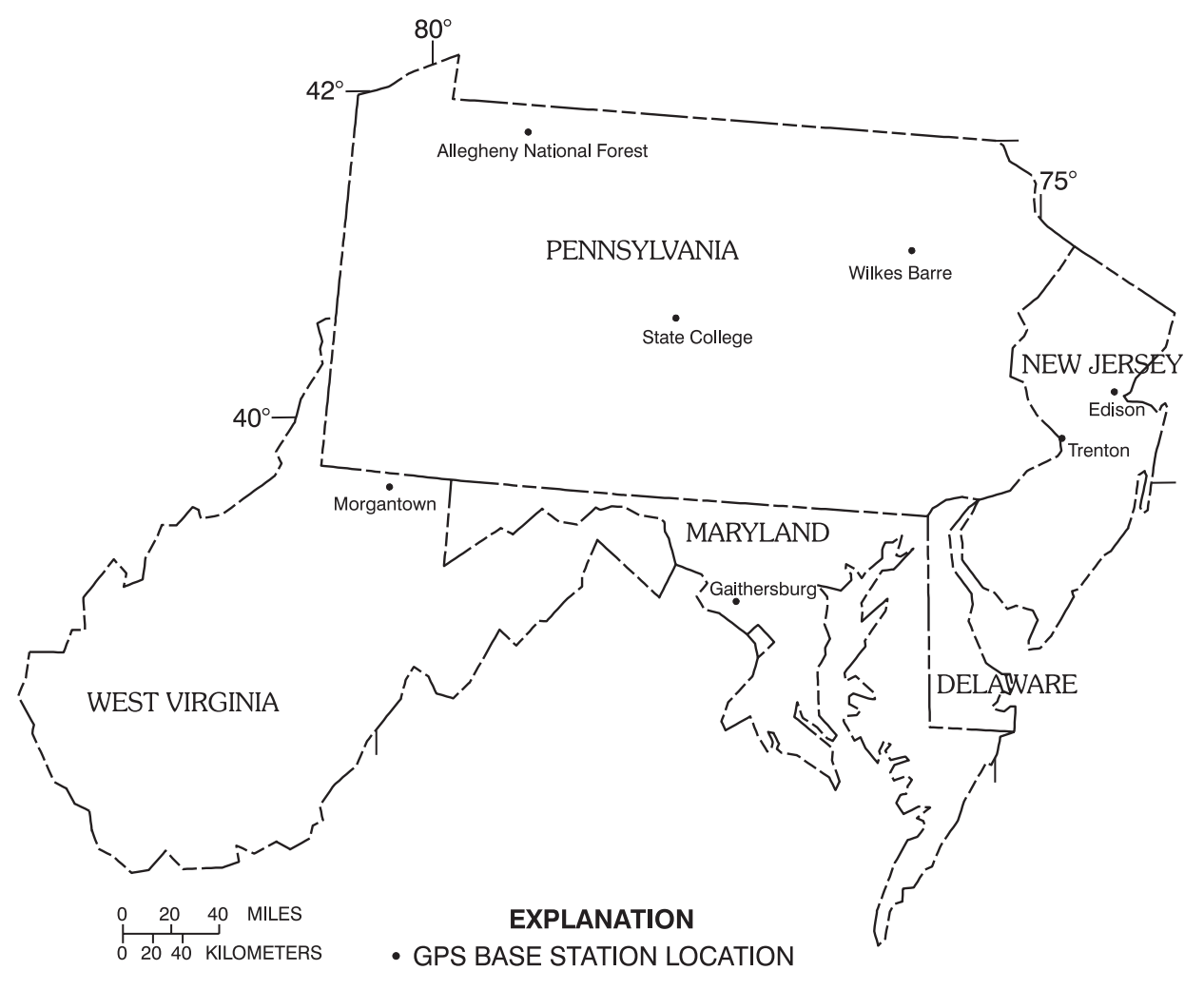

Figure 26. Location of global positioning system base stations. 
Table 7. Primary and secondary global positioning system base stations for each county in Pennsylvania

\begin{tabular}{|c|c|c|c|c|}
\hline County name & $\begin{array}{l}\text { County } \\
\text { number }\end{array}$ & $\begin{array}{c}\text { PennDOT } \\
\text { district }\end{array}$ & Primary base station & Secondary base station \\
\hline Adams & 1 & 8 & Gaithersburg, Md. & Penn State \\
\hline Allegheny & 2 & 11 & Allegheny Nat. Forest & Morgantown, W.Va. \\
\hline Armstrong & 3 & 10 & Allegheny Nat. Forest & Penn State \\
\hline Beaver & 4 & 11 & Allegheny Nat. Forest & Morgantown, W.Va. \\
\hline Bedford & 5 & 9 & Penn State & Morgantown, W.Va. \\
\hline Berks & 6 & 5 & Trenton, N.J. & Wilkes-Barre, Pa. \\
\hline Blair & 7 & 9 & Penn State & Morgantown, W.Va. \\
\hline Bradford & 8 & 3 & Wilkes-Barre, Pa. & Penn State \\
\hline Bucks & 9 & 6 & Trenton, N.J. & Edison, N.J. \\
\hline Butler & 10 & 10 & Allegheny Nat. Forest & Morgantown, W.Va. \\
\hline Cambria & 11 & 9 & Penn State & Morgantown, W.Va. \\
\hline Cameron & 12 & 2 & Penn State & Allegheny Nat. Forest \\
\hline Carbon & 13 & 5 & Wilkes-Barre, Pa. & Trenton, N.J. \\
\hline Centre & 14 & 2 & Penn State & Wilkes-Barre, Pa. \\
\hline Chester & 15 & 6 & Trenton, N.J. & Gaithersburg, Md. \\
\hline Clarion & 16 & 10 & Allegheny Nat. Forest & Penn State \\
\hline Clearfield & 17 & 2 & Penn State & Allegheny Nat. Forest \\
\hline Clinton & 18 & 2 & Penn State & Wilkes-Barre, Pa. \\
\hline Columbia & 19 & 3 & Wilkes-Barre, Pa. & Penn State \\
\hline Crawford & 20 & 1 & Allegheny Nat. Forest & Penn State \\
\hline Cumberland & 21 & 8 & Penn State & Gaithersburg, Md. \\
\hline Dauphin & 22 & 8 & Penn State & Gaithersburg, Md. \\
\hline Delaware & 23 & 6 & Trenton, N.J. & Gaithersburg, Md. \\
\hline Elk & 24 & 2 & Allegheny Nat. Forest & Penn State \\
\hline Erie & 25 & 1 & Allegheny Nat. Forest & Penn State \\
\hline Fayette & 26 & 12 & Penn State & Morgantown, W.Va. \\
\hline Forest & 27 & 1 & Allegheny Nat. Forest & Penn State \\
\hline Franklin & 28 & 8 & Penn State & Gaithersburg, Md. \\
\hline Fulton & 29 & 9 & Penn State & Gaithersburg, Md. \\
\hline Greene & 30 & 12 & Penn State & Morgantown, W.Va. \\
\hline Huntingdon & 31 & 9 & Penn State & Gaithersburg, Md. \\
\hline Indiana & 32 & 10 & Penn State & Allegheny Nat. Forest \\
\hline Jefferson & 33 & 10 & Allegheny Nat. Forest & Penn State \\
\hline Juniata & 34 & 2 & Penn State & Wilkes-Barre, Pa. \\
\hline Lackawanna & 35 & 4 & Wilkes-Barre, Pa. & Edison, N.J. \\
\hline Lancaster & 36 & 8 & Trenton, N.J. & Penn State \\
\hline Lawrence & 37 & 11 & Allegheny Nat. Forest & Morgantown, W.Va. \\
\hline Lebanon & 38 & 8 & Penn State & Wilkes-Barre, Pa. \\
\hline Lehigh & 39 & 5 & Trenton, N.J. & Wilkes-Barre, Pa. \\
\hline Luzerne & 40 & 4 & Wilkes-Barre, Pa. & Penn State \\
\hline Lycoming & 41 & 3 & Wilkes-Barre, Pa. & Penn State \\
\hline McKean & 42 & 2 & Allegheny Nat. Forest & Penn State \\
\hline Mercer & 43 & 1 & Allegheny Nat. Forest & Morgantown, W.Va. \\
\hline Mifflin & 44 & 2 & Penn State & Wilkes-Barre, Pa. \\
\hline Monroe & 45 & 5 & Wilkes-Barre, Pa. & Edison, N.J. \\
\hline Montgomery & 46 & 6 & Trenton, N.J. & Edison, N.J. \\
\hline Montour & 47 & 3 & Wilkes-Barre, Pa. & Penn State \\
\hline Northampton & 48 & 5 & Trenton, N.J. & Wilkes-Barre Pa. \\
\hline Northumberland & 49 & 3 & Wilkes-Barre, Pa. & Penn State \\
\hline
\end{tabular}


Table 7. Primary and secondary global positioning system base stations for each county in Pennsylvania-Continued

\begin{tabular}{lccll}
\hline \multicolumn{1}{c}{ County name } & $\begin{array}{c}\text { County } \\
\text { number }\end{array}$ & $\begin{array}{c}\text { PennDOT } \\
\text { district }\end{array}$ & Primary base station & Secondary base station \\
\hline Perry & 50 & 8 & Penn State & Wilkes-Barre, Pa. \\
Pike & 51 & 4 & Wilkes-Barre, Pa. & Edison, N.J. \\
Potter & 52 & 2 & Penn State & Allegheny Nat. Forest \\
Schuylkill & 53 & 5 & Wilkes-Barre, Pa. & Penn State \\
Snyder & 54 & 3 & Penn State & Wilkes-Barre, Pa. \\
Somerset & 55 & 9 & Penn State & Morgantown, W.Va. \\
Sullivan & 56 & 3 & Wilkes-Barre, Pa. & Penn State \\
Susquehanna & 57 & 4 & Wilkes-Barre, Pa. & Edison, N.J. \\
Tioga & 58 & 3 & Wilkes-Barre, Pa. & Penn State \\
Union & 59 & 3 & Penn State & Wilkes-Barre, Pa. \\
Venango & 60 & 1 & Allegheny Nat. Forest & Penn State \\
Warren & 61 & 1 & Allegheny Nat. Forest & Penn State \\
Washington & 62 & 12 & Penn State & Morgantown, W.Va. \\
Wayne & 63 & 4 & Wilkes-Barre, Pa. & Edison, N.J. \\
Westmoreland & 64 & 12 & Penn State & Morgantown, W.Va. \\
Wyoming & 65 & 4 & Wilkes-Barre, Pa. & Edison, N.J. \\
York & 66 & 8 & Penn State & Gaithersburg, Md. \\
Philadelphia & 67 & 6 & Trenton, N.J. & Edison, N.J. \\
\hline
\end{tabular}




\section{APPENDIX D \\ Procedure for Collection of Video-tape Data}




\section{PROCEDURE FOR COLLECTION OF VIDEO-TAPE DATA}

Video-tape data is collected from several locations at each field-viewed bridge site to provide a visual record of site conditions on the day of the assessment. Field personnel pan slowly and smoothly using survey rods or other points of reference to provide a relative scale to the viewer. The images must be clearly visible in the viewfinder to insure acceptable visibility on the tape with at least a 5 second pause on any image that is to be captured. Video-tape data of the bridge site includes narration by field personnel to provide a concise, detailed description of significant site characteristics.

\section{Collecting Video-tape Data from the Bridge Looking Upstream and Downstream}

Standing on the upstream side of the bridge deck or at an equivalent location, video-tape data with narration is collected to document the channel conditions and significant features (e.g. meander impacts, cut banks, and mid-channel and point bars) within two bridge lengths upstream from the bridge. The videographer begins with a view of the near roadway approach and completes a slow pan of the upstream reach ending with a view of the far roadway approach. The pan subsequently continues from the view of the far roadway approach down along the face of the bridge, showing significant features such as debris accumulation at the face of the bridge and(or) deposition, and continues back to a view of the near roadway approach. When possible, the foreground of this video includes some point of reference, such as a survey rod, that gives a sense of depth and perspective to the picture. The videographer also notes in the narration where the video was taken (on, under, or near the bridge). This process is repeated at the downstream face of the bridge viewing the downstream reach of the stream.

\section{Collecting Video-tape Data from the Upstream and Downstream Channel}

Standing in the upstream channel or in an equivalent location, video-tape data is collected illustrating the channel conditions within the upstream reach. The videographer begins by looking upstream and completes a slow 360 degree pan down stream bank toward the near abutment. As the pan passes across the bridge opening, the videographer pauses a minimum of 5 seconds with the upstream face of bridge completely framed. This pause enables the image to be captured by commercially available computer software. The pan subsequently continues from the view of the bridge face, up the opposite bank, and ends on the view looking upstream. Narration typically includes location of the videographer, comments on any erosional features, relative distances, streambed material, and any other significant characteristics of the upstream reach. When possible, the foreground of this video includes some point of reference, such as a survey rod, that gives a sense of depth and perspective to the picture. The videographer stands only as far from the bridge as is necessary to frame the entire bridge opening and wingwalls in the viewfinder. Every effort is made to frame as much of the complete bridge opening as possible and to attempt to provide a clear view through the bridge opening. If standing in the stream does not provide an acceptable view of the bridge opening, a different vantage point is selected to collect videotape data. An oblique view of the bridge face is provided if a clear view through the bridge opening cannot be provided because of vegetation or other factors. This process is repeated in the downstream channel.

\section{Additional Video}

Additional video is taken of any item that indicates a site has a significant stability problem, for example, sediment or debris blockage, failed countermeasures, significant erosion or movement, or any item that results in a designation of "PHONE" bridge. Additional video-tape data is collected only if the feature to be video-taped is significant and clearly visible. 


\section{APPENDIX E}

Form AND Procedures for Completion of the "Bridge and Channel Characteristics at OfFICE-REVIEWEd BRIDGE SITES" FORM 


\section{BRIDGE AND CHANNEL CHARACTERISTICS}

\section{AT OFFICE-REVIEWED BRIDGE SITES}

(See procedures for explanation of numbered, starred, and boxed items)

*1. Assessed Bridge \# (A01):

3. Assessment Date:

5. Information Available for This Assessment

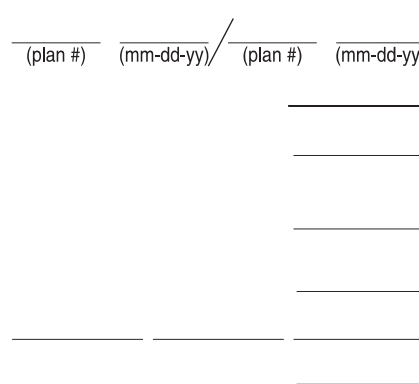

*Plan data/design drawings (enter plan number(s) \& date(s) if available)

*Hydrologic and hydraulic report (enter date if available)

Foundation report and/or approval letter (enter date if available, may not be required if plan data is present)

*Most recent PennDOT inspection report (enter date if available), which must include a complete W11-A for all substructures

Underwater inspection if applicable (enter date if available)

Dates of available photographs

Other Sources (describe in comments)

Comments:

6. Reason for Office Assessment

\section{Surface Cover:}

USLOB: $\quad$ USROB: $\quad$ DSLOB: $\quad$ DSROB: $\quad$ Overall:

$1=>50 \% \overline{\text { Paved }} \quad 2=10 \%-50 \%$ Paved $3=$ Row crop $4=\overline{\text { Pasture }}$ 5=Brush $6=$ Forest $7=$ Wetland $8=$ Structures $99=\mathrm{CNBD}$

Comments:

8. Angle of Approach (degrees): ____ (+ = Pushes RB $-=$ Pushes LB)

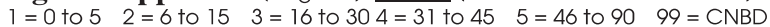

Comments:

9. Angle of Skew (degrees): ___ (

$1=90$ to $85 \quad 2=84$ to $75 \quad 3=74$ to $60 \quad 4=59$ to $45 \quad 5=44$ to $0 \quad 99=\mathrm{CNBD}$

Comments:

10. Stream Slope: $\%$

Multiply by 100 to convert ft/ft to percent slope; $99=\mathrm{CNBD}$

Comments:

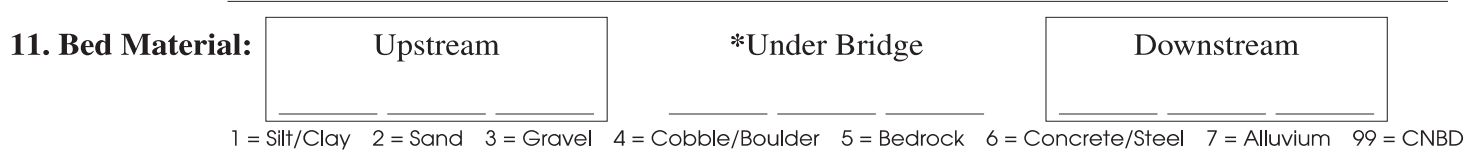

Comments

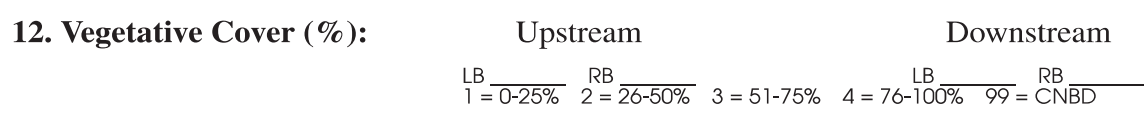

Comments:

Figure 27. "Bridge and Channel Characteristics at Office-Reviewed Bridge Sites" form. 


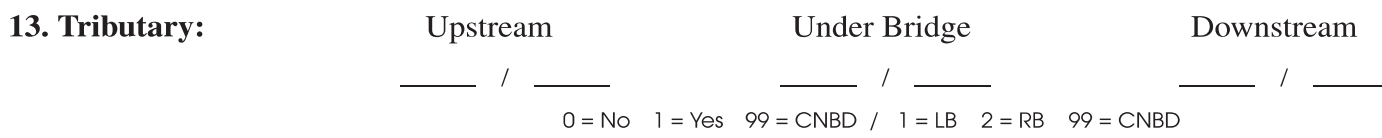

Comments

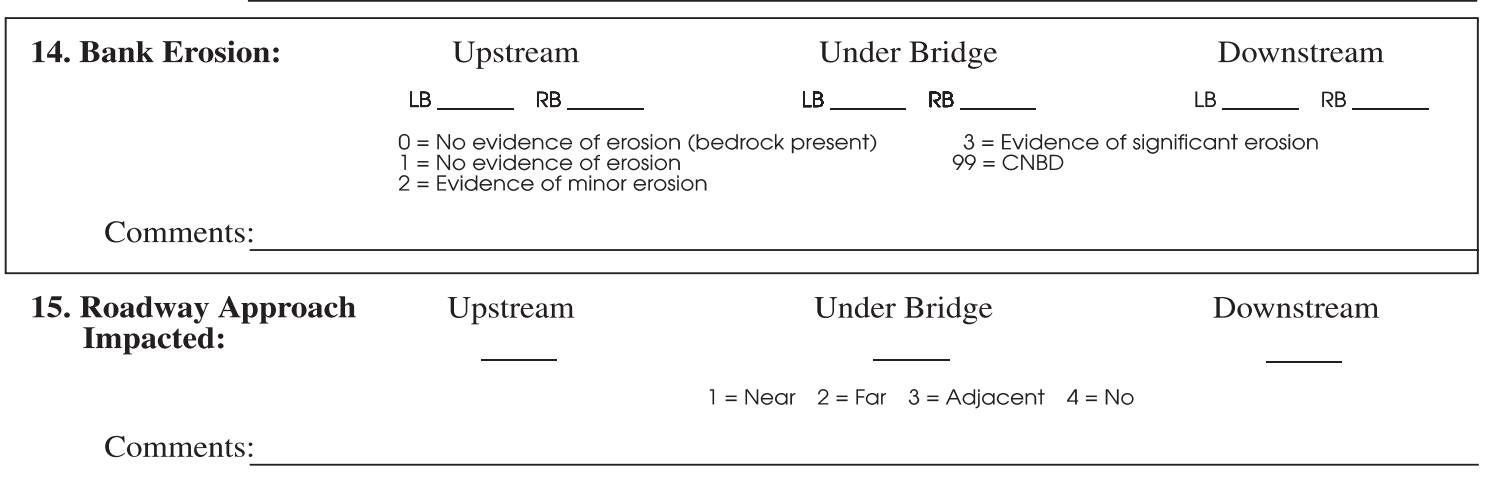

16. Meander Impact: $\quad$ Upstream Under Bridge Downstream

\begin{tabular}{ll} 
Upstream \\
\hline
\end{tabular}$=$ No $1=$ Yes $99=\mathrm{CNBD} / \quad 1=\mathrm{LB} \quad 2=\mathrm{RB} \quad 99=\mathrm{CNBD}$

Comments:

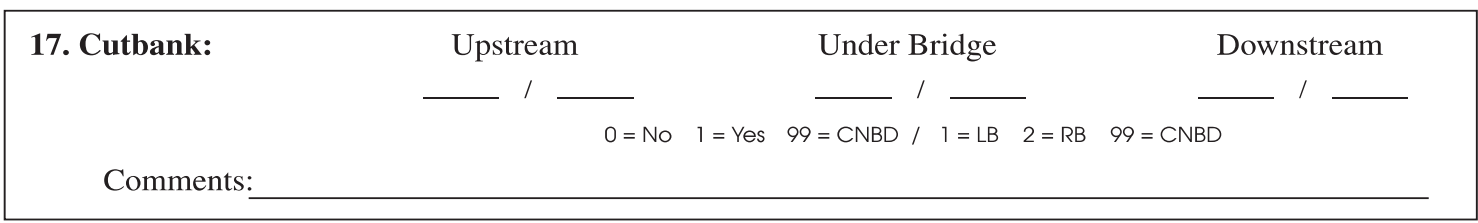

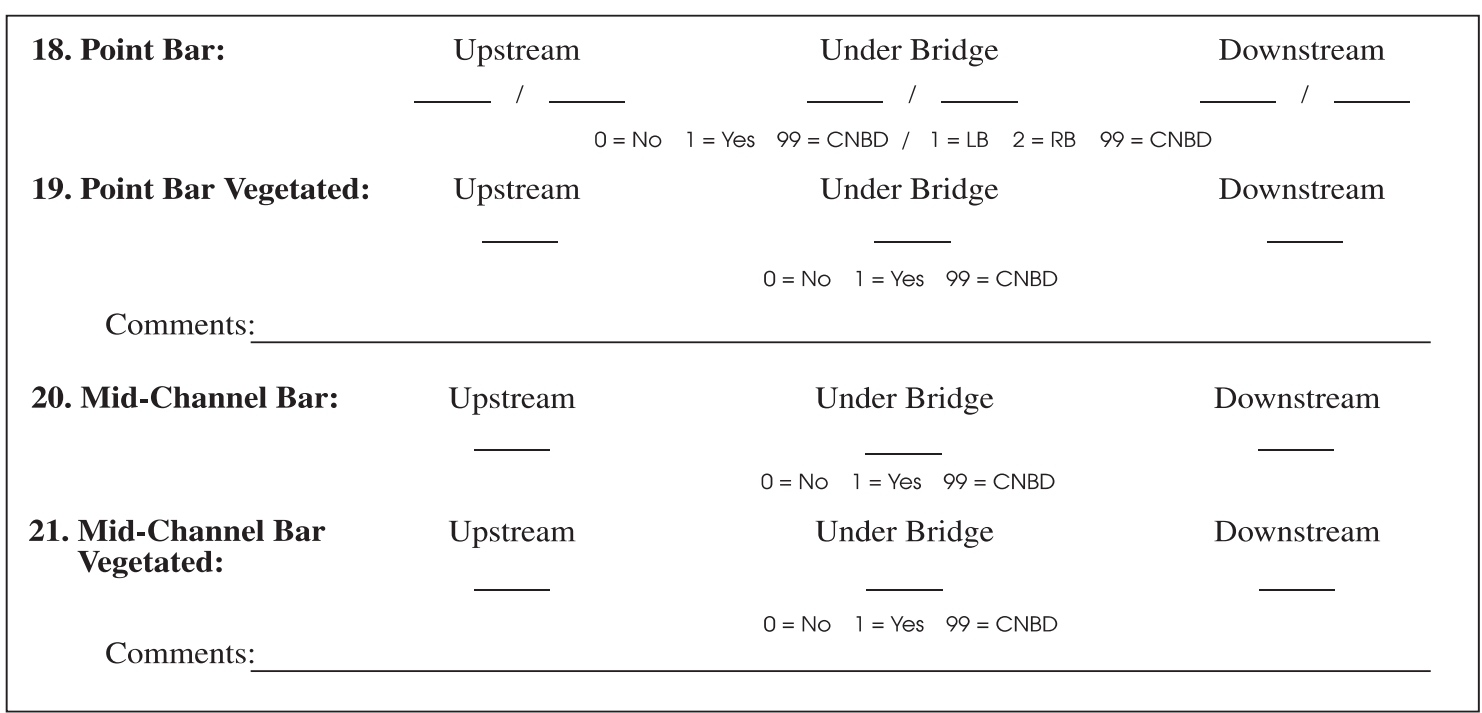

Figure 27. "Bridge and Channel Characteristics at Office-Reviewed Bridge Sites" form-Continued. 


\section{Upstream Countermeasures:}

(The comment field should include size and design velocity of rip rap, when available)

Type Locations Condition Comments

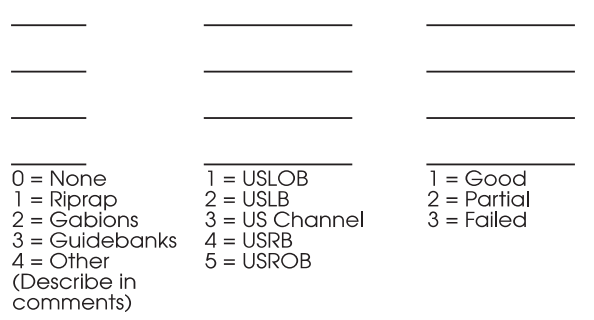

*23. Under Bridge Countermeasures:

(The comment field should include size and design velocity of rip rap, when available)

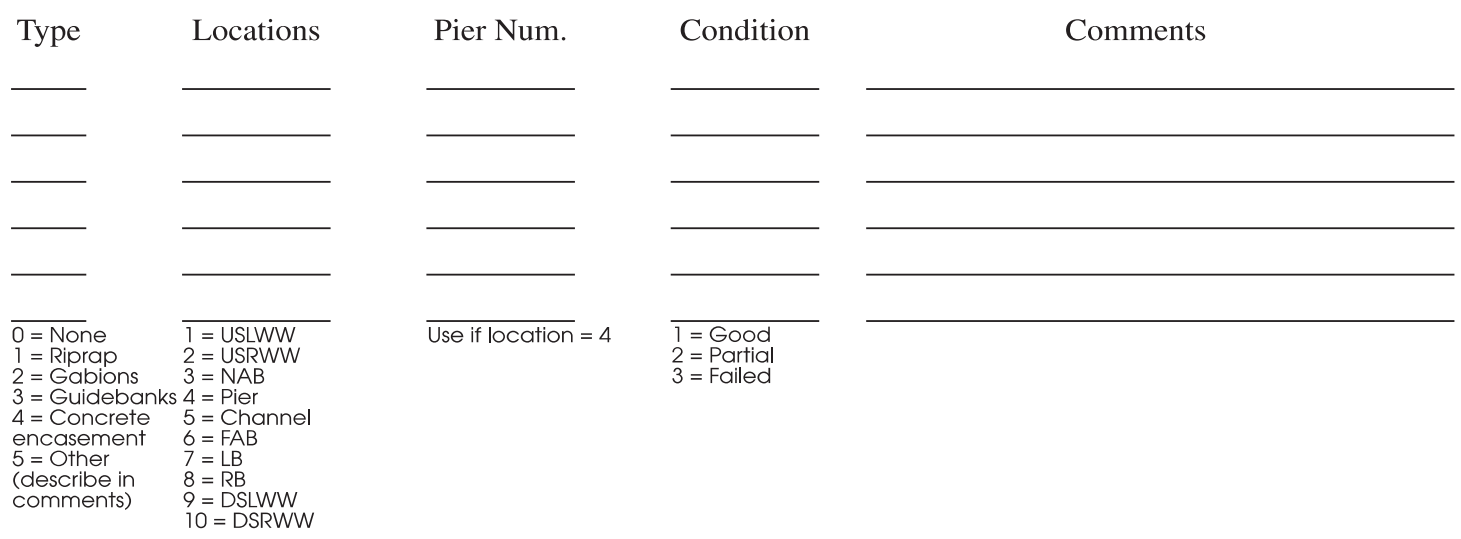

24. Downstream Countermeasures:

(The comment field should include size and design velocity of rip rap, when available)

\begin{tabular}{|c|c|c|}
\hline Type & Locations & Condition \\
\hline & & \\
\hline & & \\
\hline $\begin{array}{l}0=\text { None } \\
1=\text { Riprap } \\
2=\text { Gabions } \\
3=\text { Guidebanks } \\
4=\text { Other } \\
\text { (Describe in } \\
\text { comments) }\end{array}$ & $\begin{array}{l}=\text { DSLOB } \\
2=\text { DSLB } \\
3=\text { DS Channel } \\
4=\text { DSRB } \\
5=\text { DSROB }\end{array}$ & $\begin{array}{l}1=\text { Good } \\
2=\text { Partial } \\
3=\text { Failed }\end{array}$ \\
\hline
\end{tabular}

25. Scour Holes: (Not in contact with substructure)

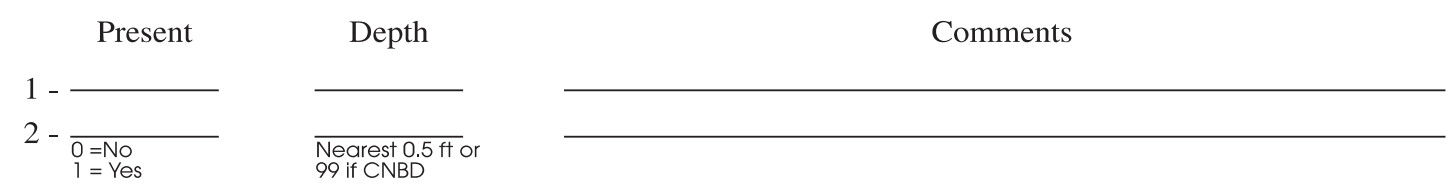

Figure 27. "Bridge and Channel Characteristics at Office-Reviewed Bridge Sites" form-Continued. 


\section{Blow Hole:}

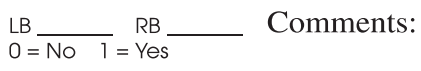

27. Channel \& Channel Protection Condition Rating (E21):

$99=\mathrm{CNBD}$

28. Design Flood: Rec. Int: Discharge:

Elevation: Maximum Velocity: $99=\mathrm{CNBD}$ Discharge: $99=\mathrm{CNBD}$

29. 100-Year Flood:
Elevation: Maximum Velocity:
$99=$ CNBD $\quad$ Maximum Velocity:

$99=\mathrm{CNBD}$ $99=\mathrm{CNBD} \quad 99=\mathrm{CNBD}$

*30. Pressure Flow at 100-Year Flood:

$$
0=\text { No } \quad 1=\text { Yes }
$$

31. Road Overtopping at 100-Year Flood:

Comments:

*32. Abutment Type: Near abutment type: ___ Far abutment type:

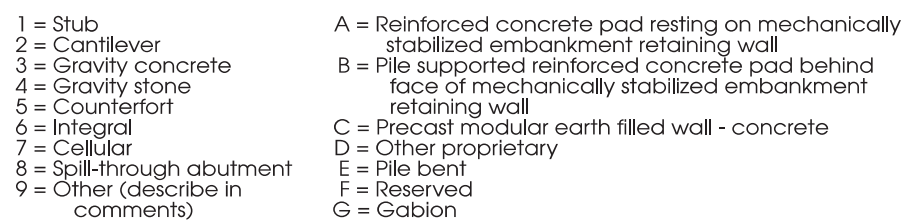

Comments:

*33. Pier Type:
P01
$\mathrm{P} 02$
P03
P04
P05
P06
P07
$0=$ None
$1=$ Timber
$2=$ Steel
$3=$ Reinforced concrete
$4=$ Plain concrete
$5=$ Prestressed concre
7 = Encased structural steel
8 = Concrete unknown, cannot determine type $6=$ Stone - masonry

Comments:

*34. Abutment/Pier Foundation Type:

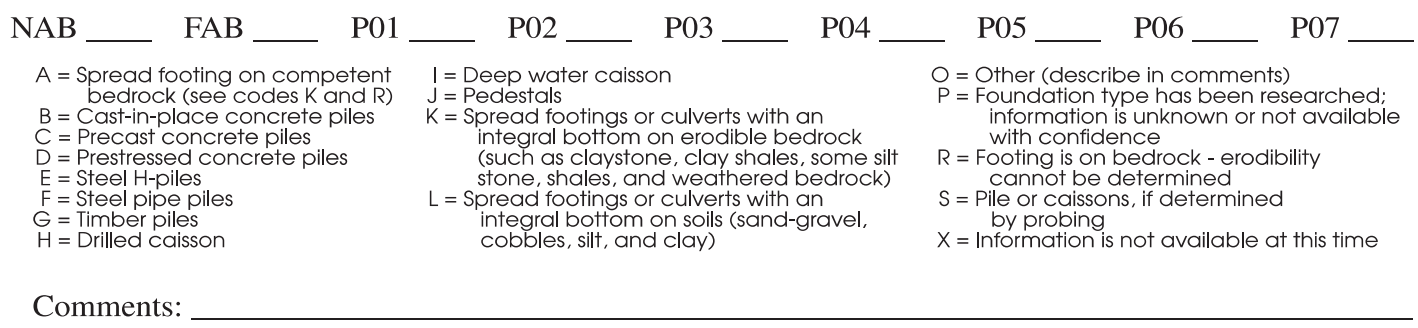

Figure 27. "Bridge and Channel Characteristics at Office-Reviewed Bridge Sites" form-Continued. 
35. Normal Water Depth:

\begin{tabular}{lrrr} 
Subunit & Normal Pool Elevation & Channel Elevation & Normal Water Depth \\
\hline & - & - \\
- & - & - \\
$\square$ & - & - & - \\
- & - & - \\
\hline \\
\hline
\end{tabular}

\section{Streambed Material near the Bridge Substructure Units:}

(This item will be recorded only from a previous PennDOT inspection. If rating is not available, an entry of 99 (CNBD) is appropriate.

NAB

$\mathrm{FAB}$

$\mathrm{P} 01$

$\mathrm{P} 02$

P03

P04

P05

P06

P07

\section{ABUTMENTS}

37.

Bank

location
38.

Abutment location
39.

Bridge opening
NAB:

FAB:

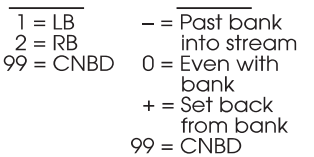
$99=$ CNBD

Comments:
40.

Attack angle $(+=\mathrm{RB})$

$* 41$.

Evidence of movement

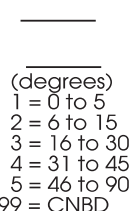

*42.

Scour condition
43.

Water depth depth (W11-C) (W11)

\section{Abutment Findings:}

NAB: W12 Findings:

FAB: W12 Findings:

USGS Comments:

Figure 27. "Bridge and Channel Characteristics at Office-Reviewed Bridge Sites" form—Continued. 
PIERS

\begin{tabular}{|c|c|c|c|c|c|c|c|}
\hline $\begin{array}{l}\text { *46. } \\
\text { Pier } \\
\text { number } \\
\text { (w09) }\end{array}$ & $\begin{array}{c}47 . \\
\text { Pier } \\
\text { location }\end{array}$ & $\begin{array}{l}48 . \\
\text { Nose } \\
\text { shape }\end{array}$ & $\begin{array}{c}49 . \\
\text { Attack } \\
\text { angle } \\
(+=R B) \\
(-=L B)\end{array}$ & $\begin{array}{l}\boldsymbol{*} \mathbf{5 0} . \\
\text { Evidence } \\
\text { of } \\
\text { movement }\end{array}$ & $\begin{array}{c}\boldsymbol{* 5 1 .} \\
\text { Scour } \\
\text { condition }\end{array}$ & $\begin{array}{l}52 . \\
\text { Scour } \\
\text { depth } \\
(W 11-C)\end{array}$ & $\begin{array}{l}\mathbf{5 3 .} \\
\text { Water } \\
\text { depth } \\
(W 11)\end{array}$ \\
\hline$P_{-}$ & & & & & & & \\
\hline$P_{-}$ & & & & . & L & 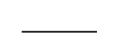 & \\
\hline$P_{-}$ & & & & & 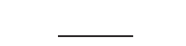 & 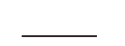 & 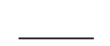 \\
\hline$P_{-}$ & & & & - & 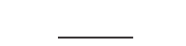 & 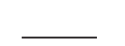 & 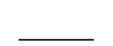 \\
\hline$P_{-}$ & & & & & 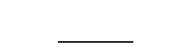 & 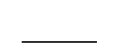 & 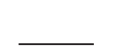 \\
\hline$P_{-}$ & & & & & & 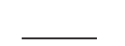 & 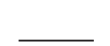 \\
\hline $\mathrm{P}$ & & & & & & & \\
\hline $0=\overline{\text { None }}$ & $\begin{aligned} 1 & =\mathrm{LFP} \\
2 & =\mathrm{LB} \\
3 & =\mathrm{MC} \\
4 & =\mathrm{RB} \\
5 & =\mathrm{RFP} \\
99 & =\mathrm{CNBD}\end{aligned}$ & $\begin{aligned} 1 & =\text { Pointed } \\
2 & =\text { Round } \\
3 & =\text { Cylinder } \\
4 & =\text { Square } \\
5 & =\text { Cylindrical cols } \\
6 & =\text { H-beam cols } \\
99 & =\text { CNBD }\end{aligned}$ & $\begin{aligned} \text { (degrees) } & \\
1 & =00 \text { to } 5 \\
2 & =6 \text { to } 15 \\
3 & =16 \text { to } 30 \\
4 & =31 \text { to } 45 \\
5 & =46 \text { to } 90 \\
99 & =\text { CNBD }\end{aligned}$ & $\begin{array}{l}\overline{0}=\text { No } \\
1=\text { Yes }\end{array}$ & $\begin{aligned} 0 & =\overline{\text { None }} \\
1 & =\text { Minor scour } \\
2 & =\text { Advanced } \\
& \text { scour } \\
3 & =\text { Serious scour }\end{aligned}$ & $\begin{array}{l}(0 \overline{.5 \mathrm{ft}) \text { or }} \\
99 \text { if CNBD }\end{array}$ & $\begin{array}{l}(0 . \overline{5 f t)} \text { or } \\
99 \text { if CNBD }\end{array}$ \\
\hline
\end{tabular}

Comments:

\section{Pier Findings:}

Pier \#

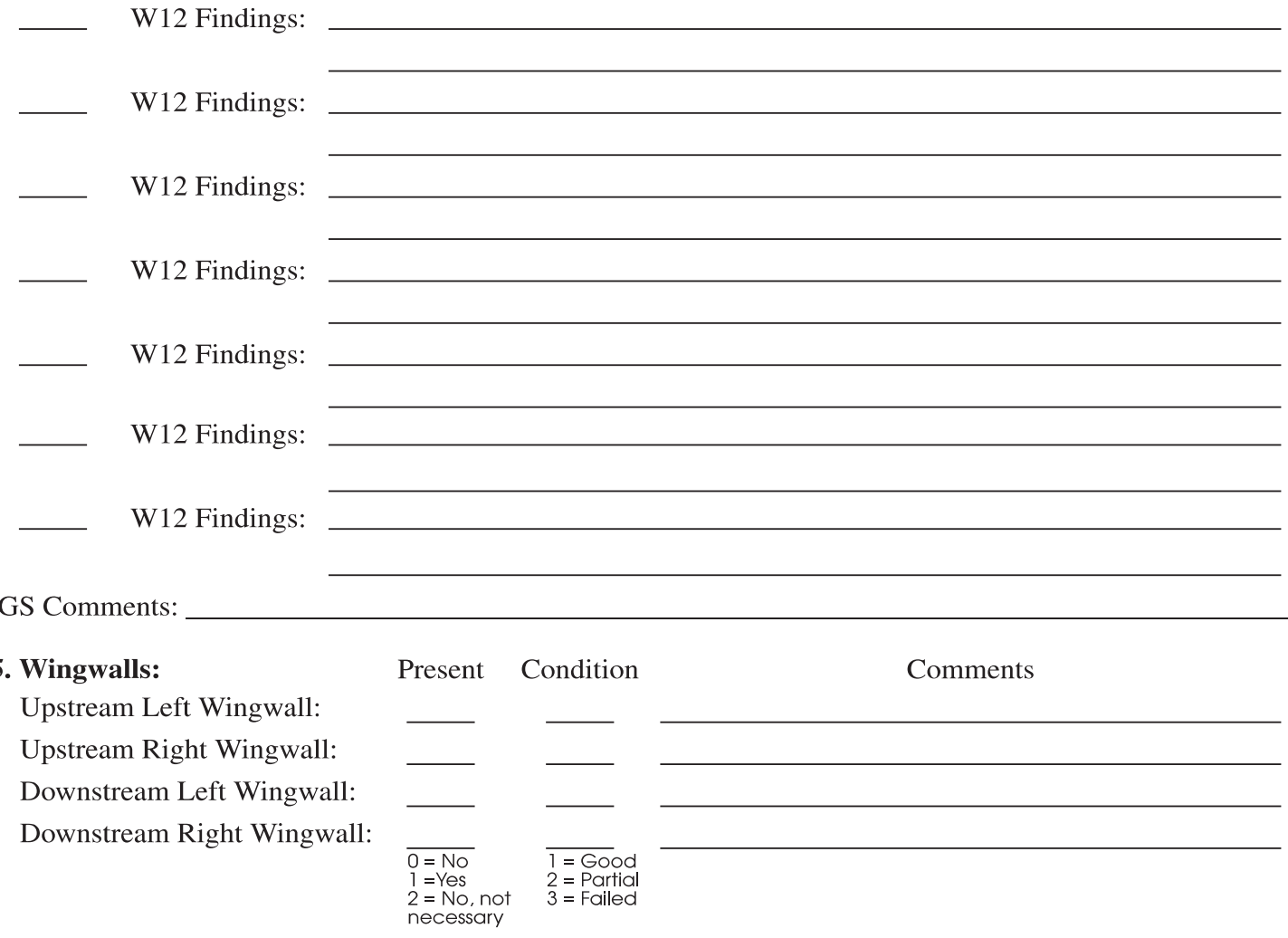

Figure 27. "Bridge and Channel Characteristics at Office-Reviewed Bridge Sites" form—Continued. 
56. Scour Depths for 100-Year Flood:

Subunit Channel elevation at subunit

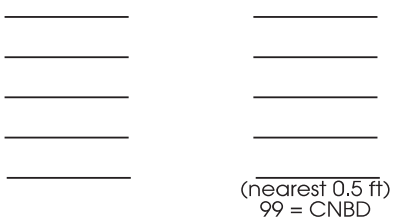

Comments:

*57. W11-A
Calculated scour depth at subunit

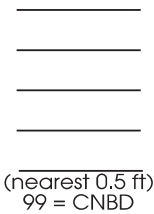

Bottom of footer elevation

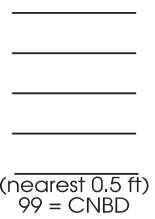

Are calculated scour depths below bottom of footer elevations?

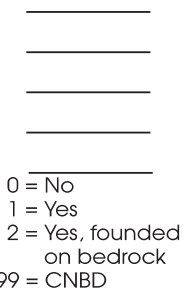

OBSERVED SCOUR RATING GUIDE

\begin{tabular}{|c|c|c|c|c|c|c|c|c|c|}
\hline \multirow[b]{3}{*}{ Rating } & \multicolumn{8}{|c|}{ ITEM NUMBER } & \multirow[b]{3}{*}{ Rating } \\
\hline & 1 & 2 & 3 & 4 & 5 & 6 & 7 & 8 & \\
\hline & $\begin{array}{c}\text { Change } \\
\text { since last } \\
\text { inspection }\end{array}$ & $\begin{array}{l}\text { Scour } \\
\text { hole }\end{array}$ & $\begin{array}{c}\text { Debris } \\
\text { potential }\end{array}$ & Scourability & $\begin{array}{l}\text { Opening } \\
\text { Adequacy/ } \\
\text { Channel }\end{array}$ & Sediment & Alignment & $\begin{array}{l}\text { Velocity/ } \\
\text { stream } \\
\text { slope }\end{array}$ & \\
\hline 9 & None & None & None & Rock/P & Good & None & Good & Low & 9 \\
\hline 8 & None & Minor & None & Rock/P/C & Good & Minor & Good & Low & 8 \\
\hline 7 & Minor & Minor & Minor & Rock/C & Fair & Minor & Good & Medium & 7 \\
\hline 6 & Minor & Advanced & Medium* & Stable & Fair & Medium & Medium & Medium & 6 \\
\hline 5 & Medium* & Advanced & High* $^{*}$ & Stable & Fair & High & Medium & High & 5 \\
\hline 4 & Medium & Serious* & High & Alluvium* & Poor* & High & Poor* + & High & 4 \\
\hline 3 & High* & Serious* & Present* & Alluvium & Overtop* & High & Poor & High & 3 \\
\hline 2 & Bridge is sc & critical, IMM & ATE actior & required ${ }^{*}$ & & & & & 2 \\
\hline 1 & Bridge is sc & critical, brids & S CLOSED & & & & & & 1 \\
\hline 0 & Bridge has & due to sco & & & & & & & 0 \\
\hline
\end{tabular}
NOTES:

Rating considerations given in highest to lowest level of importance from left to right. $\quad P=$ Pile Supported Substructures

$C=$ Effective Countermeasures

* If an item is so marked, it cannot be given a higher ranking.

+ A higher ranking may be given if the unit is founded on competent rock and no problems exist.

DETERMINATION OF RATING FOR BMS ITEM

W11-A

\begin{tabular}{|c|c|c|c|c|c|c|c|c|c|}
\hline \multirow{2}{*}{$\begin{array}{c}\text { Substructure } \\
\text { unit }\end{array}$} & 1 & 2 & 3 & 4 & 5 & 6 & 7 & 8 & \multirow{2}{*}{$\begin{array}{l}\text { W11-A } \\
\text { Overall } \\
\text { observed } \\
\text { scour } \\
\text { rating }\end{array}$} \\
\hline & $\begin{array}{l}\text { Change } \\
\text { since last } \\
\text { inspection }\end{array}$ & $\begin{array}{c}\text { Scour } \\
\text { hole }\end{array}$ & $\begin{array}{c}\text { Debris } \\
\text { potential }\end{array}$ & Scourability & $\begin{array}{l}\text { Opening } \\
\text { Adequacy/ } \\
\text { Channel }\end{array}$ & Sediment & Alignment & $\begin{array}{l}\text { Velocity/ } \\
\text { stream } \\
\text { slope }\end{array}$ & \\
\hline & & & & & & & & & \\
\hline & & & & & & & & & \\
\hline & & & & & & & & & \\
\hline & & & & & & & & & \\
\hline & & & & & & & & & \\
\hline & & & & & & & & & \\
\hline & & & & & & & & & \\
\hline
\end{tabular}

Comments:

Figure 27. "Bridge and Channel Characteristics at Office-Reviewed Bridge Sites" form—Continued. 
58. Debris Accumulation:

$$
\begin{aligned}
& 0=\text { No } \\
& 1=\text { Yes }
\end{aligned}
$$

59. Type of Debris:

$1=$ Brush
$2=$ Whole Trees

$3=$ Trash

$4=$ All others

$99=\mathrm{CNBD}$

Comments:

60. Trapping Potential:

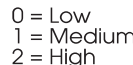

Comments:
61. Debris Potential:

$$
\begin{aligned}
& 0=\text { Low } \\
& 1=\text { Medium }
\end{aligned}
$$

62. Is the Structure Impacted by Ocean Tides?

$$
\begin{aligned}
0 & =\text { No } \\
1 & =\text { Yes } \\
99 & =\text { CNBD }
\end{aligned}
$$

*63. Possible Countermeasures:

Description of Activity

Footing Underpinning (E744803)

Abut Slopewall (Repair/Repl) (A745101)

Streambed Paving (Repair/Repl) (A705301)

Rock Protection (B745301)

Scour Hole (Backfill) (C745301)

Apron/Cutoff Wall (Repair/Repl) (B745202)

None

\section{Other Pertinent Data:}

$\begin{array}{llllll}\text { NAB } & \mathrm{P}_{-} \mathrm{P}_{-} & \text {Location } & & \\ \text { NAB } & & \mathrm{P}_{-} & \mathrm{P}_{-} & \text {FAB } \\ \text { US } & \text { UN } & \text { DS } & \\ \text { US } & \text { UN } & \text { DS } \\ \text { US } & \text { UN } & \text { DS } & \\ \text { Inlet } & & \text { Outlet } & \end{array}$

65. Effects from Site Conditions and Other Structures:

66. Reason for Bridge Replacement:

$0=$ First bridge at this site

$1=$ Insufficient roadway alignment

$4=$ Structural failure due to hydraulic conditions 5 = Structural failure due to non-hydraulic condition $6=$ Insufficient opening adequacy

$2=$ New roadway alignment
$3=$ Insufficient load capacity

Comments:

67. Do Site Conditions Warrant a Field Assessment?

$0=$ No

$1=$ Yes (describe in comments)

Comments:

Figure 27. "Bridge and Channel Characteristics at Office-Reviewed Bridge Sites" form—Continued. 


\section{PROCEDURES FOR COMPLETING "BRIDGE AND CHANNEL CHARACTERISTICS AT OFFICE-REVIEWED BRIDGES SITES” FORM}

These procedures describe the information and required data for completing the form: "Bridge and Channel Characteristics at Office-Reviewed Bridge Sites." Office-reviewed bridge-scour assessments are an evaluation of conditions at bridge sites based on historical PennDOT data and previous PennDOT bridge inspections. No field observations are made by USGS personnel for this population of bridges.

The principle objective of the assessment of an office-reviewed bridge site is the computation of the PennDOT-derived Scour Assessment Rating (Rating) and Scour-Critical Bridge Indicator Code (Code). The Rating and Code for a bridge site indicate the current scour condition at the site as it relates to type of bridge structure, the condition of countermeasures at the site, and other hydraulic, hydrologic, and geomorphic site conditions.

Two categories of office-reviewed bridges are assessed:

- Bridges built or extensively renovated after 1982;

- Bridges built prior to 1983 that cannot be adequately field assessed because of adverse site conditions. These adverse site conditions may include excessive water depths or velocities, barriers that prevent access to greater than 50 percent of the bridge subunits, and (or) potentially hazardous situations at the bridge site such as high traffic volume.

The first category of bridges, bridges built or extensively renovated after 1982, have more complete data available than the second category of bridges, bridges built prior to 1983; however, office assessment of these bridges will only be completed if the following required data sources are available:

$\begin{array}{ll}\text { Plan data and (or) design drawings } & \text { Required } \\ \text { Hydrologic and hydraulic report (H and H report) } & \text { Required } \\ \begin{array}{l}\text { Most recent PennDOT bridge inspection report, which } \\ \text { must include a complete W11-A for all subunits }\end{array} & \text { Required } \\ \text { Most recent previous underwater inspection report } & \text { Required, if applicable } \\ \text { Selected BMS data from USGS database } & \text { Required } \\ \text { Site photographs } & \text { Not required } \\ \text { Foundation report and (or) foundation approval letter } & \begin{array}{c}\text { Not required if plan data } \\ \text { available }\end{array}\end{array}$

The second category of bridges, those with accessibility problems and built prior to 1983, may have less available data. Office assessments for non-accessible sites, therefore, require fewer data sources. Office assessment of this second category of bridges will only be completed if the following required data sources are available:

Most recent PennDOT bridge inspection report, which must Required include a complete W11-A for all subunits

$\begin{array}{ll}\begin{array}{l}\text { Most underwater inspection report, that must include a } \\ \text { complete W11-A for all subunits }\end{array} & \text { Required, if applicable } \\ \text { Selected BMS data from USGS database } & \text { Required } \\ \text { Site photographs } & \text { Not required } \\ \text { Foundation report and (or) foundation approval letter } & \text { Not required } \\ \text { Plan data and Design drawings } & \text { Not required } \\ \text { Hydrologic and hydraulic report (H and H report) } & \text { Not required }\end{array}$


Other data sources and the associated dates of these data sources are documented in a supplied comment field if they are used for the assessment of a bridge site. If data is not available to complete an office assessment, the bridge site will be visited and scour assessment completed by PennDOT personnel.

Data fields required for computation of the Rating and Code are starred $\left(^{*}\right)$ on the data-collection form and in the procedures guide to ensure that these fields are completed. When required, USGS personnel work with PennDOT District personnel to compile the data to complete these fields. No officereviewed bridge assessment is complete unless all starred fields are complete, therefore, a qualitative interpretation of existing PennDOT data is commonly necessary to complete office-reviewed bridge assessments.

Boxed items on the assessment form indicate fields for which data will frequently be unavailable. An entry is $99=\mathrm{CNBD}$ (cannot be determined) in any boxed data field for which there is not a high degree of certainty. The $99=$ CNBD entry cannot be used in starred data fields.

USGS personnel assume the PennDOT data sources adequately and completely document a bridge site for the assessment of scour and channel stability. If the previous PennDOT inspection makes no recommendations for maintenance or improvements, the assessor assumes no condition exists at the site that indicates concern or problems. If assessors find inconsistencies among the PennDOT data sources, PennDOT District personnel are contacted to resolve these conflicts during the time at which USGS personnel are completing the assessments (Bryan J. Spangler P.E., Pennsylvania Department of Transportation, oral commun., 1998).

\section{*1. Assessed Bridge Number}

The assessed bridge number is the structure identification according to item A01 of BMS Pub 100A (Pennsylvania Department of Transportation, 1993) on the day of the site assessment.

Data Source(s):

BMS data

\section{Name of Assessor}

This item records the name of USGS personnel conducting the office assessment, and consist of the first and middle initials and the last name

\section{Date of Office Assessment}

This item records the date of the USGS office assessment by month, day, and year.

\section{*4. Year Built}

This item records the year the bridge was built.

Data Source(s):

BMS data

PennDOT personnel 


\section{Information Available For This Assessment}

The assessor records the type and dates of the available PennDOT information in the provided blanks. The entry is $99=\mathrm{CNBD}$ if the information is unavailable. Caution must be taken, because data for previous bridge structures located at a particular site and data for the current bridge structure may be present in the same file. Assessors must ensure that the data compiled is for the current bridge at the site. If a required data source, as listed above, is not available, the office assessment cannot be completed.

Multiple dates may be available for PennDOT inspection reports. In these cases, the date that the most recent PennDOT inspection was completed by PennDOT personnel is recorded and not the date the data was entered into the PennDOT database and was approved for use. Photographs may span multiple years and are not updated until a change at the site warrants replacement with a more current photograph; therefore, the dates of all available photographs are entered in the spaces provided. Additional sources used are noted in the comment field.

\section{Reason for Office Assessment}

This item records the reason an office review is completed instead of viewing the site in the field. The entries are 1 = Bridge built or extensively renovated after 1982, or 2 = Bridge built prior to 1983 with site-access problems.

\section{Surface Cover}

This item records the surface cover in the vicinity of the bridge. Surface cover for the upstream left overbank (USLOB), upstream right overbank (USROB), downstream left overbank (DSLOB), and downstream right overbank (DSROB) are described for a distance of two bridge-lengths or $200 \mathrm{ft}$ upstream and downstream from the bridge and up to two bridge-lengths or $200 \mathrm{ft}$ landward from the stream. The category that best describes the overall ground cover of the bridge site is recorded also. Entries are $1=>50 \%$ paved; $2=10 \%-50 \%$ paved $3=$ row crop; $4=$ pasture; $5=$ brush $6=$ forest; $7=$ wetland; $8=$ structure; or $99=\mathrm{CNBD}$ (cannot be determined)

\section{Data Source(s)}

\section{Photographs}

Site data section of $\mathrm{H}$ and $\mathrm{H}$ report

\section{Angle of Approach}

This item records the angle of approach in degrees. The angle of approach is a comparison of the upstream and downstream reaches and is determined using the low-flow channel boundaries as they appear in the site plan and not the banklines as used for field-viewed bridge assessments. The assessor determines the direction from which flow approaches the bridge and the direction along which flow exits the bridge, taking into consideration the entire reach so that sinuous thalwegs do not effect the result. Entries are $1=0$ to 5 degrees; $2=6$ to 15 degrees; $3=16$ to 30 degrees; $4=31$ to 45 degrees; $5=46$ to 90 ; or $99=\mathrm{CNBD}$ (cannot be determined). Flow paths directed toward the left bank are recorded with the angle category preceded by a minus (-) sign. Flow paths directed toward the right bank are recorded with the angle category and the positive (+) sign is assumed.

\section{Data Source(s)}

Site plan in $\mathrm{H}$ and $\mathrm{H}$ report

Site location maps

Plan data

\section{Angle of Skew}

This item records the angle of flow relative to the upstream face of the bridge. The angle of skew is determined by use of the low-flow channel boundaries as they appear in the site plan and not the banklines as used for field-viewed bridge assessments. Entries are $1=90$ to 85 degrees; $2=84$ to 
75 degrees; $3=74$ to 60 degrees; $4=59$ to 45 degrees; $5=44$ to 0 degrees; or $99=$ CNBD (cannot be determined). Flow paths directed toward the left bank are recorded with the angle category preceded by a minus (-) sign. Flow paths directed toward the right bank are recorded with the angle category and the positive sign is assumed. Care must be taken to consider enough of the upstream reach so that smaller, low-flow stream features such as sinuous thalwegs do not effect the result.

\section{Data Source(s)}

Site plan in $\mathrm{H}$ and $\mathrm{H}$ report

Site location maps

Plan data

\section{Stream Slope}

Water surface slope is the preferred entry for this item. Bed slope may be substituted and a notation made in the comment field if water surface slope is not available, as may be the case for dry streambeds. The assessor records the percent stream slope ( 3 significant figures) in the vicinity of the bridge. A slope provided in feet-per-foot is multiplied by 100 to convert the entry to percent slope. When multiple slopes are provided, the slope in the vicinity of the bridge is entered. The entry is $99=$ CNBD if a confident determination of stream slope cannot be made.

\section{Data Source(s)}

Roadway and stream profile section of $\mathrm{H}$ and $\mathrm{H}$ report

Site data summary section of $\mathrm{H}$ and $\mathrm{H}$ report

\section{*11. Bed Material}

This item describes the three most abundant particle sizes found in the channel bed upstream from the bridge, under the bridge, and downstream from the bridge. A determination of the primary, secondary and tertiary constituents may not be possible, however, the main constituent should be identifiable. The first two sizes listed are used to modify the dominant particle size recorded in the last blank. Commonly, all three blanks will not need to be completed, because a more homogenous bed material may need to be represented. If the assessor determines the bed material is smaller than "cobble sized" but the particle size cannot be determined from available PennDOT data, an entry of "Alluvium" is used. The entries are $1=$ silt/clay; $2=$ sand; $3=$ gravel; $4=$ cobble/boulder; $5=$ bedrock; $6=$ concrete $/$ steel; $7=$ alluvium; or $99=$ CNBD (cannot be determined). Note that $99=$ CNBD is only valid for the upstream and downstream channels and is not a valid entry for Under Bridge Bed Material.

\section{Data Source(s)}

\section{$\mathrm{H}$ and $\mathrm{H}$ report}

Previous PennDOT inspection report

Site photos

\section{Vegetative Cover (\%)}

This item records the percentage of the bank stabilized by the woody vegetation growing between the edge of water and the top of the banks upstream and downstream from the bridge. Entries are $1=0$ to $25 \% ; 2=26$ to $50 \% ; 3=51$ to $75 \% ; 4=76$ to $100 \%$; or $99=$ CNBD (cannot be determined).

\section{Data Source(s)}

Site photographs 


\section{Tributary}

This item records the existence and bank location of significant tributaries within two bridge lengths or $200 \mathrm{ft}$ upstream from the bridge, under the bridge, or within two bridge lengths or $200 \mathrm{ft}$ downstream from the bridge. Culvert pipes with a diameter of $3 \mathrm{ft}$ or greater are considered tributaries. Entries are $0=$ No, tributary is not present; $1=$ Yes, tributary is present; or $99=\mathrm{CNBD}$ (cannot be determined). Significant aspects of the tributary are addressed in the comment field.

Data Source(s)

Site photographs

Site plan in $\mathrm{H}$ and $\mathrm{H}$ report

\section{Bank Erosion}

This item indicates whether or not there is evidence of bank erosion in the upstream channel, under the bridge, or in the downstream channel; and, if possible, the degree to which that bank erosion is impacting the site. The entries are $0=$ no evidence of erosion (bedrock present); $1=$ no evidence of erosion; 2 = evidence of minor erosion; 3 = evidence of significant erosion; or $99=$ CNBD (cannot be determined). More specific information describing the extent of the erosion at the bridge site is noted in the comment field provided.

\section{Data Source(s)}

Site photographs

Site data section of $\mathrm{H}$ and $\mathrm{H}$ report

Embankment erosion section of $\mathrm{H}$ and $\mathrm{H}$ report

\section{Roadway Approach Impacted}

This item records the presence and location of potential impacts on roadways resulting from channel migration or instability near the bridge. Entries are $1=$ near, the near roadway approach is impacted; 2 = far, the far roadway approach is impacted; 3 = adjacent, an adjacent roadway (not carried by the bridge) is impacted; or $4=$ no, roadways are not impacted. If a roadway is impacted, the assessor comments on any significant characteristics documented in the PennDOT data sources that lead to this conclusion. No mention of a specific roadway impact is assumed to be an indication that none exists.

\section{Data Source(s)}

Approach roadway condition rating (E15) of previous PennDOT inspection report

Site photos

Site plan in $\mathrm{H}$ and $\mathrm{H}$ report

\section{Meander Impact}

This item records the presence and bank location of impacts upon the channel banks caused by a meandering channel within two bridge lengths or $200 \mathrm{ft}$ upstream from the bridge, under the bridge, and within two bridge lengths or $200 \mathrm{ft}$ downstream from the bridge. The entries are $0=$ no, meander impact is not present; 1 = yes, meander impact is present; or $99=$ CNBD (cannot be determined), presence or absence of a meander impact cannot be confidently determined.

Data Source(s)

Site plan in $\mathrm{H}$ and $\mathrm{H}$ report

Site photographs

Embankment erosion section of previous PennDOT inspection report 


\section{Cutbank}

This item records the presence and bank location of cutbanks within two bridge lengths or $200 \mathrm{ft}$ upstream, under the bridge, and within two bridge lengths or $200 \mathrm{ft}$ downstream from the bridge. The entries are $0=$ no, cutbank is not present; $1=$ yes, cutbank is present; or $99=\mathrm{CNBD}$ (cannot be determined), presence or absence of a cutbank cannot be confidently determined.

Data Source(s)

Embankment erosion section of previous PennDOT inspection report

Site photographs

Site data section of $\mathrm{H}$ and $\mathrm{H}$ report

\section{Point Bar}

This item records the presence or the absence of significant, lateral accumulations of sediment upstream from the bridge, under the bridge, and downstream from the bridge. The entries are $0=$ no, point bar is not present; 1 = yes, point bar is present; or $99=$ CNBD (cannot be determined).

Data Source(s)

Plan data

Site photographs

\section{Point Bar Vegetated}

This item records the presence or absence of woody vegetation on an existing point bar. The entries are $0=$ no, point bar vegetation is not present; $1=$ yes, point bar vegetation is present; or $99=\mathrm{CNBD}$ (cannot be determined).

\section{Data Source(s)}

Site photographs

\section{Mid-Channel Bar}

This item records the presence or absence of significant accumulations of sediment in mid-channel locations upstream from the bridge, under the bridge, and downstream from the bridge. The entries are $0=$ no, mid-channel bar is not present; $1=$ yes, mid-channel bar is present; or $99=$ CNBD (cannot be determined).

\section{Data Source(s)}

Plan data

Site photographs

\section{Mid-Channel Bar Vegetated}

This item records the presence or absence of woody vegetation on an existing mid-channel bar. The entries are $0=$ no, mid-channel bar vegetation is not present; $1=$ yes, mid-channel bar vegetation is present; or $99=$ CNBD (cannot be determined).

\section{Data Source(s)}

Site photographs

\section{Upstream Countermeasures}

This item records the presence or absence of countermeasures within two bridge lengths or $200 \mathrm{ft}$ upstream from the bridge. If no countermeasures are in place, the entry is $0=$ none under the heading "Type." If countermeasures are in place, the type, location, and condition of the countermeasure(s) is indicated. The entries for "Type" are $0=$ none; $1=$ riprap; $2=$ gabions; $3=$ guidebanks or $4=$ other. 
An entry of "other" is explained by a notation in the comment field. If there is no specific evidence for a countermeasure, an entry of 0 or "none" is appropriate. Locations of existing countermeasures are recorded by selecting from the list of abbreviations that includes: $1=$ USLOB, upstream left overbank; 2 = USLB, upstream left bank; 3 = US Channel, upstream channel; 4 = USRB, upstream right bank;

$5=$ USROB, upstream right overbank. The entries for the condition of an existing countermeasure are

$1=$ good (countermeasure provides protective barrier to erosive mechanisms at high flow); $2=$ partial (countermeasure is insufficient to provide total protective barrier to erosive mechanisms at high flow); or 3 = failed (countermeasure is not providing the protection from erosive processes for which it was installed). The condition of an existing countermeasure is assumed to be good unless specifically noted as otherwise by the available PennDOT data sources.

\section{Data Source(s)}

Plan data

Channel/embankment protection section of previous PennDOT inspection report

Maintenance and major improvement needs section (PennDOT items H01, H03, and

H05) of previous PennDOT inspection report

Hydraulic analysis section of $\mathrm{H}$ and $\mathrm{H}$ report

\section{Under Bridge Countermeasures}

This item records the presence or absence of countermeasures under the bridge. If no countermeasures are in place, the entry is $0=$ none under the heading "Type." If countermeasures are in place, the type, location, and condition of the countermeasures are indicated. The entries for "Type" are $0=$ none; 1 = riprap; 2 = gabions; 3 = guidebanks; 4 = concrete encasement; or $5=$ other. An entry of "other" is explained by a notation in the comment field provided. If there is no specific evidence of a countermeasure, an entry of "none" is appropriate. Locations of existing countermeasures are recorded by selecting from the list of abbreviations that includes: $1=$ USLWW (upstream left wingwall); 2 = USRWW (upstream right wingwall); $3=$ NAB (near abutment); 4 = pier; $5=$ channel; $6=$ FAB (far abutment); 7 = LB (left bank); $8=\mathrm{RB}$ (right bank); $9=$ DSLWW (downstream left wingwall); $10=$ DSRWW (downstream right wingwall). The condition of existing countermeasures are recorded as described in item 22: 1 = good; 2 = partial; 3 = failed. The condition of an existing countermeasure is assumed to be good unless specifically described as otherwise by the available PennDOT data sources.

\section{Data Source(s)}

Plan data

Channel/embankment protection section of previous PennDOT inspection report

Maintenance and major improvement needs section (H01, H03, H05) of previous PennDOT inspection report

Hydraulic analysis section of $\mathrm{H}$ and $\mathrm{H}$ report

\section{Downstream Countermeasures}

This item is determined as described in item 22, with the exception that described countermeasures are located within two bridge lengths or $200 \mathrm{ft}$ downstream from the bridge.

\section{Data Source(s)}

Plan data

Channel/embankment protection section of previous PennDOT inspection report

Maintenance and major improvement needs section (H01, H03, H05) of previous PennDOT inspection report

Hydraulic analysis section of $\mathrm{H}$ and $\mathrm{H}$ report 


\section{Scour Holes (Not in Contact with Substructure)}

This item records the presence and depth of significant scour holes at the bridge site that are not in contact with the substructure. The entries are $0=$ no, scour hole not present; $1=$ yes, scour hole present. No data indicative of a scour hole within the available PennDOT data sources is assumed to indicate no scour hole is present. The depth of the scour hole to the nearest half of a foot is recorded in the "Depth" field. The inability of the assessor to determine the depth of a scour hole results in an entry of $99=$ CNBD (cannot be determined) for the depth.

\section{Data Source(s)}

Previous PennDOT inspection report

$\mathrm{H}$ and $\mathrm{H}$ report

\section{Blowhole}

This item records the presence of blowholes. The entries are $0=$ no, blowhole not present; or $1=$ yes, blowhole present. This item is based almost exclusively on photographs that show the stream banks at the bridge, however, all data sources are consulted to identify the presence of a blowhole (this may include a blowhole created by the pre-existing structure). No data indicative of a blowhole within the available PennDOT data sources is assumed to indicate no blowhole is present.

\section{Data Source(s)}

Site photographs

Site sketch in previous PennDOT inspection report

$\mathrm{H}$ and $\mathrm{H}$ report

\section{Channel and Channel Protection Condition Rating (PennDOT item E21)}

The Channel and Channel Protection Condition Rating is taken directly from the most recent PennDOT inspection report, under PennDOT item E21. If item E21 is not available from the most recent inspection, the entry is $99=\mathrm{CNBD}$ (cannot be determined).

\section{Data Source(s)}

Previous PennDOT inspection report

\section{Design Flood}

This item lists the recurrence interval, discharge, elevation, and maximum velocity for which the bridge was designed. The entry is $99=\mathrm{CNBD}$ (cannot be determined) for each field where no data is available.

\section{Data Source(s)}

Plan data

$\mathrm{H}$ and $\mathrm{H}$ report

\section{100-Year Flood}

This item records the 100-year flood discharge, elevation, and maximum velocity as calculated by PennDOT. The entry is $99=$ CNBD (cannot be determined) for each field where no data is available.

\section{Data Source(s)}

Plan data

Hydrologic analysis section of $\mathrm{H}$ and $\mathrm{H}$ report 


\section{*30. Pressure Flow at 100-Year Flood}

This item records whether, based on available PennDOT information, the bridge will be subjected to pressure flow during a 100-year flood event. Entries are $0=$ no, the bridge will not be subjected to pressure flow at the 100-year flood event; or $1=$ yes, the bridge will be subjected to pressure flow at the 100 -year flood event. Note that $99=\mathrm{CNBD}$ (cannot be determined) is not a valid entry for this data item.

Data Source(s)

Plan data

Hydrologic analysis section of $\mathrm{H}$ and $\mathrm{H}$ report

PennDOT personnel

\section{Road Overtopping at 100-Year Flood}

This item records whether, based on available information, the roadway approaches will be overtopped during a 100-year flood event. Entries are $0=$ no, the roadway does not appear to be overtopped during the 100-year flood event; 1 = yes, the roadway does appear to be overtopped during the 100-year flood event; or $99=$ CNBD (cannot be determined), the potential for the roadway to be overtopped cannot be determined.

Data Source(s)

Plan data

Hydrologic analysis section of $\mathrm{H}$ and $\mathrm{H}$ report

\section{*32. Abutment Type}

This item records the type of construction used for each bridge abutment. There are 24 available entries to this field as listed on the data-collection form. An entry of 9 (other) receives a notation in the comment field provided. Note that $99=\mathrm{CNBD}$ (cannot be determined) is not a valid entry for this data item.

Data Source(s)

Plan data

Foundation report

BMS data

\section{*33. Pier Type}

This item records the type of material used in construction of each pier at a bridge site. There are nine available entries listed on the data-collection form for this field. An entry of 9 (other) receives a notation in the comment field provided. Note that $99=$ CNBD (cannot be determined) is not a valid entry for this data item.

\section{Data Source(s)}

Plan data

Foundation report

BMS data

\section{*34. Abutment/Pier Foundation Type}

This item records the foundation type at each abutment and at each pier. There are 17 available entries listed on the data-collection form for this field. An entry of $\mathrm{O}$ (other) receives a notation in the comment field provided. Note that $99=\mathrm{CNBD}$ (cannot be determined) is not a valid entry for this data item. 


\title{
Data Source(s)
}

Plan data

Foundation report

\section{Normal Water Depth}

This item records the maximum water depth at each subunit to the nearest half a foot, as computed from the difference between normal pool elevation and channel elevation at each subunit. Normal Pool Elevation and Channel Elevation entries are not back calculated from the Normal Water Depth entry. An entry of $99=$ CNBD (cannot be determined) is the entry in each field for which a confident determination cannot be made from available PennDOT data sources.

\section{Data Source(s)}

Plan data

$$
\mathrm{H} \text { and } \mathrm{H} \text { report }
$$

\section{Streambed Material Near The Bridge Substructure Units}

NOTE -- An entry of 99 = CNBD (cannot be determined) is entered into each applicable field until such time as PennDOT institutes coding of this item during PennDOT Bridge Inspections.

\section{Bank Location}

This item records the location of each abutment relative to an observer facing downstream. The available entries are 1 = LB (left bank); 2 = RB (right bank); or 99 = CNBD (cannot be determined).

\author{
Data Source(s) \\ Plan data \\ Site photographs \\ Site data in $\mathrm{H}$ and $\mathrm{H}$ report \\ Plan data
}

\section{Abutment Location}

This item records the location of the abutments relative to the top of bank. Keep in mind that the site plan data are usually representative of the edge of water on the day of the site survey. Entries for the location of the abutments are "-" = past bank into stream; 0 = even with bank; "+" = set back from bank; or $99=\mathrm{CNBD}$ (cannot be determined).

\section{Data Source(s)}

Site photographs

Site data in $\mathrm{H}$ and $\mathrm{H}$ report

Plan data

\section{Bridge Opening Type}

This item records the general geometry of the bridge openings at each span. If multiple spans exist which, because of reconstruction or other factors, do not exhibit the same opening geometry, the entry is $5=$ other. The available entries are $1=$ rectangular; 2 = trapezoidal-unhardened, for example, a sloping embankment with no countermeasures present leading from the stream channel up to a stubtype abutment; 3 = trapezoidal—hardened, for example, a sloping embankment with adequate countermeasures protecting that embankment leading from the stream channel up to a stub-type abutment; $4=$ arched; or $5=$ other. An entry of "other" receives a notation in the comment field provided. 


\section{Data Source(s)}

Site Photos

Plan data

$\mathrm{H}$ and $\mathrm{H}$ report

\section{Abutment Attack Angle}

This item records the attack angle of the streamflow as determined by using the low-flow channel boundaries as they appear in the site plan and not the banklines as are used in field-viewed bridge assessments. The assessor estimates the angle created by the long axis of an abutment and the direction of flow as flow impinges on that abutment. Care must be taken to consider enough of the upstream reach so that small stream features, such as sinuous thalwegs, do not affect the result. The available entries for this item are $1=0$ to 5 degrees; $2=6$ to 15 degrees; $3=16$ to 30 degrees; $4=31$ to 45 degrees; $5=46$ to 90 degrees; or $99=\mathrm{CNBD}$ (cannot be determined). If the flow is directed toward the left bank, the angle is recorded as negative; if directed toward the right bank, the angle is recorded as positive. The attack angle will normally be the same for all substructure units unless a feature exists in the vicinity of the bridge (e.g. a large mid-channel bar) that alters the flow direction of a significant part of the stream or the bridge subunits are skewed at different angles because of curvature of the roadway carried by the respective bridge.

\section{Data Source(s)}

Site plan in previous PennDOT inspection report

Photo location map in previous PennDOT inspection report

Photo location map in $\mathrm{H}$ and $\mathrm{H}$ report

\section{*41. Evidence of Abutment Movement}

This item records indications of movement or possible movement of the abutments. Available entries are 1 = yes (evidence of movement is present); or 2 = no (evidence of movement is not present). Evidence of movement places a bridge under consideration for a field assessment. Unless specifically addressed in available data sources it will be presumed that no movement has occurred. Note that $99=$ CNBD (cannot be determined) is not a valid entry for this data item.

Data Source(s)

Substructure section (E20) in previous PennDOT inspection report

\section{*42. Abutment Scour Condition}

This item records the scour condition at each abutment at the time of the most recent PennDOT inspection. The entries for this item are $0=$ none; $1=$ minor scour; $2=$ advanced scour; or $3=$ serious scour. Note that $99=$ CNBD (cannot be determined) is not a valid entry for this data item.

\section{Data Source(s)}

W11-A, item 2 (scour hole) in previous PennDOT inspection report

\section{Abutment Scour Depth (PennDOT item W11-C)}

This item records the depth of scour to the nearest half of a foot at a specific abutment at the time of the most recent PennDOT inspection report. The depth of the scour hole is relative to the average elevation of the streambed. If a confident determination of scour depth cannot be made, the entry is $99=$ CNBD (cannot be determined).

\section{Data Source(s)}

Previous PennDOT inspection report 


\section{Water Depth at Abutment (PennDOT item W11)}

This item records the water depth to the nearest half a foot at each abutment at the time of the most recent PennDOT inspection report. If a confident determination of water depth cannot be made, the entry is $99=\mathrm{CNBD}$ (cannot be determined).

Data Source(s)

Previous PennDOT inspection report

\section{Abutment Findings}

This is a narrative description of inspection findings at each abutment. The abutment findings are taken directly from the most recent PennDOT inspection report, item W12. Any abutment condition that may indicate a significant departure from the constructed condition is considered for a field assessment. The USGS findings data field is used to note any conflict among the available data sources or to explain unusual notations in the abutment data fields.

\section{Data Source(s)}

Previous PennDOT inspection report

\section{*46. Identification of Specific Piers (PennDOT item W09)}

This item is used to record the presence or absence of piers at a bridge. If the bridge has no piers, the first data entry is " 0 " and no further entries are required in the Pier section of the form. If piers are present, identification of each specific pier includes a " $\mathrm{P}$ " followed by the 2 digit number of the pier (pier numbers 1 through 9 are preceded by a 0). Piers are numbered sequentially from the near abutment toward the far abutment, beginning with P01. The piers to be assessed include all piers deemed to be in contact with streamflows (as determined by presence of historical evidence such as scour, abrasion, or high-water marks) or the streamward-most pier on each flood plain and all piers in the main stream channel. Note that $99=\mathrm{CNBD}$ (cannot be determined) is not a valid entry for this data item.

\section{Data Source(s)}

Plan data

$\mathrm{H}$ and $\mathrm{H}$ report

\section{Pier Location}

This item records the location of each pier relative to the stream cross section. The available entries for this item are 1 = LFP (left flood plain); 2 = LB (left bank); $3=$ MC (main channel): $4=$ RB (right bank); 5 = RFP (right flood plain); or $99=$ CNBD (cannot be determined).

\section{Data Source(s)}

Plan data

Site photos

$\mathrm{H}$ and $\mathrm{H}$ report

\section{Pier Nose Shape(s)}

This item is used to record the shape of the upstream end of each pier. The available entries are $1=$ pointed; 2 = round; $3=$ cylinder; $4=$ square; $5=$ cylindrical columns; $6=$ H-beam columns; or $99=$ CNBD (cannot be determined).

\section{Data Source(s)}

Plan data

Site photos

$\mathrm{H}$ and $\mathrm{H}$ report 


\section{Pier Attack Angle}

This item records the attack angle of streamflow on the pier as determined by using the low-flow channel boundaries as they appear in the site plan and not the tops of banks as are used in fieldviewed bridge assessments. The assessor estimates the angle created by the long axis of the pier and the direction of flow as it impinges on the pier. Care must be taken to consider enough of the upstream reach so that small stream features, such as sinuous thalwegs, do not affect the result. The available entries for this item are $1=0$ to 5 degrees; $2=6$ to 15 degrees; $3=16$ to 30 degrees; $4=31$ to 45 degrees; $5=46$ to 90 degrees; or $99=$ CNBD (cannot be determined). If the flow is directed toward the left bank, the angle is recorded as negative; if directed toward the right bank, the angle is recorded as positive. The attack angle will normally be the same for all substructure units unless a feature exists in the vicinity of the bridge (e.g. a large mid-channel bar) that alters the flow direction of a significant part of the stream or the bridge subunits are skewed at different angles because curvature of the roadway carried by the respective bridge.

\section{Data Source(s)}

Site plan in previous PennDOT inspection report

Photo location map in previous PennDOT inspection report

Photo location map in $\mathrm{H}$ and $\mathrm{H}$ report

\section{*50. Evidence of Pier Movement}

This item records indications of movement or possible movement of piers. Available entries for to this item are 1 = yes, evidence of movement is present; or $2=$ no, evidence of movement is not present. Evidence of movement places a bridge under consideration for a field assessment. Unless specifically addressed in available data sources, "no movement" is the assumed condition. If piers are present, $99=$ CNBD (cannot be determined) is not a valid entry for this data item.

Data Source(s)

Substructure section (E20) in previous PennDOT inspection report

\section{*51. Pier Scour Condition}

This item is determined as in item 42 above.

\section{Data Source(s)}

W11-A, item 2 (scour hole) in previous PennDOT inspection report

\section{Pier Scour Depth (PennDOT item W11-C)}

This item is determined as described in item 42 above.

\section{Data Source(s)}

Previous PennDOT inspection report

\section{Water Depth at Pier (PennDOT item W11)}

This item is determined as in item 43 above.

\section{Data Source(s)}

Previous PennDOT inspection report 


\section{Pier Findings}

This is a narrative description of inspection findings at each pier. The pier findings are taken directly from PennDOT item W12 in the most recent PennDOT inspection report. Any pier condition that may indicate a significant departure from the constructed condition is considered for a field-viewed assessment. The USGS findings field is used to note any conflict among the available data sources or to explain unusual notations in the pier data fields.

Data Source(s)

Previous PennDOT inspection report

\section{*55. Wingwalls}

This item records the presence and condition of upstream left and right wingwalls and downstream left and right wingwalls. The available entries for the "Present" field are $0=$ no (wingwall is not present but it would be advantageous if one existed); 1 = yes (wingwall is present); or $2=$ no, not necessary (wingwall is not present but is not required for bridge protection). The available entries for the "Condition" field are $1=$ good (the wingwall is providing adequate protection); 2 = partial (the wingwall is providing insufficient protection); or 3 = failed (the wingwall provides no protection). Comments indicating any significant condition present at or on a wingwall are noted in the comment field provided. Note that $99=\mathrm{CNBD}$ (cannot be determined) is not a valid entry for this data item. Unless specifically described in the available PennDOT data sources the wingwall condition is assumed to be good.

Data Source(s)

Plan data

Site photographs

Substructure section (E20) of previous PennDOT inspection report

\section{Scour Depths for 100-Year Flood}

This item records whether the calculated scour depths for the 100-year flood event for each substructure unit exceeds the bottom of footer elevation for that respective substructure unit (Richardson and others, 1993). The assessor records each subunit in the appropriate field. The channel elevation, the calculated scour depth, and bottom of footer elevation for each subunit are determined from the available PennDOT data sources and recorded in the appropriate data fields. The entry for unavailable data is $99=$ CNBD (cannot be determined). The assessor addresses "Are Calculated Scour Depths Below Bottom of Footer" data field with the following entries: $0=$ no; $1=$ yes; $2=$ yes, founded on bedrock (the calculated scour depth exceeds the PennDOT-supplied footer depth, but the subunit is founded on scour-resistant bedrock); or $99=$ CNBD (cannot be determined).

\section{Data Source(s)}

Plan data

$\mathrm{H}$ and $\mathrm{H}$ report

Foundation report

\section{*57. PennDOT-Derived W11-A Table}

Data to complete the PennDOT-derived W11-A table is copied directly from the W11-A table found in the most recent PennDOT bridge inspection report. Note that $99=\mathrm{CNBD}$ (cannot be determined) is not a valid entry for this data item.

\section{Data Source(s)}

Foundation report 


\section{Debris Accumulation}

This item records the presence of a significant accumulation of debris within the bridge opening. The available entries for this item are $0=$ no debris is present; or $1=$ yes, debris is present. Unless specifically described to the contrary in the available PennDOT data sources, the assumed condition is no debris is present.

\section{Data Source(s)}

W11-A, item 3 (debris potential) in previous PennDOT inspection report

Channel/Channel Protection section of previous PennDOT inspection report

$\mathrm{H}$ and $\mathrm{H}$ report

\section{Type of Debris}

This item records the type of material that is the most significant constituent in the debris accumulation recorded in item 58 , above. Available entries are $1=$ brush; $2=$ whole trees; $3=$ trash; $4=$ all others; or $99=$ CNBD (cannot be determined). This data field is left blank only if the entry in item 58 above is "no."

\section{Data Source(s)}

Previous PennDOT inspection report

Site photographs

$\mathrm{H}$ and $\mathrm{H}$ report

\section{Trapping Potential}

This item records the potential for the bridge to trap debris. As discussed previously, trapping potential is affected by such factors as size of the bridge opening, sediment deposits, presence and orientation of piers, and attack angles. The available entries are $0=$ low; $1=$ medium; or $2=$ high.

\section{Data Source(s)}

Plan data

W11-A, item 5 (opening adequacy) and item 6 (sediment deposits) in previous PennDOT inspection report

\section{Debris Potential}

This item records a qualitative determination of the potential of the upstream drainage basin to produce debris. Information that suggests the accumulation of extensive debris at a bridge site or evidence that indicates an abundance of debris nearby, results in the assumption that this basin has high potential for debris production. Extensive tree growth along the bank with some evidence of undercutting also falls into the high potential category. Moderate tree growth along the bank or in the flood plain is considered medium debris potential. A bridge site with some woody vegetation and little or no apparent debris at the bank, in the stream, or on the flood plain is assigned the rating of low debris potential. Very large streams, very large drainage basins, and streams that flow through heavily forested basins are rated as having high potential for debris production. At the other extreme, small streams and drainage basins with very little woody vegetation are assumed to have a low potential for debris production. Available entries are $0=$ low; $1=$ medium; or $2=$ high. If debris potential is not specifically addressed in the $\mathrm{H}$ and $\mathrm{H}$ report, the assessor uses data transcribed from the W11-A entry for the lowest rated (worst) subunit in the previous PennDOT inspection report

\section{Data Source(s)}

$\mathrm{H}$ and $\mathrm{H}$ report

W11-A, item 3 (debris potential) in previous PennDOT inspection report

Site photographs 


\section{Is the Structure Impacted by Ocean Tides}

This item records whether the structure is affected by tidal conditions. Available entries are $0=$ no, not affected by tides; 1 = yes, affected by tides; or $99=\mathrm{CNBD}$ (cannot be determined).

Data Source(s)

$\mathrm{H}$ and $\mathrm{H}$ report

*63. Is Repair/Replace Listed as a Recommendation?

This item records whether repair and (or) replacement of abutment slopewalls, apron and (or) cutoff walls, or streambed paving is recommended as a result of the most recent PennDOT inspection. Unless specifically reported to the contrary in the most recent PennDOT inspection report, or in the BMS data, it is assumed that repair and (or) replacement of the current countermeasures in not necessary. Note that $99=$ CNBD (cannot be determined) is not a valid entry for this data item.

\section{Data Source(s)}

Previous PennDOT inspection report

BMS data

\section{Other Pertinent Data}

This item records pertinent data not specifically addressed by the data-collection form.

\section{Effects From Site Conditions and Other Structures}

This item records any unusual site conditions resulting from bedrock banks or waterfalls, or other structures within two-bridge-lengths or $200 \mathrm{ft}$ upstream and downstream from the bridge. This information can be obtained from any of the available PennDOT data sources.

\section{Reason for Replacement/Renovation}

This item lists the reason for major renovation or replacement of the previously existing bridge. Available entries for this item are $0=$ new bridge at this site; $1=$ insufficient roadway alignment; 2 = new roadway alignment; 3 = insufficient load capacity; 4 = structural failure due to hydraulic conditions; 5 = structural failure due to non-hydraulic conditions; 6 = insufficient opening adequacy; 7 = general structural deterioration; $8=$ other; or $99=\mathrm{CNBD}$ (cannot be determined). An entry of "other" will receive a notation in the comment field. Bridges that receive an office-reviewed bridge assessment because of limited accessibility will have an entry of "other" for this data field, and have the appropriate notation added to the respective comment field.

\section{Data Source(s)}

\section{$\mathrm{H}$ and $\mathrm{H}$ report}

\section{Do Site Conditions Warrant a Field Assessment}

This item records whether the office-reviewed bridge site is reclassified as a field-viewed bridge site, at which time, USGS and (or) PennDOT personnel will visit the bridge site to collect more comprehensive data. Entries from previously completed fields such as "Change Since Last Inspection," "Evidence of Movement," and "W12 Findings" are used in this determination. Examples of conditions that warrant a field inspection are excessive blockage, significant failed countermeasures, significant bank erosion, and possible impact on substructure. Available entries are $0=$ no field assessment necessary; or $1=$ yes, field assessment recommended. If the entry recommends a field assessment, the conditions that support this decision are noted in the respective comment field. An entry of 1 indicates PennDOT personnel and the appropriate USGS personnel are notified. Note that $99=$ CNBD (cannot be determined) is not a valid entry for this data item. 


\section{APPENDIX F}

Procedure for determination of the SCOUR-Critical BRIDGE INDICATOR CODE FOR FIELD-VIEWED BRIDGE SITES 


\section{PROCEDURE FOR DETERMINATION OF THE SCOUR-CRITICAL BRIDGE INDICATOR CODE FOR FIELD-VIEWED BRIDGE SITES}

The Scour-Critical Bridge Indicator Code (Code) indicates the degree to which scour is currently a factor at the site and the vulnerability of the bridge to future scour. The code is computed using the following flow charts (figs. 28 and 29) and tables 8 through 13. The Code ranges from code 9 to code 2 and represents the site conditions for the date of the assessment. As per the data-collection methods for fieldviewed bridge sites, only subunits that meet criteria for scour assessments are coded; for example, expansive bridges that carry elevated roadways will be coded only on the basis of those subunits in contact with streamflow. The procedures described for determination of the Code for field-viewed bridge sites use USGS data and PennDOT BMS data to determine the code for subunits and, on the basis of the most vulnerable subunits for a bridge, the bridge structure is assigned an overall code. PennDOT BMS data are compared with data observed by USGS for subunit type and subunit foundation type. The following flowchart and selection tables determine how these two data sources are used in the determination of the Code for the bridge site.

The Code is based on PennDOT BMS item W06. Item W06 is further defined in the PennDOT Bridge Management System Coding Guide of 1993. The codes described in PennDOT item W06 are equivalent to the codes described in the Federal Highway Administration (FHWA) database item I-113 (Federal Highway Administration report FHWA-ED-89-044: "Recording and Coding Guide for the Structure Inventory and Appraisal of the Nation's Bridges" 77p). In the past, PennDOT has added additional clarification to the FHWA item descriptors as indicated in the notes for item W06 in the PennDOT BMS Coding Guide.

A subunit can only be coded if data are complete for the following USGS data fields:

subunit type

subunit foundation type

scour condition

change since last inspection

under-the-bridge primary bed material OR streambed material near the subunit

condition of countermeasures at subunit

recommendations of possible countermeasures under bridge

evidence of movement

and the BMS data field:

C05A (Structural Configuration and Material Used for Main Unit and Approach Span)

The data field, streambed material near the subunit, was added to the field data-collection protocol in January 1996, therefore, the Code for bridges having field observations completed prior to that date are determined using the under-the-bridge primary bed material data field. 
A subunit may meet the criteria for more than one code, however it receives the code that is closest to the top of the ordered list below. If a subunit meets the criteria for one or two cases within a specific code, both cases for that code will be indicated to the user. A code of 6 indicates further evaluation is required for the subunit by PennDOT.

Code 6 , cases 1-3

Code 2

Code 8

Code 7

Code 5

Code 4

Code 3

Code 6 , case 4

Because the subunits are components of the overall structure code, the overall bridge structure receives the code equal to the code for the subunit rated closest to the top of the ordered list below. For example, if the three subunits for a bridge are rated 2, 6 case 3, and 5, the bridge structure receives a code of 6 .

Code 6

Code 2

Code 3

Code 4

Code 5

Code 7

Code 8

Pier type and pier foundation type data are stored in the PennDOT BMS database in items C39 and C40, respectively. These two items contain four subfields each in which PennDOT personnel enter pier data. The following assumptions must be made for use of BMS pier data in determining the Code for bridges:

1. If only 1 set of pier data ( 1 subfield complete for pier type and 1 subfield complete for foundation type) is available, assume that these data apply to all piers for the bridge.

For example; all piers of a bridge structure are constructed of the same type of material with the same foundation type, therefore, only one entry is made in the BMS database to describe all piers.

2. If the number of subfields of pier data equal the number of piers, assume that first subfield describes P01, the second subfield describes P02, and so on. For example; the variation among piers of a specific bridge is substantial enough to warrant individual entries for each pier and the overall number of piers does not exceed the capacity of the BMS data base to contain the associated data.

3. If no data are available for piers or if data can not be assigned to specific piers according to assumptions 1 and 2 above, the subunit can not be coded and receives a code of 6.

For example; PennDOT, when required, uses a description of groups of piers with similar characteristics in the BMS database. These group descriptions cannot be used for completion of the Rating and Code and, therefore, these bridge sites require manual computation by PennDOT personnel. 
When BMS data for foundation type or subunit type are blank, indicated as "other," or when the foundation type is "not determined," the subunit receives a code of 6 . In rare cases, a subunit may not meet the criteria for codes 9-7 or 5-2 because of other circumstances as noted in the following flowchart, tables, and list of criteria; in this case, the subunit and the bridge are assigned a code of 6 .

Several combinations of subunit types and foundation types cannot occur in the construction of a bridge (tables 11 and 12). In these cases, the subunit receives a code of 6 to indicate that further evaluation by PennDOT is required. For example, a bridge may be supported by a temporary substructure unit prior to repair.

For cases where a foundation type of "not observed" is used in the determination of the Code, a foundation type of alluvium is used for that specific subunit. An alluvium foundation type is considered a worst-case scenario. In reality, the foundation type may be more stable and requires further investigation. Comments in the USGS database or in the BMS database must be consulted for additional information.

Several combinations of conflicting data are flagged to alert the user that a more thorough review is required than for sites where data are similar or compatible. The flag states that a special condition at this site requires PennDOT review. Other site conditions are flagged as indicated in the coding criteria below. The combinations of conflicting codes that are flagged are:

1. USGS foundation type $=$ bedrock BMS foundation type $=\mathrm{L}$

2. USGS foundation type $=$ piles $/$ caissons BMS foundation type $=\mathrm{A}, \mathrm{R}$

3. USGS foundation type $=$ other BMS foundation type $=\mathrm{A}, \mathrm{R}, \mathrm{K}, \mathrm{B}-\mathrm{J}, \mathrm{S}, \mathrm{L}$. 


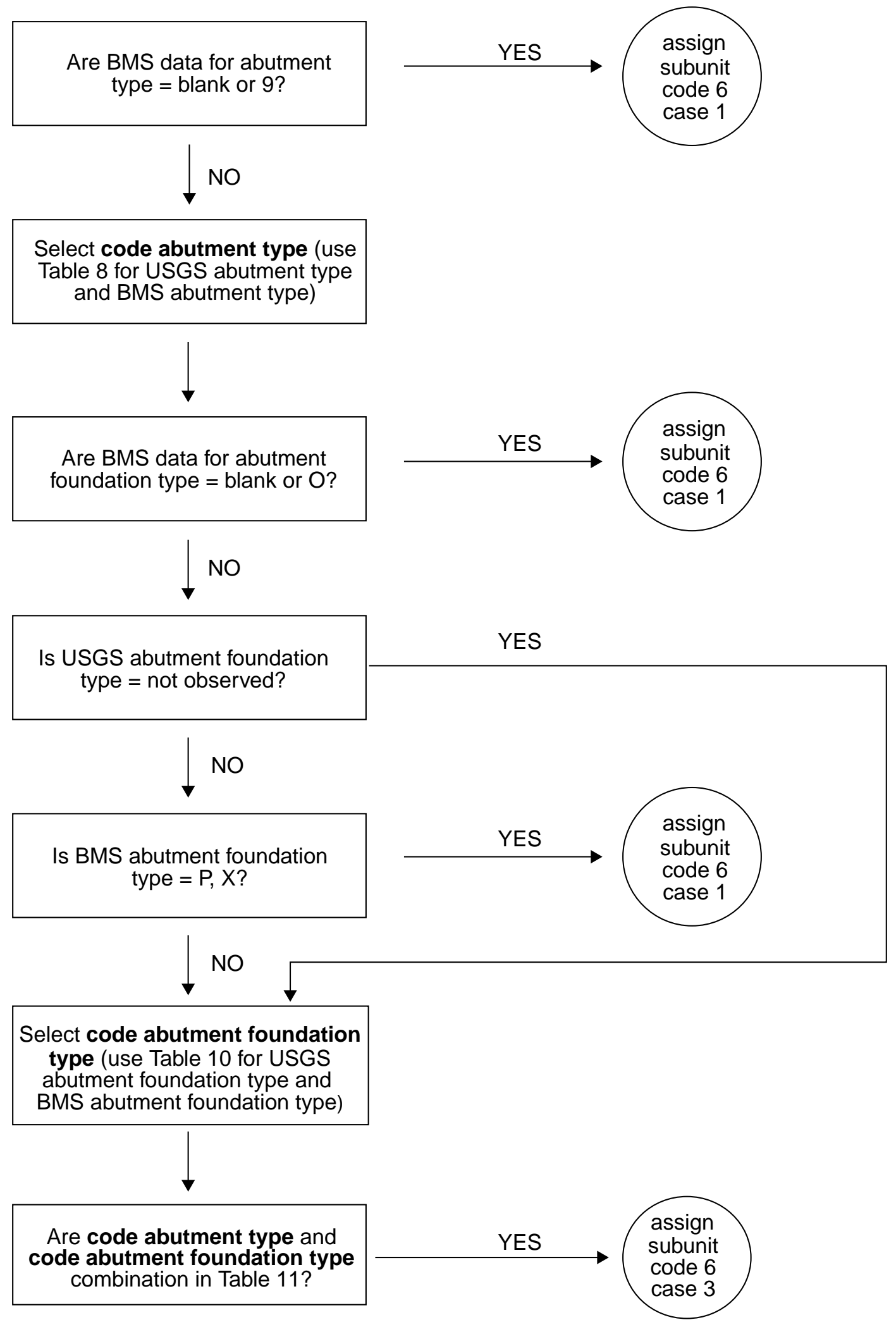

Figure 28. Determination of Scour-Critical Bridge Indicator Code for abutments at field-viewed bridge sites. 
$1 \mathrm{NO}$
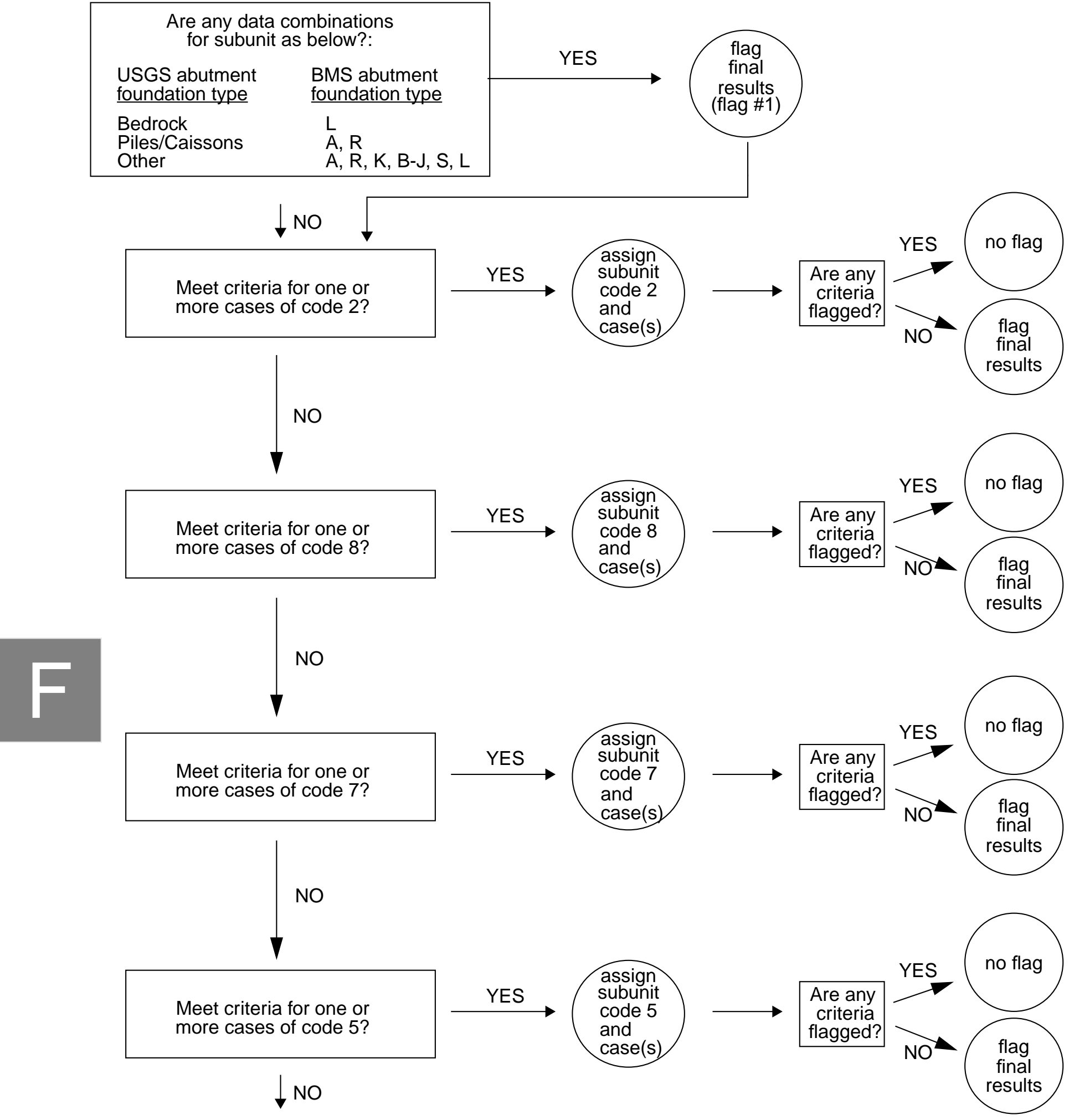

Figure 28. Determination of Scour-Critical Bridge Indicator Code for abutments at field-viewed bridge sites-Continued. 


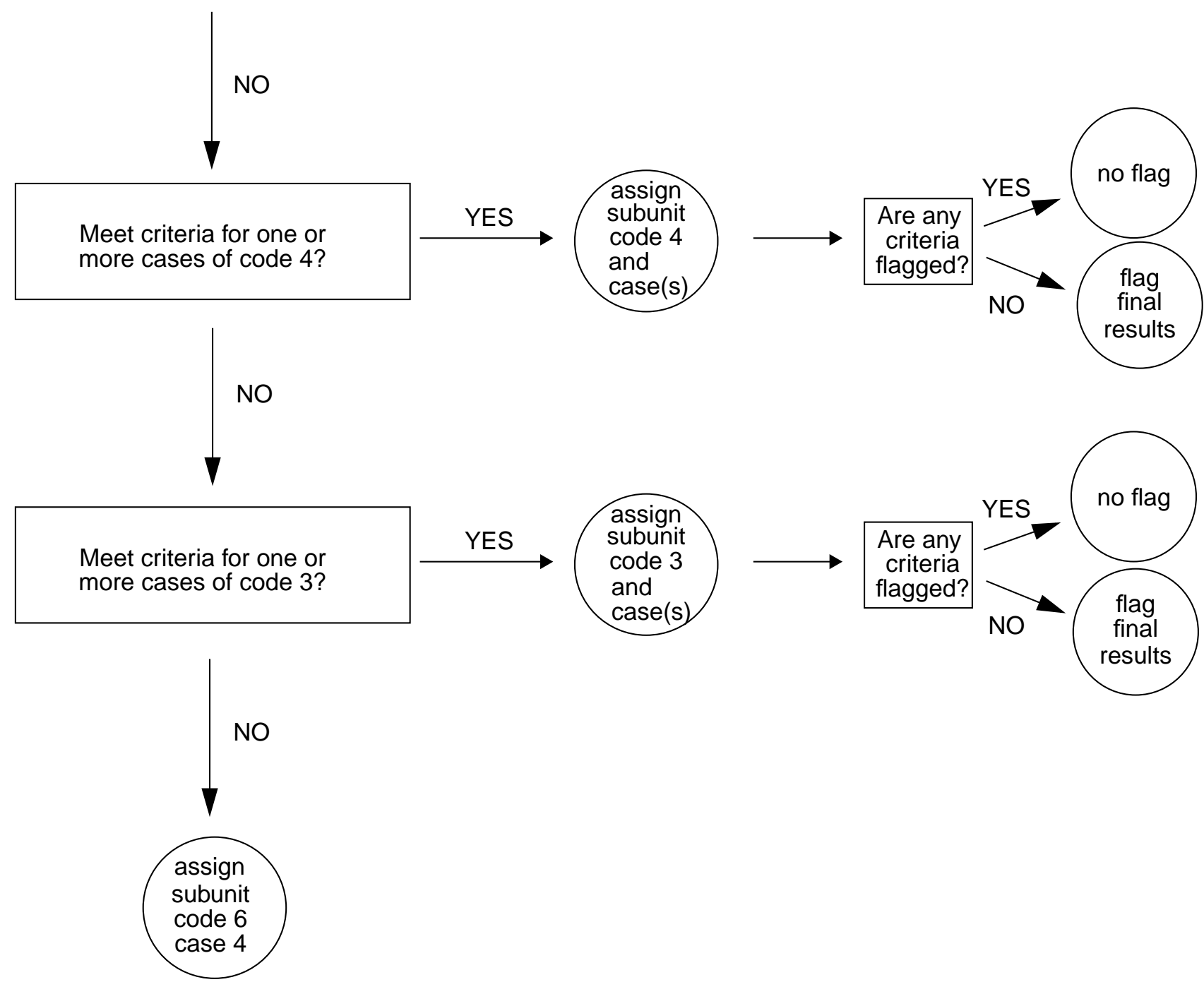

Figure 28. Determination of Scour-Critical Bridge Indicator Code for abutments at field-viewed bridge sites—Continued. 


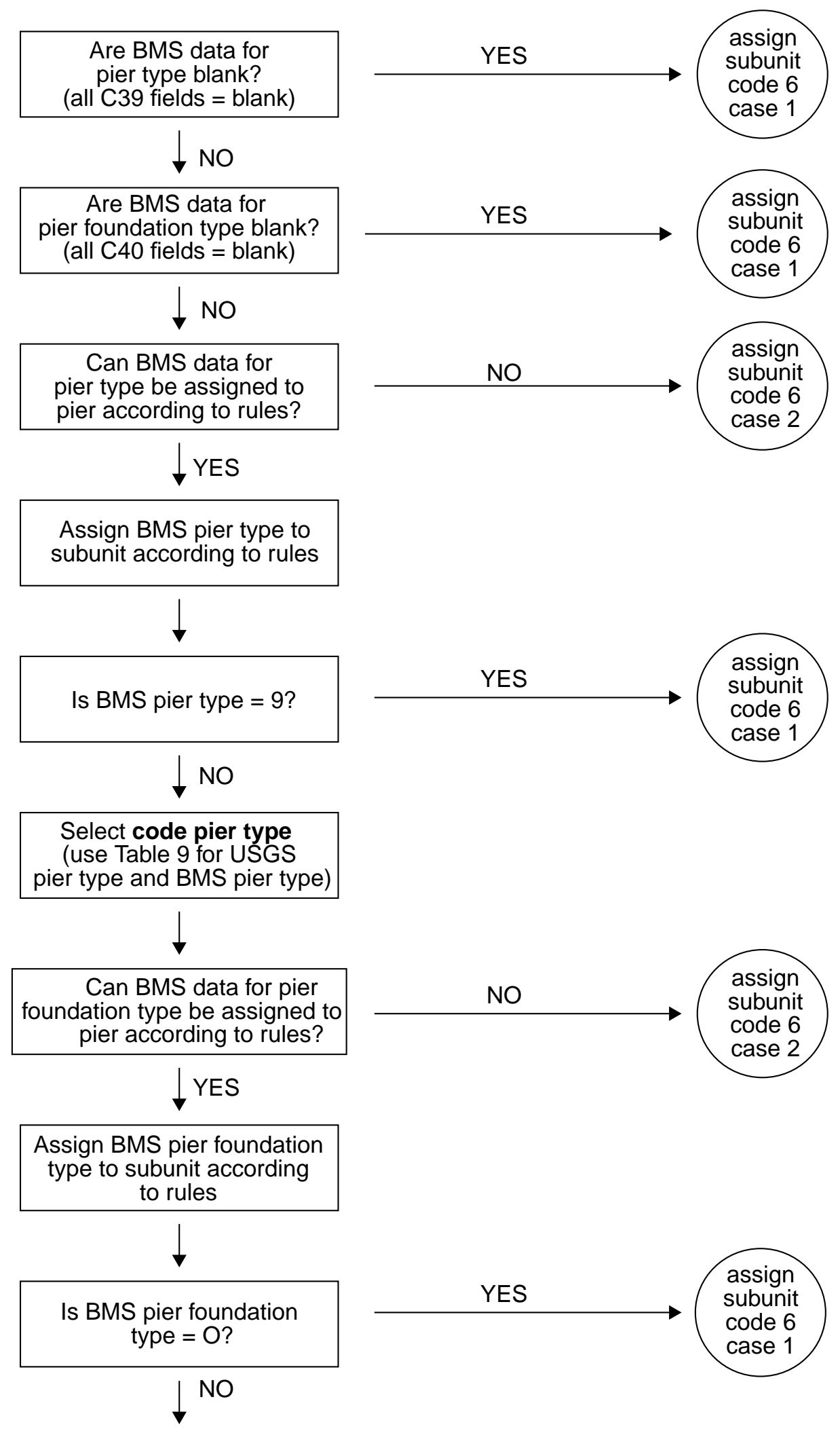

Figure 29. Determination of Scour-Critical Bridge Indicator Code for piers at field-viewed bridge sites. 


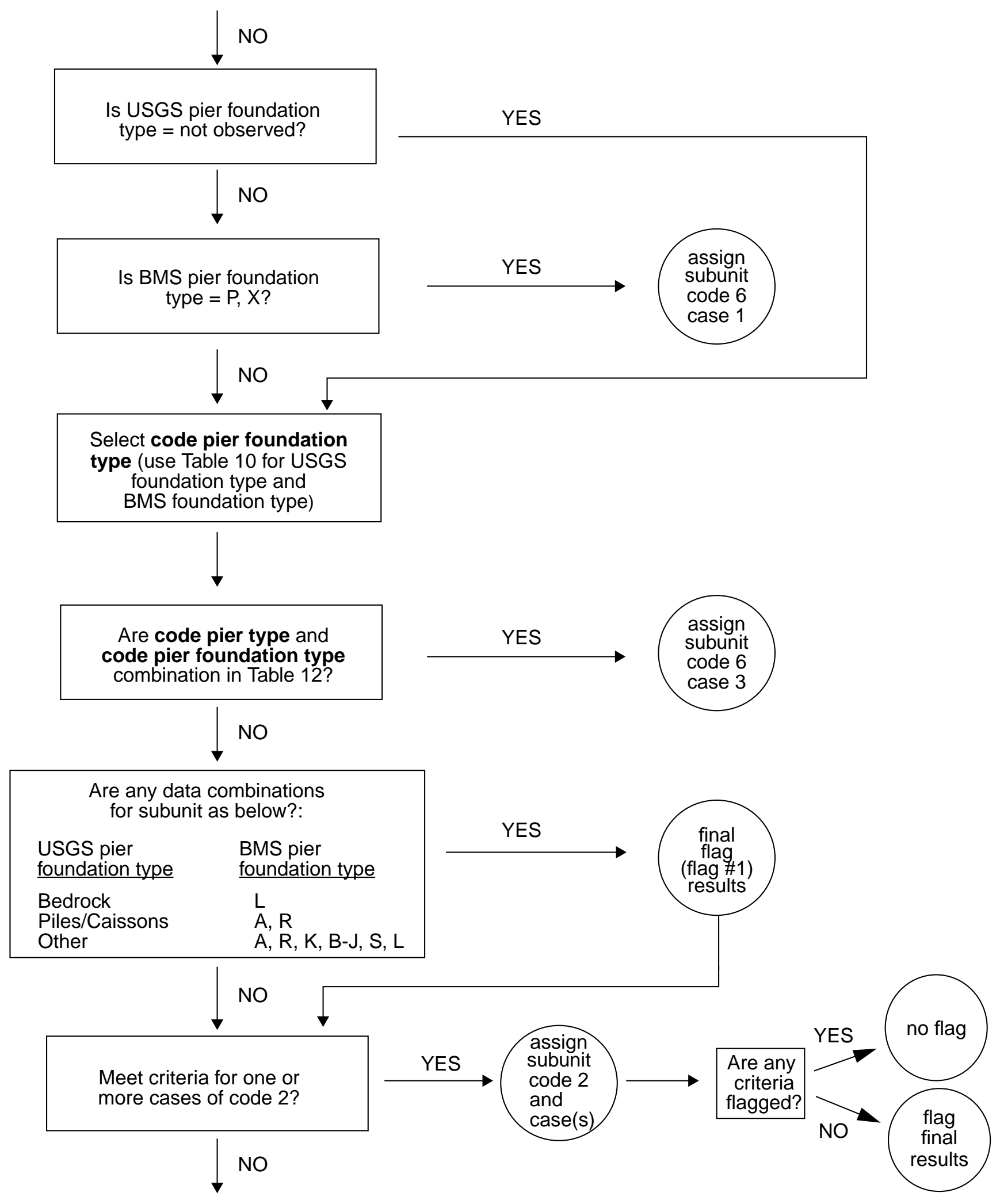

Figure 29. Determination of Scour-Critical Bridge Indicator Code for piers at field-viewed bridge sites-Continued. 


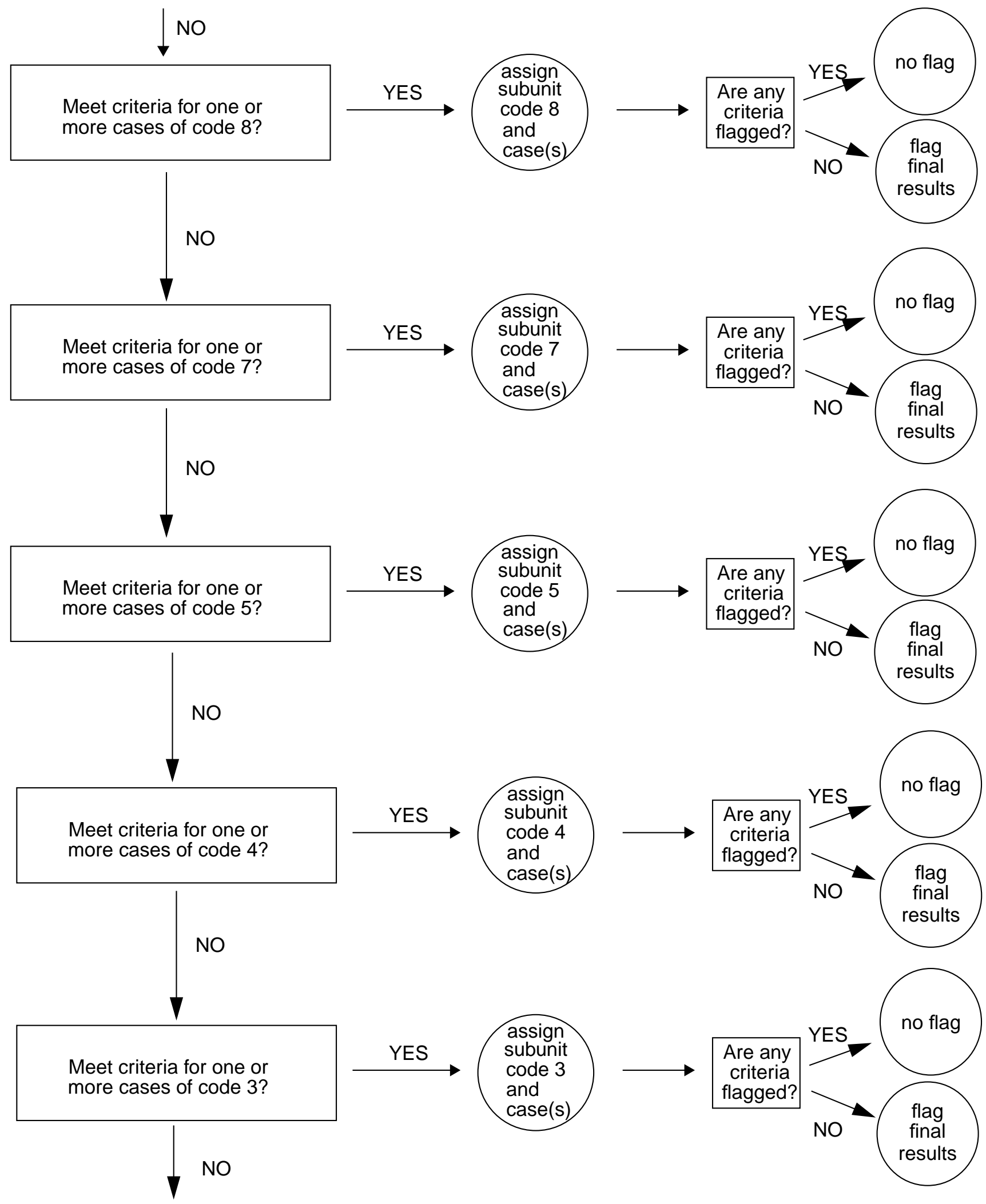

Figure 29. Determination of Scour-Critical Bridge Indicator Code for piers at field-viewed bridge sites—Continued. 


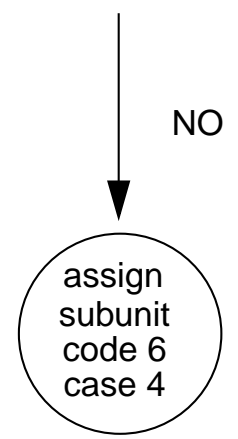

Figure 29. Determination of Scour-Critical Bridge Indicator Code for piers at field-viewed bridge sites -Continued. 
Table 8. Selection of abutment type used in the Scour-Critical Bridge Indicator Code for field-viewed bridge sites

[w/o, without; 6.1 indicates that no choice of abutment type is necessary, subunit is coded 6.1]

\begin{tabular}{|c|c|c|c|c|c|c|c|c|c|c|}
\hline$\frac{\text { USGS Type } \rightarrow}{\text { BMS Type } \downarrow}$ & 1 & 2 & 3 & 4 & 5 & 6 & 7 & 8 & 9 & 10 \\
\hline 1 & stub (1) & cantilever (2) & gravity concrete (3) & spill-through (4) & $\begin{array}{l}\text { unknown } \\
\text { concrete (5) }\end{array}$ & stone masonry (6) & piles/bents (7) & $\begin{array}{l}\text { concrete } \mathrm{w} / \mathrm{o} \\
\text { piles/bents (8) }\end{array}$ & $\begin{array}{c}\text { mechanically } \\
\text { stabilized } \\
\text { earth (9) }\end{array}$ & stub (1) \\
\hline 2 & stub (1) & cantilever (2) & gravity concrete (3) & spill-through (4) & $\begin{array}{l}\text { unknown } \\
\text { concrete (5) }\end{array}$ & $\begin{array}{c}\text { stone } \\
\text { masonry (6) }\end{array}$ & piles/bents (7) & $\begin{array}{l}\text { concrete } \mathrm{w} / \mathrm{o} \\
\text { piles/bents (8) }\end{array}$ & $\begin{array}{c}\text { mechanically } \\
\text { stabilized } \\
\text { earth (9) }\end{array}$ & cantilever (2) \\
\hline 3 & stub (1) & cantilever(2) & gravity concrete (3) & spill-through (4) & $\begin{array}{l}\text { unknown } \\
\text { concrete (5) }\end{array}$ & $\begin{array}{c}\text { stone } \\
\text { masonry (6) }\end{array}$ & piles/bents (7) & $\begin{array}{l}\text { concrete w/o } \\
\text { piles/bents (8) }\end{array}$ & $\begin{array}{c}\text { mechanically } \\
\text { stabilized } \\
\text { earth (9) }\end{array}$ & $\begin{array}{c}\text { gravity } \\
\text { concrete (3) }\end{array}$ \\
\hline 4 & stub (1) & cantilever(2) & gravity concrete (3) & spill-through (4) & $\begin{array}{l}\text { unknown } \\
\text { concrete (5) }\end{array}$ & $\begin{array}{c}\text { stone } \\
\text { masonry (6) }\end{array}$ & piles/bents (7) & $\begin{array}{l}\text { concrete } \mathrm{w} / \mathrm{o} \\
\text { piles/bents (8) }\end{array}$ & $\begin{array}{c}\text { mechanically } \\
\text { stabilized } \\
\text { earth (9) }\end{array}$ & stone masonry (6) \\
\hline 5 & stub (1) & cantilever(2) & gravity concrete (3) & spill-through (4) & $\begin{array}{l}\text { unknown } \\
\text { concrete (5) }\end{array}$ & $\begin{array}{c}\text { stone } \\
\text { masonry (6) }\end{array}$ & piles/bents (7) & $\begin{array}{l}\text { concrete } \mathrm{w} / \mathrm{o} \\
\text { piles/bents (8) }\end{array}$ & $\begin{array}{c}\text { mechanically } \\
\text { stabilized } \\
\text { earth (9) }\end{array}$ & $\begin{array}{c}\text { gravity } \\
\text { concrete (3) }\end{array}$ \\
\hline 6 & stub (1) & cantilever(2) & gravity concrete (3) & spill-through (4) & $\begin{array}{l}\text { unknown } \\
\text { concrete (5) }\end{array}$ & $\begin{array}{c}\text { stone } \\
\text { masonry (6) }\end{array}$ & piles/bents (7) & $\begin{array}{l}\text { concrete w/o } \\
\text { piles/bents (8) }\end{array}$ & $\begin{array}{c}\text { mechanically } \\
\text { stabilized } \\
\text { earth (9) }\end{array}$ & stub (1) \\
\hline 7 & stub (1) & cantilever(2) & gravity concrete (3) & spill-through (4) & $\begin{array}{l}\text { unknown } \\
\text { concrete (5) }\end{array}$ & $\begin{array}{c}\text { stone } \\
\text { masonry (6) }\end{array}$ & piles/bents (7) & $\begin{array}{l}\text { concrete } \mathrm{w} / \mathrm{o} \\
\text { piles/bents (8) }\end{array}$ & $\begin{array}{c}\text { mechanically } \\
\text { stabilized } \\
\text { earth (9) }\end{array}$ & $\begin{array}{c}\text { mechanically } \\
\text { stabilized } \\
\text { earth (9) }\end{array}$ \\
\hline 8 & stub (1) & cantilever(2) & gravity concrete (3) & spill-through (4) & $\begin{array}{l}\text { unknown } \\
\text { concrete (5) }\end{array}$ & $\begin{array}{c}\text { stone } \\
\text { masonry (6) }\end{array}$ & piles/bents (7) & $\begin{array}{l}\text { concrete w/o } \\
\text { piles/bents (8) }\end{array}$ & $\begin{array}{c}\text { mechanically } \\
\text { stabilized } \\
\text { earth (9) }\end{array}$ & spill-through (4) \\
\hline 9 & 6.1 & 6.1 & 6.1 & 6.1 & 6.1 & 6.1 & 6.1 & 6.1 & 6.1 & 6.1 \\
\hline A & stub (1) & cantilever(2) & gravity concrete (3) & spill-through (4) & $\begin{array}{l}\text { unknown } \\
\text { concrete (5) }\end{array}$ & $\begin{array}{c}\text { stone } \\
\text { masonry (6) }\end{array}$ & piles/bents (7) & $\begin{array}{l}\text { concrete w/o } \\
\text { piles/bents (8) }\end{array}$ & $\begin{array}{c}\text { mechanically } \\
\text { stabilized } \\
\text { earth (9) }\end{array}$ & $\begin{array}{l}\text { mechanically } \\
\text { stabilized } \\
\text { earth (9) }\end{array}$ \\
\hline B & stub (1) & cantilever(2) & gravity concrete (3) & spill-through (4) & $\begin{array}{l}\text { unknown } \\
\text { concrete (5) }\end{array}$ & $\begin{array}{c}\text { stone } \\
\text { masonry (6) }\end{array}$ & piles/bents (7) & $\begin{array}{l}\text { concrete } \mathrm{w} / \mathrm{o} \\
\text { piles/bents (8) }\end{array}$ & $\begin{array}{c}\text { mechanically } \\
\text { stabilized } \\
\text { earth (9) }\end{array}$ & $\begin{array}{c}\text { mechanically } \\
\text { stabilized } \\
\text { earth (9) }\end{array}$ \\
\hline $\mathrm{C}$ & stub (1) & cantilever(2) & gravity concrete (3) & spill-through (4) & $\begin{array}{l}\text { unknown } \\
\text { concrete (5) }\end{array}$ & $\begin{array}{c}\text { stone } \\
\text { masonry (6) }\end{array}$ & piles/bents (7) & $\begin{array}{l}\text { concrete } \mathrm{w} / \mathrm{o} \\
\text { piles/bents (8) }\end{array}$ & $\begin{array}{c}\text { mechanically } \\
\text { stabilized } \\
\text { earth (9) }\end{array}$ & $\begin{array}{l}\text { mechanically } \\
\text { stabilized } \\
\text { earth (9) }\end{array}$ \\
\hline
\end{tabular}


Table 8. Selection of abutment type used in the Scour-Critical Bridge Indicator Code for field-viewed bridge sites-Continued [w/o, without; 6.1 indicates that no choice of abutment type is necessary, subunit is coded 6.1]

\begin{tabular}{|c|c|c|c|c|c|c|c|c|c|c|}
\hline $\begin{array}{c}\text { USGS Type } \rightarrow \\
\text { BMS Type } \downarrow\end{array}$ & 1 & 2 & 3 & 4 & 5 & 6 & 7 & 8 & 9 & 10 \\
\hline $\mathrm{D}$ & stub (1) & cantilever(2) & gravity concrete (3) & spill-through (4) & $\begin{array}{l}\text { unknown } \\
\text { concrete (5) }\end{array}$ & stone masonry (6) & piles/bents (7) & $\begin{array}{l}\text { concrete } \mathrm{w} / \mathrm{o} \\
\text { piles/bents (8) }\end{array}$ & $\begin{array}{c}\text { mechanically } \\
\text { stabilized } \\
\text { earth (9) }\end{array}$ & other (10) \\
\hline E & stub (1) & cantilever(2) & gravity concrete (3) & spill-through (4) & $\begin{array}{l}\text { unknown } \\
\text { concrete (5) }\end{array}$ & stone masonry (6) & piles/bents (7) & $\begin{array}{l}\text { concrete } \mathrm{w} / \mathrm{o} \\
\text { piles / bents (8) }\end{array}$ & $\begin{array}{c}\text { mechanically } \\
\text { stabilized } \\
\text { earth (9) }\end{array}$ & piles/bents (7) \\
\hline $\mathrm{F}$ & stub (1) & cantilever(2) & gravity concrete (3) & spill-through (4) & $\begin{array}{l}\text { unknown } \\
\text { concrete (5) }\end{array}$ & stone masonry (6) & piles/bents (7) & $\begin{array}{l}\text { concrete } \mathrm{w} / \mathrm{o} \\
\text { piles / bents (8) }\end{array}$ & $\begin{array}{c}\text { mechanically } \\
\text { stabilized } \\
\text { earth (9) }\end{array}$ & other $(10)$ \\
\hline G & stub (1) & cantilever(2) & gravity concrete (3) & spill-through (4) & $\begin{array}{l}\text { unknown } \\
\text { concrete (5) }\end{array}$ & stone masonry (6) & piles/bents (7) & $\begin{array}{l}\text { concrete } \mathrm{w} / \mathrm{o} \\
\text { piles / bents (8) }\end{array}$ & $\begin{array}{c}\text { mechanically } \\
\text { stabilized } \\
\text { earth (9) }\end{array}$ & stone masonry (6) \\
\hline $\mathrm{H}$ & stub (1) & cantilever(2) & gravity concrete (3) & spill-through (4) & $\begin{array}{l}\text { unknown } \\
\text { concrete (5) }\end{array}$ & stone masonry (6) & piles/bents (7) & $\begin{array}{l}\text { concrete } \mathrm{w} / \mathrm{o} \\
\text { piles / bents ( } 8 \text { ) }\end{array}$ & $\begin{array}{c}\text { mechanically } \\
\text { stabilized } \\
\text { earth (9) }\end{array}$ & $\begin{array}{c}\text { mechanically } \\
\text { stabilized } \\
\text { earth (9) }\end{array}$ \\
\hline I & stub (1) & cantilever(2) & gravity concrete (3) & spill-through (4) & $\begin{array}{l}\text { unknown } \\
\text { concrete (5) }\end{array}$ & stone masonry (6) & piles/bents (7) & $\begin{array}{l}\text { concrete } \mathrm{w} / \mathrm{o} \\
\text { piles / bents ( } 8)\end{array}$ & $\begin{array}{c}\text { mechanically } \\
\text { stabilized } \\
\text { earth (9) }\end{array}$ & $\begin{array}{c}\text { mechanically } \\
\text { stabilized } \\
\text { earth (9) }\end{array}$ \\
\hline $\mathrm{J}$ & stub (1) & cantilever(2) & gravity concrete (3) & spill-through (4) & $\begin{array}{l}\text { unknown } \\
\text { concrete (5) }\end{array}$ & stone masonry (6) & piles/bents (7) & $\begin{array}{l}\text { concrete } \mathrm{w} / \mathrm{o} \\
\text { piles / bents (8) }\end{array}$ & $\begin{array}{c}\text { mechanically } \\
\text { stabilized } \\
\text { earth (9) }\end{array}$ & $\begin{array}{c}\text { mechanically } \\
\text { stabilized } \\
\text { earth (9) }\end{array}$ \\
\hline K & stub (1) & cantilever(2) & gravity concrete (3) & spill-through (4) & $\begin{array}{l}\text { unknown } \\
\text { concrete (5) }\end{array}$ & stone masonry (6) & piles/bents (7) & $\begin{array}{l}\text { concrete w/o } \\
\text { piles / bents ( } 8 \text { ) }\end{array}$ & $\begin{array}{c}\text { mechanically } \\
\text { stabilized } \\
\text { earth (9) }\end{array}$ & other (10) \\
\hline $\mathrm{L}$ & stub (1) & cantilever(2) & gravity concrete (3) & spill-through (4) & $\begin{array}{l}\text { unknown } \\
\text { concrete (5) }\end{array}$ & stone masonry (6) & piles/bents (7) & $\begin{array}{l}\text { concrete w/o } \\
\text { piles/bents (8) }\end{array}$ & $\begin{array}{c}\text { mechanically } \\
\text { stabilized } \\
\text { earth (9) }\end{array}$ & other (10) \\
\hline$X$ & stub (1) & cantilever(2) & gravity concrete (3) & spill-through (4) & $\begin{array}{l}\text { unknown } \\
\text { concrete (5) }\end{array}$ & stone masonry (6) & piles/bents (7) & $\begin{array}{l}\text { concrete } \mathrm{w} / \mathrm{o} \\
\text { piles/bents (8) }\end{array}$ & $\begin{array}{c}\text { mechanically } \\
\text { stabilized } \\
\text { earth (9) }\end{array}$ & $\begin{array}{l}\text { unknown } \\
\text { concrete (5) }\end{array}$ \\
\hline Y & stub (1) & cantilever(2) & gravity concrete (3) & spill-through (4) & $\begin{array}{l}\text { unknown } \\
\text { concrete (5) }\end{array}$ & stone masonry (6) & piles/bents (7) & $\begin{array}{l}\text { concrete } \mathrm{w} / \mathrm{o} \\
\text { piles / bents (8) }\end{array}$ & $\begin{array}{c}\text { mechanically } \\
\text { stabilized } \\
\text { earth (9) }\end{array}$ & spill-through (4) \\
\hline Z & stub (1) & cantilever(2) & gravity concrete (3) & spill-through (4) & $\begin{array}{l}\text { unknown } \\
\text { concrete (5) }\end{array}$ & stone masonry (6) & piles/bents (7) & $\begin{array}{l}\text { concrete } \mathrm{w} / \mathrm{o} \\
\text { piles/bents (8) }\end{array}$ & $\begin{array}{c}\text { mechanically } \\
\text { stabilized } \\
\text { earth (9) }\end{array}$ & $\begin{array}{c}\text { mechanically } \\
\text { stabilized } \\
\text { earth (9) }\end{array}$ \\
\hline blank & 6.1 & 6.1 & 6.1 & 6.1 & 6.1 & 6.1 & 6.1 & 6.1 & 6.1 & 6.1 \\
\hline
\end{tabular}


Table 9. Selection of pier type used in the Scour-Critical Bridge Indicator Code for field-viewed bridge sites

[6.1 indicates that no choice of pier type is necessary, subunit is coded 6.1]

\begin{tabular}{cccccc}
\cline { 1 - 4 } USGS Type $\rightarrow$ & \multirow{2}{*}{$\begin{array}{c}\text { 2 } \\
\text { BMS Type } \downarrow\end{array}$} & & 3 & 4 & 5 \\
\cline { 1 - 4 } 1 & timber (1) & steel (2) & concrete (3) & stone masonry (4) & timber (1) \\
2 & timber (1) & steel (2) & concrete (3) & stone masonry (4) & steel (2) \\
3 & timber (1) & steel (2) & concrete (3) & stone masonry (4) & concrete (3) \\
4 & timber (1) & steel (2) & concrete (3) & stone masonry (4) & concrete (3) \\
5 & timber (1) & steel (2) & concrete (3) & stone masonry (4) & concrete (3) \\
6 & timber (1) & steel (2) & concrete (3) & stone masonry (4) & stone masonry (4) \\
7 & timber (1) & steel (2) & concrete (3) & stone masonry (4) & concrete (3) \\
9 & timber (1) & steel (2) & concrete (3) & stone masonry (4) & other (5) \\
Blank & 6.1 & 6.1 & 6.1 & 6.1 & 6.1 \\
\hline
\end{tabular}

Table 10. Selection of abutment and pier foundation type used in the Scour-Critical Bridge Indicator Code for field-viewed bridge sites

[6.1 indicates that no choice of abutment and pier foundation type is necessary, subunit is coded 6.1]

\begin{tabular}{|c|c|c|c|c|c|}
\hline$\frac{\text { USGS Type } \rightarrow}{\text { BMS Type } \downarrow}$ & 1 & 2 & 3 & 4 & 5 \\
\hline $\bar{A}$ & bedrock (1) & bedrock (1) & piles/caissons (3) & bedrock (1) & bedrock (1) \\
\hline B-J & piles/caissons (3) & piles/caissons (3) & piles/caissons (3) & piles/caissons (3) & piles/caissons (3) \\
\hline K & alluvium (2) & alluvium (2) & piles/caissons (3) & alluvium (2) & alluvium (2) \\
\hline L & bedrock (1) & alluvium (2) & piles/caissons (3) & alluvium (2) & alluvium (2) \\
\hline O / blank & 6.1 & 6.1 & 6.1 & 6.1 & 6.1 \\
\hline $\mathrm{P}$ & 6.1 & 6.1 & 6.1 & 6.1 & not observed (5) \\
\hline $\mathrm{R}$ & bedrock (1) & bedrock (1) & piles/caissons (3) & bedrock (1) & bedrock (1) \\
\hline$S$ & piles/caissons (3) & piles/caissons (3) & piles/caissons (3) & piles/caissons (3) & piles/caissons (3) \\
\hline $\mathrm{X}$ & 6.1 & 6.1 & 6.1 & 6.1 & not observed (5) \\
\hline
\end{tabular}


Table 11. Incompatible combinations of abutment types and foundation types in the Scour-Critical Bridge Indicator Code for field-viewed bridge sites

[w/o, without]

\begin{tabular}{ll}
\hline \multicolumn{1}{c}{ Abutment Type } & \multicolumn{1}{c}{ Abutment Foundation Type } \\
\hline stub (1) & alluvium (2) \\
stub (1) & not observed (5) \\
piles/bents (7) & bedrock (1) \\
piles/bents (7) & alluvium (2) \\
piles/bents (7) & not observed (5) \\
concrete w/o piles/bents (8) & piles/caissons (3) \\
other (10) & bedrock (1) \\
other (10) & alluvium (2) \\
other (10) & piles/caissons (3) \\
other (10) & not observed (5) \\
\hline
\end{tabular}

Table 12. Incompatible combinations of pier types and foundation types in the Scour-Critical Bridge Indicator Code for field-viewed bridge sites

\begin{tabular}{ll}
\hline \multicolumn{1}{c}{ Pier type } & \multicolumn{1}{c}{ Pier foundation type } \\
\hline steel (2) & bedrock (1) \\
steel (2) & alluvium (2) \\
steel (2) & not observed (5) \\
other (5) & bedrock (1) \\
other (5) & alluvium (2) \\
other (5) & piles/caissons (3) \\
other (5) & not observed (5) \\
\hline
\end{tabular}


Table 13. Criteria for determination of Scour-Critical Bridge Indicator Code for field-viewed bridge sites

Use the following subunit type and foundation type selections in the criteria that follows:

$\begin{array}{ll}\quad \text { Abutment type: } & \text { Pier type: } \\ 1=\text { stub } & 1=\text { timber } \\ 2=\text { cantilever } & 2=\text { steel } \\ 3=\text { gravity concrete } & 3=\text { concrete } \\ 4=\text { spill-through } & 4=\text { stone } \\ 5=\text { unknown concrete } & 5=\text { other } \\ 6=\text { stone masonry } & \\ 7=\text { piles } / \text { bents } & \\ 8=\text { concrete without piles/bents } & \\ 9=\text { mechanically stabilized earth } & \\ 10=\text { other } & \end{array}$

$$
\begin{aligned}
& \quad \text { abutment and pier foundation type: } \\
& 1=\text { bedrock } \\
& 2=\text { alluvium } \\
& 3=\text { piles } / \text { caissons } \\
& 5=\text { not observed }
\end{aligned}
$$

All other site data are located on the form: "Bridge and Channel Characteristics at Field-Viewed Bridge Sites" (Appendix A).

\section{CODE 9}

\section{Only PennDOT District personnel assign Code 9 to bridges.}

\section{$\underline{\text { CASE } 1}$}

\section{Criteria}

Bridge over high gorge, all subunits are above the 500-year flood elevation.

\section{CASE 2}

\section{Criteria}

Bridge over roads or railroads where the channel is small and does not threaten the subunits. 
Table 13. Criteria for determination of Scour-Critical Bridge Indicator Code for field-viewed bridge sites —Contined

\section{CODE 8}

\section{Code 8 indicates bridges classified as culverts by PennDOT or subunits founded on} competent bedrock.

\section{CASE 1}

\section{Criteria}

1. BMS C05A (digits 4 and 5) $=30,31,32,33,34,35$

2. scour condition $=0,1,2,3$

3. movement $=0$

4. change since last inspection $=4,5,6,7,8,9$

Flag

1. scour condition $=3$

AND (OR)

2. change since last inspection $=4,5,6$

\section{CASE 2}

\section{Criteria}

1. abutment foundation type $=1$

2. abutment type $=1,2,3,4,5,6$

OR

1. pier foundation type $=1$

2. pier type $=1,3,4$

AND

3. scour condition $=0,1,2$

4. movement $=0$

5. change since last inspection $=4,5,6,7,8,9$

6. streambed material near the subunit $=$ A3, A4, A5, A6, R7, R8, R9, P7, P8

If 6 . not available, subunit coded based on criteria 1 - 5 above only.

Flag

1. change since last inspection $=4,5,6$ 
Table 13. Criteria for determination of Scour-Critical Bridge Indicator Code for field-viewed bridge sites-Continued

\section{CODE 8-Continued}

\section{CASE 3}

\section{Criteria}

1. abutment foundation type $=5$

2. abutment type $=2,3,4,5,6$

OR

1. pier foundation type $=5$

2. pier type $=1,3,4$

\section{AND}

3. scour condition $=0,1,2$

4. movement $=0$

5. change since last inspection $=4,5,6,7,8,9$

6. under-the-bridge primary bed material $=5$

Flag

1. change since last inspection $=4,5,6$

\section{CASE 4}

\section{Criteria}

1. abutment foundation type $=3$

2. abutment type $=1,2,3,4,5,6,7$

\section{OR}

1. pier foundation type $=3$

2. pier type $=1,2,3,4$

\section{AND}

3. scour condition $=0,1$

4. movement $=0$

5. change since last inspection $=7,8,9$

6A. streambed material near the subunit $=A 5, A 6$ If $6 \mathrm{~A}$. not available, use 6B.:

6B. under-the-bridge primary bed material $=4$ 
Table 13. Criteria for determination of Scour-Critical Bridge Indicator Code for field-viewed bridge sites—Continued

\section{CODE 7}

Code 7 indicates subunits that are adequately protected by countermeasures.

\section{CASE 1}

Criteria

1. condition of all under-the-bridge countermeasures at the subunit $=1$

2. scour condition $=0,1,2$

3. movement $=0$

4. change since last inspection $=4,5,6,7,8,9$

Flag

1. change since last inspection $=4,5,6$

\section{CASE 2}

\section{Criteria}

1. none of the listed possible countermeasures are recommended at the subunit OR under the bridge:

POSSIBLE COUNTERMEASURES

Footing underpinning

Abutment slopewall (repair/replace)

Streambed paving (repair/replace)

Rock protection

Scour hole (backfill)

Apron/cutoff wall (repair/replace)
LOCATION

[at subunit]

[at subunit]

UN

UN

$\mathrm{UN}$

Inlet/Outlet

2. scour condition $=0,1,2$

3. movement $=0$

4. change since last inspection $=4,5,6,7,8,9$

5A. streambed material near the subunit $=\mathrm{P} 7, \mathrm{P} 8$

If $5 \mathrm{~A}$. not available, use 5B.:

5B. under-the-bridge primary bed material $=6$

Flag

1. change since last inspection $=4,5,6$ 
Table 13. Criteria for determination of Scour-Critical Bridge Indicator Code for field-viewed bridge sites_Continued

\section{CODE 6}

CASE 1

\section{Criteria}

For subunits for which BMS data for subunit type or subunit foundation type is blank, not determined, or other.

CASE 2

\section{Criteria}

For piers for which BMS data for pier type and/or pier foundation type could not be identified to a specific pier.

\section{CASE 3}

\section{Criteria}

For subunits for which BMS data and USGS data for subunit type and subunit foundation type are incompatible.

\section{CASE 4}

Criteria

For subunits that do not meet any case criteria for assigning codes 2-5, 7-8, code 6 cases 1-3. 
Table 13. Criteria for determination of Scour-Critical Bridge Indicator Code for field-viewed bridge sites_Continued

\section{CODE 5}

Code 5 indicates subunits in contact with streambed material consisting predominantly of cobbles and boulders and showing little or no evidence of streambed instability.

\section{CASE 1}

Criteria

1. abutment foundation type $=2,5$

2. abutment type $=2,3,4,5$

OR

1. pier foundation type $=2,5$

2. pier type $=3$

\section{AND}

3. scour condition $=0,1$

4. movement $=0$

5. change since last inspection $=7,8,9$

6A. streambed material near the subunit $=A 5, A 6, R 7, R 8$

If $6 \mathrm{~A}$. not available, use 6B.:

6B. under-the-bridge primary bed material $=4,5$

\section{CASE 2}

Criteria

1. abutment foundation type $=1$

2. abutment type $=1,2,3,4,5$

OR

1. pier foundation type $=1$

2. pier type $=3$

\section{AND}

3. scour condition $=0,1$

4. movement $=0$

5. change since last inspection $=7,8,9$

6. streambed material near the subunit $=\mathrm{R} 4$

If 6. not available, criteria for this case can not be met 
Table 13. Criteria for determination of Scour-Critical Bridge Indicator Code for field-viewed bridge sites_Continued

\section{CODE 5-Continued}

\section{CASE 3}

\section{Criteria}

1. abutment foundation type $=3$

2. abutment type $=1,2,3,4,5,7$

OR

1. pier foundation type $=3$

2. pier type $=2,3$

\section{AND}

3. scour condition $=0,1,2$

4. movement $=0$

5. change since last inspection $=7,8,9$

6A. streambed material near the subunit $=\mathrm{A} 5, \mathrm{~A} 6$ If 6A. not available, use 6B.:

6B. under-the-bridge primary bed material $=4$ 
Table 13. Criteria for determination of Scour-Critical Bridge Indicator Code for field-viewed bridge sites_Continued

\section{CODE 4}

Code 4 indicates subunits in contact with streambed material consisting predominately of cobbles and boulders, and showing some evidence of streambed instability.

\section{CASE 1}

Criteria

1. abutment foundation type $=2,5$

2. abutment type $=2,3,4,5$

OR

1. pier foundation type $=2,5$

2. pier type $=3$

\section{AND}

3. scour condition $=0,1,2$

4. movement $=0$

5. change since last inspection $=4,5,6,7,8,9$

6A. streambed material near the subunit $=A 5, A 6, R 7, R 8$

If $6 \mathrm{~A}$. not available, use 6B.:

6B. under-the-bridge primary bed material $=4,5$

\section{CASE 2}

\section{Criteria}

1. abutment foundation type $=1$

2. abutment type $=1,2,3,4,5$

\section{OR}

1. pier foundation type $=1$

2. pier type $=3$

\section{AND}

3. scour condition $=0,1,2$

4. movement $=0$

5. change since last inspection $=4,5,6,7,8,9$

6. streambed material near the subunit $=\mathrm{R} 4$

If 6. not available, criteria for this case can not be met 
Table 13. Criteria for determination of Scour-Critical Bridge Indicator Code for field-viewed bridge sites-Continued

\section{CODE 4-Continued}

\section{CASE 3}

\section{Criteria}

1. abutment foundation type $=3$

2. abutment type $=1,2,3,4,5,7$

OR

1. pier foundation type $=3$

2. pier type $=2,3$

\section{AND}

3. scour condition $=0,1,2,3$

4. movement $=0$

5. change since last inspection $=4,5,6,7,8,9$

6A. streambed material near the subunit $=A 5, A 6$

If $6 \mathrm{~A}$. not available, use 6B.:

6B. under-the-bridge primary bed material $=4$

Flag

1. scour condition $=3$

\section{CASE 4}

\section{Criteria}

1. abutment foundation type $=3$

2. abutment type $=1,2,3,4,5,7$

\section{OR}

1. pier foundation type $=3$

2. pier type $=2,3$

\section{AND}

3. scour condition $=0,1,2,3$

4. movement $=0$

5. change since last inspection $=7,8,9$

6A. streambed material near the subunit $=\mathrm{A} 3, \mathrm{~A} 4$

If 6A. not available, use 6B.:

6B. under-the-bridge primary bed material $=1,2,3$

\section{CASE 5}

\section{Criteria}

1. abutment type $=9$

2. scour condition $=0$

3. movement $=0$ 
Table 13. Criteria for determination of Scour-Critical Bridge Indicator Code for field-viewed bridge sites_Continued

\section{CODE 4-Continued}

\section{CASE 6}

\section{Criteria}

1. abutment foundation type $=2,5$

2. abutment type $=6$

OR

1. pier foundation type $=2,5$

2. pier type $=1,4$

\section{AND}

3. scour condition $=0,1$

4. movement $=0$

5. change since last inspection $=7,8,9$

6A. streambed material near the subunit $=A 5, A 6, R 7, R 8$

If 6A. not available, use 6B.:

6B. under-the-bridge primary bed material $=4,5$

\section{CASE 7}

\section{Criteria}

1. abutment foundation type $=1$

2. abutment type $=6$

OR

1. pier foundation type $=1$

2. pier type $=1,4$

\section{AND}

3. scour condition $=0,1,2$

4. movement $=0$

5. change since last inspection $=7,8,9$

6. streambed material near the subunit $=R 4$

If 6 . not available, criteria for this case can not be met 
Table 13. Criteria for determination of Scour-Critical Bridge Indicator Code for field-viewed bridge sites—Continued

\section{CODE 4-Continued}

\section{CASE 8}

\section{Criteria}

1. abutment foundation type $=3$

2. abutment type $=6$

OR

1. pier foundation type $=3$

2. pier type $=1,4$

\section{AND}

3. scour condition $=0,1,2$

4. movement $=0$

5. change since last inspection $=4,5,6,7,8,9$

6. streambed material near the subunit $=\mathrm{A} 5, \mathrm{~A} 6$

If 6A. not available, use 6B.:

6B. under-the-bridge primary bed material $=4$

\section{CASE 9}

\section{Criteria}

1. abutment foundation type $=3$

2. abutment type $=6$

OR

1. pier foundation type $=3$

2. pier type $=1,4$

\section{AND}

3. scour condition $=0,1,2$

4. movement $=0$

5. change since last inspection $=7,8,9$

6. streambed material near the subunit $=\mathrm{A} 3, \mathrm{~A} 4$

If $6 \mathrm{~A}$. not available, use 6B.:

6B. under-the-bridge primary bed material $=1,2,3$ 
Table 13. Criteria for determination of Scour-Critical Bridge Indicator Code for field-viewed bridge sites—Continued

\section{CODE 3}

Code 3 indicates subunits in contact with streambed material consisting predominantly of erodible, fine material.

\section{CASE 1}

\section{Criteria}

1. abutment foundation type $=2,5$

2. abutment type $=2,3,4,5$

OR

1. pier foundation type $=2,5$

2. pier type $=3$

\section{AND}

3. scour condition $=0,1,2$

4. movement $=0$

5. change since last inspection $=4,5,6,7,8,9$

6A. streambed material near the subunit $=\mathrm{A} 3, \mathrm{~A} 4, \mathrm{R} 4$

If $6 \mathrm{~A}$. not available, use 6B.:

6B. under-the-bridge primary bed material $=1,2,3$

\section{CASE 2}

Criteria

1. abutment foundation type $=3$

2. abutment type $=1,2,3,4,5,7$

OR

1. pier foundation type $=3$

2. pier type $=2,3$

AND

3. scour condition $=0,1,2,3$

4. movement $=0$

5. change since last inspection $=4,5,6,7,8,9$

6A. streambed material near the subunit $=\mathrm{A} 3, \mathrm{~A} 4$

If $6 \mathrm{~A}$. not available, use 6B.:

6B. under-the-bridge primary bed material $=1,2,3$ 
Table 13. Criteria for determination of Scour-Critical Bridge Indicator Code for field-viewed bridge sites-Continued

\section{CODE 3-Continued}

CASE 3

\section{Criteria}

1. abutment type $=9$

2. scour condition $=1$

3. movement $=0$

4. change since last inspection $=4,5,6,7,8,9$

\section{CASE 4}

\section{Criteria}

1. abutment foundation type $=2,5$

2. abutment type $=6$

\section{OR}

1. pier foundation type $=2,5$

2. pier type $=1,4$

\section{AND}

3. scour condition $=0,1,2$

4. movement $=0$

5. change since last inspection $=4,5,6,7,8,9$

6A. streambed material near the subunit $=\mathrm{A} 3, \mathrm{~A} 4, \mathrm{~A} 5, \mathrm{~A} 6, \mathrm{R} 4$

$$
\text { If } 6 \mathrm{~A} \text {. not available, use 6B.: }
$$

6B. under-the-bridge primary bed material $=1,2,3,4$

\section{CASE 5}

\section{Criteria}

1. abutment foundation type $=1$

2. abutment type $=6$

\section{OR}

1. pier foundation type $=1$

2. pier type $=1,4$

\section{AND}

3. scour condition $=0,1,2$

4. movement $=0$

5. change since last inspection $=4,5,6,7,8,9$

6. streambed material near the subunit $=\mathrm{R} 4$

If 6. not available, criteria for case can not be met 
Table 13. Criteria for determination of Scour-Critical Bridge Indicator Code for field-viewed bridge sites_Continued

\section{CODE 3-Continued}

CASE 6

\section{Criteria}

1. abutment foundation type $=1$

2. abutment type $=1,2,3,4,5$

OR

1. pier foundation type $=1$

2. pier type $=3$

AND

3. scour condition $=3$

4. movement $=0$

5. change since last inspection $=4,5,6,7,8,9$

Flag

For all criteria

\section{CASE 7}

\section{Criteria}

1. abutment foundation type $=3$

2. abutment type $=6$

OR

1. pier foundation type $=3$

2. pier type $=1,4$

\section{AND}

3. scour condition $=0,1,2$

4. movement $=0$

5. change since last inspection $=4,5,6,7,8,9$

6A. streambed material near the subunit $=A 3, A 4$

If $6 \mathrm{~A}$. not available, use 6B.:

6B. under-the-bridge primary bed material $=1,2,3$ 
Table 13. Criteria for determination of Scour-Critical Bridge Indicator Code for field-viewed bridge sites—Continued

\section{CODE 2}

Code 2 indicates subunits having critical site conditions related to scour, such as; movement of the subunit, significant change since last inspection, or scour condition for foundation that potentially threatens bridge structure.

\section{CASE 1}

Criteria
1. abutment type $=9$
2. scour condition $=2,3$

\section{CASE 2}

\section{Criteria}

1. movement $=1$

\section{CASE 3}

\section{Criteria}

1. abutment foundation type $=2,5$

2. abutment type $=2,3,4,5$

$$
\text { OR }
$$

1. pier foundation type $=2,5$

2. pier type $=3$

\section{AND}

3. scour condition $=3$

$\underline{\text { CASE } 4}$

Criteria

1. abutment type $=6$

OR

1. pier type $=1,4$

$$
\text { AND }
$$

2. scour condition $=3$

\section{CASE 5}

\section{Criteria}

1. abutment type $=8$

\section{CASE 6}

\section{Criteria}

1. change since last inspection $=3$

Flag

For all criteria 


\section{APPENDIX G}

Procedure for determination OF THE SCOUR-Critical BRIDGE INDICATOR CODE FOR OFFICE-REVIEWED BRIDGE SITES 


\section{PROCEDURE FOR DETERMINATION OF THE SCOUR-CRITICAL BRIDGE INDICATOR CODE FOR OFFICE-REVIEWED BRIDGE SITES}

The Scour-Critical Bridge Indicator Code (Code) for office-reviewed bridge sites serves the same purpose as that for field-viewed bridge sites. The Code is computed using the following flowcharts (figs. 30 and 31) and tables 14 through 17. The Code ranges from code 9 to code 2 and represents the site conditions based on existing PennDOT data compiled from PennDot data sources. As per the datacollection methods for office-reviewed bridge sites, only subunits that meet criteria for scour assessments are coded; for example, expansive bridges that carry elevated roadways will be coded only for those subunits that are in contact with streamflow.

Existing PennDOT data as compiled by the USGS during the office-review is used for the determination of the Code for office-reviewed bridge sites. This data is date specific for the date PennDOT personnel collected the data. Any discrepancies existing between various PennDOT data sources are resolved with the assistance of PennDOT district personnel during the office-review. The entire bridge structure is assigned a code based on the code received by the most scour vulnerable (worst) subunit.

A subunit can only be coded if PennDOT data are available for the following data fields:

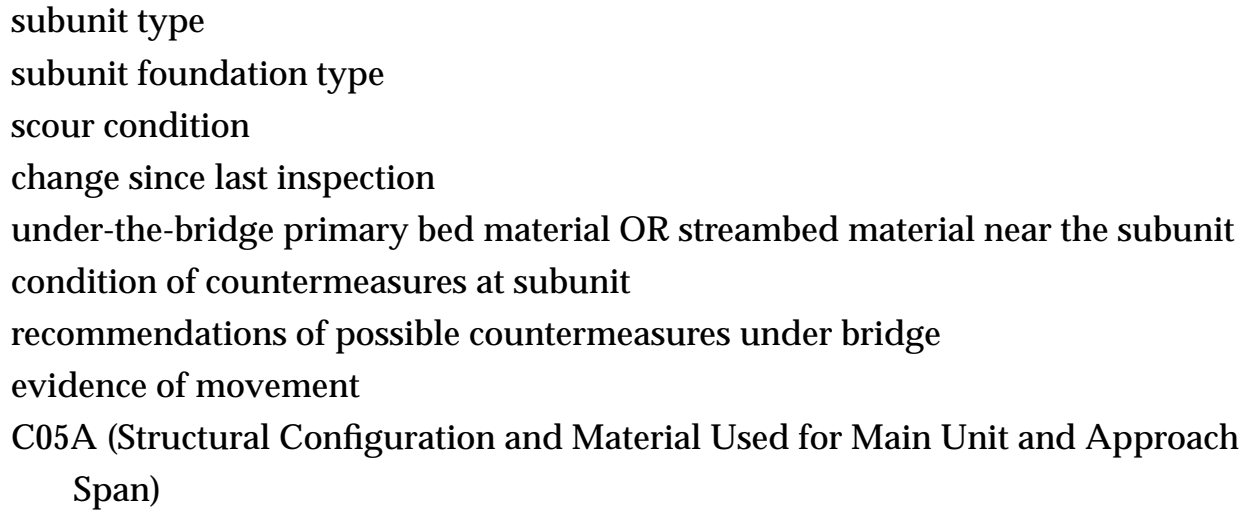

The abutment type, pier type, and foundation types used to compute the Code are determined through the use of a flowchart and tables 14 through 17. Subunit types and foundation types described as "other" within the tables receive a code of 6 . Subunits that do not meet the criteria for codes 2 through 5 or 7 through 9 are also assigned a code of 6 . A code of 6 indicates that further evaluation of site conditions by PennDOT personnel is required. Unusual site conditions are defined and assigned a flag. A flag indicates that a special condition exists at this bridge site that requires further PennDOT review. 
An individual subunit may meet the criteria for more than one code, however it receives the code that is closest to the top of the ordered list below. If a subunit meets the criteria for one or two cases within a specific code, both cases for that code will be indicated to the user.

Code 6, case 1

Code 2

Code 8

Code 7

Code 5

Code 4

Code 3

Code 6 , case 4

Because individual subunits are only components of the overall bridge structure, the bridge structure receives the code assigned to the subunit rated closest to the top of the ordered list below. For example, if the three subunits for a bridge are rated 2, 6 case 1, and 5, the overall bridge structure receives a code of 6 .

Code 6

Code 2

Code 3

Code 4

Code 5

Code 7

Code 8 
Based on existing PennDOT data, assign abutment type from table 14.

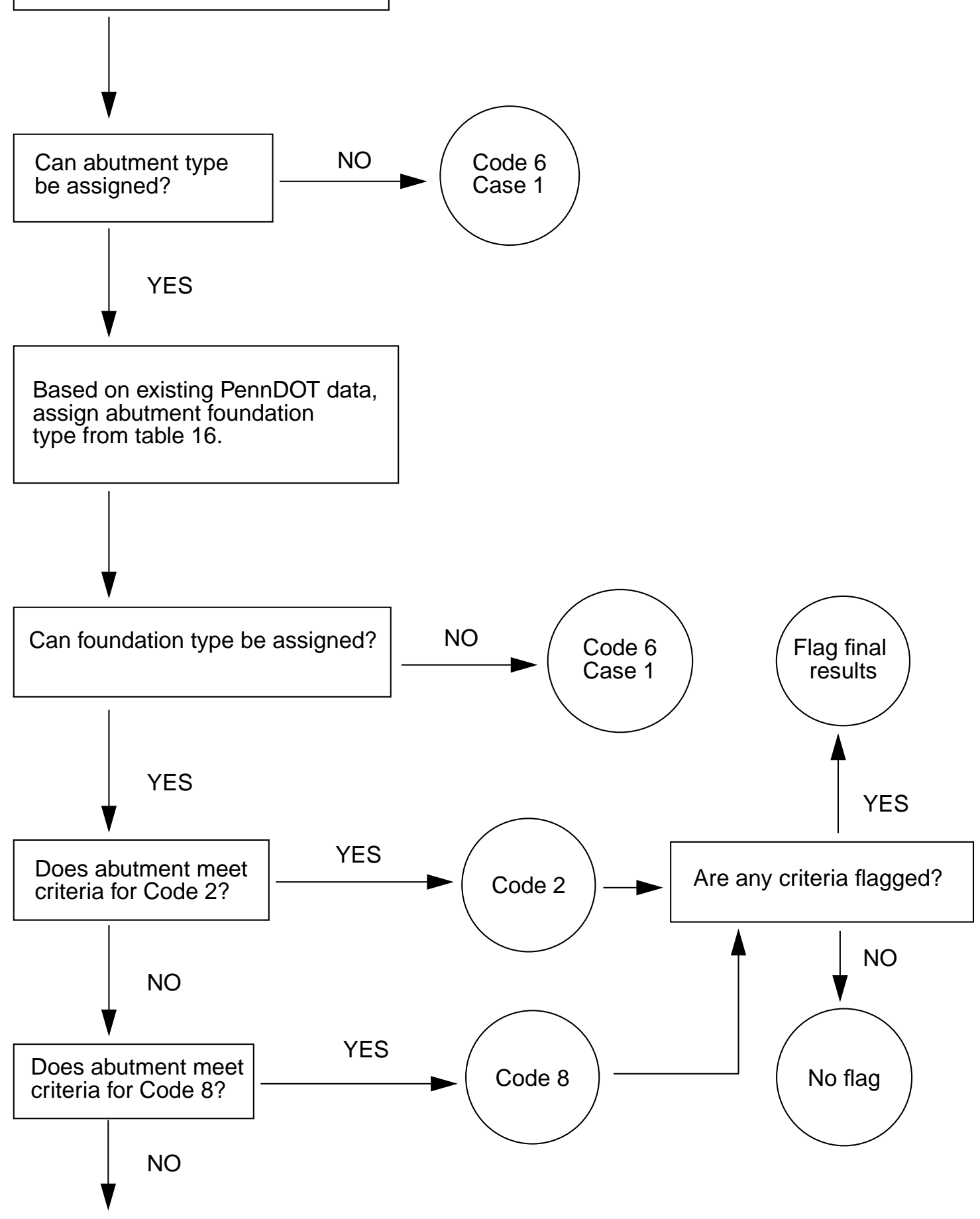

Figure 30. Determination of Scour-Critical Bridge Indicator Code for abutments at office-reviewed bridge sites. 


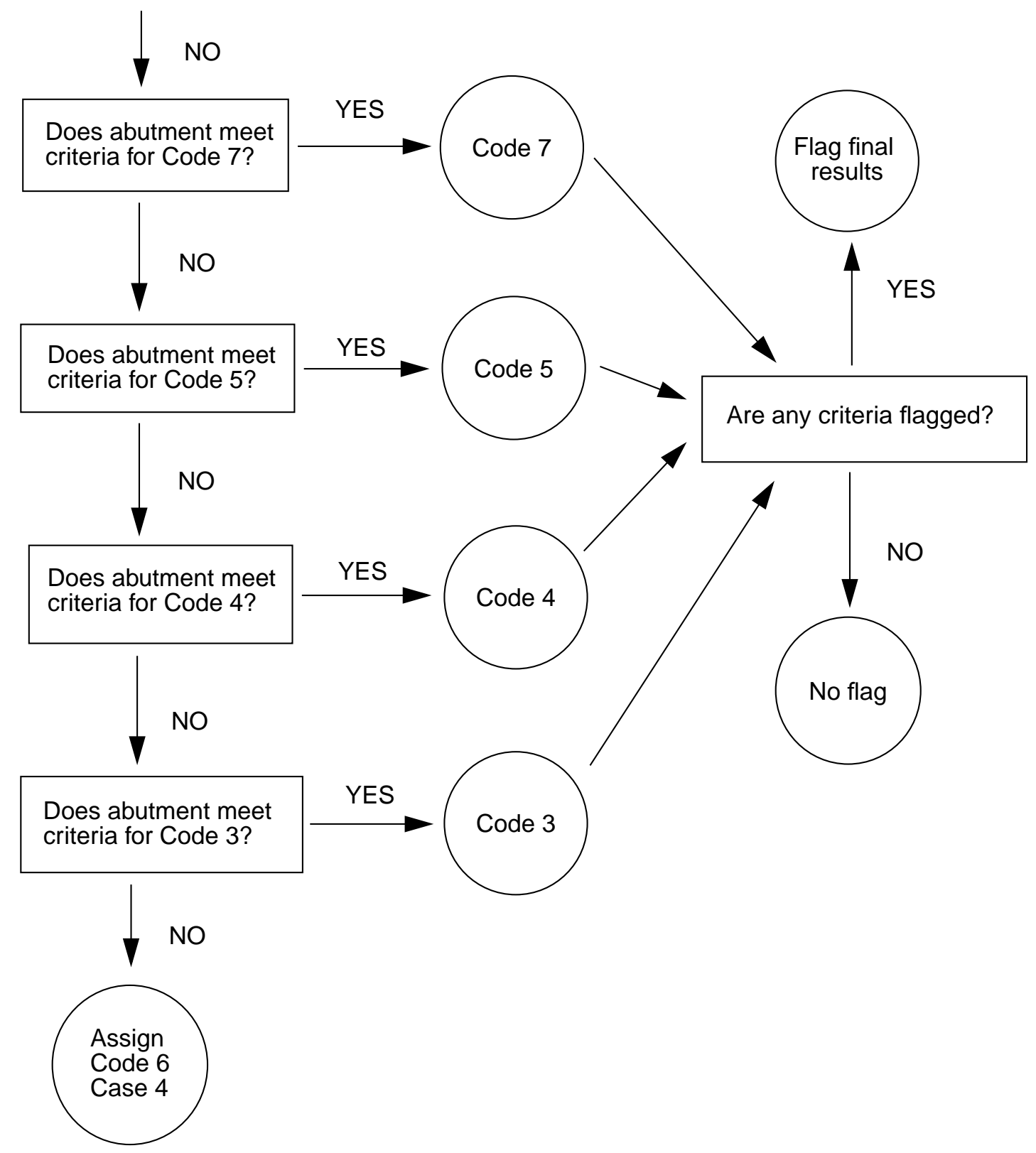

Figure 30. Determination of Scour-Critical Bridge Indicator Code for abutments at office-reviewed bridge sites-Continued. 


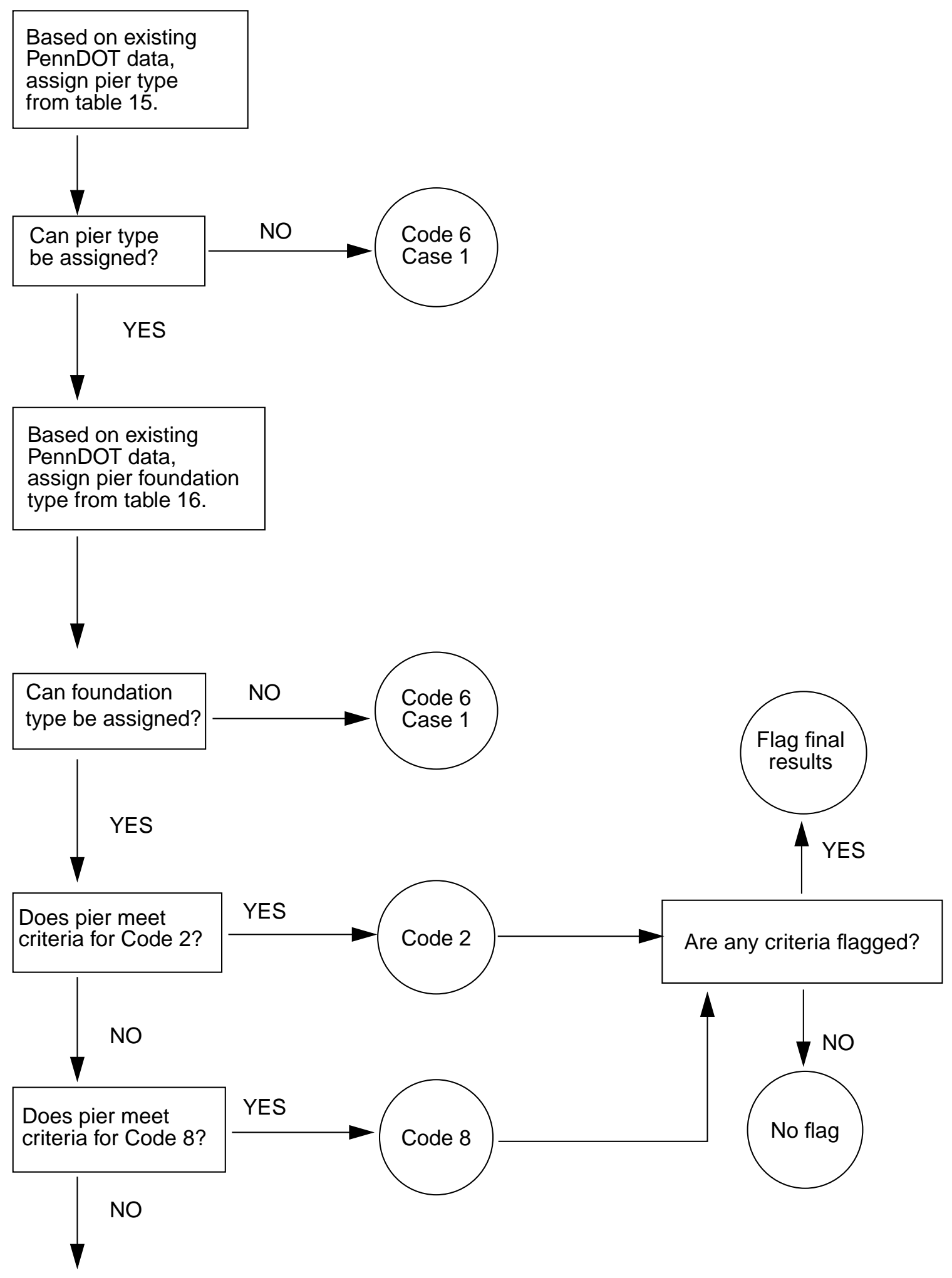

Figure 31. Determination of Scour-Critical Bridge Indicator Code for piers at office-reviewed bridge sites. 


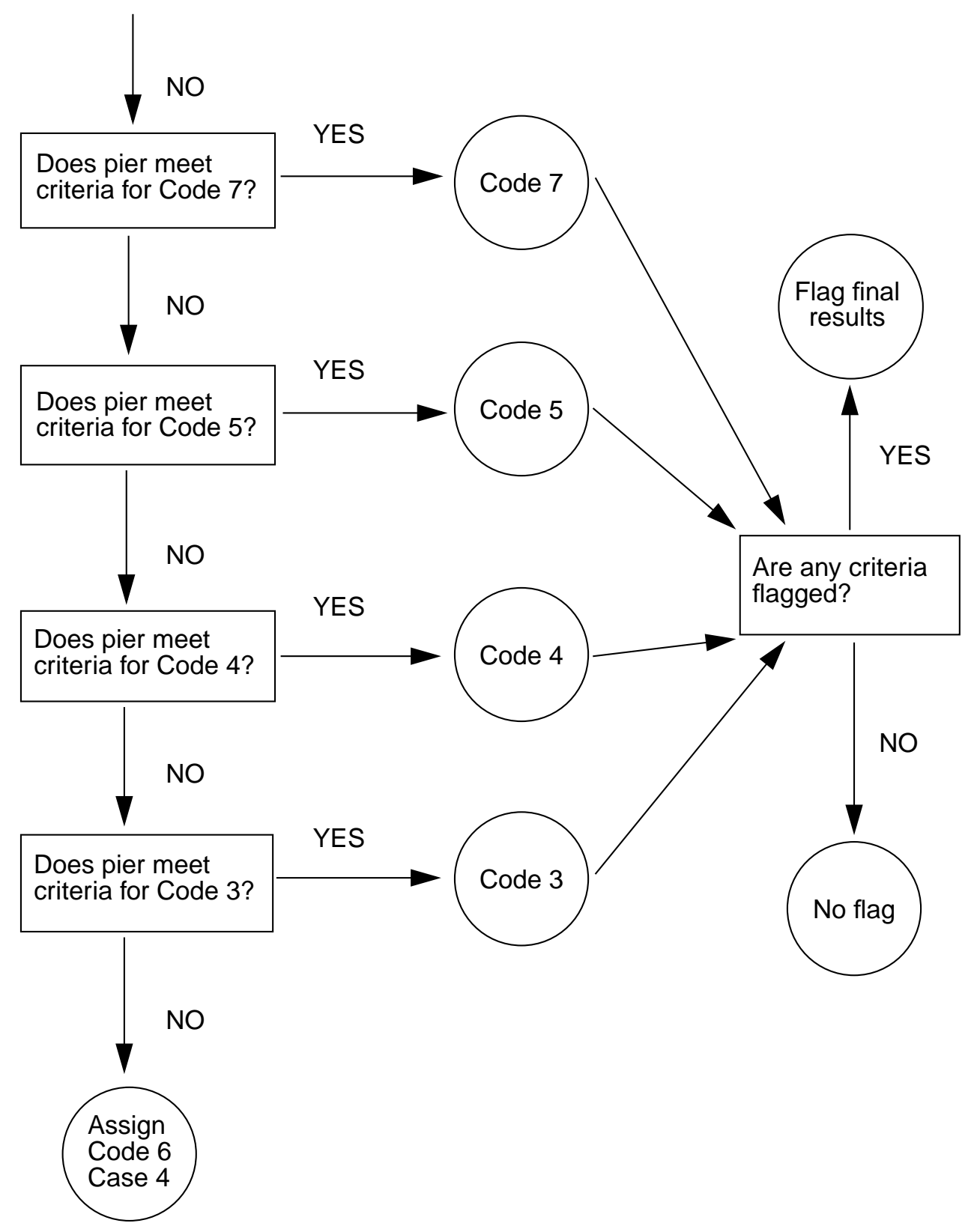

Figure 31. Determination of Scour-Critical Bridge Indicator Code for piers at office-reviewed bridge sites-Continued. 
Table 14. Selection of abutment type used in the Scour-Critical Bridge Indicator Code for office-reviewed bridge sites

\begin{tabular}{|c|c|}
\hline $\begin{array}{l}\text { Existing PennDOT data choice } \\
(()=\text { BMS abutment type }\end{array}$ & $\begin{array}{l}\text { Abutment type assigned for Code } \\
\text { [ ] = USGS abutment type }\end{array}$ \\
\hline Stub (1) & Stub abutment [1] \\
\hline Cantilever (2) & Cantilever abutment [2] \\
\hline Gravity concrete (3) & Gravity concrete abutment [3] \\
\hline Gravity stone-masonry (4) & Stone-masonry abutment [6] \\
\hline Counterfort (5) & Gravity concrete abutment [3] \\
\hline Integral (6) & Stub abutment [1] \\
\hline Cellular (7) & Mechanically stabilized abutment [9] \\
\hline Spill-through abutment(8) & Spill-through abutment [4] \\
\hline Other (9) & $\begin{array}{l}\text { Bridge cannot be coded, must be resolved with } \\
\text { PennDOT district personnel }\end{array}$ \\
\hline Reinforced concrete pad on MSE (A) & Mechanically stabilized abutment [9] \\
\hline Pile supported reinforced concrete pad on MSE (B) & Mechanically stabilized abutment [9] \\
\hline Precast modular earth-filled wall (C) & Mechanically stabilized abutment [9] \\
\hline Other proprietary (D) & $\begin{array}{l}\text { Bridge cannot be coded, must be resolved with } \\
\text { PennDOT district personnel }\end{array}$ \\
\hline Pile bent (E) & Piles/bents abutment [7] \\
\hline Reserved (F) & $\begin{array}{l}\text { Bridge cannot be coded, must be resolved with } \\
\text { PennDOT district personnel }\end{array}$ \\
\hline Gabion $(\mathrm{G})$ & Stone-masonry abutment [6] \\
\hline VSL retained earth $(\mathrm{H})$ & Mechanically stabilized abutment [9] \\
\hline Reinforced earth (I) & Mechanically stabilized abutment [9] \\
\hline Doublewall (J) & Mechanically stabilized abutment [9] \\
\hline Flexible anchored wall (K) & $\begin{array}{l}\text { Bridge cannot be coded, must be resolved with } \\
\text { PennDOT district personnel }\end{array}$ \\
\hline Flexible non-anchored wall (L) & $\begin{array}{l}\text { Bridge cannot be coded, must be resolved with } \\
\text { PennDOT district personnel }\end{array}$ \\
\hline Concrete unknown, cannot determine type $(X)$ & Unknown concrete abutment [5] \\
\hline Concrete spill-through sloping front face to channel flood flows $(\mathrm{Y})$ & Spill-through abutment [4] \\
\hline Mechanically stabilized panels (Z) & Mechanically stabilized abutment [9] \\
\hline blank & $\begin{array}{l}\text { Bridge cannot be coded, must be resolved with } \\
\text { PennDOT district personnel }\end{array}$ \\
\hline
\end{tabular}

Table 15. Selection of pier type used in the Scour-Critical Bridge Indicator Code for office-reviewed bridge sites

\begin{tabular}{ll}
\multicolumn{1}{c}{$\begin{array}{c}\text { Existing PennDOT data choice } \\
(~)=\text { BMS pier type }\end{array}$} & \multicolumn{1}{c}{$\begin{array}{c}\text { Pier type assigned for Code } \\
{[\text { ] = USGS pier type }}\end{array}$} \\
\hline Timber (1) & Timber pier [1] \\
Steel (2) & Steel pier [2] \\
Reinforced concrete (3) & Concrete pier [3] \\
Plain concrete (4) & Concrete pier [3] \\
Prestressed concrete (5) & Concrete pier [3] \\
Encased structural steel (7) & Concrete pier [3] \\
Concrete unknown(8) & Concrete pier [3] \\
Stone-masonry (6) & Stone-masonry pier [4] \\
Other (9) & Bridge cannot be coded, must be resolved with \\
& PennDOT district personnel \\
blank & Bridge cannot be coded, must be resolved with \\
& PennDOT district personnel \\
\hline
\end{tabular}


Table 16. Selection of abutment and pier foundation type used in the Scour-Critical Bridge Indicator Code for officereviewed bridge sites.

\begin{tabular}{|c|c|}
\hline $\begin{array}{l}\text { Existing PennDOT data choice } \\
\qquad()=\text { BMS foundation type }\end{array}$ & $\begin{array}{l}\text { Foundation type assigned for Code } \\
{[\text { [ ] = USGS foundation type }}\end{array}$ \\
\hline Spread footing on competent bedrock (A) & on bedrock [1] \\
\hline Footing is on bedrock - erodibility cannot be determined (R) & on bedrock [1] \\
\hline $\begin{array}{l}\text { Spread footings or culverts with an integral bottom on erodible } \\
\text { bedrock (such as claystone, clay shales, some silt stone, } \\
\text { shales, and weathered bedrock) (K) }\end{array}$ & on alluvium [2] \\
\hline Cast-in-place concrete piles (B) & on piles/caissons [3] \\
\hline Precast concrete piles $(\mathrm{C})$ & on piles/caissons [3] \\
\hline Prestressed concrete piles (D) & on piles/caissons [3] \\
\hline Steel H-piles (E) & on piles/caissons [3] \\
\hline Steel pipe piles (F) & on piles/caissons [3] \\
\hline Timber piles $(\mathrm{G})$ & on piles/caissons [3] \\
\hline Drilled caisson $(\mathrm{H})$ & on piles/caissons [3] \\
\hline Deep water caisson (I) & on piles/caissons [3] \\
\hline Pedestals $(\mathrm{J})$ & on piles/caissons [3] \\
\hline $\begin{array}{l}\text { Spread footings or culverts with an integral bottom on soils } \\
\text { (sand-gravel, cobbles, silt, and clay) (L) }\end{array}$ & on alluvium [2] \\
\hline Other $(\mathrm{O})$ & $\begin{array}{l}\text { Bridge cannot be coded, must be resolved with } \\
\text { PennDOT district personnel }\end{array}$ \\
\hline $\begin{array}{l}\text { Foundation type has been researched; Information is unknown } \\
\text { or not available with confidence }(P)\end{array}$ & $\begin{array}{l}\text { Bridge cannot be coded, must be resolved with } \\
\text { PennDOT district personnel }\end{array}$ \\
\hline Pile or caissons, If determined by probing (S) & on piles/caissons [3] \\
\hline Information is not available at this time $(X)$ & $\begin{array}{l}\text { Bridge cannot be coded, must be resolved with } \\
\text { PennDOT district personnel }\end{array}$ \\
\hline
\end{tabular}

Table 17. Criteria for determination of Scour-Critical Bridge Indicator Code for office-reviewed bridge sites

Use the following subunit type and foundation type selections in the criteria that follows:

$\begin{array}{llrl}\quad \text { abutment type: } & & \text { pier type: } \\ 1 & =\text { stub } & & 1=\text { timber } \\ 2 & =\text { cantilever } & 2=\text { steel } \\ 3 & =\text { gravity concrete } & 3=\text { concrete } \\ 4 & =\text { spill-through } & & 4=\text { stone } \\ 5 & =\text { unknown concrete } & & \\ 6 & =\text { stone masonry } & \\ 7 & =\text { piles/bents } & \\ 9 & =\text { mechanically stabilized earth } & \end{array}$

abutment and pier foundation type:

$1=$ bedrock

$2=$ alluvium

$3=$ piles $/$ caissons

All other site data are located on the form: "Bridge and Channel Characteristics at Office-Reviewed Bridge Sites." 
Table 17. Criteria for determination of Scour-Critical Bridge Indicator Code for office-reviewed bridge sitesContinued

\section{CODE 9}

\section{Only PennDOT District personnel assign Code 9 to bridges.}

\section{CASE 1}

\section{Criteria}

Bridge over high gorge, all subunits are above the 500-year flood elevation.

\section{CASE 2}

\section{Criteria}

Bridge over roads or railroads where the channel is small and does not threaten the subunits.

\section{CODE 8}

Code 8 indicates bridges classified as culverts by PennDOT or subunits founded on competent bedrock.

\section{CASE 1}

Criteria

1. BMS C05A (digits 4 and 5) $=30,31,32,33,34,35$

2. scour condition $=0,1,2,3$

3. movement $=0$

4. change since last inspection $=4,5,6,7,8,9$

Flag

1. scour condition $=3$

AND (OR)

1. change since last inspection $=4,5,6$

\section{CASE 2}

Criteria

1. abutment foundation type $=1$

2. abutment type $=1,2,3,4,5,6$

OR

1. pier foundation type $=1$

2. pier type $=1,3,4$

AND

3. scour condition $=0,1,2$

4. movement $=0$

5. change since last inspection $=4,5,6,7,8,9$

6. streambed material near the subunit $=\mathrm{A} 3, \mathrm{~A} 4, \mathrm{~A} 5, \mathrm{~A} 6, \mathrm{R} 7, \mathrm{R} 8, \mathrm{R} 9, \mathrm{P} 7, \mathrm{P} 8$

If 6. not available, subunit coded based on criteria 1 - 4 above only.

Flag

1. change since last inspection $=4,5,6$ 
Table 17. Criteria for determination of Scour-Critical Bridge Indicator Code for office-reviewed bridge sitesContinued

\section{CODE 8-Continued}

\section{CASE 3}

\section{Criteria}

1. abutment foundation type $=5$

2. abutment type $=2,3,4,5,6$

OR

1. pier foundation type $=5$

2. pier type $=1,3,4$

\section{AND}

3. scour condition $=0,1,2$

4. movement $=0$

5. change since last inspection $=4,5,6,7,8,9$

6. under-the-bridge primary bed material $=5$

\section{Flag}

1. change since last inspection $=4,5,6$

\section{CASE 4}

\section{Criteria}

1. abutment foundation type $=3$

2. abutment type $=1,2,3,4,5,6,7$

OR

1. pier foundation type $=3$

2. pier type $=1,2,3,4$

\section{AND}

3. scour condition $=0,1$

4. movement $=0$

5. change since last inspection $=7,8,9$

6A. streambed material near the subunit $=\mathrm{A} 5, \mathrm{~A} 6$

If 6A. not available, use 6 B.:

6B. under-the-bridge primary bed material $=4$ 
Table 17. Criteria for determination of Scour-Critical Bridge Indicator Code for office-reviewed bridge sitesContinued

\section{CODE 7}

\section{Code 7 indicates subunits that are adequately protected by countermeasures.}

\section{CASE 1}

\section{Criteria}

1. condition of all under-the-bridge countermeasures at the subunit $=1$

2. scour condition $=0,1,2$

3. movement $=0$

4. change since last inspection $=4,5,6,7,8,9$

Flag

1. change since last inspection $=4,5,6$

\section{CASE 2}

\section{Criteria}

1. none of the listed possible countermeasures are recommended at the subunit OR under the bridge:

\section{POSSIBLE COUNTERMEASURES}

Footing underpinning

Abutment slopewall (repair/replace)

Streambed paving (repair/replace)

Rock protection

Scour hole (backfill)

Apron/cutoff wall (repair/replace)
LOCATION

[at subunit]

[at subunit]

$\mathrm{UN}$

UN

$\mathrm{UN}$

Inlet/Outlet

2. scour condition $=0,1,2$

3. movement $=0$

4. change since last inspection $=4,5,6,7,8,9$

5A. streambed material near the subunit $=\mathrm{P} 7, \mathrm{P} 8$

If 5A. not available, use 5B.:

5B. under-the-bridge primary bed material $=6$

Flag

1. change since last inspection $=4,5,6$ 
Table 17. Criteria for determination of Scour-Critical Bridge Indicator Code for office-reviewed bridge sitesContinued

\section{CODE 6}

\section{CASE 1}

\section{Criteria}

For subunits for which existing PennDOT data for subunit type or subunit foundation type is not determined or other.

\section{CASE 4}

\section{Criteria}

For subunits that do not meet any case criteria for assigning codes 2 through 5, 7 through 8 , and code 6 case 1 . 
Table 17. Criteria for determination of Scour-Critical Bridge Indicator Code for office-reviewed bridge sitesContinued

\section{CODE 5}

Code 5 indicates subunits in contact with streambed material consisting predominately of cobbles and boulders, and showing little or no evidence of streambed instability.

\section{CASE 1}

\section{Criteria}

1. abutment foundation type $=2$

2. abutment type $=2,3,4,5$

OR

1. pier foundation type $=2$

2. pier type $=3$

\section{AND}

3. scour condition $=0,1$

4. movement $=0$

5. change since last inspection $=7,8,9$

6A. streambed material near the subunit $=A 5, A 6, R 7, R 8$

If $6 \mathrm{~A}$. not available, use 6B.:

6B. under-the-bridge primary bed material $=4,5$

\section{CASE 2}

Criteria

1. abutment foundation type $=1$

2. abutment type $=1,2,3,4,5$

OR

1. pier foundation type $=1$

2. pier type $=3$

AND

3. scour condition $=0,1$

4. movement $=0$

5. change since last inspection $=7,8,9$

6. streambed material near the subunit $=\mathrm{R} 4$

If 6. not available, criteria for this case cannot be met 
Table 17. Criteria for determination of Scour-Critical Bridge Indicator Code for office-reviewed bridge sitesContinued

\section{CODE 5-Continued}

\section{CASE 3}

\section{Criteria}

1. abutment foundation type $=3$

2. abutment type $=1,2,3,4,5,7$

OR

1. pier foundation type $=3$

2. pier type $=2,3$

\section{AND}

3. scour condition $=0,1,2$

4. movement $=0$

5. change since last inspection $=7,8,9$

6A. streambed material near the subunit $=\mathrm{A} 5, \mathrm{~A} 6$

If 6A. not available, use 6B.:

6B. under-the-bridge primary bed material $=4$ 
Table 17. Criteria for determination of Scour-Critical Bridge Indicator Code for office-reviewed bridge sitesContinued

\section{CODE 4}

Code 4 indicates subunits in contact with streambed material consisting predominately of cobbles and boulders, and showing some evidence of streambed instability.

\section{CASE 1}

\section{Criteria}

1. abutment foundation type $=2$

2. abutment type $=2,3,4,5$

OR

1. pier foundation type $=2$

2. pier type $=3$

\section{AND}

3. scour condition $=0,1,2$

4. movement $=0$

5. change since last inspection $=4,5,6,7,8,9$

6A. streambed material near the subunit $=\mathrm{A} 5, \mathrm{~A} 6, \mathrm{R} 7, \mathrm{R} 8$

If $6 \mathrm{~A}$. not available, use 6B.:

6B. under-the-bridge primary bed material $=4,5$

\section{CASE 2}

\section{Criteria}

1. abutment foundation type $=1$

2. abutment type $=1,2,3,4,5$

OR

1. pier foundation type $=1$

2. pier type $=3$

AND

3. scour condition $=0,1,2$

4. movement $=0$

5. change since last inspection $=4,5,6,7,8,9$

6. streambed material near the subunit $=\mathrm{R} 4$

If 6. not available, criteria for this case cannot be met 
Table 17. Criteria for determination of Scour-Critical Bridge Indicator Code for office-reviewed bridge sitesContinued

\section{CODE 4-Continued}

\section{CASE 3}

\section{Criteria}

1. abutment foundation type $=3$

2. abutment type $=1,2,3,4,5,7$

OR

1. pier foundation type $=3$

2. pier type $=2,3$

\section{AND}

3. scour condition $=0,1,2,3$

4. movement $=0$

5. change since last inspection $=4,5,6,7,8,9$

6A. streambed material near the subunit $=A 5, A 6$

If $6 \mathrm{~A}$. not available, use 6B.:

6B. under-the-bridge primary bed material $=4$

Flag

1. scour condition $=3$

\section{$\underline{\text { CASE } 4}$}

\section{Criteria}

1. abutment foundation type $=3$

2. abutment type $=1,2,3,4,5,7$

$$
\text { OR }
$$

1. pier foundation type $=3$

2. pier type $=2,3$

$$
\text { AND }
$$

3. scour condition $=0,1,2,3$

4. movement $=0$

5. change since last inspection $=7,8,9$

6A. streambed material near the subunit $=\mathrm{A} 3, \mathrm{~A} 4$

$$
\text { If } 6 \mathrm{~A} \text {. not available, use } 6 \mathrm{~B} . \text { : }
$$

6B. under-the-bridge primary bed material $=1,2,3,7$

\section{CASE 5}

\section{Criteria}
1. abutment type $=9$
2. scour condition $=0$
3. movement $=0$ 
Table 17. Criteria for determination of Scour-Critical Bridge Indicator Code for office-reviewed bridge sitesContinued

\section{CODE 4-Continued}

\section{CASE 6}

\section{Criteria}

1. abutment foundation type $=2$

2. abutment type $=6$

OR

1. pier foundation type $=2$

2. pier type $=1,4$

\section{AND}

3. scour condition $=0,1$

4. movement $=0$

5. change since last inspection $=7,8,9$

6A. streambed material near the subunit $=A 5, A 6, R 7, R 8$

If $6 \mathrm{~A}$. not available, use 6B.:

6B. under-the-bridge primary bed material $=4,5$

\section{CASE 7}

Criteria

1. abutment foundation type $=1$

2. abutment type $=6$

OR

1. pier foundation type $=1$

2. pier type $=1,4$

AND

3. scour condition $=0,1,2$

4. movement $=0$

5. change since last inspection $=7,8,9$

6. streambed material near the subunit $=\mathrm{R} 4$

If 6. not available, criteria for this case cannot be met

\section{CASE 8}

\section{Criteria}

1. abutment foundation type $=3$

2. abutment type $=6$

OR

1. pier foundation type $=3$

2. pier type $=1,4$

\section{AND}

3. scour condition $=0,1,2$

4. movement $=0$

5. change since last inspection $=4,5,6,7,8,9$

6A. streambed material near the subunit $=\mathrm{A} 5, \mathrm{~A} 6$

If $6 \mathrm{~A}$. not available, use 6B.:

6B. under-the-bridge primary bed material $=4$ 
Table 17. Criteria for determination of Scour-Critical Bridge Indicator Code for office-reviewed bridge sitesContinued

\section{CODE 4-Continued}

\section{CASE 9}

\section{Criteria}

1. abutment foundation type $=3$

2. abutment type $=6$

OR

1. pier foundation type $=3$

2. pier type $=1,4$

$$
\text { AND }
$$

3. scour condition $=0,1,2$

4. movement $=0$

5. change since last inspection $=7,8,9$

6. streambed material near the subunit $=\mathrm{A} 3, \mathrm{~A} 4$

If $6 \mathrm{~A}$. not available, use 6B.:

6B. under-the-bridge primary bed material $=1,2,3,7$ 
Table 17. Criteria for determination of Scour-Critical Bridge Indicator Code for office-reviewed bridge sitesContinued

\section{CODE 3}

Code 3 indicates subunits in contact with streambed material consisting predominately of erodible, fine material.

\section{CASE 1}

\section{Criteria}

1. abutment foundation type $=2$

2. abutment type $=2,3,4,5$

OR

1. pier foundation type $=2$

2. pier type $=3$

\section{AND}

3. scour condition $=0,1,2$

4. movement $=0$

5. change since last inspection $=4,5,6,7,8,9$

6A. streambed material near the subunit $=\mathrm{A} 3, \mathrm{~A} 4, \mathrm{R} 4$

If $6 \mathrm{~A}$. not available, use 6B.:

6B. under-the-bridge primary bed material $=1,2,3,7$

\section{CASE 2}

Criteria

1. abutment foundation type $=3$

2. abutment type $=1,2,3,4,5,7$

OR

1. pier foundation type $=3$

2. pier type $=2,3$

AND

3. scour condition $=0,1,2,3$

4. movement $=0$

5. change since last inspection $=4,5,6,7,8,9$

6A. streambed material near the subunit $=\mathrm{A} 3, \mathrm{~A} 4$

If $6 \mathrm{~A}$. not available, use 6B.:

6B. under-the-bridge primary bed material $=1,2,3,7$

CASE 3

Criteria

1. abutment type $=9$

2. scour condition $=1$

3. movement $=0$

4. change since last inspection $=4,5,6,7,8,9$ 
Table 17. Criteria for determination of Scour-Critical Bridge Indicator Code for office-reviewed bridge sitesContinued

\section{CODE 3-Continued}

\section{CASE 4}

\section{Criteria}

1. abutment foundation type $=2$

2. abutment type $=6$

OR

1. pier foundation type $=2$

2. pier type $=1,4$

\section{AND}

3. scour condition $=0,1,2$

4. movement $=0$

5. change since last inspection $=4,5,6,7,8,9$

6A. streambed material near the subunit $=\mathrm{A} 3, \mathrm{~A} 4, \mathrm{~A} 5, \mathrm{~A} 6, \mathrm{R} 4$

If 6A. not available, use 6B.:

6B. under-the-bridge primary bed material $=1,2,3,4,7$

\section{CASE 5}

Criteria

1. abutment foundation type $=1$

2. abutment type $=6$

OR

1. pier foundation type $=1$

2. pier type $=1,4$

AND

3. scour condition $=0,1,2$

4. movement $=0$

5. change since last inspection $=4,5,6,7,8,9$

6. streambed material near the subunit $=\mathrm{R} 4$

If 6. not available, criteria for case cannot be met

\section{CASE 6}

\section{Criteria}

1. abutment foundation type $=1$

2. abutment type $=1,2,3,4,5$

OR

1. pier foundation type $=1$

2. pier type $=3$

\section{AND}

3. scour condition $=3$

4. movement $=0$

5. change since last inspection $=4,5,6,7,8,9$

Flag

For all criteria 
Table 17. Criteria for determination of Scour-Critical Bridge Indicator Code for office-reviewed bridge sitesContinued

\section{CODE 3-Continued}

\section{CASE 7}

\section{Criteria}

1. abutment foundation type $=3$

2. abutment type $=6$

OR

1. pier foundation type $=3$

2. pier type $=1,4$

$$
\text { AND }
$$

3. scour condition $=0,1,2$

4. movement $=0$

5. change since last inspection $=4,5,6,7,8,9$

6A. streambed material near the subunit $=A 3, A 4$

If $6 \mathrm{~A}$. not available, use 6B.:

6B. under-the-bridge primary bed material $=1,2,3,7$ 
Table 17. Criteria for determination of Scour-Critical Bridge Indicator Code for office-reviewed bridge sitesContinued

\section{CODE 2}

Code 2 indicates subunits having critical site conditions related to scour, such as; movement of the subunit, significant change since last inspection, or scour condition for foundation that potentially threatens bridge structure.

\section{CASE 2}

\section{Criteria}

1. movement $=1$

\section{CASE 3}

\section{Criteria}

1. abutment foundation type $=2$

2. abutment type $=2,3,4,5$

$$
\text { OR }
$$

1. pier foundation type $=2$

2. pier type $=3$

AND

3. scour condition $=3$

CASE 4

Criteria

1. abutment type $=6$

OR

1. pier type $=1,4$

AND

2. scour condition $=3$

\section{CASE 6}

\section{Criteria}

1. change since last inspection $=3$

Flag

For all criteria 


\section{APPENDIX H}

Procedure for computation OF the Scour Assessment RATING FOR FIELD-VIEWED BRIDGE SITES 


\section{PROCEDURE FOR COMPUTATION OF THE SCOUR ASSESSMENT RATING FOR FIELD- VIEWED BRIDGE SITES}

The Scour Assessment Rating (Rating) rates or ranks the hydraulic threat of the stream to the bridge. The Rating is composed of individual component values for selected site conditions that are combined to provide an overall Rating for the entire bridge structure. The Rating ranges from 0 to 100 where 0 indicates a serious threat to the bridge and 100 indicates little or no threat to the bridge. Only subunits that meet the criteria for scour assessments as outlined in this report are rated; for example, an expansive bridge that carries an elevated roadway will be rated based only on those subunits in contact with stream flow.

PennDOT BMS data are compared with data observed by USGS for subunit type and subunit foundation type. The following flowcharts (figs. 32 and 33) and selection tables (tables 18-21) determine how PennDOT and USGS data are used in the computation of the Scour Assessment Rating for fieldviewed bridge sites on the worksheet presented in figure 34. When subunits cannot be rated because of conflicting or unavailable data, they receive a rating of "999." This rating serves only to indicate that no score could be computed and does not imply any indication of bridge site or bridge structure stability. Because the individual subunits are components of the overall bridge structure, if an individual subunit receives a rating of "999," the entire structure cannot be rated and also receives a rating of "999."

For cases where a foundation type of "not observed" is used in the computation of the Rating (as determined by the following flowchart and tables), the foundation type for that subunit is rated as if founded on alluvium, which is a worst-case scenario. In reality, the foundation type may be more stable and PennDOT personnel will investigate these bridge sites and recompute the Rating and Code as information becomes available. Comments on the USGS data-collection form or in the BMS database must be consulted for additional information.

A field-viewed subunit can only be rated if data are complete for the following USGS data fields:

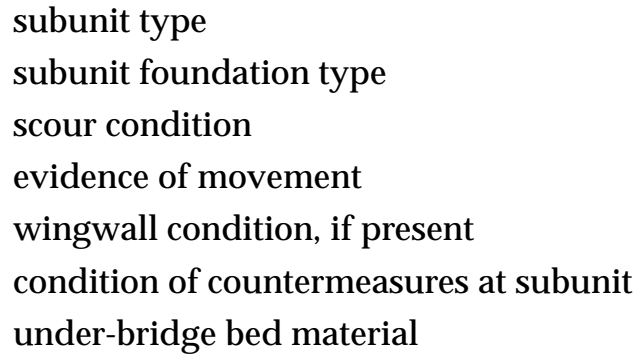

Rating an entire field-viewed bridge structure requires that all subunits that meet criteria for scour assessments are capable of being rated, as stated above, and that the following USGS data fields also are complete:

trapping potential

debris potential

debris horizontal and vertical location

evidence of pressure flow

When BMS data for foundation or type of a subunit are blank or indicated as "other" or, in some cases, when the BMS foundation type is not determined, the subunit is not rated and receives a "999" in the database. PennDOT District personnel are instructed to revise the BMS data or check bridge records prior to rating by PennDOT personnel. 
Pier type and pier foundation type data are stored in the PennDOT BMS database in items C39 and C40, respectively. These 2 PennDOT items contain 4 subfields each for PennDOT entry of pier information. The following assumptions must be made for use of BMS pier data in computing the Rating for bridges:

1. If only 1 set of pier data ( 1 subfield complete for pier type and 1 subfield complete for foundation type) is available, assume that these data apply to all piers for the bridge. For example; all piers of s bridge structure are of the same type with the same foundation type, therefore, only one entry is made in the BMS database to describe all piers.

2. If the number of subfields of pier data equal the number of piers, assume that first subfield describes P01, the second subfield describes P02, and so on. For example; the variation among piers of a specific bridge is substantial enough to warrant individual entries for each pier.

3. If no data are available for piers or if data cannot be assigned to specific piers according to assumptions 1 . and 2. above, the subunit cannot be rated and receives a rating of "999." For example; there are too many piers with too much variation in pier type and (or) foundation type to list each pier separately in the database so descriptions of groups of piers are used in the BMS database. These group descriptions cannot be used for completion of the Rating and Code and the bridges, therefore, require manual computation by PennDOT personnel.

Several combinations of conflicting data are flagged to alert PennDOT reviewers that a more thorough review is required than for sites where USGS and PennDOT data are similar or compatible. The flag states that a special condition at this site requires PennDOT review. The combinations of data that are flagged are:

1. USGS foundation type $=$ bedrock BMS foundation type $=\mathrm{L}$

2. USGS foundation type $=$ piles $/$ caissons BMS foundation type $=\mathrm{A}, \mathrm{R}$

3. USGS foundation type $=$ other BMS foundation type $=\mathrm{A}, \mathrm{R}, \mathrm{K}, \mathrm{B}-\mathrm{J}, \mathrm{S}, \mathrm{L}$

Several combinations of abutment types and abutment foundation types cannot occur in the construction of a bridge and these combinations are not rated (table 21). In these cases the subunit and the bridge structure receive a rating of "999" to indicate that no rating was computed and PennDOT District personnel are instructed to revise the BMS data or check bridge records prior to rating the bridge site manually. 
Are BMS data for abutment type $=$ blank or $9 ?$
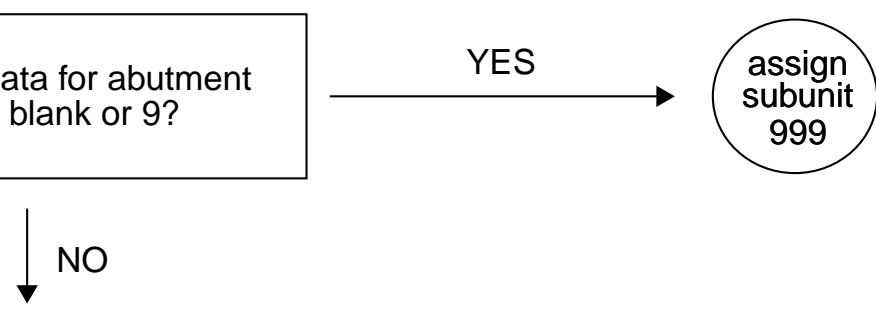

Select rating abutment type (use Table 18 for USGS abutment type and BMS abutment type)

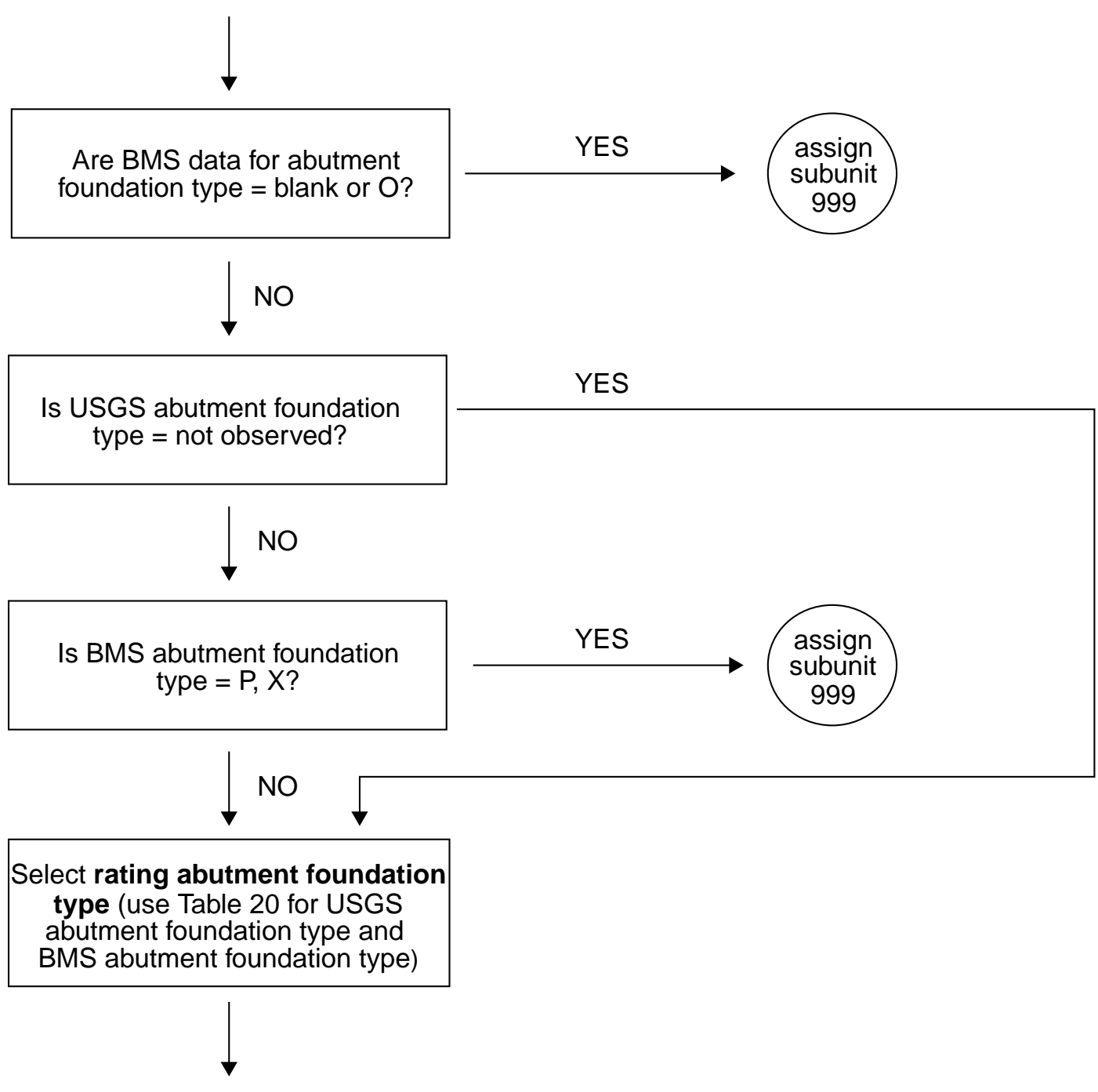

Figure 32. Computation of Scour Assessment Rating for abutments at field-viewed bridge sites. 


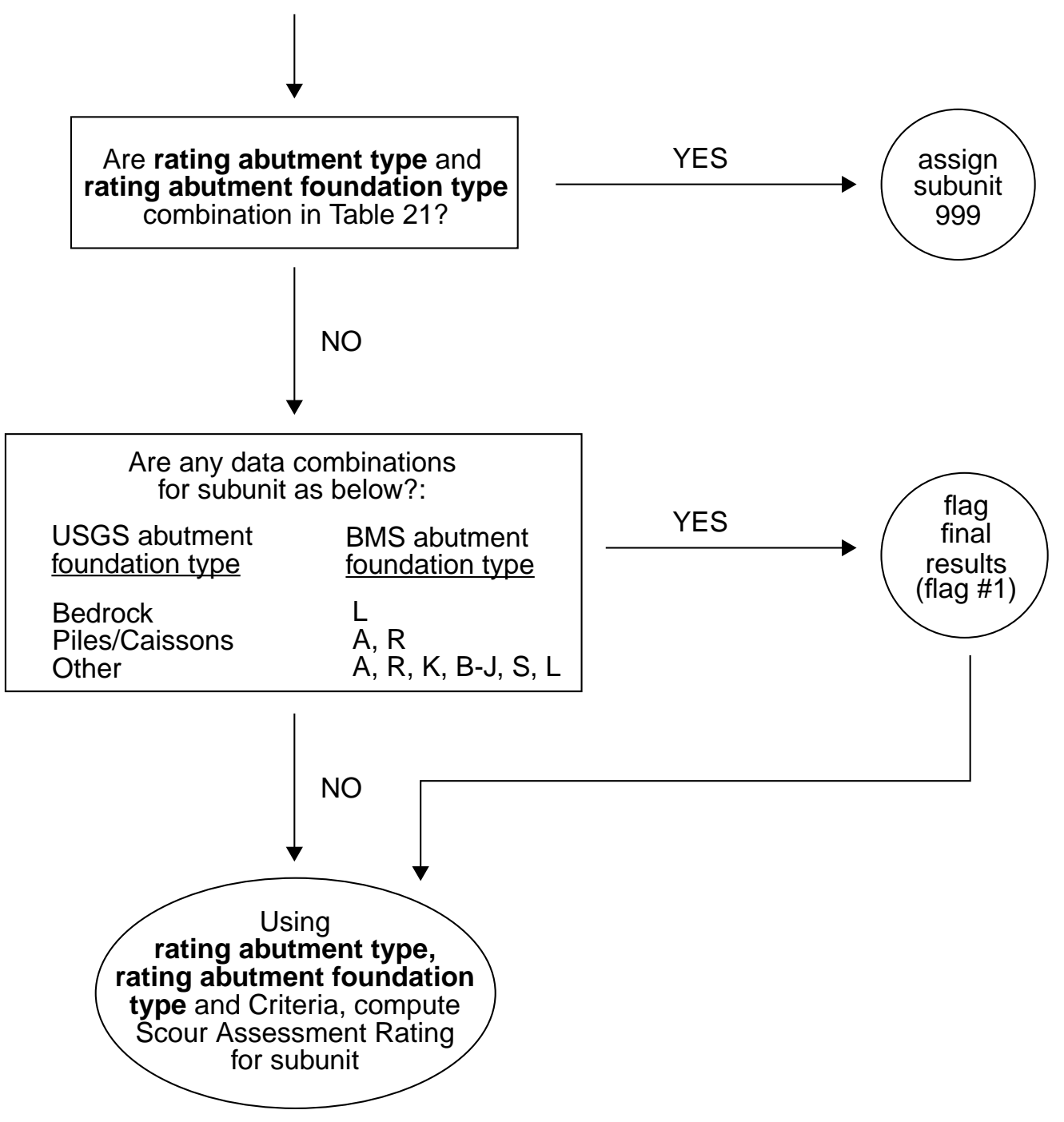

Figure 32. Computation of Scour Assessment Rating for abutments at field-viewed bridge sites -Continued. 


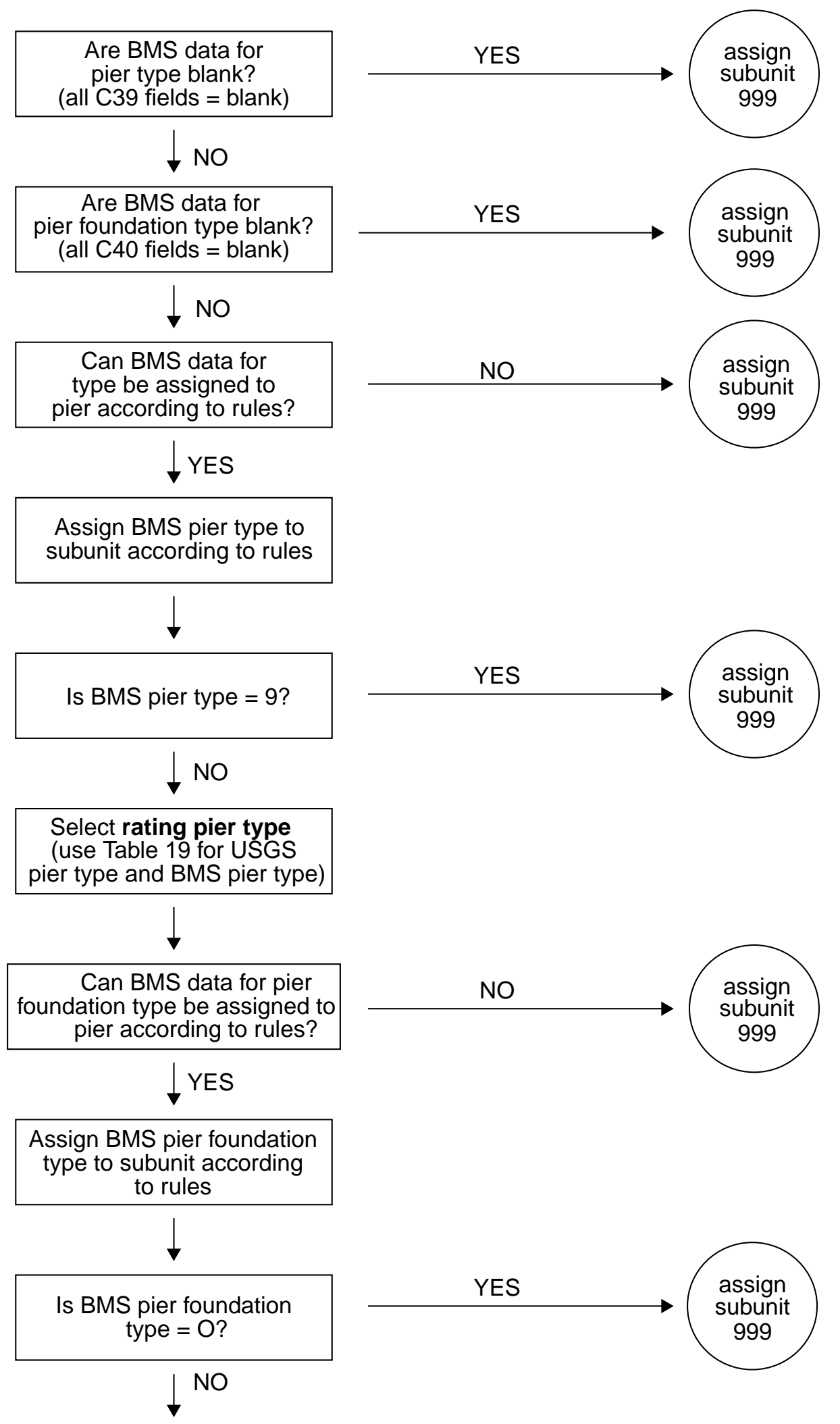

Figure 33. Computation of Scour Assessment Rating for piers at field-viewed bridge sites. 


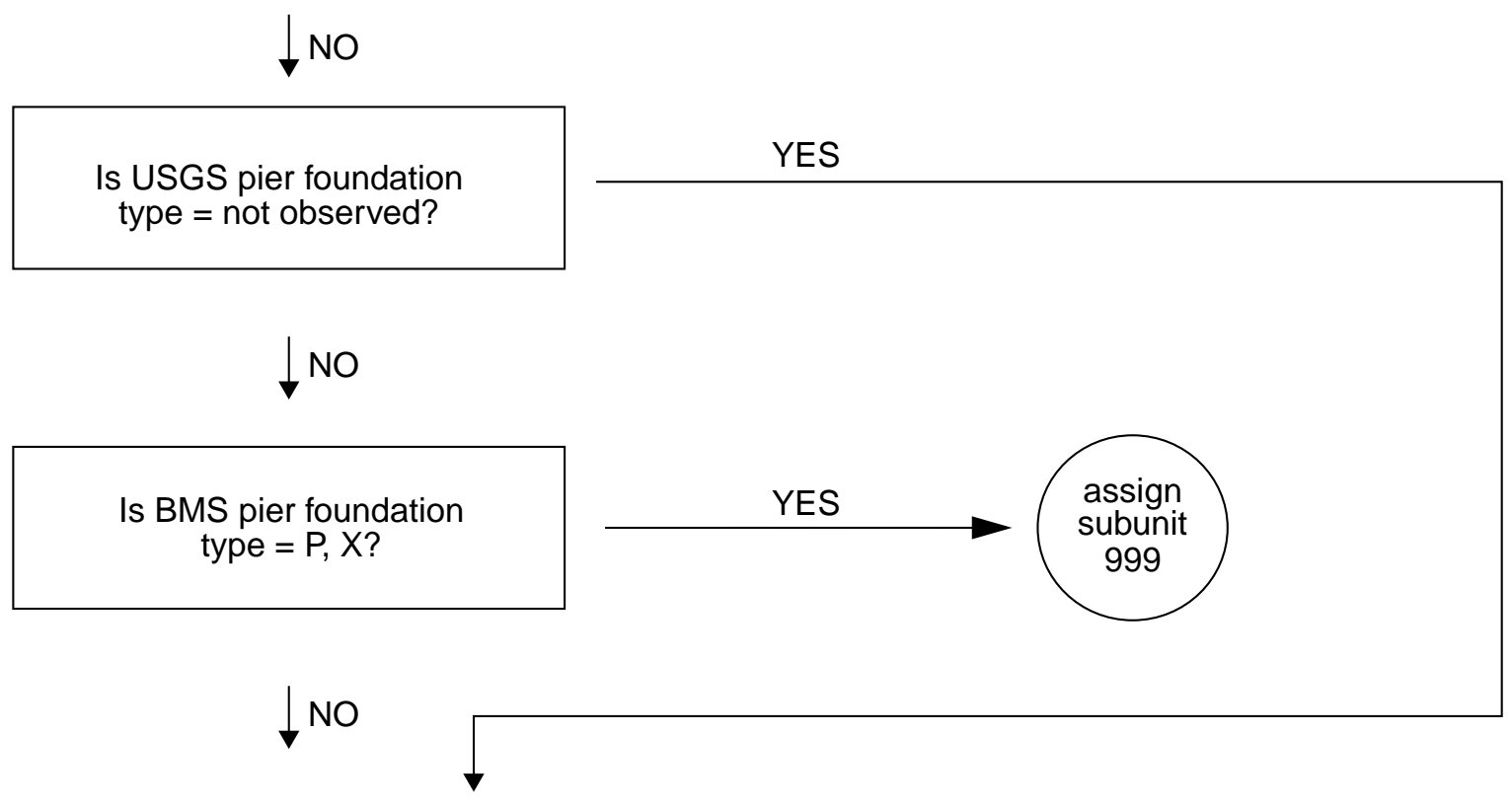

\section{Select rating pier foundation}

type (use Table 20 for

USGS foundation type and BMS foundation type)
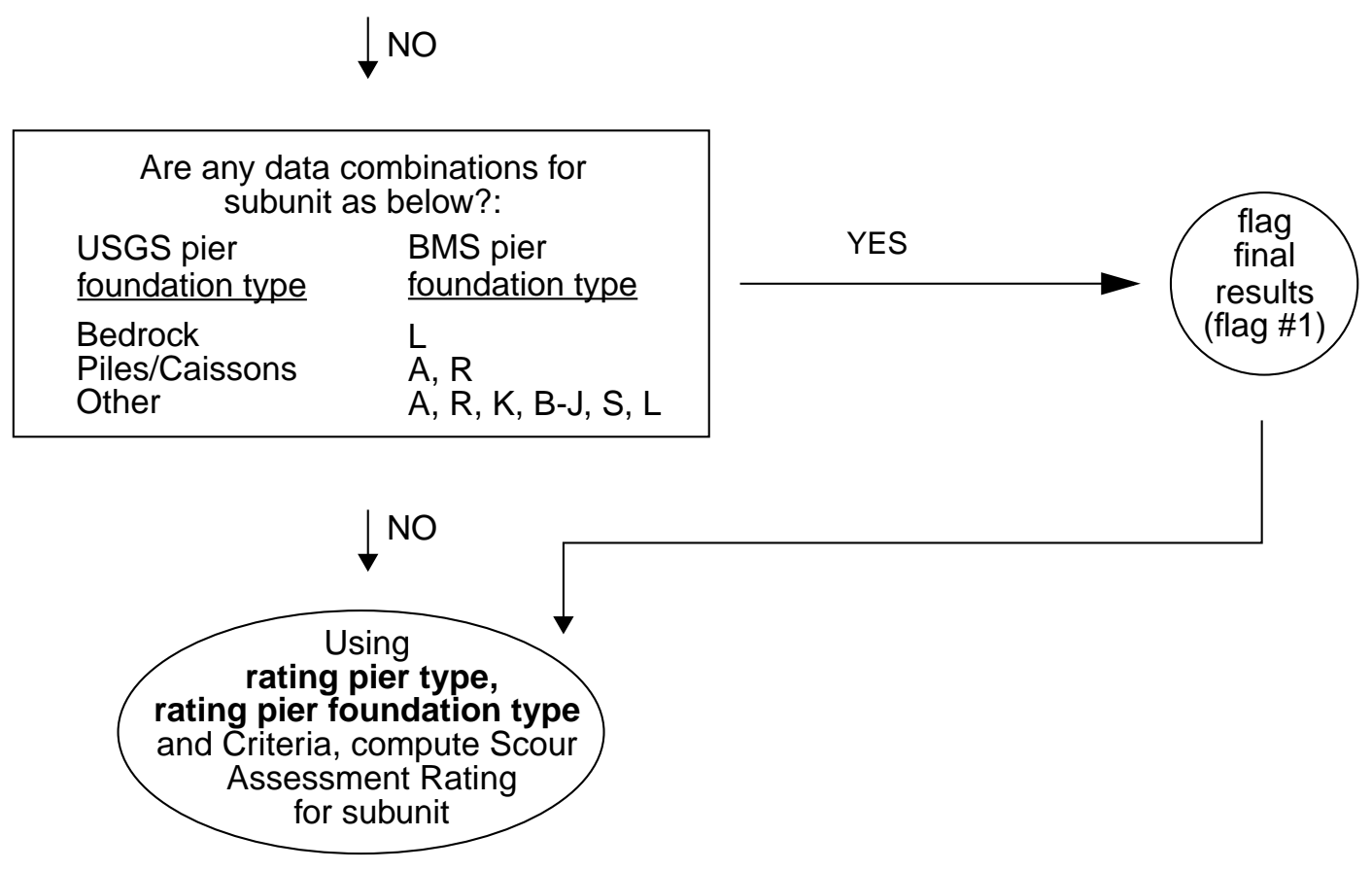

Figure 33. Computation of Scour Assessment Rating for piers at field-viewed bridge sites-Continued. 


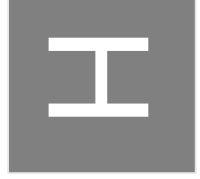

Table 18. Selection of abutment type used in the Scour Assessment Rating for field-viewed bridge sites

[w/o, without; 999 indicates that no choice of abutment type is necessary, subunit cannot be rated]

\begin{tabular}{|c|c|c|c|c|c|c|c|c|c|c|}
\hline$\frac{\text { USGS Type } \rightarrow}{\text { BMS Type } \downarrow}$ & 1 & 2 & 3 & 4 & 5 & 6 & 7 & 8 & 9 & 10 \\
\hline 1 & stub (1) & cantilever (2) & gravity concrete (3) & spill-through (4) & $\begin{array}{c}\text { unknown } \\
\text { concrete (5) }\end{array}$ & stone masonry (6) & piles/bents (7) & $\begin{array}{l}\text { concrete } \mathrm{w} / \mathrm{o} \\
\text { piles/bents (8) }\end{array}$ & $\begin{array}{c}\text { mechanically } \\
\text { stabilized } \\
\text { earth (9) }\end{array}$ & stub (1) \\
\hline 2 & stub (1) & cantilever (2) & gravity concrete (3) & spill-through (4) & $\begin{array}{l}\text { unknown } \\
\text { concrete (5) }\end{array}$ & stone masonry (6) & piles/bents (7) & $\begin{array}{l}\text { concrete w/o } \\
\text { piles/bents (8) }\end{array}$ & $\begin{array}{c}\text { mechanically } \\
\text { stabilized } \\
\text { earth (9) }\end{array}$ & cantilever (2) \\
\hline 3 & stub (1) & cantilever (2) & gravity concrete (3) & spill-through (4) & $\begin{array}{l}\text { unknown } \\
\text { concrete (5) }\end{array}$ & stone masonry (6) & piles/bents (7) & $\begin{array}{l}\text { concrete w/o } \\
\text { piles/bents (8) }\end{array}$ & $\begin{array}{c}\text { mechanically } \\
\text { stabilized } \\
\text { earth (9) }\end{array}$ & gravity concrete (3) \\
\hline 4 & stub (1) & cantilever (2) & gravity concrete (3) & spill-through (4) & $\begin{array}{l}\text { unknown } \\
\text { concrete (5) }\end{array}$ & stone masonry (6) & piles/bents (7) & $\begin{array}{l}\text { concrete w/o } \\
\text { piles/bents (8) }\end{array}$ & $\begin{array}{c}\text { mechanically } \\
\text { stabilized } \\
\text { earth (9) }\end{array}$ & stone masonry (6) \\
\hline 5 & stub (1) & cantilever (2) & gravity concrete (3) & spill-through (4) & $\begin{array}{l}\text { unknown } \\
\text { concrete (5) }\end{array}$ & stone masonry (6) & piles/bents (7) & $\begin{array}{l}\text { concrete w/o } \\
\text { piles/bents (8) }\end{array}$ & $\begin{array}{c}\text { mechanically } \\
\text { stabilized } \\
\text { earth (9) }\end{array}$ & gravity concrete (3) \\
\hline 6 & stub (1) & cantilever (2) & gravity concrete (3) & spill-through (4) & $\begin{array}{l}\text { unknown } \\
\text { concrete (5) }\end{array}$ & stone masonry (6) & piles/bents (7) & $\begin{array}{l}\text { concrete w/o } \\
\text { piles/bents (8) }\end{array}$ & $\begin{array}{c}\text { mechanically } \\
\text { stabilized } \\
\text { earth (9) }\end{array}$ & stub (1) \\
\hline 7 & stub (1) & cantilever (2) & gravity concrete (3) & spill-through (4) & $\begin{array}{c}\text { unknown } \\
\text { concrete (5) }\end{array}$ & stone masonry (6) & piles/bents (7) & $\begin{array}{l}\text { concrete w/o } \\
\text { piles/bents (8) }\end{array}$ & $\begin{array}{c}\text { mechanically } \\
\text { stabilized } \\
\text { earth (9) }\end{array}$ & $\begin{array}{c}\text { mechanically } \\
\text { stabilized } \\
\text { earth (9) }\end{array}$ \\
\hline 8 & stub (1) & cantilever (2) & gravity concrete (3) & spill-through (4) & $\begin{array}{l}\text { unknown } \\
\text { concrete (5) }\end{array}$ & stone masonry (6) & piles/bents (7) & $\begin{array}{l}\text { concrete w/o } \\
\text { piles/bents (8) }\end{array}$ & $\begin{array}{c}\text { mechanically } \\
\text { stabilized } \\
\text { earth (9) }\end{array}$ & spill-through (4) \\
\hline 9 & 999 & 999 & 999 & 999 & 999 & 999 & 999 & 999 & 999 & 999 \\
\hline A & stub (1) & cantilever (2) & gravity concrete (3) & spill-through (4) & $\begin{array}{c}\text { unknown } \\
\text { concrete (5) }\end{array}$ & stone masonry (6) & piles/bents (7) & $\begin{array}{l}\text { concrete w/o } \\
\text { piles/bents ( } 8)\end{array}$ & $\begin{array}{c}\text { mechanically } \\
\text { stabilized } \\
\text { earth (9) }\end{array}$ & $\begin{array}{c}\text { mechanically } \\
\text { stabilized } \\
\text { earth (9) }\end{array}$ \\
\hline B & stub (1) & cantilever (2) & gravity concrete (3) & spill-through (4) & $\begin{array}{c}\text { unknown } \\
\text { concrete (5) }\end{array}$ & stone masonry (6) & piles/bents (7) & $\begin{array}{l}\text { concrete w/o } \\
\text { piles/bents (8) }\end{array}$ & $\begin{array}{c}\text { mechanically } \\
\text { stabilized } \\
\text { earth (9) }\end{array}$ & $\begin{array}{c}\text { mechanically } \\
\text { stabilized } \\
\text { earth (9) }\end{array}$ \\
\hline C & stub (1) & cantilever (2) & gravity concrete (3) & spill-through (4) & $\begin{array}{c}\text { unknown } \\
\text { concrete (5) }\end{array}$ & stone masonry (6) & piles/bents (7) & $\begin{array}{l}\text { concrete w/o } \\
\text { piles/bents (8) }\end{array}$ & $\begin{array}{c}\text { mechanically } \\
\text { stabilized } \\
\text { earth (9) }\end{array}$ & $\begin{array}{c}\text { mechanically } \\
\text { stabilized } \\
\text { earth (9) }\end{array}$ \\
\hline $\mathrm{D}$ & stub (1) & cantilever (2) & gravity concrete (3) & spill-through (4) & $\begin{array}{l}\text { unknown } \\
\text { concrete (5) }\end{array}$ & stone masonry (6) & piles/bents (7) & $\begin{array}{l}\text { concrete w/o } \\
\text { piles/bents (8) }\end{array}$ & $\begin{array}{c}\text { mechanically } \\
\text { stabilized } \\
\text { earth (9) }\end{array}$ & other (10) \\
\hline
\end{tabular}


Table 18. Selection of abutment type used in the Scour Assessment Rating for field-viewed bridge sites-Continued [w/o, without; 999 indicates that no choice of abutment type is necessary, subunit cannot be rated]

\begin{tabular}{|c|c|c|c|c|c|c|c|c|c|c|}
\hline$\frac{\text { USGS Type } \rightarrow}{\text { BMS Type } \downarrow}$ & 1 & 2 & 3 & 4 & 5 & 6 & 7 & 8 & 9 & 10 \\
\hline $\mathrm{E}$ & stub (1) & cantilever (2) & gravity concrete (3) & spill-through (4) & $\begin{array}{l}\text { unknown } \\
\text { concrete (5) }\end{array}$ & stone masonry (6) & piles/bents (7) & $\begin{array}{l}\text { concrete } \mathrm{w} / \mathrm{o} \\
\text { piles/bents (8) }\end{array}$ & $\begin{array}{c}\text { mechanically } \\
\text { stabilized } \\
\text { earth (9) }\end{array}$ & piles/bents (7) \\
\hline $\mathrm{F}$ & stub (1) & cantilever (2) & gravity concrete (3) & spill-through (4) & $\begin{array}{l}\text { unknown } \\
\text { concrete (5) }\end{array}$ & stone masonry (6) & piles/bents (7) & $\begin{array}{l}\text { concrete w/o } \\
\text { piles/bents ( } 8 \text { ) }\end{array}$ & $\begin{array}{c}\text { mechanically } \\
\text { stabilized } \\
\text { earth (9) }\end{array}$ & other (10) \\
\hline G & stub (1) & cantilever (2) & gravity concrete (3) & spill-through (4) & $\begin{array}{l}\text { unknown } \\
\text { concrete (5) }\end{array}$ & stone masonry (6) & piles/bents (7) & $\begin{array}{l}\text { concrete w/o } \\
\text { piles/bents ( } 8 \text { ) }\end{array}$ & $\begin{array}{c}\text { mechanically } \\
\text { stabilized } \\
\text { earth (9) }\end{array}$ & stone masonry (6) \\
\hline $\mathrm{H}$ & stub (1) & cantilever (2) & gravity concrete (3) & spill-through (4) & $\begin{array}{l}\text { unknown } \\
\text { concrete (5) }\end{array}$ & stone masonry (6) & piles/bents (7) & $\begin{array}{c}\text { concrete w/o } \\
\text { piles/bents (8) }\end{array}$ & $\begin{array}{c}\text { mechanically } \\
\text { stabilized } \\
\text { earth (9) }\end{array}$ & $\begin{array}{c}\text { mechanically } \\
\text { stabilized } \\
\text { earth (9) }\end{array}$ \\
\hline I & stub (1) & cantilever (2) & gravity concrete (3) & spill-through (4) & $\begin{array}{l}\text { unknown } \\
\text { concrete (5) }\end{array}$ & stone masonry (6) & piles/bents (7) & $\begin{array}{l}\text { concrete w/o } \\
\text { piles/bents ( } 8 \text { ) }\end{array}$ & $\begin{array}{c}\text { mechanically } \\
\text { stabilized } \\
\text { earth (9) }\end{array}$ & $\begin{array}{c}\text { mechanically } \\
\text { stabilized } \\
\text { earth (9) }\end{array}$ \\
\hline $\mathrm{J}$ & stub (1) & cantilever (2) & gravity concrete (3) & spill-through (4) & $\begin{array}{l}\text { unknown } \\
\text { concrete (5) }\end{array}$ & stone masonry (6) & piles/bents (7) & $\begin{array}{c}\text { concrete w/o } \\
\text { piles/bents (8) }\end{array}$ & $\begin{array}{c}\text { mechanically } \\
\text { stabilized } \\
\text { earth (9) }\end{array}$ & $\begin{array}{c}\text { mechanically } \\
\text { stabilized } \\
\text { earth (9) }\end{array}$ \\
\hline K & stub (1) & cantilever (2) & gravity concrete (3) & spill-through (4) & $\begin{array}{l}\text { unknown } \\
\text { concrete (5) }\end{array}$ & stone masonry (6) & piles/bents (7) & $\begin{array}{l}\text { concrete w/o } \\
\text { piles/bents ( } 8 \text { ) }\end{array}$ & $\begin{array}{c}\text { mechanically } \\
\text { stabilized } \\
\text { earth (9) }\end{array}$ & other (10) \\
\hline $\mathrm{L}$ & stub (1) & cantilever (2) & gravity concrete (3) & spill-through (4) & $\begin{array}{l}\text { unknown } \\
\text { concrete (5) }\end{array}$ & stone masonry (6) & piles/bents ( 7 ) & $\begin{array}{l}\text { concrete w/o } \\
\text { piles/bents (8) }\end{array}$ & $\begin{array}{c}\text { mechanically } \\
\text { stabilized } \\
\text { earth (9) }\end{array}$ & other (10) \\
\hline $\mathrm{X}$ & stub (1) & cantilever (2) & gravity concrete (3) & spill-through (4) & $\begin{array}{l}\text { unknown } \\
\text { concrete (5) }\end{array}$ & stone masonry (6) & piles/bents (7) & $\begin{array}{l}\text { concrete w/o } \\
\text { piles/bents (8) }\end{array}$ & $\begin{array}{c}\text { mechanically } \\
\text { stabilized } \\
\text { earth (9) }\end{array}$ & $\begin{array}{l}\text { unknown } \\
\text { concrete (5) }\end{array}$ \\
\hline Y & stub (1) & cantilever (2) & gravity concrete (3) & spill-through (4) & $\begin{array}{l}\text { unknown } \\
\text { concrete (5) }\end{array}$ & stone masonry (6) & piles/bents (7) & $\begin{array}{l}\text { concrete w/o } \\
\text { piles/bents (8) }\end{array}$ & $\begin{array}{c}\text { mechanically } \\
\text { stabilized } \\
\text { earth (9) }\end{array}$ & spill-through (4) \\
\hline Z & stub (1) & cantilever (2) & gravity concrete (3) & spill-through (4) & $\begin{array}{l}\text { unknown } \\
\text { concrete (5) }\end{array}$ & stone masonry (6) & piles/bents (7) & $\begin{array}{l}\text { concrete w/o } \\
\text { piles/bents (8) }\end{array}$ & $\begin{array}{c}\text { mechanically } \\
\text { stabilized } \\
\text { earth (9) }\end{array}$ & $\begin{array}{c}\text { mechanically } \\
\text { stabilized } \\
\text { earth (9) }\end{array}$ \\
\hline blank & 999 & 999 & 999 & 999 & 999 & 999 & 999 & 999 & 999 & 999 \\
\hline
\end{tabular}


Table 19. Selection of pier type used in the Scour Assessment Rating for field-viewed bridge sites [999 indicates that no choice of abutment type is necessary, subunit cannot be rated]

\begin{tabular}{|c|c|c|c|c|c|}
\hline $\begin{array}{c}\text { USGS Type } \rightarrow \\
\text { BMS Type } \downarrow\end{array}$ & 1 & 2 & 3 & 4 & 5 \\
\hline 1 & timber (1) & steel (2) & concrete (3) & stone masonry (4) & timber (1) \\
\hline 2 & timber (1) & steel (2) & concrete (3) & stone masonry (4) & steel (2) \\
\hline 3 & timber (1) & steel (2) & concrete (3) & stone masonry (4) & concrete (3) \\
\hline 4 & timber (1) & steel (2) & concrete (3) & stone masonry (4) & concrete (3) \\
\hline 5 & timber (1) & steel (2) & concrete (3) & stone masonry (4) & concrete (3) \\
\hline 6 & timber (1) & steel (2) & concrete (3) & stone masonry (4) & stone masonry (4) \\
\hline 7 & timber (1) & steel (2) & concrete (3) & stone masonry (4) & concrete (3) \\
\hline 9 & timber (1) & steel (2) & concrete (3) & stone masonry (4) & other (5) \\
\hline Blank & 999 & 999 & 999 & 999 & 999 \\
\hline
\end{tabular}

Table 20. Selection of abutment and pier foundation type used in the Scour Assessment Rating for field-viewed bridge sites

[999 indicates that no choice of abutment type is necessary, subunit cannot be rated]

\begin{tabular}{|c|c|c|c|c|c|}
\hline $\begin{array}{c}\begin{array}{c}\text { USGS foundation } \\
\text { type } \rightarrow\end{array} \\
\begin{array}{c}\text { BMS foundation } \\
\text { type } \downarrow\end{array}\end{array}$ & 1 & 2 & 3 & 4 & 5 \\
\hline $\mathrm{A}$ & bedrock (1) & bedrock (1) & piles/caissons (3) & bedrock (1) & bedrock (1) \\
\hline B-J & piles/caissons (3) & piles/caissons (3) & piles/caissons (3) & piles/caissons (3) & piles/caissons (3) \\
\hline K & alluvium (2) & alluvium (2) & piles/caissons (3) & alluvium (2) & alluvium (2) \\
\hline $\mathrm{L}$ & bedrock (1) & alluvium (2) & piles/caissons (3) & alluvium (2) & alluvium (2) \\
\hline O / blank & 999 & 999 & 999 & 999 & 999 \\
\hline $\mathrm{P}$ & 999 & 999 & 999 & 999 & not observed (5) \\
\hline $\mathrm{R}$ & bedrock (1) & bedrock (1) & piles/caissons (3) & bedrock (1) & bedrock (1) \\
\hline$S$ & piles/caissons (3) & piles/caissons (3) & piles/caissons (3) & piles/caissons (3) & piles/caissons (3) \\
\hline$x$ & 999 & 999 & 999 & 999 & not observed (5) \\
\hline
\end{tabular}

Table 21. Incompatible combinations of abutment types and foundation types in the Scour Assessment Rating for field-viewed bridge sites [w/o, without]

\begin{tabular}{ll}
\hline \multicolumn{1}{c}{ Abutment type } & \multicolumn{1}{c}{ Abutment foundation type } \\
\hline Stub (1) & Alluvium (2) \\
Stub (1) & Not observed (5) \\
Piles/bents (7) & Bedrock (1) \\
Concrete w/o piles/bents (8) & Piles/caissons (3) \\
\hline
\end{tabular}


Figure 34. Worksheet for computation of Scour Assessment Rating for field-viewed bridge sites.

Use the rating abutment type, rating abutment foundation type, rating pier type, and rating pier foundation type determined above in the worksheet that follows. All other required site data are gathered from the field-viewed bridge site data-collection form. 
Figure 34. Worksheet for computation of Scour Assessment Rating for field-viewed bridge sites-Continued.

\section{Overall Score:}

Bridge ID:

\section{ABUTMENTS}

NEAR

FAR

A. Scour condition at abutments:

1. Movement

a. Foundation type:

1) Alluvium, not observed

a) Abutment type:

(1) Piles/bents, spill-through (-75)

(2) Cantilever, gravity, unknown concrete, concrete without piles/bents (-75)

(3) Stone masonry, mechanically stabilized, other (-90)

2) Piles/caissons

a) Abutment type:

(1) Piles/bents, stub, spill-through (-75)

(2) Cantilever, gravity, unknown concrete (-75)

(3) Stone masonry, mechanically stabilized, other (-80)

3) Bedrock

a) Abutment type:

(1) Cantilever, gravity, spill-through, unknown concrete, stub (-75)

(2) Stone masonry, concrete without piles/bents mechanically stabilized, other (-75)

2. Serious scour

a. Foundation type:

1) Alluvium, not observed

a) Abutment type:

(1) Piles/bents, spill-through (-40)

(2) Cantilever, gravity, unknown concrete, concrete without piles/bents (-60)

(3) Stone masonry, mechanically stabilized, other (-85)

2) Piles/caissons

a) Abutment type:

(1) Piles/bents, stub, spill-through (-40)

(2) Cantilever, gravity, unknown concrete (-50)

(3) Stone masonry, mechanically stabilized, other (-75) 
Figure 34. Worksheet for computation of Scour Assessment Rating for field-viewed bridge sites-Continued.

I. ABUTMENTS-Continued

NEAR

FAR

A. Scour condition at abutments:-Continued

2. Serious scour-Continued

a. Foundation type:-Continued

3) Bedrock

a) Abutment type:

(1) Cantilever, gravity, spill-through, unknown concrete, stub (-60)

(2) Stone masonry, concrete without piles/bents, mechanically stabilized, other (-75)

3. Advanced scour

a. Wingwall condition $=$ good or wingwall not necessary

1) Foundation type:

a) Alluvium, not observed

(1) Abutment type:

(a) Piles/bents, spill-through (-20)

(b) Cantilever, gravity, unknown concrete, concrete without piles/bents (-40)

(c) Stone masonry, mechanically stabilized, other (-70)

b) Piles/caissons

(1) Abutment type:

(a) Piles/bents, stub, spill-through (-20)

(b) Cantilever, gravity, unknown concrete (-20)

(c) Stone masonry, mechanically stabilized, other (-50)

c) Bedrock

(1) Abutment type:

(a) Cantilever, gravity, spill-through, unknown concrete, stub (-10)

(b) Stone masonry, concrete without piles/bents, mechanically stabilized, other (-15)

b. Wingwall condition $=$ partial or no wingwall but one is needed

1) Foundation type:

a) Alluvium, not observed

(1) Abutment type:

(a) Piles/bents, spill-through (-40)

(b) Cantilever, gravity, unknown concrete, concrete without piles/bents (-50)

(c) Stone masonry, mechanically stabilized, other (-75) 
Figure 34. Worksheet for computation of Scour Assessment Rating for field-viewed bridge sites-Continued.

I. ABUTMENTS-Continued

NEAR

FAR

A. Scour condition at abutments:-Continued

3. Advanced scour-Continued

b. Wingwall condition $=$ partial or no wingwall but one is needed - Continued

1) Foundation type:-Continued

b) Piles/caissons

(1) Abutment type:

(a) Piles/bents, stub, spill-through (-40)

(b) Cantilever, gravity, unknown concrete (-40)

(c) Stone masonry, mechanically stabilized, other (-60)

c) Bedrock

(1) Abutment type:

(a) Cantilever, gravity, spill-through, unknown concrete, stub (-30)

(b) Stone masonry, concrete without pile/bents mechanically stabilized, other (-35)

c. Wingwall condition $=$ failed

1) Foundation type:

a) Alluvium, not observed

(1) Abutment type:

(a) Piles/bents, spill-through (-55)

(b) Cantilever, gravity, unknown concrete, concrete without piles/bents (-65)

(c) Stone masonry, mechanically stabilized, other (-80)

b) Piles/caissons

(1) Abutment type:

(a) Piles/bents, stub, spill-through (-55)

(b) Cantilever, gravity, unknown concrete (-55)

(c) Stone masonry, mechanically stabilized, other (-70)

c) Bedrock

(1) Abutment type:

(a) Cantilever, gravity, spill-through, unknown concrete, stub (-50)

(b) Stone masonry, concrete without pile/bents mechanically stabilized, other (-55) 
Figure 34. Worksheet for computation of Scour Assessment Rating for field-viewed bridge sites-Continued.

I. ABUTMENTS-Continued

NEAR

FAR

A. Scour condition at abutments:-Continued

4. Minor scour

a. Wingwall condition $=$ good or wingwall not necessary

1) Foundation type:

a) Alluvium, not observed

(1) Abutment type:

(a) Piles/bents, spill-through (-5)

(b) Cantilever, gravity, unknown concrete, concrete without piles/bents (-15)

(c) Stone masonry, mechanically stabilized, other (-35)

b) Piles/caissons

(1) Abutment type:

(a) Piles/bents, stub, spill-through (-5)

(b) Cantilever, gravity, unknown concrete (-10)

(c) Stone masonry, mechanically stabilized, other (-30)

c) Bedrock

(1) Abutment type:

(a) Cantilever, gravity, spill-through, unknown concrete, stub (0)

(b) Stone masonry, concrete without piles/bents mechanically stabilized, other (-5)

b. Wingwall condition $=$ partial or no wingwall but one is needed

1) Foundation type:

a) Alluvium, not observed

(1) Abutment type:

(a) Piles/bents, spill-through (-30)

(b) Cantilever, gravity, unknown concrete, concrete without piles/bents (-40)

(c) Stone masonry, mechanically stabilized, other (-55)

b) Piles/caissons

(1) Abutment type:

(a) Piles/bents, stub, spill-through (-30)

(b) Cantilever, gravity, unknown concrete (-35)

(c) Stone masonry, mechanically stabilized, other (-50)

c) Bedrock

(1) Abutment type:

(a) Cantilever, gravity, spill-through, unknown concrete, stub (-25)

(b) Stone masonry, concrete without piles/bents, mechanically stabilized, other (-30) 
Figure 34. Worksheet for computation of Scour Assessment Rating for field-viewed bridge sites-Continued.

I. ABUTMENTS-Continued

NEAR

FAR

A. Scour condition at abutments:-Continued

4. Minor scour-Continued

c. Wingwall condition $=$ failed

1) Foundation type:

a) Alluvium, not observed

(1) Abutment type:

(a) Piles/bents, spill-through (-40)

(b) Cantilever, gravity, unknown concrete, concrete without pile/bents (-60)

(c) Stone masonry, mechanically stabilized, other (-65)

b) Piles/caissons

(1) Abutment type:

(a) Piles/bents, stub, spill-through (-40)

(b) Cantilever, gravity, unknown concrete (-45)

(c) Stone masonry, mechanically stabilized, other (-60)

c) Bedrock

(1) Abutment type:

(a) Cantilever, gravity, spill-through, unknown concrete, stub (-30)

(b) Stone masonry, concrete without pile/bents, mechanically stabilized, other (-35)

5. No scour

a. Wingwall condition = good or wingwall not necessary

1) Foundation type:

a) Alluvium, not observed

(1) Abutment type:

(a) Piles/bents, spill-through (-5)

(b) Cantilever, gravity, unknown concrete, concrete without piles/bents (-10)

(c) Stone masonry, mechanically stabilized, other (-25)

b) Piles/caissons

(1) Abutment type:

(a) Piles/bents, stub, spill-through (-5)

(b) Cantilever, gravity, unknown concrete (-5)

(c) Stone masonry, mechanically stabilized, other (-20)

c) Bedrock

(1) Abutment type:

(a) Cantilever, gravity, spill-through, unknown concrete, stub (0)

(b) Stone masonry, concrete without piles/bents mechanically stabilized, other (-5) 
Figure 34. Worksheet for computation of Scour Assessment Rating for field-viewed bridge sites-Continued.

I. ABUTMENTS-Continued

NEAR

FAR

A. Scour condition at abutments:-Continued

5. No scour-Continued

b. Wingwall condition $=$ partial or no wingwall but one is needed

1) Foundation type:

a) Alluvium, not observed

(1) Abutment type:

(a) Piles/bents, spill-through (-25)

(b) Cantilever, gravity, unknown concrete, concrete without piles/bents (-35)

(c) Stone masonry, mechanically stabilized, other (-45)

b) Piles/caissons

(1) Abutment type:

(a) Piles/bents, stub, spill-through (-25)

(b) Cantilever, gravity, unknown concrete (-35)

(c) Stone masonry, mechanically stabilized, other (-45)

c) Bedrock

(1) Abutment type:

(a) Cantilever, gravity, spill-through, unknown concrete, stub (-20)

(b) Stone masonry, concrete without piles/bents, mechanically stabilized, other (-25)

c. Wingwall condition $=$ Failed

1) Foundation type:

a) Alluvium, not observed

(1) Abutment type:

(a) Piles/bents, spill-through (-35)

(b) Cantilever, gravity, unknown concrete, concrete without piles/bents (-50)

(c) Stone masonry, mechanically stabilized, other (-60)

b) Piles/caissons

(1) Abutment type:

(a) Piles/bents, stub, spill-through (-35)

(b) Cantilever, gravity, unknown concrete (-40)

(c) Stone masonry, mechanically stabilized, other (-55)

c) Bedrock

(1) Abutment type:

(a) Cantilever, gravity, spill-through, unknown concrete, stub (-25)

(b) Stone masonry, concrete without piles/bents, mechanically stabilized, other (-30) 
Figure 34. Worksheet for computation of Scour Assessment Rating for field-viewed bridge sites—Continued.

I. ABUTMENTS-Continued

NEAR

FAR

B. Has every countermeasure, located at an abutment, received a condition rating of Good?

NOTE:

--Under-bridge bed material $=6$ (concrete/steel) is a good countermeasure

--If no countermeasures at the subunit, answer NO

1. Yes $(+10)$

2. No (0)

ABUTMENT SUBSCORES

II. PIERS

A. Scour condition at piers

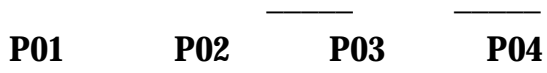

1. Movement:

a. Pier foundation type:

1) Alluvium, not observed

a) Pier type:

(1) Steel, concrete (-85)

(2) Timber, stone masonry, other (-85)

2) Piles/caissons

a) Pier type:

(1) Steel, concrete (-85)

(2) Timber, stone masonry, other (-85)

3) Bedrock

a) Pier type:

(1) Steel, concrete (-80)

(2) Timber, stone masonry, other (-85)

2. Serious scour

a. Pier foundation type:

1) Alluvium, not observed

a) Pier type:

(1) Steel, concrete (-70)

(2) Timber, stone masonry, other (-85)

2) Piles/caissons

a) Pier type:

(1) Steel, concrete (-65)

(2) Timber, stone masonry, other (-75)

3) Bedrock

a) Pier type:

(1) Steel, concrete (-65)

(2) Timber, stone masonry, other (-75)

3. Advanced scour

a. Pier foundation type:

1) Alluvium, not observed

a) Pier type:

(1) Steel, concrete (-50)

(2) Timber, stone masonry, other (-70) 
Figure 34. Worksheet for computation of Scour Assessment Rating for field-viewed bridge sites—Continued.

\section{PIERS-Continued}

A. Scour condition at piers-Continued

3. Advanced scour-Continued

a. Pier foundation type:-Continued

2) Piles/caissons

a) Pier type:

(1) Steel, concrete (-25)

(2) Timber, stone masonry, other (-50)

3) Bedrock

a) Pier type:

(1) Steel, concrete (-15)

(2) Timber, stone masonry, other (-20)

4. Minor scour

a. Pier foundation type:

1) Alluvium, not observed

a) Pier type:

(1) Steel, concrete (-20)

(2) Timber, stone masonry, other (-30)

2) Piles/caissons

a) Pier type:

(1) Steel, concrete (-10)

(2) Timber, stone masonry, other (-20)

3) Bedrock

a) Pier type:

(1) Steel, concrete (0)

(2) Timber, stone masonry, other (0)

5. No scour

a. Pier foundation type:

1) Alluvium, not observed

a) Pier type:

(1) Steel, concrete (-10)

(2) Timber, stone masonry, other (-15)

2) Piles/caissons

a) Pier type:

(1) Steel, concrete (-5)

(2) Timber, stone masonry, other $(-10)$

3) Bedrock

a) Pier type:

(1) Steel, concrete (0)

(2) Timber, stone masonry, other (-5) 
Figure 34. Worksheet for computation of Scour Assessment Rating for field-viewed bridge sites—Continued.

\section{PIERS-Continued}

P01

P02

P03

B. Has every countermeasure, located at a pier, received a condition rating of Good?

NOTE:

--Under-bridge bed material $=6$ (concrete $/$ steel) is a good countermeasure

--If no countermeasures at the subunit, answer NO

1. Yes $(+10)$

2. No (0)

PIER SUBSCORES 
Figure 34. Worksheet for computation of Scour Assessment Rating for field-viewed bridge sites—Continued.

\section{DEBRIS POTENTIAL}

For USGS debris potential not available (1995 field season only)

III a. Debris potential (use lowest item 3 of W11-A for all subunits at bridge):

1. High or present (-12)

2. Medium (-7)

3. Minor (-3)

4. None (0)

For USGS debris potential available (all field seasons except 1995)

III b. USGS Debris/Trapping Potential:

1. Debris $=$ low, trapping $=$ low $(0)$

2. Debris $=$ low, trapping $=$ medium, or vice versa $(-1)$

3. Debris $=$ low, trapping $=$ high, or vice versa $(-3)$

4. Debris $=$ medium, trapping $=$ medium $(-7)$

5. Debris $=$ medium, trapping $=$ high, or vice versa $(-10)$

6. Debris $=$ high , trapping $=$ high $(-15)$

DEBRIS POTENTIAL SUBSCORE

\section{OPENING BLOCKAGE UNDER BRIDGE}

A. Percent of opening blockage:

1. Blockage is $<$ or $=5 \%(0)$

2. $5 \%<$ Blockage $<$ or $=20 \%(-10)$

3. $20 \%<$ Blockage $<$ or $=40 \%(-20)$

4. Blockage is $>40 \%(-50)$

OPENING BLOCKAGE SUBSCORE

\section{OPENING ADEQUACY}

A. Evidence of pressure flow?

1. Yes $(-20)$

2. No (0)

OPENING ADEQUACY SUBSCORE

To compute the Scour Assessment Rating (Rating) for the bridge, add the worst subunit subscore to the DEBRIS POTENTIAL SUBSCORE, OPENING BLOCKAGE SUBSCORE, and OPENING ADEQUACY SUBSCORE. Subtract this total from 100 to obtain the raw Rating. If the raw Rating is $<0$, the final Rating equals 0 . If the raw Rating is $>100$, the final Rating equals 100. 
Figure 34. Worksheet for computation of Scour Assessment Rating for field-viewed bridge sites—Continued.

The following site conditions are considered important in evaluating the scour vulnerability of a bridge site; however, they are not used in computation of the Rating

(Check appropriate boxes)

\section{ABUTMENTS}

NEAR

FAR

A. Opening type:

1. Hardened, trapezoid

2. Unhardened, trapezoid

3. Rectangular, arched, other

a. Set back from bank?

1) Yes

2) No

B. Abutment attack angle:

1. $>45$ degrees

2. 31 - 45 degrees

3. 16 - 30 degrees

4. 0 - 15 degrees

C. Change in abutment since last inspection:

1. Significant change that could affect substructure

2. Some change but poses no threat to structure

3. No significant change

4. No change

D. Is a blow hole present?
1. Yes
2. No

\section{PIERS}

A. Pier attack angle:

1. $>45$ degrees

2. $31-45$ degrees

3. 16 -30 degrees

4. 0 - 15 degrees

B. Ratio of debris width to pier width:
1. Ratio $>3$
2. Ratio $=3$
3. Ratio $=2$
4. Ratio $=1$
5. No debris

$\begin{array}{llll}\text { P01 P02 } & \text { P03 } & \text { P04 }\end{array}$

s


Figure 34. Worksheet for computation of Scour Assessment Rating for field-viewed bridge sites—Continued.

\section{PIERS-Continued}

C. Shape of pier nose:

1. H-beam columns, square

2. Cylindrical columns, cylinder, round

3. Pointed

D. Pier location:

1. Mid-channel

2. On bank

3. Over bank

E. Change in pier since last inspection

1. Significant change, could affect substructure

2. Some change but poses no threat

3. No significant change

4. No change

\section{CHANNEL}

A. Scour hole not in contact with substructure?

1. Yes

2. No

B. Stream slope:

1. High

2. Medium

3. Low

C. Underbridge bed material:

1. Silt/clay, sand

2. Gravel

3. Cobble/ boulder

4. Bedrock, concrete, steel

D. Failed or possible scour hole backfill or rock protection?

1. Upstream

2. Downstream

3. No $\begin{array}{llll}\text { P01 P02 } & \text { P03 } & \text { P04 }\end{array}$
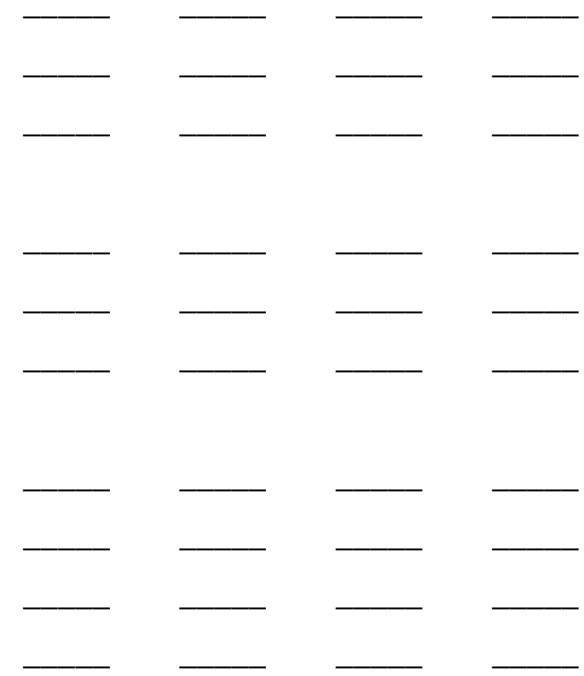
Figure 34. Worksheet for computation of Scour Assessment Rating for field-viewed bridge sites—Continued.

\section{BANKS}

A. Upstream bank material:

1. Silt/clay, sand

2. Gravel

3. Cobble/boulder

4. Bedrock, concrete, steel

B. Vegetative cover:
1. $0 \%-25 \%$
2. $26 \%-50 \%$
3. $51 \%-75 \%$
4. $76 \%-100 \%$

C. Bank erosion:

1. Mass wasting

2. Heavy fluvial erosion

3. Light fluvial erosion

4. None

D. Cutbank:
1. $<$ or $=1 \mathrm{~B}$
2. $1 \mathrm{~B}<$ cutbank $<2 \mathrm{~B}$
3. $>2 \mathrm{~B}$ or none
E. Meander impact:
1. $<$ or $=1 \mathrm{~B}$
2. $1 \mathrm{~B}<$ meander impact $<2 \mathrm{~B}$
3. $>2 \mathrm{~B}$ or none

\section{OPENING ADEQUACY}

A. Is opening adequacy rated good?
1. Yes
2. No

\section{ROADWAY OVERTOPPING}

A. Evidence of roadway overtopping?
1. Yes
2. No

\section{ROADWAY APPROACH}

A. Is approach roadway subject to meander impact/cutbank?

1. Yes

2. No 


\section{APPENDIX I}

Procedure for Computation of the SCOUR Assessment RATING FOR OFFICE-REVIEWED BRIDGE SITES 


\title{
PROCEDURE FOR COMPUTATION OF THE SCOUR ASSESSMENT RATING FOR OFFICE-REVIEWED BRIDGE SITES
}

The Scour Assessment Rating (Rating) for office-reviewed bridge sites serves the same purpose as that for field-viewed bridge sites. The office-reviewed Rating is composed of component values for individual bridge subunits and selected site conditions that are combined to provide an overall bridge structure rating similar to the field-viewed Rating. Only subunits that meet the criteria for scour assessments as outlined in this report are rated; for example, an expansive bridge that carries an elevated roadway will be rated on only those subunits in contact with stream flow.

An office-reviewed subunit can only be rated if PennDOT data are complete for the following data fields:

\author{
subunit type \\ subunit foundation type \\ scour condition \\ evidence of movement \\ wingwall condition, if present \\ condition of countermeasures at subunit \\ under-bridge bed material
}

Rating an entire office-reviewed bridge structure requires that all subunits that meet criteria for scour assessments are capable of being rated and that the following PennDOT data fields are complete:

trapping potential

debris potential

evidence of pressure flow

When subunits cannot be rated, they receive a rating of "999." Because individual subunits are components of the overall bridge structure, if a subunit of the bridge is rated "999," then the entire structure cannot be rated and also receives a rating of "999." When existing PennDOT data for foundation or type of a subunit are indicated as "other" or "not determined," the subunit cannot be rated and receives a rating "999." PennDOT District personnel are instructed to revise the BMS data or check bridge records prior to PennDOT personnel subsequently rating the bridge structure manually. If possible, discrepancies between existing PennDOT data, (for example, plans, hydrologic and hydraulic reports, and(or) foundation reports) and BMS data must be resolved at the time of the office review, or the bridge cannot be rated. Abutment type, pier type, and subunit foundation type are determined in a manner similar to that of field-viewed bridges with the prescribed flowcharts (figs. 35 and 36) and tables (tables 22-24).

The worksheet presented in figure 37 is then used to determine the Rating of each substructure unit and the overall bridge structure. 
Based on existing PennDOT data, assign abutment type from table 22

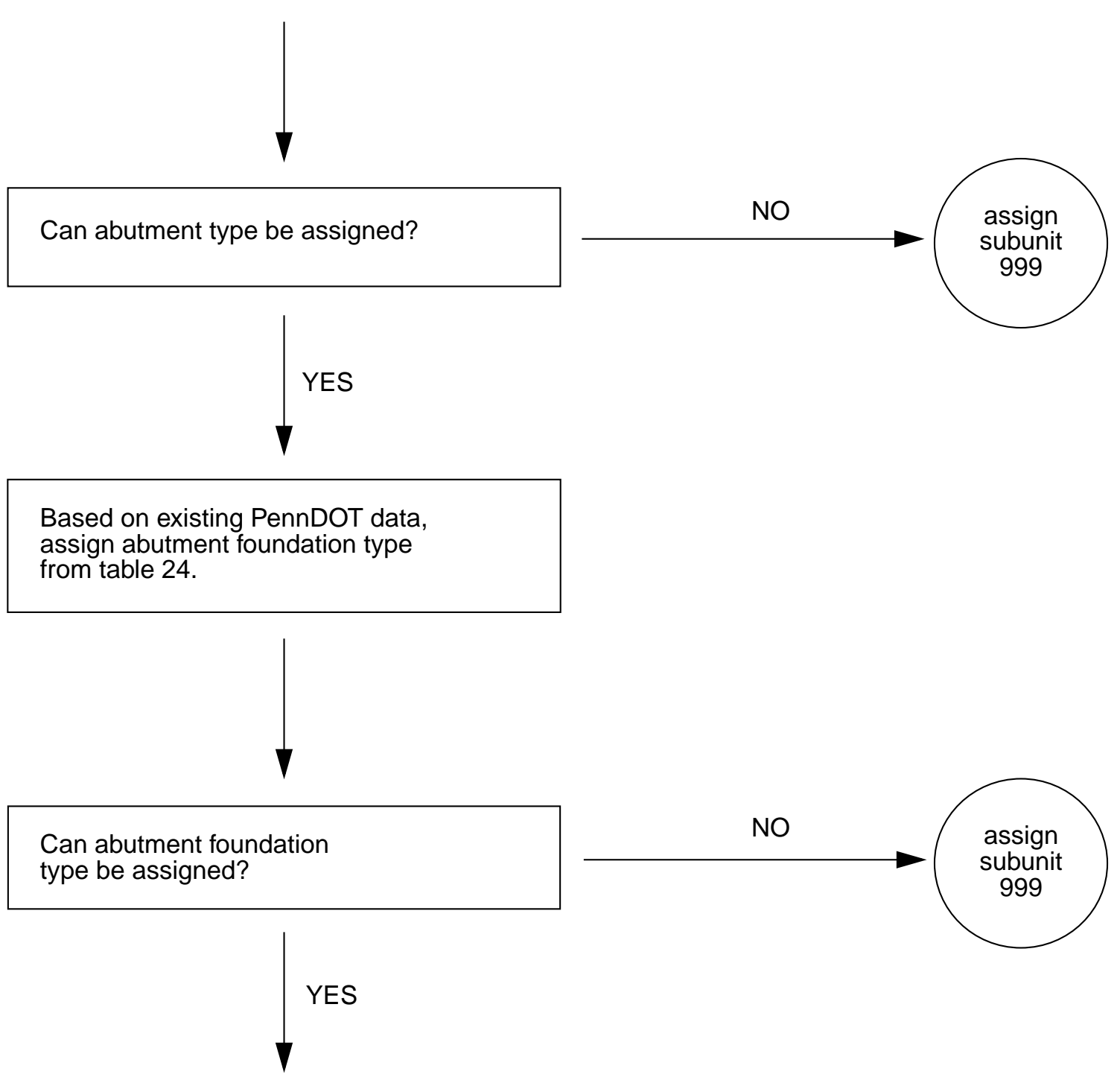

Compute Rating using abutment type and abutment foundation type with the following worksheet (fig. 37).

Figure 35. computation of Scour Assessment Rating for abutments at office-reviewed bridge sites. 
Based on existing PennDOT data, assign pier type from table 23.

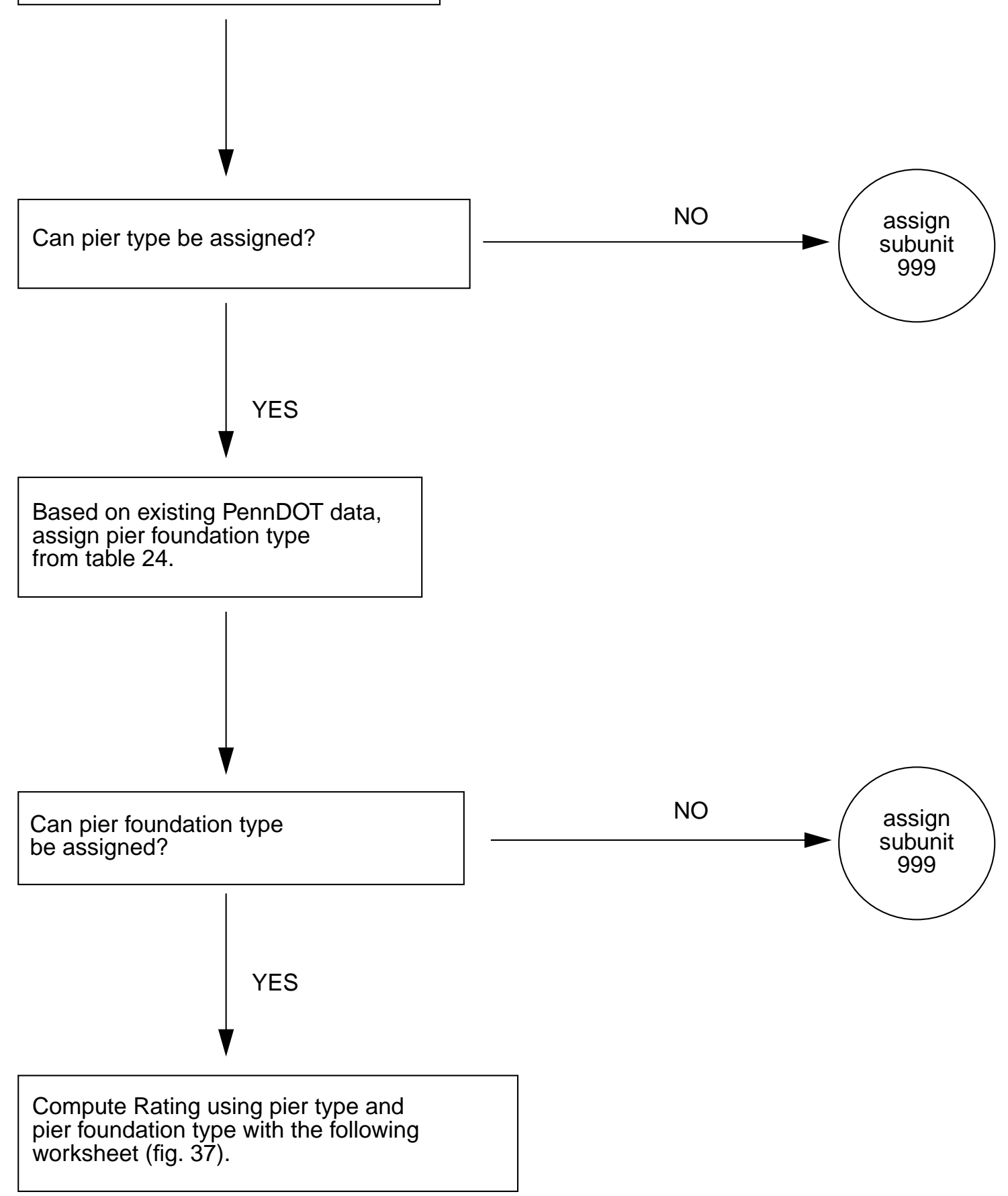

Figure 36. computation of Scour Assessment Rating for piers at office-reviewed bridge sites. 
Table 22. Selection of abutment type used in the Scour Assessment Rating for office-reviewed bridge sites

\begin{tabular}{|c|c|}
\hline $\begin{array}{l}\text { Existing PennDOT data choice } \\
\qquad()=\text { BMS abutment type }\end{array}$ & $\begin{array}{l}\text { Abutment type assigned for Rating } \\
\text { [ ] = USGS abutment type }\end{array}$ \\
\hline Stub (1) & Stub abutment [1] \\
\hline Cantilever (2) & Cantilever abutment [2] \\
\hline Gravity concrete (3) & Gravity concrete abutment [3] \\
\hline Gravity stone (4) & Stone-masonry abutment [6] \\
\hline Counterfort (5) & Gravity concrete abutment [3] \\
\hline Integral (6) & Stub abutment $[1]$ \\
\hline Cellular (7) & Mechanically stabilized abutment [9] \\
\hline Spill-through abutment(8) & Spill-through abutment [4] \\
\hline Other (9) & $\begin{array}{l}\text { Bridge cannot be rated, must be resolved with } \\
\text { PennDOT district personnel }\end{array}$ \\
\hline Reinforced concrete pad on MSE (A) & Mechanically stabilized abutment [9] \\
\hline Pile supported reinforced concrete pad on MSE (B) & Mechanically stabilized abutment [9] \\
\hline Precast modular earth-filled wall (C) & Mechanically stabilized abutment [9] \\
\hline Other proprietary (D) & $\begin{array}{l}\text { Bridge cannot be rated, must be resolved with } \\
\text { PennDOT district personnel }\end{array}$ \\
\hline Pile / bent (E) & Piles/bents abutment [7] \\
\hline Reserved (F) & $\begin{array}{l}\text { Bridge cannot be rated, must be resolved with } \\
\text { PennDOT district personnel }\end{array}$ \\
\hline Gabion (G) & Stone-masonry abutment [6] \\
\hline VSL retained earth $(\mathrm{H})$ & Mechanically stabilized abutment [9] \\
\hline Reinforced earth (I) & Mechanically stabilized abutment [9] \\
\hline Doublewall (J) & Mechanically stabilized abutment [9] \\
\hline Flexible anchored wall (K) & $\begin{array}{l}\text { Bridge cannot be rated, must be resolved with } \\
\text { PennDOT district personnel }\end{array}$ \\
\hline Flexible non-anchored wall (L) & $\begin{array}{l}\text { Bridge cannot be rated, must be resolved with } \\
\text { PennDOT district personnel }\end{array}$ \\
\hline Concrete unknown, cannot determine type $(X)$ & Unknown concrete abutment [5] \\
\hline Concrete spill-through sloping front face to channel flood flows $(\mathrm{Y})$ & Spill-through abutment [4] \\
\hline Mechanically stabilized panels (Z) & Mechanically stabilized abutment [9] \\
\hline Blank & $\begin{array}{l}\text { Bridge cannot be rated, must be resolved with } \\
\text { PennDOT district personnel }\end{array}$ \\
\hline
\end{tabular}

Table 23. Selection of pier type used in the Scour Assessment Rating for office-reviewed bridge sites

\begin{tabular}{ll}
\hline \multicolumn{1}{c}{$\begin{array}{c}\text { Existing PennDOT data choice } \\
()=\text { BMS pier type }\end{array}$} & \multicolumn{1}{c}{$\begin{array}{c}\text { Pier type assigned for rating } \\
{[] \text { = USGS pier type }}\end{array}$} \\
\hline Timber (1) & Timber pier [1] \\
Steel (2) & Steel pier [2] \\
Reinforced concrete (3) & Concrete pier [3] \\
Plain concrete (4) & Concrete pier [3] \\
Prestressed concrete (5) & Concrete pier [3] \\
Encased structural steel (7) & Concrete pier [3] \\
Concrete unknown(8) & Concrete pier [3] \\
Stone (6) & Stone-masonry pier [4] \\
Other (9) & Bridge cannot be rated, must be resolved with \\
& PennDOT district personnel \\
blank & Bridge cannot be rated, must be resolved with \\
& PennDOT district personnel \\
\hline
\end{tabular}


Table 24. Selection of abutment and pier foundation types used in the Scour Assessment Rating for office-reviewed bridge sites

Existing PennDOT data choice

$($ ) = BMS foundation type

Spread footing on competent bedrock (A)

Footing is on bedrock - erodibility cannot be determined (R)

Spread footings or culverts with an integral bottom on erodible bedrock (such as claystone, clay shales, some silt stone, shales, and weathered bedrock) (K)

Cast-in-place concrete piles (B)

Precast concrete piles (C)

Prestressed concrete piles (D)

Steel H-piles (E)

Steel pipe piles $(\mathrm{F})$

Timber piles $(\mathrm{G})$

Drilled caisson $(\mathrm{H})$

Deep water caisson (I)

Pedestals (J)

Spread footings or culverts with an integral bottom on soils (sand-gravel, cobbles, silt, and clay) (L) Other $(\mathrm{O})$

Foundation type has been researched; Information is unknown or not available with confidence $(\mathrm{P})$

Pile or caissons, If determined by probing (S)

Information is not available at this time $(\mathrm{X})$
Foundation type assigned for rating [ ] = USGS foundation type

on bedrock [1]

on bedrock [1]

on alluvium [2]

on piles/caissons [3]

on piles/caissons [3]

on piles/caissons [3]

on piles/caissons [3]

on piles/caissons [3]

on piles/caissons [3]

on piles/caissons [3]

on piles/caissons [3]

on piles/caissons [3]

on alluvium [2]

Bridge cannot be rated, must be resolved with PennDOT district personnel

Bridge cannot be rated, must be resolved with PennDOT district personnel

on piles/caissons [3]

Bridge cannot be rated, must be resolved with PennDOT district personnel 
Figure 37. Worksheet for computation of Scour Assessment Rating for office-reviewed bridge sites.

Use the rating abutment type, rating abutment foundation type, rating pier type, and rating pier foundation type determined above in the worksheet that follows. All other required site data are gathered from the office-reviewed bridge site data-collection form. 
Figure 37. Worksheet for computation of Scour Assessment Rating for office-reviewed bridge sites-Continued.

\section{Overall Score:}

Bridge ID:

\section{ABUTMENTS}

NEAR

FAR

A. Scour condition at abutments:

1. Movement

a. Foundation type:

1) Alluvium

a) Abutment type:

(1) Piles/bents, spill-through (-75)

(2) Cantilever, gravity, unknown concrete (-75)

(3) Stone masonry, mechanically stabilized (-90)

2) Piles/caissons

a) Abutment type:

(1) Piles/bents, stub, spill-through (-75)

(2) Cantilever, gravity, unknown concrete (-75)

(3) Stone masonry, mechanically stabilized (-80)

3) Bedrock

a) Abutment type:

(1) Cantilever, gravity, spill-through, unknown concrete, stub (-75)

(2) Stone masonry, mechanically stabilized (-75)

2. Serious scour

a. Foundation type:

1) Alluvium

a) Abutment type:

(1) Piles/bents, spill-through (-40)

(2) Cantilever, gravity, unknown concrete (-60)

(3) Stone masonry, mechanically stabilized (-85)

2) Piles/caissons

a) Abutment type:

(1) Piles/bents, stub, spill-through (-40)

(2) Cantilever, gravity, unknown concrete (-50)

(3) Stone masonry, mechanically stabilized (-75) 
Figure 37. Worksheet for computation of Scour Assessment Rating for office-reviewed bridge sites-Continued.

I. ABUTMENTS-Continued

NEAR

FAR

A. Scour condition at abutments:-Continued

2. Serious scour-Continued

a. Foundation type:-Continued

3) Bedrock

a) Abutment type:

(1) Cantilever, gravity, spill-through, unknown concrete, stub (-60)

(2) Stone masonry, mechanically stabilized (-75)

3. Advanced scour

a. Wingwall condition = good or wingwall not necessary

1) Foundation type:

a) Alluvium

(1) Abutment type:

(a) Piles/bents, spill-through (-20)

(b) Cantilever, gravity, unknown concrete $(-40)$

(c) Stone masonry, mechanically stabilized (-70)

b) Piles/caissons

(1) Abutment type:

(a) Piles/bents, stub, spill-through (-20)

(b) Cantilever, gravity, unknown concrete (-20)

(c) Stone masonry, mechanically stabilized (-50)

c) Bedrock

(1) Abutment type:

(a) Cantilever, gravity, spill-through, unknown concrete, stub (-10)

(b) Stone masonry, mechanically stabilized (-15)

b. Wingwall condition $=$ partial or no wingwall but one is needed

1) Foundation type:

a) Alluvium

(1) Abutment type:

(a) Piles/bents, spill-through (-40)

(b) Cantilever, gravity, unknown concrete (-50)

(c) Stone masonry, mechanically stabilized (-75)

b) Piles/caissons

(1) Abutment type:

(a) Piles/bents, stub, spill-through (-40)

(b) Cantilever, gravity, unknown concrete $(-40)$

(c) Stone masonry, mechanically stabilized (-60) 
Figure 37. Worksheet for computation of Scour Assessment Rating for office-reviewed bridge sites-Continued.

I. ABUTMENTS-Continued

NEAR

FAR

A. Scour condition at abutments:-Continued

3. Advanced scour-Continued

b. Wingwall condition $=$ partial or no wingwall but one is needed - Continued

1) Foundation type:-Continued

c) Bedrock

(1) Abutment type:

(a) Cantilever, gravity, spill-through, unknown concrete, stub (-30)

(b) Stone masonry, mechanically stabilized (-35)

c. Wingwall condition $=$ failed

1) Foundation type:

a) Alluvium

(1) Abutment type:

(a) Piles/bents, spill-through (-55)

(b) Cantilever, gravity, unknown concrete (-65)

(c) Stone masonry, mechanically stabilized (-80)

b) Piles/caissons

(1) Abutment type:

(a) Piles/bents, stub, spill-through (-55)

(b) Cantilever, gravity, unknown concrete (-55)

(c) Stone masonry, mechanically stabilized (-70)

c) Bedrock

(1) Abutment type:

(a) Cantilever, gravity, spill-through, unknown concrete, stub (-50)

(b) Stone masonry, mechanically stabilized (-55)

4. Minor scour

a. Wingwall condition = good or wingwall not necessary

1) Foundation type:

a) Alluvium

(1) Abutment type:

(a) Piles/bents, spill-through (-5)

(b) Cantilever, gravity, unknown concrete (-15)

(c) Stone masonry, mechanically stabilized (-35) 
Figure 37. Worksheet for computation of Scour Assessment Rating for office-reviewed bridge sites-Continued.

I. ABUTMENTS-Continued

NEAR

FAR

A. Scour condition at abutments:-Continued

4. Minor scour-Continued

a. Wingwall condition $=$ good or wingwall not necessary-Continued

1) Foundation type:-Continued

b) Piles/caissons

(1) Abutment type:

(a) Piles/bents, stub, spill-through (-5)

(b) Cantilever, gravity, unknown concrete $(-10)$

(c) Stone masonry, mechanically stabilized (-30)

c) Bedrock

(1) Abutment type:

(a) Cantilever, gravity, spill-through, unknown concrete, stub (0)

(b) Stone masonry, mechanically stabilized (-5)

b. Wingwall condition $=$ partial or no wingwall but one is needed

1) Foundation type:

a) Alluvium

(1) Abutment type:

(a) Piles/bents, spill-through (-30)

(b) Cantilever, gravity, unknown concrete $(-40)$

(c) Stone masonry, mechanically stabilized (-55)

b) Piles/caissons

(1) Abutment type:

(a) Piles/bents, stub, spill-through (-30)

(b) Cantilever, gravity, unknown concrete (-35)

(c) Stone masonry, mechanically stabilized (-50)

c) Bedrock

(1) Abutment type:

(a) Cantilever, gravity, spill-through, unknown concrete, stub (-25)

(b) Stone masonry, mechanically stabilized (-30)

c. Wingwall condition $=$ failed

1) Foundation type:

a) Alluvium

(1) Abutment type:

(a) Piles/bents, spill-through (-40)

(b) Cantilever, gravity, unknown concrete (-60)

(c) Stone masonry, mechanically stabilized (-65) 
Figure 37. Worksheet for computation of Scour Assessment Rating for office-reviewed bridge sites-Continued.

I. ABUTMENTS-Continued

NEAR

FAR

A. Scour condition at abutments:-Continued

4. Minor scour-Continued

c. Wingwall condition $=$ failed - Continued

1) Foundation type:-Continued

b) Piles/caissons

(1) Abutment type:

(a) Piles/bents, stub, spill-through (-40)

(b) Cantilever, gravity, unknown concrete (-45)

(c) Stone masonry, mechanically stabilized (-60)

c) Bedrock

(1) Abutment type:

(a) Cantilever, gravity, spill-through, unknown concrete, stub (-30)

(b) Stone masonry, mechanically stabilized (-35)

5. No scour

a. Wingwall condition = good or wingwall not necessary

1) Foundation type:

a) Alluvium

(1) Abutment type:

(a) Piles/bents, spill-through (-5)

(b) Cantilever, gravity, unknown concrete (-10)

(c) Stone masonry, mechanically stabilized (-25)

b) Piles/caissons

(1) Abutment type:

(a) Piles/bents, stub, spill-through (-5)

(b) Cantilever, gravity, unknown concrete (-5)

(c) Stone masonry, mechanically stabilized (-20)

c) Bedrock

(1) Abutment type:

(a) Cantilever, gravity, spill-through, unknown concrete, stub (0)

(b) Stone masonry, mechanically stabilized (-5)

b. Wingwall condition $=$ partial or no wingwall but one is needed

1) Foundation type:

a) Alluvium

(1) Abutment type:

(a) Piles/bents, spill-through (-25)

(b) Cantilever, gravity, unknown concrete (-35)

(c) Stone masonry, mechanically stabilized (-45) 
Figure 37. Worksheet for computation of Scour Assessment Rating for office-reviewed bridge sites-Continued.

I. ABUTMENTS-Continued

NEAR

FAR

A. Scour condition at abutments:-Continued

5. No scour-Continued

b. Wingwall condition $=$ partial or no wingwall but one is needed - Continued

1) Foundation type:-Continued

b) Piles/caissons

(1) Abutment type:

(a) Piles/bents, stub, spill-through (-25)

(b) Cantilever, gravity, unknown concrete (-35)

(c) Stone masonry, mechanically stabilized (-45)

c) Bedrock

(1) Abutment type:

(a) Cantilever, gravity, spill-through, unknown concrete, stub (-20)

(b) Stone masonry, mechanically stabilized (-25)

c. Wingwall condition $=$ failed

1) Foundation type:

a) Alluvium

(1) Abutment type:

(a) Piles/bents, spill-through (-35)

(a) Cantilever, gravity, unknown concrete (-50)

(b) Stone masonry, mechanically stabilized (-60)

b) Piles/caissons

(1) Abutment type:

(a) Piles/bents, stub, spill-through (-35)

(b) Cantilever, gravity, unknown concrete (-40)

(c) Stone masonry, mechanically stabilized (-55)

c) Bedrock

(1) Abutment type:

(a) Cantilever, gravity, spill-through, unknown concrete, stub (-25)

(b) Stone masonry, mechanically stabilized (-30)

B. Has every countermeasure, located at an abutment, received a condition rating of good?

NOTE:

-- Under-bridge bed material $=6$ (concrete $/$ steel) is a good countermeasure

-- If no countermeasures at the subunit, answer NO

1. Yes $(+10)$

2. No $(0)$

ABUTMENT SUBSCORES 
Figure 37. Worksheet for computation of Scour Assessment Rating for office-reviewed bridge sites-Continued.

II. PIERS

A. Scour condition at piers

1. Movement:

a. Pier foundation type:

1) Alluvium

a) Pier type:

(1) Steel, concrete (-85)

(2) Timber, stone masonry (-85)

2) Piles/caissons

a) Pier type:

(1) Steel, concrete (-85)

(2) Timber, stone masonry (-85)

3) Bedrock

a) Pier type:

(1) Steel, concrete (-80)

(2) Timber, stone masonry (-85)

2. Serious scour

a. Pier foundation type:

1) Alluvium

a) Pier type:

(1) Steel, concrete (-70)

(2) Timber, stone masonry (-85)

2) Piles/caissons

a) Pier type:

(1) Steel, concrete (-65)

(2) Timber, stone masonry (-75)

3) Bedrock

a) Pier type:

(1) Steel, concrete (-65)

(2) Timber, stone masonry (-75)

3. Advanced scour

a. Pier foundation type:

1) Alluvium

a) Pier type:

(1) Steel, concrete $(-50)$

(2) Timber, stone masonry (-70) 
Figure 37. Worksheet for computation of Scour Assessment Rating for office-reviewed bridge sites-Continued.

\section{PIERS-Continued}

A. Scour condition at piers-Continued

3. Advanced scour-Continued

a. Pier foundation type:-Continued

2) Piles/caissons

a) Pier type:

(1) Steel, concrete (-25)

(2) Timber, stone masonry (-50)

3) Bedrock

a) Pier type:

(1) Steel, concrete (-15)

(2) Timber, stone masonry (-20)

4. Minor scour

a. Pier foundation type:

1) Alluvium

a) Pier type:

(1) Steel, concrete (-20)

(2) Timber, stone masonry (-30)

2) Piles/caissons

a) Pier type:

(1) Steel, concrete (-10)

(2) Timber, stone masonry (-20)

3) Bedrock

a) Pier type:

(1) Steel, concrete (0)

(2) Timber, stone masonry (0)

5. No scour

a. Pier foundation type:

1) Alluvium

a) Pier type:

(1) Steel, concrete (-10)

(2) Timber, stone masonry (-15)

2) Piles/caissons

a) Pier type:

(1) Steel, concrete (-5)

(2) Timber, stone masonry (-10)

3) Bedrock

a) Pier type:

(1) Steel, concrete (0)

(2) Timber, stone masonry (-5)
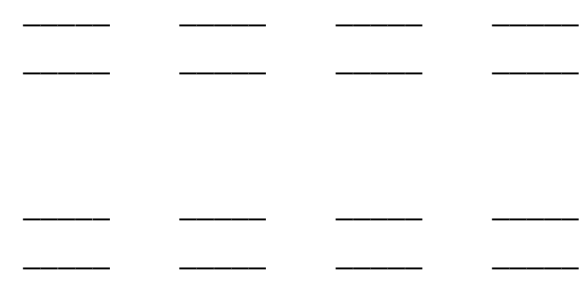
Figure 37. Worksheet for computation of Scour Assessment Rating for office-reviewed bridge sites-Continued.

$\begin{array}{lllll}\text { II. PIERS-Continued } & \text { P01 } & \text { P02 } & \text { P03 } & \text { P04 }\end{array}$

B. Has every countermeasure, located at a pier, received a condition rating of good?

\section{NOTE:}

-- Under-bridge bed material $=6$ (concrete/steel) is a good countermeasure

-- If no countermeasures at the subunit, answer NO

1. Yes $(+10)$

2. No (0)

PIER SUBSCORES 
Figure 37. Worksheet for computation of Scour Assessment Rating for office-reviewed bridge sites-Continued.

\section{DEBRIS POTENTIAL}

A. Debris Potential (Use lowest item 3 of W11-A for all subunits at bridge):

1. High or present $(-12)$

2. Medium (-7)

3. Minor (-3)

4. None (0)

DEBRIS POTENTIAL SUBSCORE

\section{OPENING ADEQUACY}

A. History /Evidence of pressure flow at 100-year flood?

1. YES (-20)

2. $\mathrm{NO}(0)$

\section{OPENING ADEQUACY SUBSCORE}

To compute the Scour Assessment Rating (Rating) for the bridge, add the worst subunit subscore to the DEBRIS POTENTIAL SUBSCORE, OPENING BLOCKAGE SUBSCORE, and OPENING ADEQUACY SUBSCORE. Subtract this total from 100 to obtain the raw Rating. If the raw Rating $<0$, the final Rating equals 0 . If the raw Rating > 100, the final Rating equals 100.

The following site conditions are considered important in evaluating the scour vulnerability of a bridge site, however are not used in the computation of the Rating. (Check appropriate boxes)

\section{ABUTMENTS}

NEAR

A. Opening type:

1. Hardened, trapezoid

2. Unhardened, trapezoid

3. Rectangular, arched

a) Set back from bank?

(1) Yes

(2) No

(3) Cannot be determined

4. Cannot be determined 
Figure 37. Worksheet for computation of Scour Assessment Rating for office-reviewed bridge sites-Continued.

\section{ABUTMENTS-Continued}

B. Abutment attack angle:

1. $>45$ degrees

2. 31 - 45 degrees

3. 16 - 30 degrees

4. 0 - 15 degrees

5. Cannot be determined

C. Change in abutment since last inspection:

1. Significant change that could affect substructure

2. Some change but poses no threat to structure

3. No significant change

4. No change

D. Is a blow hole present?

1. Yes

2. No

\section{PIERS}

A. Pier attack angle:

1. > 45 degrees

2. 31 - 45 degrees

3. 16 -30 degrees

4. 0 - 15 degrees

5. Cannot be determined

B. Shape of pier nose:

1. H-beam columns, square

2. Cylindrical columns, cylinder, round

3. Pointed

4. Cannot be determined

C. Pier location:

1. Mid-channel

2. On bank

3. Over bank

4. Cannot be determined

D. Change in pier since last inspection:

1. Significant change, could affect substructure

2. Some change but poses no threat

3. No significant change

4. No change

NEAR

FAR 
Figure 37. Worksheet for computation of Scour Assessment Rating for office-reviewed bridge sites-Continued.

\section{CHANNEL}

A. Scour hole not in contact with substructure?

1. Yes

2. No

3. Cannot be determined

B. Stream slope:

1. High

2. Medium

3. Low

C. Underbridge bed material:

1. Silt/ clay, sand

2. Gravel

3. Cobble/boulder

4. Bedrock, concrete, steel

5. Alluvium (undetermined size)

D. Failed or possible scour hole backfill or rock protection?
1. Upstream
2. Downstream
3. No

\section{BANKS}

A. Vegetative cover:
1. $0 \%-25 \%$
2. $26 \%-50 \%$
3. $51 \%-75 \%$
4. $76 \%-100 \%$

B. Bank erosion:
1. Significant erosion

2. Minor erosion

3. None

4. Cannot be determined

C. Cutbank:
1. Yes
2. No
3. Cannot be determined

D. Meander impact:
1. Yes
2. No
3. Cannot be determined 
Figure 37. Worksheet for computation of Scour Assessment Rating for office-reviewed bridge sites-Continued.

\section{OPENING ADEQUACY RATED GOOD}

A. Is opening adequacy rated good?

1. Yes

2. No

\section{ROADWAY OVERTOPPING}

A. Evidence of roadway overtopping?
1. Yes
2. No
3. Cannot be determined

\section{ROADWAY APPROACH SUBJECT TO MEANDER IMPACT / CUTBANK}

A. Is approach roadway subject to meander impact / cutbank
1. Yes
2. No 